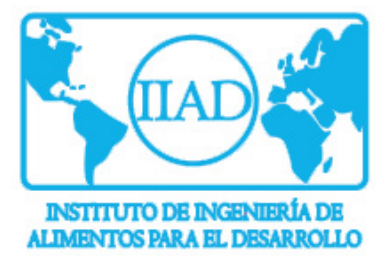

\title{
ANTIFUNGAL CHITOSAN-BASED FILMS AND COATINGS \\ CONTAINING ESSENTIAL OILS FOR FRUIT APPLICATIONS
}

\section{DOCTORAL THESIS}

Ángela Perdones Montero

Supervisors:

Amparo Chiralt Boix

Maria Vargas Colás 



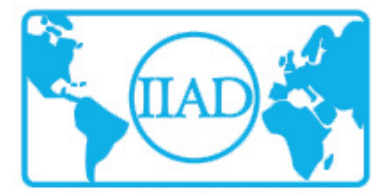

INSTITUTO DE INGENIERTA DE ALMIENTOS PARA EL DESARROLLO

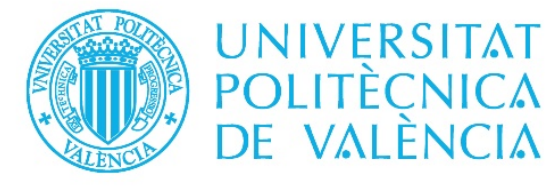

Dra. Amparo Chiralt Boix, Catedrática de Universidad, perteneciente al Departamento de Tecnología de Alimentos de la Universitat Politècnica de València.

Dra. Maria Vargas Colás, Profesora Titular de Universidad, perteneciente al Departamento de Tecnología de Alimentos de la Universitat Politècnica de València.

Hacen constar que:

La memoria titulada "Antifungal Chitosan-Based Films and Coatings containing Essential Oils for Fruit Applications" que presenta Dạ Ángela Perdones Montero para optar al grado de Doctor por la Universitat Politècnica de València, ha sido realizada en el Instituto de Ingeniería de Alimentos para el Desarrollo (IuIAD - UPV) bajo su dirección y que reúne las condiciones para ser defendida por su autora.

Valencia, 15 de Octubre 2015

Fdo. Amparo Chiralt Boix

Fdo. Maria Vargas Colás 

A mi familia 



\section{ACKNOWLEDGEMENTS}

Me gustaría expresar mis más sinceros agradecimientos a mis directoras de Tesis, Dra. Amparo Chiralt y Dra. Maria Vargas, por ofrecerme esta gran oportunidad. Muchas gracias por vuestra dedicación, apoyo, enseñanzas, y sobre todo por vuestra cercanía, siempre me he sentido muy afortunada de formar parte de vuestro equipo. Agradezco también su dedicación a la Dra. Chelo González, a la Dra. Isabel Escriche, a la Dra. Maite Cháfer, a la Dra. Lorena Atarés y a la Dra. Laura Sánchez. Ha sido un gran placer poder colaborar con vosotras.

Gracias al "Laboratoire d'Ingénierie et des Biomolécules" y en especial al Dr. Stéphane Desobry y a la Dra. Elmira Arab Tehrany de la Université de Lorraine. Gracias a "BioTeam", al Dr. Luc Avérous y a todos mis compañeros del "Institute de Chimie et Procédés pour l'Energie, l'Environnement et la Santé". Ha sido una experiencia inolvidable haber podido compartir mis estancias con vosotros.

A todos mis compañeros del laboratorio, los de dentro y los de fuera, los que están y los que se han ido. De cada uno de vosotros me llevo un pedacito.

A todos mis amigos, por estar ahí siempre que os necesito.

Por último, a mi familia, vuestro apoyo continuo es fundamental, en esta etapa de mi vida, y en las que están por llegar. Gracias Albert por estar siempre a mi lado. 



\section{PREFACE}

\section{DISSERTATION OUTLINE}

This Doctoral Thesis is structured in five sections: Introduction, Objectives, Chapters, General Discussion and Conclusions. The Introduction section discusses the state of the art concerning properties and antimicrobial action of chitosan and essential oils. The Objectives section presents the general and specific objectives of the Thesis. The obtained results are presented in five Chapters, as a collection of scientific publications, including the usual sections: introduction, material and methods and results and discussion. The General Discussion section discusses, from an overall perspective, the most relevant results obtained in this Doctoral Thesis. Finally, the most important conclusions are presented.

According to the general objective of the thesis, different strategies to obtain chitosan films with antifungal properties, to be applied in fruit preservation, were used; different homogenization conditions of the chitosan solutions and lipid emulsions were applied to the film-forming systems and different essential oils were used, selected on the basis of the their aroma compatibility with the coated products (strawberries and tomatoes) and their previously described antifungal activity. The effect of oleic acid, as emulsifier in the film formulations, was also analysed in its double action: to facilitate the essential oil emulsification and retention in the films and to reduce the hygroscopic character of chitosan films. The blending of chitosan with a neutral and safe polymer, methylcellulose (MC), was also investigated in coating applications to tomato plants in different growth stages, to mitigate the possible adverse effects of pure chitosan on the early stages of the plants. All the obtained results are organized as follows:

Chapter 1, entitled "Effect of homogenization conditions on physicochemical properties of chitosan based film-forming dispersion and films", analyses the effect of the homogenization treatments on the physicochemical properties of the chitosan-oleic acid film-forming emulsions and functional properties of the films. Results showed that 
microfluidization (high pressure homogenization) led to a significant decrease in the lipid droplet particle size, depending on the pressure, which, in turn, reduced the water vapour permeability of the films and enhanced their stiffness. So, this technique appears to be a suitable approach to develop chitosan edible films with lipids adapted to a specific target application.

In Chapter 2, "Application of Chitosan films containing essential oils in preservation of strawberries", the effect of chitosan coatings on the strawberry quality parameters throughout the storage time was studied. Chitosan coatings did not significantly affect the physicochemical parameters of strawberries throughout storage, while they slowed down their respiration rate when lemon essential oil was added to the formulation. Adding lemon essential oil enhanced the chitosan antifungal activity against Botrytis cinerea, both in in vitro tests and during cold storage of inoculated strawberries. The study of the impact of coatings on the strawberry volatile profile revealed significant changes in the analysed compounds for both, coatings with and without lemon essential oil. Nevertheless, sensory appreciation of these changes was only notably for samples coated with chitosan-lemon oil films. In this sense, possible sensory advantages of cinnamon leaf essential oil were tested, as described in Chapter 3.

\section{Chapter 3, "Effect of oleic acid on the essential oil performance in chitosan} matrix", analyses physical and antimicrobial properties of chitosan films with different essential oils (basil, cinnamon leaf and thyme), containing or not oleic acid. This compound was added to favour the stability of the essential oil emulsions, thus reducing the oil losses by evaporation during the film drying step. Although this aim was reached and more oil retention in the film was obtained when oleic acid was added, its incorporation reduced the antifungal effectiveness of the essential oil containing films, in line with the encapsulating effect. Nevertheless, all the coatings with cinnamon leaf were effective in extending the shelf-life of cold-stored strawberries, mainly at the higher essential oil:polymer ratios.

In Chapter 4 "Effect of chitosan coatings containing essential oils on tomato plants and fruits" chitosan-methylcellulose films were applied with the aim of controlling the growth of Rhizopus stolonifer in tomatoes, in pre- and postharvest treatments. Coating formulations included methylcellulose, to 
inhibit the previously commented possible adverse effects of pure chitosan in preharvest treatments, and oregano essential oil. Although coatings with the essential oil caused phytotoxic effects at "3 Leaves" stage of tomato plants in preharvest applications, they had no negative effects when applied in the "Fruit" stage. Coatings significantly reduced the respiration rate of tomato fruits and their fungal decay when fruits were inoculated with Rhizopus stolonifer spores.

Chapter 5 analyses the "Retention of essential oils in chitosan films and their release to food simulants" for the polymer formulations used in Chapter 4, The purpose of this study was to determine the specific losses of the major compounds of oregano essential oil (i.e. carvacrol and thymol) during the film formation, which in turn can affect their bioactivity. Likewise, the specific migration of these main compounds in different food simulants was analysed in order to know how the packaging legal requirements are met in this kind of materials.

In order to open new perspectives in the use of essential oils as antifungal agents, a screening of the antifungal effect of 10 different essential oils against three common fungi causing alterations in fruits (Aspergillus niger, Botrytis cinerea and Rhizopus stolonifer) were also carried out and the obtained results are given in Annex I, together with the chemical compounds of each oil. 


\section{DISSEMINATION OF RESULTS}

International Journals JCR

Published:

Vargas, M., Perdones, A., Chiralt, A., Cháfer, M., González-Martínez, C. Effect of homogenization conditions on physicochemical properties of chitosan-based film-forming dispersions and films. Food Hydrocolloids 25 (2011) $1158-1164$.

Perdones, A., Sánchez-González, L., Chiralt, A., Vargas, M. Effect of chitosan-lemon essential oil coatings on storage-keeping quality of strawberry. Postharvest Biology and Technology 70 (2012) $32-41$.

Perdones, A., Vargas, M., Atarés, L., Chiralt, A. Physical, antioxidant and antimicrobial properties of chitosan-cinnamon leaf oil films as affected by oleic acid. Food Hydrocolloids 36 (2014) $256-264$.

Randazzo, W., Jiménez-Belenguer, A., Settanni, L., Perdones, A., Moschetti, M., Palazzolo, E., Guarrasi, V., Vargas, M., Germanà, M.A., Moschetti, G. Antilisterial effect of citrus essential oils and their performance in edible film formulations. Food Control 59 (2016) 750 - 758.

In Press:

Perdones, A., Escriche, I., Chiralt, A., Vargas, M. Effect of chitosan-lemon essential oil coatings on volatile profile of strawberries during storage. Food Chemistry (2015).

Accepted:

Perdones, A., Tur, N., Chiralt, A., Vargas, M. Effect on tomato plant and fruit of the application of biopolymer-oregano essential oils coatings. Journal of the Science of Food and Agriculture.

Submitted:

Perdones, A., Vargas, M., Chiralt, A. Properties of film-forming dispersions and films based on chitosan containing basil and thyme essential oils. Food Hydrocolloids. 


\section{Communications in International congresses}

Vargas, M., Perdones, A., Cháfer, M., Albors, A., Chiralt, A., González Martínez, C. (2009). Effect of high-pressure microfluidization treatment on the physicochemical properties of chitosan-based film-forming dispersions. EFFost Annual Meeting: New Challenges in Food Preservation. Processing, Safety and Sustainability (EFFoST), Budapest, Hungary.

\section{Poster}

Perdones, A., Vargas, M., Atarés, L., Chiralt, A. (2012). Barrier and antifungal properties of chitosan-cinnamon leaf oil films. Effect of oleic acid. $2^{\text {nd }}$ International Meeting on Material/Bioproduct Interaction, MATBIM 2012, Dijon, France.

\section{Oral communication}

Perdones, A., Vargas, M, Chiralt A. (2013). Characterization of chitosan-thyme essential oil edible films. Effect of oleic acid content. $11^{\text {th }}$ International Conference of the European Chitin Society, EUCHIS 2013, Porto, Portugal.

\section{Poster and article.}

Perdones, A., Vargas, M, Chiralt A. (2013). Physicochemical properties of chitosan-basil essential oil edible Ffilms as affected by oleic acid addition. $11^{\text {th }}$ International Conference of the European Chitin Society, EUCHIS 2013, Porto, Portugal.

\section{Poster and article.}

Perdones, A., Sánchez-González, L., Vargas, M., Chiralt, A. (2014). Efecto de la adición de aceite de colza o pescado en las propiedades físico-químicas y antimicrobianas de películas comestibles de quitosano. IX Congreso Iberoamericano de Ingeniería de Alimentos, CIBIA9, Valencia, Spain.

Poster and article.

Perdones, A., Atarés, L., Vargas, M., Chiralt, A. Properties of pea starch-chitosan films as affected by cinnamon leaf essential oil and oleic acid. (2014). II Congreso Internacional de Investigación e Innovación en Ingeniería, Ciencia y Tecnología de Alimentos, IICTA 2014, Medellín, Colombia.

\section{Poster and article.}


Perdones, A., Atarés, L., Vargas, M., Chiralt, A. (2015). Effect of Pea-starch based films on the oxidative stabilization of lard. VIII CYTA/CESIA 2015, Badajoz, Spain.

Poster.

Communication in scientific events:

Perdones, A., Cháfer, M., González-Martínez, C., Chiralt, A., Vargas, M. (2009). Aplicación de recubrimientos a base de quitosano y aceite esencial de limón en fresones. II Jornada de la Cátedra FOMESA, Valencia, Spain. Poster and oral communication

Perdones, A. (2014). Recubrimientos de quitosano como vehículo de antifúngicos. Aplicaciones en fresa. I Encuentro de estudiantes de Doctorado de la UPV. Universitat Politècnica de València, Valencia, Spain. Poster and article.

\section{PREDOCTORAL STAYS AT FOREIGN INSTITUTIONS}

BioTeam, Institut de Chimie et Procédés pour l'Energie, l'Environnement et la Santé (ICPEES), Ecole Européenne de Chimie, Polymères et Matériaux (ECPM), Université de Strasbourg, Strasbourg, France. From May 2015 to August 2015, under the supervision of Dr. Luc Avérous. Design and study of thermoplastic chitosan matrices enriched with cinnamon leaf essential oil.

Laboratoire d'Ingénierie et des Biomolécules (LIBio), École Nationale Supérieure d'Agronomie et des Industries Alimentaies (ENSAIA), Université de Lorraine, Nancy, France. From May 2012 to August 2012, under the supervision of Dr. Stéphane Desobry. Encapsulation of active essential oils in chitosan films for antimicrobial film development. 


\section{TABLE OF CONTENTS}

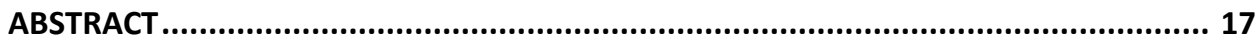

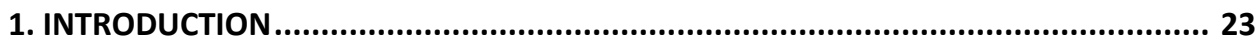

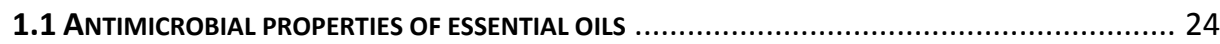

1.2 PRoperties of ChItosan Of INTEREST TO DEVELoP EDIBLE FILMS OR COATINGS .................... 28

1.2.1 Molecular structure of chitosan and properties of their aqueous dispersions 28

1.2.2 Antimicrobial properties of chitosan ........................................................... 30

1.2.3 Physical properties of chitosan-based films................................................. 32

1.2.4 Antimicrobial properties of chitosan-based films and coatings ..................... 35

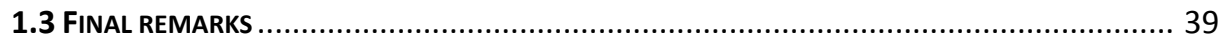

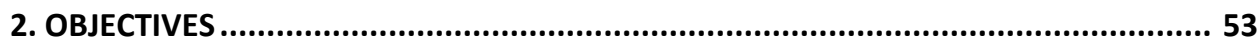

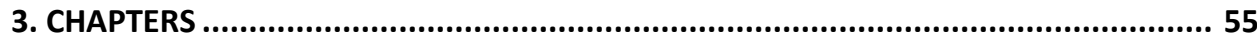

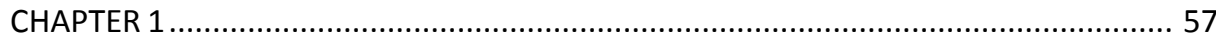

EFFECT OF HOMOGENIZATION CONDITIONS ON PHYSICOCHEMICAL PROPERTIES

OF CHITOSAN-BASED FILM-FORMING DISPERSIONS AND FILMS .......................... 57

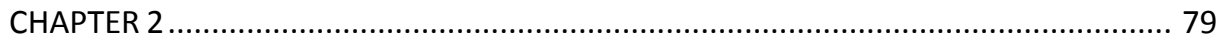

EFFECT OF CHITOSAN-LEMON ESSENTIAL OIL COATINGS ON STORAGE-KEEPING

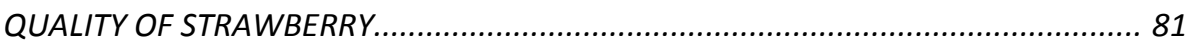

EFFECT OF CHITOSAN-LEMON ESSENTIAL OIL COATINGS ON VOLATILE PROFILE OF STRAWBERRIES DURING STORAGE ....................................................... 115

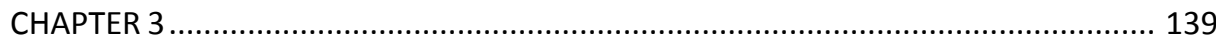

PROPERTIES OF FILM-FORMING DISPERSIONS AND FILMS BASED ON CHITOSAN

CONTAINING BASIL AND THYME ESSENTIAL OILS ............................................ 141

PHYSICAL AND ANTIMICROBIAL PROPERTIES OF CHITOSAN-CINNAMON LEAF

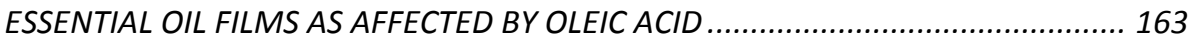

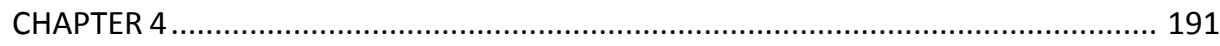

EFFECT ON TOMATO PLANT AND FRUIT OF THE APPLICATION OF

BIOPOLYMER-OREGANO ESSENTIAL OILS COATINGS ...................................... 193

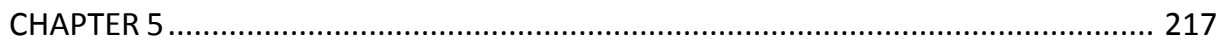

RETENTION AND MIGRATION OF OREGANO ESSENTIAL OIL IN CHITOSAN BASED

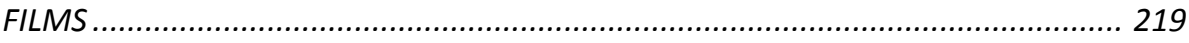

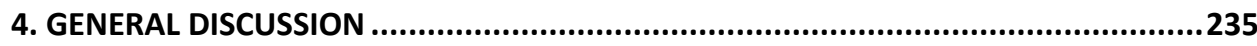

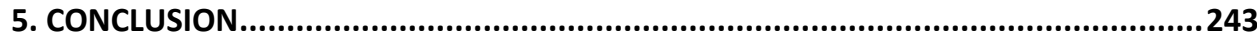

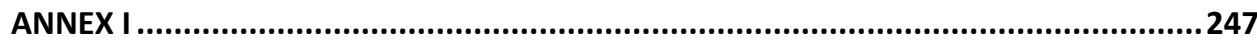





\section{ABSTRACT}

Chitosan films and coatings have been obtained, by incorporating different essential oils (EO) and using different homogenization conditions of the film-forming emulsions, in order to obtain antifungal materials for fruit preservation. The effect of oleic acid (OA) on the stability of the initial emulsions and on the film properties was analysed. Coatings were applied to control fungal decay in strawberries. The blending of chitosan with methylcellulose (MC) was also used in coating applications to tomato plants and fruits to prevent fungal infections. The films' functional properties as a function of their composition were analysed, as well as their antimicrobial activity through in vitro and in vivo tests.

OA incorporation in the chitosan films (1:1 wt. ratio) reduced water vapour permeability (WVP) values to about $50 \%$ of those of net chitosan films, with a small positive effect of the microfluidization process. EO (basil, cinnamon leaf and thyme) did not notably reduced the WVP values of the chitosan films but a significant improvement in water barrier capacity was induced when OA was also added at 1:1 or 1:0.5 $\mathrm{CH}$ :OA ratios. In contrast, lipids slightly promoted oxygen permeability of the films. Lipid addition decreased the film stretchability and stiffness, with a lesser impact on the resistance to break, slightly depending on the droplet sizes. Essential oils also modulated the mechanical behaviour of the films, depending on their composition. Basil or thyme EO greatly promoted film stiffness and resistance to break, whereas cinnamon leaf essential oil slightly reduced these mechanical attributes. Optical properties of the chitosan films were also affected by lipid incorporation. OA reduced the film transparency and gloss depending on the concentration, but provoked small changes in the colour parameters and whiteness index. EO affected transparency to a lesser extent, but had greater impact on the colour coordinates and whiteness index of the chitosan films due to the selective light absorption of their compounds. EO blend with oleic acid mitigated the colour changes in the films. Likewise, blending of OA with EO significantly reduced the losses of volatiles during the film formation due to the promotion of the stability of the film-forming emulsions. 
Films containing cinnamon leaf EO were effective in reducing the growth of Aspergillus niger, Botrytis cinerea and Rhizopus stolonifer, although basil or thyme EO encapsulated in the films did not exhibit antifungal action against these three fungi. When chitosan-cinnamon leaf EO coatings were applied to strawberries inoculated with $R$. stolonifer, they reduced the fungal decay of the fruits during 14 days, at $10{ }^{\circ} \mathrm{C}$, at the same time that total coliform counts were maintained at the initial levels.

Chitosan coatings with lemon essential oil were also active at controlling fungal decay in strawberries. These did not significantly affect the physicochemical parameters of strawberries throughout cold storage, while they slowed down the respiration rate of the fruits and enhanced the chitosan antifungal activity against $B$. cinerea. The coatings, with and without lemon EO, affected the strawberry volatile profile, although it was only sensory appreciated for samples coated with chitosan-lemon oil.

Blend films of $\mathrm{CH}$ and $\mathrm{MC}(1: 1)$ containing oregano EO caused phytotoxic problems at " 3 Leaves" stage of tomato plants, although the total biomass and crop yield was not affected. In the "Fruit" stage, the treatments had no negative effects. Coatings reduced the respiration rate of tomatoes, diminished weight loss during postharvest storage and were effective to decrease the fungal decay of tomatoes inoculated with $R$. stolonifer.

Migration of thymol and carvacrol from $\mathrm{CH}-\mathrm{MC}$ films in food simulants could overcome the stablished specific migration limit $(60 \mathrm{mg} / \mathrm{kg}$ ) for food contact packaging materials in aqueous and low pH systems if films contain a 1:1 polymer essential oil weight ratio. 


\section{RESUMEN}

En la presente tesis doctoral se han desarrollado y analizado diferentes materiales antifúngicos para su uso en conservación de frutas. Para ello, se han incorporado diferentes aceites esenciales (AE) en recubrimientos $y$ películas de quitosano ( $Q$ ). Se ha analizado el efecto de la adición de ácido oleico (AO) y las condiciones de homogeneización sobre la estabilidad de las emulsiones y sobre las propiedades de las películas obtenidas. También, se ha estudiado el efecto de los recubrimientos de $Q$ sobre el deterioro fúngico en fresas y el efecto preventivo frente a infecciones fúngicas de las mezclas de metilcelulosa ( $\mathrm{MC}$ ) con $\mathrm{Q}$ sobre plantas de tomate. Se ha estudiado el efecto de la composición de las películas sobre las propiedades funcionales de las mismas, así como su actividad antimicrobiana mediante análisis in vitro e in vivo.

La incorporación de $\mathrm{AO}$ en las películas de $\mathrm{Q}$ (proporción en peso 1:1) redujo la permeabilidad al vapor de agua en un $50 \%$ comparado con la matriz de $Q$ puro. El proceso de microfluidización indujo un pequeño efecto positivo sobre dicha reducción. La adición de AE (albahaca, hoja de canela y tomillo) no supuso una disminución notable de los valores de permeabilidad obtenidos para las películas de $Q$. En cambio, cuando se añadió $\mathrm{AO}$ a las formulaciones de $\mathrm{Q}$ y $\mathrm{AE}$ en las proporciones 1:1 o 1:2 con respecto al $Q$, se promovió una mejora significativa en las propiedades barrera al agua de las películas. Por el contrario, la adición de lípidos aumentó ligeramente la permeabilidad al oxígeno, disminuyó la elasticidad y la rigidez, y produjo un menor impacto sobre la resistencia a la rotura de las películas, en coherencia con el tamaño de partícula del lípido en la matriz polimérica. A su vez, la adición de AE modificó el comportamiento mecánico de las películas, dependiendo de su composición. Los AE de albahaca y tomillo aumentaron considerablemente la rigidez y la resistencia a la rotura de las películas, mientras que el $A E$ de hoja de canela redujo estos parámetros ligeramente. La adición de lípidos a las películas de Q también afectó las propiedades ópticas de los mismos. El AO redujo la transparencia y el brillo de las películas, en función de la concentración añadida. Sin embargo, provocó cambios poco significativos sobre los parámetros de color o el índice de blancura. Por el contrario, la adición de AE tuvo un pequeño impacto sobre la transparencia, y los parámetros de 
color y el índice de blancura de las películas de $\mathrm{Q}$ se vieron altamente afectados, debido a la absorción selectiva de la luz de los componentes del AE. Las mezclas de AE y AO mitigaron estos cambios de color. Además, la incorporación del $A E$ conjuntamente con el $A O$ redujo las pérdidas de volátiles del $A E$ durante la formación de las películas, debido a la mayor estabilidad de estas emulsiones formadoras de películas.

Las películas formuladas con el AE de hoja de canela fueron efectivas contra el crecimientos de Aspergillus niger, Botrytis cinerea y Rhizopus stolonifer, aunque los AE de albahaca y tomillo encapsulados en las películas no mostraron ninguna actividad antifúngica contra los citados hongos. La aplicación de los diferentes recubrimientos de Q-AE de hoja de canela en fresas inoculadas con $R$. stolonifer dio lugar a una reducción en el deterioro fúngico de los frutos almacenados durante 14 días a $10{ }^{\circ} \mathrm{C}$. Además, mantuvieron los recuentos de coliformes totales a niveles iniciales.

Los recubrimientos de Q-AE de limón también fueron efectivos en el control del deterioro fúngico en fresas. Estos recubrimientos no afectaron significativamente los parámetros físico-químicos de las fresas durante el almacenamiento en refrigeración, disminuyeron la tasa de respiración de los frutos y acentuaron la actividad antifúngica del $Q$ frente a $B$. cinerea. Tanto los recubrimientos con AE como los de $Q$ puro modificaron el perfil de volátiles de las fresas, aunque estos cambios solo fueron apreciados sensorialmente en el caso de los frutos recubiertos con AE.

Las mezclas de $\mathrm{Q}$ y $\mathrm{MC}(1: 1)$ que contenían $\mathrm{AE}$ de orégano causaron efectos fitotóxicos en plantas de tomate en el estadio "3 hojas", aunque no afectaron a la biomasa total. En el estadio "frutos" los tratamientos no tuvieron ningún efecto negativo. Los recubrimientos redujeron la tasa de respiración de los tomates, disminuyeron la pérdida de peso durante el almacenamiento post-cosecha y fueron efectivos contra el deterioro fúngico de tomates inoculados con $R$. stolonifer.

La migración de los compuestos fenólicos timol y carvacrol, contenidos en las películas de Q-MC, podría superar el límite de migración específica establecido (60 mg/Kg) para materiales de envase en contacto con alimentos en los casos de sistemas acuosos y de bajo $\mathrm{pH}$, en el caso de las películas cuya proporción polímero-AE sea 1:1. 


\section{RESUM}

En la present tesi doctoral s'han desenvolupat i analitzat diferents materials antifúngics per al seu ús en conservació de fruites. Per a això, s'han incorporat diferents olis essencials (OE) en recobriments i pel-lícules de quitosano (Q). S'ha analitzat l'efecte de l'addició d'àcid oleic (AO) i les condicions d'homogeneïtzació sobre l'estabilitat de les emulsions i sobre les propietats de les pel-lícules obtingudes. També, s'ha estudiat l'efecte dels recobriments de $Q$ sobre la deterioració fúngica en maduixes i l'efecte preventiu enfront d'infeccions fúngiques de les mescles de metilcelulosa (MC) amb Q sobre plantes de tomaca. S'ha estudiat l'efecte de la composició de les pel.lícules sobre les propietats funcionals de les mateixes, així com la seua activitat antimicrobiana mitjançant anàlisi in vitro i in vivo.

La incorporació de $\mathrm{AO}$ en les pel.lícules de $\mathrm{Q}$ (proporció en pes 1:1) va reduir la permeabilitat al vapor d'aigua en un $50 \%$ comparat amb la matriu de $Q$ pur. El procés de microfluidització va induir un petit efecte positiu sobre aquesta reducció. L'addició de AE (alfàbrega, fulla de canyella i timó) no va suposar una disminució notable dels valors de permeabilitat obtinguts per a les pel.lícules de $Q$. En canvi, quan es va afegir $A O$ a les formulacions de $Q$ i AE en les proporcions 1:1 o 1:2, es va promoure una millora significativa en les propietats barrera a l'aigua de les pel-lícules. Per contra, l'addició de lípids va augmentar lleugerament la permeabilitat a l'oxigen, va disminuir l'elasticitat i la rigidesa, i va produir un menor impacte sobre la resistència al trencament de les pel-lícules, en coherència amb la grandària de partícula del lípid en la matriu polimèrica. Al seu torn, l'addició de OE va modificar el comportament mecànic de les pel.lícules, depenent de la seua composició. Els OE d'alfàbrega i de timó van augmentar considerablement la rigidesa i la resistència al trencament de les pel.lícules, mentre que l'OE de fulla de canyella va reduir aquests paràmetres lleugerament. L'addició de lípids a les pel.lícules de $Q$ també va afectar les propietats òptiques dels mateixos. L'àcid oleic va reduir la transparència i la lluentor de les pel-lícules, en funció de la concentració afegida. No obstant això, va provocar canvis poc significatius sobre els paràmetres de color o l'índex de blancor. Per contra, l'addició d'OE va tenir un petit impacte sobre la transparència, i els paràmetres de color i l'índex de blancor de les pel-lícules de $Q$ es van veure 
altament afectats, a causa de l'absorció selectiva de la llum dels components de l'OE. Les mescles d'OE i AO van mitigar aquests canvis de color. A més, la incorporació de l'OE conjuntament amb AO va reduir les pèrdues de volàtils de l'OE durant la formació de les pel-lícules, a causa de la major estabilitat d'aquestes emulsions formadores de pel-lícules.

Les pel-lícules formulades amb l'OE de fulla de canyella van ser efectives contra el creixements d'Aspergillus niger, Botrytis cinerea i Rhizopus stolonifer, encara que els $\mathrm{OE}$ d'alfàbrega i de timó encapsulats en les pel-lícules no van mostrar cap activitat antifúngica contra els citats fongs. L'aplicació dels diferents recobriments de Q-OE de fulla de canyella en maduixes inoculades amb $R$. stolonifer va donar lloc a una reducció en la deterioració fúngica dels fruits emmagatzemats durant 14 dies a $10{ }^{\circ} \mathrm{C}$. A més, van mantenir els recomptes de coliformes totals a nivells inicials.

Els recobriments de Q-OE de llimona també van ser efectius en el control de la deterioració fúngica en maduixes. Aquests recobriments no van afectar significativament els paràmetres fisicoquímics de les maduixes durant l'emmagatzematge en refrigeració, van disminuir la taxa de respiració dels fruits i van accentuar l'activitat antifúngica del $Q$ enfront de B. cinerea. Tant els recobriments amb OE com els de Q pur van modificar el perfil de volàtils de les maduixes, encara que aquests canvis sol van ser apreciats sensorialment en el cas dels fruits recoberts amb OE.

Les mescles de Q i MC (1:1) que contenien OE d'orenga van causar efectes fitotòxics en plantes de tomaca en l'estadi "3 fulles", encara que no van afectar a la biomassa total. En l'estadi "fruits" els tractaments no van tenir cap efecte negatiu. Els recobriments van reduir la taxa de respiració de les tomaques, van disminuir la pèrdua de pes durant l'emmagatzematge post collita i van ser efectius contra la deterioració fúngica de tomaques inoculades amb $R$. stolonifer.

La migració dels compostos fenòlics timol i carvacrol, continguts en les pel-lícules de Q-MC, podria superar el límit de migració específica establit (60 mg/Kg) per a materials d'envàs en contacte amb aliments en els casos de sistemes aquosos i de baix $\mathrm{pH}$, en el cas de les pel-lícules que presentaven una proporció polímer-OE de 1:1. 


\section{INTRODUCTION}

Consumers demand for natural, healthy and safe food, as well as their awareness concerning environmental problems, has highly increased over the last years. To enhance food safety and quality, food packaging is a key point. In this sense, synthetic plastics have been widely used, which nowadays represent a source of environmental pollution and recycle costs. The development of biodegradable and active packaging materials, which allow us to adequately preserve foods, without causing contamination problems, is a social challenge which requires research and development.

Food spoilage is the result of the different actions caused by microbial contamination or physical, chemical and biological processes. Microbial action can lead to relevant changes in the product quality, but also can imply serious problems concerning the food safety when pathogens contaminate the product. Among food preservation processes to control the different spoilage mechanisms, the use of active packaging materials to prevent microbial action or oxidation processes is an interesting strategy to enlarge the product shelf-life. Active materials are based on polymers that act as carriers of antimicrobial or antioxidant compounds. They appear to be a promising choice to reduce food spoilage, especially when biodegradable polymers are used, thus reducing their environmental impact. Likewise, active biopolymer coatings and films can be used as sustained release devices of the active compounds to the food surface, in order to extend the food shelf-life, at the same time that they are environmentally-friendly materials.

Chitosan is the only pseudo natural cationic polysaccharide and thus, it has many applications that follow from its unique character (flocculants for protein recovery, depollution, etc.). Being soluble in acid aqueous solutions, it is largely used in different systems such as solutions, gels, or films and fibres. In this sense, chitosan offers a wide range of food applications, including formation of biodegradable films and coatings, immobilization of enzymes, preservation through its antimicrobial action or dietary supplement with hypocholesterolemic properties (Vargas and González-Martínez, 2010). 
As concerns film or coating development, chitosan exhibits several advantages such as antimicrobial, antioxidant and emulsifying properties and compatibility with other biopolymers and lipids. Thus, chitosan can yield films which can be adapted to a great variety of food applications. Besides its antimicrobial activity per se, chitosan also can be used as a carrier of bioactive substances to control microbial contamination on fresh or processed foods. In this sense the use of edible films or coatings containing antimicrobial substances can be more efficient than the direct addition of antimicrobial agents to the food since active compounds may selectively and gradually migrate from the package onto the surface of the food (Elsabee and Abdou, 2013).

Among natural antimicrobials, different essential oils (EO) have shown antibacterial and antifungal properties against a considerable number of pathogens and spoilage microorganism (Bakkali, Averbeck, Averbeck and Idaomar, 2008; Burt, 2004; Rivera Calo, Crandall, O'Bryan and Ricke, 2015; Sivakumar and Bautista-Baños, 2014). These compounds have been considered as safe and many EO currently in use, are approved by the FDA as flavouring agents, and widely used in the food industry. Therefore, EO could be incorporated into the food products to exert antimicrobial functions. Nevertheless, the main drawbacks of these compounds are their high volatility and the intense impact on the sensory perception, which limits their use for a great part of the food applications.

In this section, different studies into antimicrobial properties of essential oils and chitosan, as well as composite chitosan-essential oil films, are reviewed and summarized.

\subsection{Antimicrobial properties of essential oils}

Essential oils are gaining popularity and drawing the attention of researchers globally due to their biodegradable, eco-friendly and safety characteristics. Traditionally, essential oils and their components have been used in food industry as flavourings of some beverages and foods. However, these compounds have a great potential as food preservatives due to their high antimicrobial capacity, thus giving response to the consumer's demand for natural and healthy preservatives (Burt, 2004; Dorman and Deans, 2000). 
However, the use of essential oils as food preservatives is limited by their flavour characteristics. To inhibit their flavour impact, their encapsulation by different techniques, such as the inclusion in a polymer film, could be effective. In these cases, essential oil could also contribute to preserve the film, at the same time that their compounds interact with the polymer molecules and can act as plasticizers (Ruiz-Navajas, Viuda-Martos, Sendra, Pérez-Alvarez and Fernández-López, 2013). The release of antimicrobial agents from the edible films depends of many factors, including electrostatic interactions between the antimicrobial agent and the polymer chains, structural changes induced by the presence of antimicrobial, and environmental conditions (Avila-Sosa et al., 2012). In spite of this, it has been stated that, in comparison with direct application, smaller amounts of antimicrobial agents would be needed when films are used as carriers in order to achieve a specific food shelf life due to the gradual release on food surfaces (Ponce, Roura, del Valle and Moreira, 2008).

EO are aromatic liquids obtained from plant materials (flowers, buds, seeds, leaves, bark, etc.). Steam distillation is the most common method for extracting EO without loss of their properties. EO can include more than sixty individual components but major components can constitute up to $85 \%$ of the oil, whereas other components are present only as a trace (Burt, 2004). The main constituents of EO are terpenes (such as limonene, $\beta$-pinene, $p$-cymene, $\beta$-linalool, citral, $\gamma$-terpinene and estragol) and phenols (such as carvacrol, thymol and eugenol). Table I.1 shows the main components of the essential oils used in this doctoral thesis.

The small terpenoids and phenolic compounds found in their chemical composition appear to be responsible for antimicrobial activity of different essential oils (Helander et al., 1998), since the pure compounds are able to significantly decrease pathogenic bacteria counts in foods (Burt, 2004). Their mode of action has been described as a combination of different mechanisms acting at different level in the cell (Burt, 2004). On the one hand, hydrophobicity of the EO allows them to dissolve into the bacterial cell membrane and mitochondria, disturbing the structures and rendering them more permeable. Leakage of ions and other cell contents can then occur and inhibition of electron transport, protein translocation or phosphorylation cascades can ensue. Moreover, EO compounds can interact with ATPases of the cytoplasmic membrane (Burt, 2004; Tiwari et 
Table I.1 Main constituents of different essential oils and their wt. percentage (range), as reported by several authors.

\begin{tabular}{|c|c|c|c|c|}
\hline Essential oil & & Compounds & $\%$ & References \\
\hline \multirow[t]{5}{*}{ Basil } & \multirow{5}{*}{$\begin{array}{l}\text { Ocimum } \\
\text { basilicum }\end{array}$} & estragol & $45.8-86.1$ & \multirow{5}{*}{$\begin{array}{l}\text { Baratta et al., } 1998 \\
\text { Hussain et al., } 2008 \\
\text { Bozin et al., } 2006 \\
\text { Tampieri et al., } 2005\end{array}$} \\
\hline & & linalool & $20.3-60.6$ & \\
\hline & & menthone & 0-33.1 & \\
\hline & & cadinol, epi- $\alpha$ & $0-12.4$ & \\
\hline & & $\alpha$-bergamotene & $7.4-9.2$ & \\
\hline \multirow[t]{7}{*}{ Cinnamon leaf } & \multirow{5}{*}{$\begin{array}{l}\text { Cinnamomum } \\
\text { zeylacum }\end{array}$} & eugenol & $76.74-87.3$ & \multirow{5}{*}{$\begin{array}{l}\text { Paranagama et al., } 2001 \\
\text { Singh et al., } 2007\end{array}$} \\
\hline & & benzyl benzoate & 4.01 & \\
\hline & & bicyclogermacrene & 3.6 & \\
\hline & & $\beta$-caryophyllene & $1.9-3.47$ & \\
\hline & & $\alpha$-phellandrene & 1.9 & \\
\hline & \multirow{2}{*}{$\begin{array}{l}\text { Cinnamomum } \\
\text { verum }\end{array}$} & Eugenol & 74.1 & \multirow{2}{*}{ Tampieri et al., 2005} \\
\hline & & $\beta$-caryophyllene & 5.26 & \\
\hline \multirow[t]{3}{*}{ Lemon } & \multirow[t]{3}{*}{ Citrus lemon } & limonene & $59.10-71.06$ & \multirow{3}{*}{$\begin{array}{c}\text { Baratta et al., } 1998 \\
\text { Randazzo et al., } 2016 \\
\text { Caccioni et al., } 1998 \\
\text { Espina et al., } 2011\end{array}$} \\
\hline & & $\beta$-pinene & $5.20-12.8$ & \\
\hline & & $\gamma$-terpinene & $\operatorname{tr}-9.66$ & \\
\hline \multirow[t]{8}{*}{ Oregano } & \multirow{4}{*}{$\begin{array}{l}\text { Origanum } \\
\text { vulgaris }\end{array}$} & carvacrol & $32.0-61.3$ & \multirow{4}{*}{$\begin{array}{l}\text { Bozin et al., } 2006 \\
\text { Kulisic et al., } 2004 \\
\text { Tampieri et al., } 2005 \\
\text { Roselló et al., } 2015\end{array}$} \\
\hline & & thymol & $13.9-35.0$ & \\
\hline & & $\gamma$-terpinene & $4.75-10.5$ & \\
\hline & & p-cymene & $9.1-15.4$ & \\
\hline & \multirow{4}{*}{$\begin{array}{l}\text { Origanum } \\
\text { compactum }\end{array}$} & carvacroll & $22.0-36.5$ & \multirow{4}{*}{$\begin{array}{l}\text { Babili et al., } 2011 \\
\text { Bouhdid et al., } 2008 \\
\text { Mezzoug et al., } 2007\end{array}$} \\
\hline & & thymol & $19.4-29.7$ & \\
\hline & & $\gamma$-terpinene & $1.1-22.9$ & \\
\hline & & p-cymene & $7.9-24.3$ & \\
\hline \multirow[t]{13}{*}{ Thyme } & \multirow{4}{*}{$\begin{array}{l}\text { Thymus } \\
\text { vulgaris }\end{array}$} & thymol & $5.34-57.7$ & \multirow{4}{*}{$\begin{array}{c}\text { Rota et al., } 2008 \\
\text { Bozin et al., } 2006 \\
\text { Tampieri et al., } 2005\end{array}$} \\
\hline & & p-cymene & $17-53-18.7$ & \\
\hline & & $\gamma$-terpinene & 8.3-9.92 & \\
\hline & & carvacrol & $2.8-41.33$ & \\
\hline & \multirow[t]{4}{*}{ Thymus zygis } & thymol & $0.5-68.1$ & \multirow{4}{*}{ Rota et al., 2008} \\
\hline & & linalool & $2.0-39.2$ & \\
\hline & & E-sabinene hydrate & $0.2-18.2$ & \\
\hline & & terpinen-4-ol & $0.2-11.0$ & \\
\hline & \multirow{5}{*}{$\begin{array}{l}\text { Thymus } \\
\text { hyemalis }\end{array}$} & thymol & $2.9-43$ & \multirow{5}{*}{ Rota et al., 2008} \\
\hline & & carvacrol & $0.3-40.1$ & \\
\hline & & p-cymene & $16.0-19.8$ & \\
\hline & & $\gamma$-terpinene & $\operatorname{tr}-9.8$ & \\
\hline & & linalool & $2.1-16.6$ & \\
\hline
\end{tabular}


al., 2009). These interactions of the EO with the cell membranes and subsequent leakage of cellular components, such as the ATP (the main energy-storing molecule) lead to the cell death (Sivakumar and Bautista Baños, 2014).

On the other hand, low concentrations of EO components can affect energetic production of enzymes, whereas high concentrations can provoke protein denaturation. Furthermore, EO components can also affect the proteins of the cytoplasmic membrane or even can cross the porines of Gram-negative bacteria, thus gaining access to their periplasm (Bakkali, Averbeck, Averbeck and Idaomar, 2008; Burt, 2004; Dorman and Deans, 2000; Lambert, Skandamis, Coote and Nychas, 2001). As a result of the non-specific mechanism of action, in contrast with antibiotics, there are no published works on the microbial resistance or adaptation to biocide concentrations of EO (Bakkali, Averbeck, Averbeck and Idaomar, 2008).

Different studies reported antimicrobial, allelopathic, antioxidant and bio regulatory properties of some EO (Caccioni and Guizzardi, 1994; Vaughn and Spencer, 1991) and therefore they can be ideal candidates for use as pesticides (Macias, Castellano, Oliva, Cross and Torres, 1997). Some EO, exhibited fungicidal properties and could be applied to suppress fungal growth in different fresh produce (Imelouane, Elbachiri, Ankit, Benzeid and Khedid, 2009; Meepagala, Sturtz and Wedge, 2002; Wilson et al., 1997a; Wilson, Solar, El Ghaouth and Wisniewski, 1997b) while also being safer for the environment than synthetic fungicides. Nevertheless, EO can be toxic if they are used in high concentrations (Burt, 2004; Gutiérrez, Barry-Ryan and Bourke, 2008; Holley and Patel, 2005).

The antimicrobial effect of EO against bacteria has been extensively studied and reported (Bakkali, Averbeck, Averbeck and Idaomar, 2008; Burt, 2004; Rivera Calo, Crandall, O'Bryan and Ricke, 2015; Sivakumar and Bautista Baños, 2014). There is no general agreement regarding the antimicrobial activity of EO against Gram-positive and Gram-negative bacteria. Most studies have concluded that Gram-positive bacteria are more susceptible to EO action. Nevertheless, several studies report similar or stronger inhibiting action against Gram-negative bacteria (Kunicka-Styczyńska, 2011; Valencia-Chamorro, Palou, Del Río and Pérez-Gago, 2011). However, the studies on their effect against fungi are limited. Roselló, Sempere, Sanz-Berzosa, Chiralt and Santamarina (2015) 
studied the potential of different EO's (bay leaf, oregano, cinnamon and clove) to control the growth of two fungal pathogens (Fusarium culmorum and Fusarium verticillioides), resulting in a growth inhibition over $90 \%$, being the oregano EO the most effective product. Tzortzakis (2009) studied the in vitro antifungal activity of cinnamon EO against Aspergillus niger, Botrytis cinerea, Cladosporium herbarum, Colletotrichum coccodes and Rhizopus stolonifer and reported a significant reduction of the colony development, and a total inhibition of fungal sporulation (except for B. cinerea). Muriel-Galet, Cran, Bigger, Hernández-Muñoz and Gavara (2015) studied the antifungal properties of oregano EO, incorporated into an ethyl-ene-vinyl alcohol copolymer (EVOH), against Penicillium expansum, detecting a total inhibition of the fungal growth. Some authors have explained the effect of EO on postharvest fungal pathogens mainly due to their direct effect on the mycelial growth and spore germination by affecting the cellular metabolism (Regnier, Combrinck, Du Plooy and Botha, 2010; Serrano, Martínez-Romero, Castillo, Guillen and Valero, 2005; Tzortzakis, 2007a, 2007b).

\subsection{Properties of chitosan of interest to develop edible films or coatings}

Chitosan $(\mathrm{CH})$ exhibits very good film-forming properties, which are affected by its molecular weight distribution and solvent conditions in the film-forming solutions (Vargas, Albors, Chiralt and González-Martínez, 2011a). These determine the chain extension and the establishment of inter-chain bonds and packing when water evaporates. Several advantages of chitosan in films, such its antimicrobial, antioxidant and emulsifying properties and its compatibility with other biopolymers and lipids have also reported (Dutta, Tripathi, Mehrotra and Dutta, 2009; Elsabee and Abdou, 2013). Different aspects related with the chitosan properties for film development are commented below.

\subsubsection{Molecular structure of chitosan and properties of their aqueous dispersions}

Chitosan, is a cationic polysaccharide obtained from partial N-deacetylation of chitin (more than 50 \% of deacetylation, Rinaudo, 2006). Its molecular structure corresponds to $(1 \rightarrow 4)$-2-amine-2-deoxy- $\beta$-D-glucan and $(1 \rightarrow 4)$-2-acetamide-2-deoxy- $\beta$-D-glucan co-polymer (Figure I.1). Chitin, poly (b-(1-4)-N-acetyl-D-glucosamine), is a natural polysaccharide 
synthesized from the shells of crustacean such as crab, shrimp, and crawfish (No, Park, Lee and Meyers, 2002) and it is the most abundant polymer after cellulose. The most widely used industrial method to obtaining $\mathrm{CH}$ is the chemical method and the result is a mixture of $\mathrm{CH}$ chains with different molecular weights and deacetylation degrees, which determine the properties and functionality of the polymer (Shahidi and Abuzaytoun, 2005). Thereby, different types of $\mathrm{CH}$ can be found: low (50,000-190,000 Da), medium (190,000-310,000 Da) and high (310,000 - 375,000 Da) molecular weight.

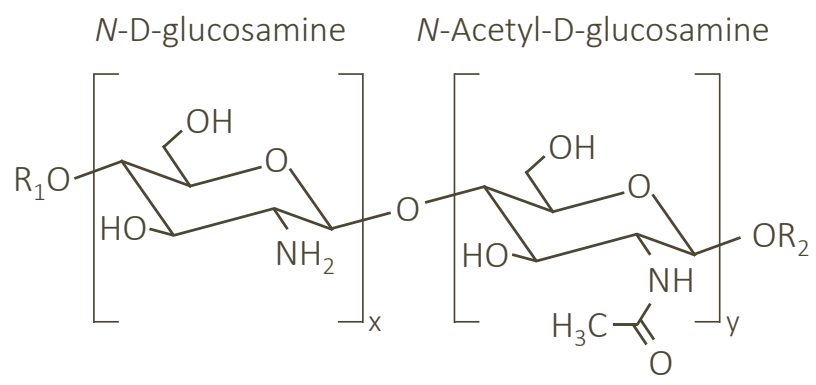

Figure I.1 Molecular structure of chitosan

In contrast with chitin, $\mathrm{CH}$ is soluble in low $\mathrm{pH}$ aqueous media. The dissolution occurs by protonation of the $-\mathrm{NH}_{2}$ function on the $\mathrm{C}-2$ position of the D-glucosamine repeat unit, whereby the polysaccharide is converted to a polyelectrolyte in aqueous solutions. The conformation of $\mathrm{CH}$ in solution greatly depends on the structural parameters of the molecule (i.e. degree of deacetylation and chain length) and solution parameters, such as ionic strength, $\mathrm{pH}$ and dielectric constant of the solvent, etc. (Sorlier, Viton and Domard, 2002). Therefore, the properties of the solvent (ionic concentration, $\mathrm{pH}$ ) play a very important role in the behaviour of chitosan-based film-forming solutions or dispersions. Functional properties of films or coatings based on $\mathrm{CH}$ are greatly affected by physicochemical properties of chitosan-based dispersions (Vargas, Albors, Chiralt and González-Martínez, 2011a). The analysis of the surface charge of the macromolecules, their size distribution and rheological properties, among other factors (McClements, 2007) allows us to obtain useful criteria to understand differences in the film properties. 


\subsubsection{Antimicrobial properties of chitosan}

The positive charges of the polymer chains are also responsible for the antimicrobial effect against bacteria, fungi and yeasts (Agulló, Rodríguez, Ramos and Albertengo, 2003; No, Meyers, Prinyawiwatkul and Xu, 2007; Shahidid, Arachchi and Jeon, 1999).

There is no general agreement in the literature regarding the antimicrobial activity of $\mathrm{CH}$. The mechanism of antibacterial action of $\mathrm{CH}$ against Gram-positive and Gram-negative bacteria is different because of the structural differences of the bacteria (Kong, Chen, Xing and Park, 2010). Positive $\mathrm{CH}$ chains electrostatically interact with negative charges of the cell membrane of the bacteria. Binding of chitosan with DNA and inhibition of mRNA synthesis occurs through chitosan penetration toward the nuclei of the microorganisms and interference with the synthesis of mRNA and proteins (Coma, 2012; Dutta, Tripathi, Mehrotra and Dutta, 2009; Shahidi, Arachchi and Jeon, 1999). In Gram-negative bacteria, CH could also compete with the lipopolysaccharide and proteins of the surface for the divalent cations of the external membrane, thus altering the cell function or provoking the cell lysis. The mechanism of action of $\mathrm{CH}$ with Gram-positive bacteria could be the formation of a polymeric membrane of $\mathrm{CH}$ on the cell surface, which inhibits nutrients from entering the cell or the interaction with negative charges of phosphoryl groups of phospholipid components of cell membranes.

The effect of the molecular weight on some antibacterial and antifungal activities has been explored (Chen, Liau and Tsai, 1998). Low molecular weight $\mathrm{CH}(10,000$ to $100,000 \mathrm{Da})$ have been found to be helpful in restraining the growth of bacteria. However, chitosan with of 9,300 molecular weight was effective in restraining Escherichia coli, whereas it accelerated the growth when molecular weight was 2,200 (Seiichi, Yoshiaki, Masayoshi, Norio and Shin-Ichiro, 1994). Low molecular weight CH can diffuse through the cell wall altering the cell metabolism (Dutta, Tripathi, Mehrotra and Dutta, 2009; Kong, Chen, Xing and Park, 2010; No, Meyers, Prinyawiwatkul and $\mathrm{Xu}, 2007)$. The antibacterial activity of chitosan is also affected by its deacetylation degree, its concentration in solution, and the pH of the medium (Dutta, Tripathi, Mehrotra and Dutta, 2009; Kong, Chen, Xing and Park, 2010). 
Nevertheless, numerous previous studies have shown that chitosan could directly inhibit spore germination, germ tube elongation and mycelial growth of many phytopathogens, such as Botrytis cinerea (Chien and Chou 2006; El Ghaouth, Arul, Grenier and Asselin, 1992; Liu, Tian, Meng and Xu, 2007), Fusarium solani (Eweis, Elkholy and Elsabee, 2006), Rhizopus stolonifer (El Ghaouth, Arul, Grenier and Asselin, 1992; Hernández-Lauzardo et al., 2008), Penicillium (Chien and Chou, 2006; Liu, Tian, Meng and Xu, 2007), and Sclerotium rolfsii (Eweis, Elkholy and Elsabee, 2006). Liu, Tian, Meng and Xu (2007) reported that chitosan completely inhibited spore germination of $P$. expansum at $0.5 \%$ and $B$. cinerea at $1 \%$. Likewise, it significantly inhibited germ tube elongation of both pathogens when the concentration was higher than $0.01 \%$ while the plasma membranes of spores were damaged in both cases.

The reasons for the antimicrobial character of chitosan remain controversial and different mechanisms have been proposed to describe the antifungal effect of CH (Agulló, Rodríguez, Ramos and Albertengo, 2003; Dutta, Tripathi, Mehrotra and Dutta, 2009; Kong, Chen, Xing and Park, 2010). Two hypotheses are as follows: (a) The polycationic chitosan consumes the electronegative charges on cell surfaces and the cell permeability is changed, thus this interaction results in the leakage of intracellular electrolytes and proteinaceous constituents; (b) chitosan enters fungal cells and then essential nutrients are adsorbed, which inhibit or slow down the synthesis of mRNA and protein (Avadi et al., 2004; Chen, Liau and Tsai, 1998; Chen, Wu and Zeng, 2005; El Ghaouth, Arul, Wilson and Benhamou, 1997; Jia, Shen and Xu, 2001).

Applied in preharvest treatments, chitosan has a dual function: (a) to direct interfere of fungal growth and (b) to activate several defence processes (Bai, Huang and Jiang, 1988). These defence mechanisms include accumulation of chitinases, synthesis of proteinase inhibitors, and lignification and induction of callous synthesis (El Ghaouth et al., 2000). It produced different alterations such as lignification or phytoalexin production when applied on wheat leaves and germinating peanuts, respectively (Cuero, Duffus, Osuji and Pettit, 1991a; Cuero, Osuji and Washington, 1991b). Chitosan has also been found to inhibit growth and toxin production by Alternaria alternata fungal species in lycopersici culture 
(Dornenburg and Knorr, 1997; Dutta, Tripathi, Mehrotra and Dutta, 2009; Reddy et al., 1998)

\subsubsection{Physical properties of chitosan-based films}

Chitosan has an excellent film-forming ability with no need for plasticizing compounds (Domard and Domard, 2001; Kittur, Kumar, and Tharanathan 1998; Vargas and González-Martínez, 2010). In fact, some physical and chemical advantages of chitosan as coating material are the hydrophilicity introduced by the polar groups able to form secondary interactions ( $-\mathrm{OH}$ and $-\mathrm{NH}_{2}$ groups involved in $\mathrm{H}$ bonds) which reinforce film matrix, thus leading to films with good mechanical performance and barrier capacity. Chitosan films exhibit low permeability to oxygen and carbon dioxide and they show good mechanical properties. However, one of the most important drawbacks in relation to their potential food application is their high water vapour permeability (WVP), derived from the hydrophilic nature.

In order to improve the water vapour barrier properties of $\mathrm{CH}$ films, lipid compounds can be added to chitosan-based matrices. These, in turn, can have an effect on the microstructural, mechanical, optical and oxygen-transfer properties of $\mathrm{CH}$ coatings. The effect of the lipid incorporation on the film properties depends on the concentration on the type of molecules and the structure and stability of the film-forming emulsion (lipid droplets in the chitosan aqueous phase). Differences in the emulsion droplet size and charge and the other factors determining the emulsion stability could lead to films with different characteristics. In these sense, it is remarkable that during the film drying step, water evaporation overlaps with different destabilization phenomena occurring in the emulsion (flocculation, coalescence and creaming) leading to a determined lipid arrangement in the final film structure (Chiralt, Talens, Monedero and Fabra, 2015).

Lipid compounds can enhance the water-barrier properties of chitosan-based films due to their hydrophobic nature and the structural effects. The presence of an oil dispersed phase in the film matrix increases the tortuosity factor for water transfer through the film, thus increasing the distance travelled by the diffusing water molecules, slowing the mass transfer rate. The tortuosity factor is higher when the oil phase ratio 
increases or when the oil particle size is reduced (Morillon, Debeaufort, Blond, Capelle and Voilley 2002). In this sense, the use of microfluidization has led to a significant reduction in the particle size of chitosan-oleic acid FFD when compared with rotor-stator homogenization. The tortuosity factor increases (higher number of dispersed particles in the film matrix) and a significant decrease in the WVP is promoted (Vargas, Perdones, Chiralt, Cháfer and González-Martínez, 2011b).

Optical properties of chitosan-based coatings are also affected by the nature and the concentration of the added lipids. The gloss of the films is linked to the morphology of their surface; the smoother the surface, the higher the gloss. Lipids such as essential oils led to a decrease in the gloss of $\mathrm{CH}$ films, regardless of EO concentration. The decrease in gloss with the incorporation of EO might be explained by the increase in the surface roughness of the composite films. This roughness appears as a consequence of the migration of droplets or aggregates to the top of the coating during drying, which leads to surface irregularities. A consequence of the highly volatile nature of the EO is that the coating surface shows plenty of voids. In turn, this contributes to the reduction in gloss (Sánchez-González, Cháfer, Chiralt and González-Martínez, 2010b). In contrast, the gloss of $\mathrm{CH}$ films significantly increased by incorporating of oleic acid (Vargas, Albors, Chiralt and González-Martínez, 2009a). This increase has been explained by the coalescence and creaming of the oleic acid droplets during film drying, which leads the presence of a thin layer of lipid at the film surface which reduces its roughness, increasing the specular reflectance at the air-film interface (Vargas, Albors, Chiralt and González-Martínez, 2009a).

Typical values of physical properties of chitosan films (pure or containing other compounds) are shown in Table 1.2, as reported by different authors. Comparing these values with those of exhibited by other biopolymer films, it can be stated that $\mathrm{CH}$ has good mechanical and optical properties, excellent oxygen barrier capacity and moderate water vapour permeability which could be improved by lipid incorporation (Sánchez-González, Chiralt, González-Martínez and Cháfer, 2011a; Vargas, Albors, Chiralt and González-Martínez, 2009a). 
Table I.2 Reported values of elastic modulus (EM, MPa), tensile strength (TS, MPa), elongation at break (E, \%), water vapour permeability (WVP $\left.\times 10^{11}, \mathrm{~g} \cdot \mathrm{Pa}^{-1} \cdot \mathrm{s}^{-1} \cdot \mathrm{m}^{-1}\right)$, oxygen permeability (OP, $\left.\mathrm{cm}^{3} \cdot \mu \mathrm{m} \cdot \mathrm{m}^{-2} \cdot \mathrm{d}^{-1} \cdot \mathrm{KPa}^{-1}\right)$, gloss and transparency $(\mathrm{Ti}, \lambda=450 \mathrm{~nm})$ for films of chitosan (pure or containing other component- $\mathrm{X})$, conditioned at a determined temperature $\left(\mathrm{T},{ }^{\circ} \mathrm{C}\right)$ and relative humidity $(\mathrm{RH}, \%)$.

\begin{tabular}{|c|c|c|c|c|c|c|c|c|c|c|c|}
\hline $\begin{array}{l}\text { Other film } \\
\text { compounds }(X)\end{array}$ & $\begin{array}{l}\mathrm{CH}: \mathrm{X} \\
\text { ratio }\end{array}$ & $\mathrm{T}$ & $\mathrm{RH}$ & EM & TS & $E$ & WVP & $\mathrm{OP}$ & Gloss $60^{\circ}$ & $T_{i}$ & Reference \\
\hline None & & 5 & 58 & $2448(252)$ & $74(11)$ & $4.6(0.8)$ & $61(6)$ & & $14(4)$ & & \multirow{5}{*}{$\begin{array}{l}\text { Bonilla et al., } 2011 \\
\text { Bonilla et al., } 2012\end{array}$} \\
\hline Basil EO & $2: 1$ & & & 1932 (341) & $68(18)$ & $19(9)$ & $61(7)$ & & $7(2)$ & & \\
\hline Basil EO & $1: 1$ & & & $1199(138)$ & $43(6)$ & $18(10)$ & $73(6)$ & & $9(3)$ & & \\
\hline Thyme EO & $2: 1$ & & & & & & $58.9(0.9)$ & & $9(2)$ & & \\
\hline Thyme EO & $1: 1$ & & & & & & $73(3)$ & & $5.2(1.5)$ & & \\
\hline None & & 25 & 75 & $2739(93)$ & $94(15)$ & $14(7)$ & $120(10)$ & $14.4(0.5)$ & $47(13)$ & & \multirow{3}{*}{ Pastor et al., 2013} \\
\hline Resveratrol & 1:0.01 & & & $2585(151)$ & $78(2)$ & $6(2)$ & $120(20)$ & $16(1)$ & $36(14)$ & & \\
\hline Resveratrol & $1: 0.1$ & & & $1550(195)$ & $43(3)$ & $5.1(0.4)$ & $119(5)$ & $11.2(0.4)$ & $20(6)$ & & \\
\hline None & & 20 & 54.4 & $2182(277)$ & $113(20)$ & $22(5)$ & $124(12)$ & & $32(5)$ & $0.801(0.013)$ & \multirow{11}{*}{$\begin{array}{l}\text { Sánchez-González et al., 2010b } \\
\text { Sánchez-González et al., 2011a }\end{array}$} \\
\hline Bergamot EO & $2: 1$ & & & 766 (205) & $65(10)$ & $7(4)$ & $130.2(0.3)$ & & $9(3)$ & $0.761(0.012)$ & \\
\hline Bergamot EO & $1: 1$ & & & $799(163)$ & $63(21)$ & $5.5(0.7)$ & $86(5)$ & & $4.9(1.2)$ & $0.746(0.014)$ & \\
\hline Bergamot EO & $1: 2$ & & & $747(225)$ & $50(8)$ & $6(2)$ & $92(9)$ & & $8.8(1.5)$ & $0.744(0.012)$ & \\
\hline Bergamot EO & $1: 3$ & & & $682(196)$ & $22(8)$ & $1.7(0.4)$ & $65(2)$ & & & & \\
\hline Lemon EO & $2: 1$ & & & $1534(185)$ & $94(9)$ & $18.1(0.8)$ & $88(4)$ & & $17(2)$ & $0.764(0.015)$ & \\
\hline Lemon EO & $1: 1$ & & & $1466(160)$ & $57(7)$ & $14.6(0.4)$ & $77(3)$ & & $15(2)$ & $0.765(0.009)$ & \\
\hline Lemon EO & $1: 2$ & & & 954 (113) & $37(3)$ & $6.4(0.2)$ & $99(4)$ & & $9.9(1.8)$ & $0.782(0.009)$ & \\
\hline Tea Tree EO & $2: 1$ & & & 1447 (308) & $75(15)$ & $20(8)$ & $97(4)$ & & $28(5)$ & $0.757(0.018)$ & \\
\hline Tea Tree EO & $1: 1$ & & & 1419 (322) & $72(12)$ & $17(6)$ & $100.9(1.3)$ & & $19(2)$ & $0.764(0.009)$ & \\
\hline Tea Tree EO & $1: 2$ & & & $653(157)$ & $54(6)$ & $8(2)$ & $74.8(1.8)$ & & $5.7(1.2)$ & $0.789(0.013)$ & \\
\hline None & & 5 & 58.5 & $310(256)$ & $12(8)$ & $17(8)$ & 160 & & & & \multirow{4}{*}{ Vargas et al., 2009a } \\
\hline Oleic acid & $1: 1$ & & & $495(282)$ & $18(5)$ & $15(8)$ & 145 & & & & \\
\hline Oleic acid & $1: 2$ & & & 202 (126) & $7(2)$ & $11(7)$ & 95 & & & & \\
\hline Oleic acid & $1: 4$ & & & $223(51)$ & $7.4(1.9)$ & $11(5)$ & 70 & & & & \\
\hline
\end{tabular}




\subsubsection{Antimicrobial properties of chitosan-based films and coatings}

Many studies about the antimicrobial characteristics of films made from $\mathrm{CH}$ have been carried out in the last few years (Chen, Yeh and Chiang, 1996; Coma, Martial-Gros, Garreau, Copinet and Deschamps, 2002; Ouattara, Simard, Piette, Begin and Holley, 2000a, 2000b). The wide spectrum of the antimicrobial action of $\mathrm{CH}$, which has been effective against fungi, yeasts and bacteria, has been pointed out in numerous studies; and several hypothesis about the mode of action of $\mathrm{CH}$ in liquid and solid media have been reported (Kong, Chen, Xing and Park, 2010). However, the exact mechanism of bacterial and fungal inhibition of chitosan-based coatings is not fully understood (since other factors such as anaerobic conditions promoted by the low oxygen permeability of $\mathrm{CH}$ coatings should be considered). The incorporation of antimicrobial compounds such as peptides, metals or EO in the film matrix can also enhance the antimicrobial action of CH films or coatings (Dutta, Tripathi, Mehrotra and Dutta, 2009).

Recent approaches have shown an improvement in the antimicrobial effect of chitosan-based films with the addition of silver nanoparticles alone (Yoksan and Chirachanchai, 2010) or in combination with zinc oxide (Li, Deng, Deng, Liu and Li, 2010). Essential oils have been extensively evaluated as antimicrobial compounds that can be incorporated into edible films and coatings (Bonilla, Vargas, Atarés and Chiralt, 2011; Bonilla, Atarés, Vargas and Chiralt, 2012; Ojagh, Rezaei, Razavi and Hosseini, 2010; Sánchez-González, González-Martínez, Chiralt and Cháfer, 2010a; Sánchez-González, Cháfer, Chiralt and González-Martínez, 2010b; Sánchez-González, Vargas, González-Martínez, Chiralt and Cháfer, 2011b; Zivanovic, Chi and Draughon, 2005). The antimicrobial effect of chitosan-essential oil films has been found to depend on the target microorganisms. For instance, pure $\mathrm{CH}$ films have promoted a complete inhibition of the growth of Escherichia coli in in vitro studies, whereas this effect was not been observed for $\mathrm{CH}$-EO composite films. The dilution effect of $\mathrm{CH}$ provoked by the non-active EO (bergamot oil or tea tree essential oils) could explain this result (Sánchez-González, Chiralt, González-Martínez and Cháfer, 2011a). However, pure CH films were not effective against Penicillium italicum, whereas $\mathrm{CH}$-EO composite films show significant antifungal properties (Sánchez-González, Cháfer, Hernández, Chiralt and González-Martínez, 2011c). 
An important issue that has to be considered when incorporating antimicrobial agents into $\mathrm{CH}$ coatings is the control of the release and diffusion of active compounds. These depend on the solubility of active compounds, as well as on film microstructure, the characteristics of the solvent, the migrant and the type of food coated, together with storage conditions (Cagri, Ustunol and Ryser, 2004). The release kinetics of limonene from $\mathrm{CH}$ films containing bergamot essential oil has been evaluated in different food simulants (ethanol aqueous solutions and isooctane). The antimicrobial efficacy of chitosan-bergamot essential oil films could be improved by maintaining higher water content in the films, since it favours the diffusion of limonene towards the product surface. The solubility of limonene is higher in non-polar foods media, such as fats, but its release from the film is slower with film contacts with non-polar food simulants due to the lack of film hydration which facilitates mass transfer (Sánchez-González, Cháfer, González-Martínez, Chiralt and Desobry, 2011d).

Chitosan-based coatings have been applied to a great variety of agro-food products such as fresh and minimally-processed fruits and vegetables in order to improve their preservation. A summary of the most recent applications and the observed effects is shown in Table I.3.

As regards fresh fruits and vegetables, the reported effects of $\mathrm{CH}$ coatings include, among others, a reduction in respiration rate, a preservation of fruit colour and firmness and, in general, an extension of shelf-life. Moreover, the addition of fatty acids or $\mathrm{EO}$ into the $\mathrm{CH}$ matrix can improve the water vapour barrier of coatings, thus diminishing product weight loss. The latter was observed for bergamot essential oil-CH coatings applied to grapes (Sánchez-González et al., 2011e) in agreement with the reduction of WVP values of the corresponding stand-alone films (Sánchez-González, Cháfer, Chiralt and González-Martínez, 2010b). CH-bergamot essential oil coatings have also inhibited both oxygen consumption and carbon dioxide generation throughout storage, which can be due to the low oxygen permeability of chitosan-based coatings.

$\mathrm{CH}$ coatings alone or in combination with lemon essential oil or oleic acid have also promoted a significant reduction in the postharvest metabolism of cold-stored strawberries (Perdones, Sánchez-González, Chiralt and Vargas, 2012; Vargas, Albors, Chiralt and González-Martínez, 2006). 
Table I.3 Applications of chitosan-based films to agro-food products.

\begin{tabular}{|c|c|c|c|}
\hline Other film compounds (X) & Product & Main effect & References \\
\hline None & $\begin{array}{l}\text { Papaya } \\
\text { Litchi }\end{array}$ & Decrease in respiration rate & $\begin{array}{l}\text { Ali et al., } 2011 \\
\text { Lin et al., } 2011\end{array}$ \\
\hline Oleic acid & Strawberry & Control of fungal decay & Vargas et al., 2006 \\
\hline Lemon essential oil & Strawberry & Control of fungal decay & Perdones et al., 2012 \\
\hline Bergamot EO & Grape & Reduction in weight loss & Sánchez-González et al., 2011e \\
\hline $\begin{array}{l}\text { Tea tree essential oil } \\
\text { Thyme essential oil } \\
\text { Bergamot essential oil }\end{array}$ & Orange & Control of fungal decay caused by $P$. italicum & Cháfer et al., 2012 \\
\hline $\begin{array}{l}\text { Essential oil } \\
\text { Bioactive compounds }\end{array}$ & Fresh-cut broccoli & $\begin{array}{l}\text { Control of the survival of } E \text {. coli and } L \text {. } \\
\text { monocytogenes }\end{array}$ & $\begin{array}{l}\text { Moreira et al., } 2011 \\
\text { Alvarez et al., } 2013\end{array}$ \\
\hline $\begin{array}{l}\text { Lime essential oil } \\
\text { Thyme essential oil }\end{array}$ & Tomato & Inhibition of growth of $R$. stolonifer and E. coli & Ramos García et al., 2012 \\
\hline Oregano essential oil & Grape & Inhibition of growth of $R$. stolonifer and A. niger & dos Santos et al., 2012 \\
\hline Cinnamon essential oil & Sweet pepper & Decrease in fungal infection levels & Xing et al., 2011 \\
\hline
\end{tabular}


$\mathrm{CH}$ based coatings also affected the colour and appearance of fresh fruits and vegetables. A decrease in lightness after coating application was detected in strawberries coated with $\mathrm{CH}$-oleic acid films (Vargas, Albors, Chiralt and González-Martínez, 2006). The incorporation of oleic acid into these coatings diminished the changes in lightness, in agreement with the lower WVP of these coatings and their better preservation effect on fruit water content (Vargas, Albors, Chiralt and González-Martínez, 2009a). The application of chitosan-based coatings to strawberries also caused a decrease in the percentage of fungal infected fruits. The addition of oleic acid or lemon EO enhanced the antifungal effect of $\mathrm{CH}$ in strawberries (Perdones, Sánchez-González, Chiralt and Vargas, 2012; Vargas, Albors, Chiralt and González-Martínez, 2006). Cinnamon oil incorporated into chitosan coatings exhibited the best control on fungal decay (below $5 \%$ ) in sweet peppers, as compared with un-coated samples, which showed a decay incidence of $34 \%$ (Xing et al., 2011).

$\mathrm{CH}$ based coatings have been used to extend the shelf-life of different types of fresh-cut or minimally-processed fruits and vegetables. The reported effects of such coatings are similar to those of coatings used for fresh fruits and vegetables, with a special focus on the inhibition of enzymatic browning that occurs after cutting (Vargas, Pastor, Chiralt, McClements and González-Martínez, 2008). In some cases, coatings preserve the initial colour of the coated fresh-cut samples. This is the case with fresh-cut carrots, in which $\mathrm{CH}$ coatings delay the occurrence of white-blush during storage. White blush in fresh-cut carrots is caused, among other factors, by surface dehydration, and the latter may be delayed by maintaining an excess of moisture on the surface of the carrot. Highly hydrophilic coatings, such as chitosan-based coatings, have created a wet film that covers the cut surface of fresh-cut carrots, thus preventing surface dehydration and reducing the whiteness index (Vargas, Chiralt, Albors and González-Martínez, 2009b). The effectiveness of $\mathrm{CH}$ is also influenced by the method of application, being dipping in the film-forming dispersion the most common technique. In this sense, the use of a vacuum pulse during sample immersion enhanced the adhesion of $\mathrm{CH}$ coatings and their protective effect (Talens, Pérez-Masiá, Fabra, Vargas and Chiralt, 2012). 


\subsection{Final remarks}

Chitosan-based films have shown great potential to extend the shelf-life of a diversity of agro-food products. Since $\mathrm{CH}$ coatings can encapsulate bioactive compounds, more studies are required to develop practical applications of chitosan based films and coatings for food preservation and self-life extension. These should be focused into different aspects: selection of specific active compounds for a target microorganism and product, effect of these compounds on the film functional properties, release kinetics and total migration of the actives in different food simulants and specific foods, antimicrobial studies in model and real foods. 


\section{REFERENCES}

Agulló, E., Rodríguez, M.S., Ramos, V., Albertengo, L. Present and future role of chitin and chitosan in food. Macromolecular Bioscience 3:10 (2003) $521-530$.

Ali, A., Muhammad, M.T.M., Sijam, K., Siddiqui, Y. Effect of chitosan coatings on the physicochemical characteristics of Eksotika II papaya (Carica papaya L.) fruit during cold storage. Food Chemistry 124:2 (2011) $620-626$.

Alvarez, M.V., Ponce, A.G., Moreira, M.D.R. Antimicrobial efficiency of chitosan coating enriched with bioactive compounds to improve the safety of fresh cut broccoli. LWT - Food Science and Technology 50:1 (2013) $78-87$.

Avadi, M.R., Sadeghi, A.M.M., Tahzibi, A., Bayati, K., Pouladzadeh, M., Zohuriaan-Mehr, M.J. Diethylmethyl chitosan as an antimicrobial agent: Synthesis, characterization and antibacterial effects. European Polymer Journal 40:7 (2004) 1355 - 1361.

Avila-Sosa, R., Palou, E., Jiménez Munguía, M.T., Nevárez-Moorillon, G.V, Cruz, A.R.N., López-Malo. Antifungal activity by vapor contact of essential oils added to amaranth, chitosan, or starch edible films. International Journal of Food Microbiology 153:1 (2012) 66- 72.

Babili, F. E., Bouajila, J., Souchard, J. P., Bertrand, C., Bellvert, F., Fouraste, I., Moulis, C., Valentin, A. Oregano: Chemical analysis and evaluation of its antimalarial, antioxidant, and cytotoxic activities. Journal of Food Science 76:3 (2011) C512 - C518.

Bai, R.K., Huang, M.Y., Jiang, Y.Y. Selective permeabilities of chitosanacetic acid complex membrane and chitosan-polymer complex membranes for oxygen and carbon dioxide. Polymer Bulletin 20 (1988) 83 - 88. 
Baratta, M.T., Dorman, H.J.D., Deans, S.G., Figueiredo, A.C., Barroso, J.G., Ruberto, G. Antimicrobial and antioxidant properties of some commercial essential oils. Flavour and Fragrance Journal 13:4 (1998) 235 - 244.

Bakkali, F., Averbeck, S., Averbeck, D., Idaomar, M. Biological effects of essential oils $-a$ review. Food and Chemical Toxicology 46:2 (2008) $446-475$.

Bonilla, J., Vargas, M., Atarés, L, Chiralt, A. Physical properties of chitosanbasil essential oil edible films as affected by oil content and homogenization conditions. Procedia Food Science 1 (2011) 50 - 56.

Bonilla, J., Atarés, L., Vargas, M., Chiralt, A. Effect of essential oils and homogenization conditions on properties of chitosan based films. Food Hydrocolloids 26:1 (2012) $9-16$.

Bouhdid, S., Skali, S. N., Idaomar, M., Zhiri, A., Baudoux, D., Amensour, M., Abrini, J. Antibacterial and antioxidant activities of Origanum compactum essential oil. African Journal of Biotechnology 7:10 (2008) 1563 - 1570.

Bozin, B., Mimica-Dukic, N., Simin, N., Anackov, G. Characterization of the volatile composition of essential oils of some Lamiaceae spices and the antimicrobial and antioxidant activities of the entire oils. Journal of Agricultural and Food Chemistry 54:5 (2006) 1822 - 1828.

Burt, S. Essential oils: Their antibacterial properties and potential applications in foods. International Journal of Food Microbiology 94:3 (2004) $223-253$.

Caccioni, D.R.L., Guizzardi, M. Evaluation of the potential of commercial post-harvest application of essential oils to control citrus decay. Journal of Horticultural Science and Biotechnology 76 (1994) 935 - 940.

Caccioni, D.R.L., Guizzardi, M., Biondi, D.M., Renda, A., Ruberto, G. Relationship between volatile components of citrus fruit essential oils and antimicrobial action on Penicillium digitatum and Penicillium italicum. International Journal of Food Microbiology 43:1 (1998) 73 - 79.

Cagri, A., Ustunol, Z., Ryser, E.T. Antimicrobial edible films and coatings. Journal of Food Protection 67:4 (2004) 833 - 848. 
Cháfer, M., Sánchez-González, L., González-Martínez, C., Chiralt, A. Fungal decay and shelf life of oranges coated with chitosan and bergamot, thyme, and tea tree essential oils. Journal of Food Science 77:8 (2012) E182 - E187.

Chen, C.S., Liau, W.Y., Tsai, G.J. Antibacterial effects of N-sulfonated and $\mathrm{N}$-sulfobenzoyl chitosan and application to oyster preservation. Journal of Food Protection 61:9 (1998) $1124-1128$.

Chen, M.C., Yeh, G.H.C., Chiang, B.H. Antimicrobial and physicochemical properties of methylcellulose and chitosan films containing a preservative. Journal of Food Processing and Preservation 20:5 (1996) 379 - 390.

Chen, S.P., Wu, G.Z., Zeng, H.Y. Preparation of high antimicrobial activity thiourea chitosan- $\mathrm{Ag}^{+}$complex. Carbohydrate Polymers 60:1 (2005) $33-38$.

Chien, P.J., Chou, C.C. Antifungal activity of chitosan and its application to control post-harvest quality and fungal rotting of Tankan citrus fruit (Citrus tankan Hayata). Journal of the Science and Food and Agriculture 86:12 (2006) $1964-1969$.

Chiralt, A., Talens, P., Monedero, F.M., Fabra, M.J. Effect of different components of edible/biodegradable composite films on water relationships in the polymer matrix. In Gutiérrez-López, G., Alamilla-Beltran, L., Buera, M.d.P., Welti-Chanes, J., Parada-Arias, E., Barbosa-Cánovas, G.V. (Eds.). Water stress in biological, chemical, pharmaceutical and food systems. (pp. $101-114)$. Springer International Publishing AG (New York) 2015.

Coma, V. Recent developments in chitin and chitosan bio-based materials used for food preservation. In Habibi, Y., Lucia L.A. (Ed.) Polysaccharide Building Blocks: A Sustainable Approach to the Development of Renewable Biomaterials (pp. 143 - 175). John Wiley \& Sons, Inc. (New Jersey) 2012.

Coma, V., Martial-Gros, A., Garreau, S., Copinet, A., Deschamps, A. Edible antimicrobial films based on chitosan matrix. Journal of Food Science, 67:3 (2002) 1162-1169. 
Cuero, R.G., Duffus, E., Osuji, G., Pettit, R. Aflatoxin control in preharvest maize: Effects of chitosan and two microbial agents. Journal of Agricultural Science, 117:2 (1991a) 165 - 169.

Cuero, R.G., Osuji, G., Washington, A. N-carboxymethyl chitosan inhibition of aflatoxin production: Role of zinc. Biotechnology Letters, 13:6 (1991b) $441-444$.

Domard, A., Domard, M. Chitosan: Structure-properties relationship and biomedical applications. In D. Severian (Ed.) Polymeric biomaterials (pp. 187 - 212). Marcel Decker Inc. (New York) 2001.

Dorman, H.J.D., Deans, S.G. Antimicrobial agents from plants: antibacterial activity of plant volatile oils. Journal of Applied Microbiology 88:2 (2000) $308-316$.

Dornenburg, H., Knorr, D. Evaluation of elicitor- and high-pressure induced enzymatic browning utilizing potato (solanum tuberosum) suspension cultures as a model system for plant tissues. Journal of Agricultural and Food Chemistry 45:10 (1997) 4173 - 4177.

dos Santos, N.S.T., Athayde Aguiar, A.J.A., de Oliveira, C.E.V., Veríssimo de Sales, C., de Melo e Silva, S., Sousa da Silva, R., Stamford, T.C.M., de Souza, E. L. Efficacy of the application of a coating composed of chitosan and Origanum vulgare L. essential oil to control Rhizopus stolonifer and Aspergillus niger in grapes (Vitis labrusca L.). Food Microbiology 32:2 (2012) 345 - 353.

Dutta, P.K., Tripathi, S., Mehrotra, G.K., Dutta, J. Perspectives for chitosan based antimicrobial films in food applications. Food Chemistry 114:4 (2009) $1173-1182$.

El Ghaouth, A., Arul, J., Grenier, J., Asselin, A. Antifungal activity of chitosan on two postharvest pathogens of strawberry fruits. Phytopathology 82:4 (1992) $398-402$.

El Ghaouth, A., Arul, J., Wilson, C., Benhamou, N. Biochemical and cytochemical aspects of the interactions of chitosan and Botrytis cinerea in bell pepper fruit. Postharvest Biology and Technology 12:2 (1997) $183-194$. 
El Ghaouth, A., Smilanick, J. L., Brown, G. E., Ippolito, A., Wisniewski, M., Wilson, C.L. Application of Candida saitoana and glycolchitosan for the control of postharvest diseases of apple and citrus fruit under semi-commercial conditions. Plant Disease 84:3 (2000) 243- 248.

Elsabee, M.Z., Abdou, E.S. Chitosan based edible films and coatings: A review. Materials Science and Engineering: C 33:4 (2013) $1819-1841$.

Espina, L., Somolinos, M., Lorán, S., Conchello, P., García, D., Pagán, R. Chemical composition of commercial citrus fruit essential oils and evaluation of their antimicrobial activity acting alone or in combined processes. Food Control 22:6 (2011) 896 - 902.

Eweis, M., Elkholy, S.S., Elsabee, M.Z. Antifungal efficacy of chitosan and its thiourea derivatives upon the growth of some sugar-beet pathogens. International Journal of Biological Macromolecules 38:1 (2006) 1 - 8.

Gutiérrez, J., Barry-Ryan, C., Bourke, R. The antimicrobial efficacy of plant essential oil combinations and interactions with food ingredients. International Journal of Food Microbiology 124:1 (2008) 91 - 97.

Helander, I.M., Alakomi, H.L., Latva-Kala, K., Mattila-Sandholm, T., Pol, I., Smid, E.J., Gorris, L.G.M., Wright, A.V. Characterization of the action of selected essential oil components on Gram-negative bacteria. Journal of Agricultural and Food Chemistry 46:9 (1998) 3590 - 3595.

Hernández-Lauzardo, A.N., Bautista-Baños, S., Velázquez-del Valle, M.G., Méndez-Montealvo, M.G., Sánchez-Rivera, M.M., Bello-Pérez, L.A. Antifungal effects of chitosan with different molecular weights on in vitro development of Rhizopus stolonifer (Ehrenb.:Fr.) Vuill. Carbohydrate Polymers 73:4 (2008) 541- 547.

Holley, R.A., Patel, D. Improvement in shelf-life and safety of perishable foods by plant essential oils and smoke antimicrobials. Food Microbiology 22:4 (2005) $273-292$.

Hussain, A.I., Anwar, F., Sherazi, S.T.H., Przybylski, R. Chemical composition, antioxidant and antimicrobial activities of basil (Ocimum basilicum) essential oils depends on seasonal variations. Food Chemistry 108:3 (2008) $986-995$. 
Imelouane, B., Elbachiri, A., Ankit, M., Benzeid, H., Khedid, K. Physicochemical compositions and antimicrobial activity of essential oil of Eastern Moroccan Lavandula dentata. International Journal of Agriculture and Biology 11:2 (2009) $113-118$.

Jia, Z.S., Shen, D.F., Xu, W.L. Synthesis and antibacterial activities of quaternary ammonium salt of chitosan. Carbohydrate Research 333:1 (2001) $1-6$.

Kittur, F.S., Kumar, K.R., and Tharanathan, R.N. Functional packaging properties of chitosan films. Zeitschrift für Lebensmitteluntersuchung und-Forschung A 206:1 (1998) $44-47$.

Kong, M., Chen, X.G., Xing, K., Park, H.J. Antimicrobial properties of chitosan and mode of action: A state of the art review. International Journal of Food Microbiology 144:1 (2010) $51-63$.

Kulisic, T., Radonic, A., Katalinic, V., Milos, M. Use of different method for testing antioxidative activity of oregano essential oil. Food Chemistry 85:4 (2004) $633-640$.

Kunicka-Styczyńska, A. Activity of essential oils against food-spoiling yeast. A review. Flavour and Fragrance Journal 26:5 (2011) 326 - 328.

Lambert, R.J.W., Skandamis, P.N., Coote, P.J., Nychas, G.J.E. A study of the minimum inhibitory concentration and mode of action of oregano essential oil, thymol and carvacrol. Journal of Applied Microbiology 91:3 (2001) $453-462$.

Li, L.H., Deng, J.C., Deng, H.R., Liu, Z.L., Li, X.L. Preparation, characterization and antimicrobial activities of chitosan/Ag/ZnO blend films. Chemical Engineering Journal, 160:1 (2010) 378-382.

Lin, B., Du, Y., Liang, X., Wang, X., Wang, X., Yang, J. Effect of chitosan coating on respiratory behavior and quality of stored litchi under ambient temperature. Journal of Food Engineering, 102:1 (2011) 94 - 99.

Liu, J., Tian, S.P., Meng, X.H., Xu, Y. Effects of chitosan on control of postharvest diseases and physiological response of tomato fruit. Postharvest Biology and Technology 44:3 (2007) 300 - 306. 
Macias, F.A., Castellano, D., Oliva, R.M., Cross, P., Torres, A. Potential use of allelopathic agents as natural agrochemicals. Proceedings of Brighton Crop Protection Conference: Weeds (1997) $33-38$.

McClements, D.J. Critical review of techniques and methodologies for characterization of emulsion stability. Critical Reviews in Food Science and Nutrition 47:7 (2007) 611-649.

Meepagala, K.M., Sturtz, G., Wedge, D.E. Antifungal constituents of the essential oil fraction of Artemisia dracunculus L. var. dracunculus. Journal of Agricultural and Food Chemistry 50:24 (2002) 6989 - 6992.

Mezzoug, M., Elhadri, A., Dallouh, A., Amkiss, S., Skali, N.S., Abrini, J., Zhiri, A., Baodoux, D., Diallo, B., El Jaziri, M., Idaomar, M. Investigation of the mutagenic and antimutagenic effects of Origanum compactum essential oil and some of its constituents. Mutation Research/Genetic Toxicology and Environmental Mutagenesis 629:2 (2007) 100 - 110.

Moreira, M.R., Roura, S.I., Ponce, A.G. Effectiveness of chitosan edible coatings to improve microbiological and sensory quality of fresh cut broccoli. LWT - Food Science and Technology 40:10 (2011) 2335 - 2341.

Morillon, V., Debeaufort, F., Blond, G., Capelle, M., Voilley, A. Factors affecting the moisture permeability of lipid-based edible films: a review. Critical Reviews in Food Science and Nutrition, 42:1 (2002), 67 - 89.

Muriel-Galet, V., Cran, M.J., Bigger, S.W., Hernández-Muñoz, P., Gavara, R. Antioxidant and antimicrobial properties of ethylene vinyl alcohol copolymer films based on the release of oregano essential oil and green tea extract components. Journal of Food Engineering 149 (2015) 9 - 16.

No, H.K., Park, N.Y., Lee, S.H., Meyers, S.P. Antibacterial activity of chitosans and chitosan oligomers with different molecular weights. International Journal of Food Microbiology 74:1 (2002) $65-72$.

No, H.K., Meyers, S.P., Prinyawiwatkul, W., Xu, Z. Applications of chitosan for improvement of quality and shelf life of foods: a review. Journal of Food Science 72:5 (2007) R87 - R100. 
Ojagh, S.M., Rezaei, M., Razavi, S.H., Hosseini, S.M.H. Development and evaluation of a novel biodegradable film made from chitosan and cinnamon essential oil with low affinity toward water. Food Chemistry 122:1 (2010) $161-166$.

Ouattara, B., Simard, R.E., Piette, G., Begin, A., Holley, R.A. Diffusion of acetic and propionic acids from chitosan-based antimicrobial packaging films. Journal of Food Science, 65:5 (2000a) 768 - 773.

Ouattara, B., Simard, R.E., Piette, G., Begin, A., Holley, R.A. Inhibition of surface spoilage bacteria in processed meats by application of antimicrobial films prepared with chitosan. International Journal of Food Microbiology 62:1 (2000b) $139-148$.

Paranagama, P.A., Wimalasena, S., Jayatilake, G.S., Jayawardena, A.L., Senanayake, U.M., Mubarak, A.M. A comparison of essential oil constituents of bark, leaf, root and fruit of cinnamon (Cinnamomum zeylanicum Blum) grown in Sri Lanka. Journal of the National Science Foundation of Sri Lanka 29:3 (2001) 147 - 153.

Pastor, C., Sánchez-González, L., Chiralt, A., Cháfer, M., González-Martínez, C. Physical and antioxidant properties of chitosan and methylcellulose based films containing resveratrol. Food Hydrocolloids 30:1 (2013) $272-280$.

Perdones, A., Sánchez-González, L., Chiralt, M., Vargas, M. Effect of chitosan-lemon essential oil coatings on storage-keeping quality of strawberry. Postharvest Biology and Technology 70 (2012) $32-41$.

Ponce, A.G., Roura, S.I., del Valle, C.E., Moreira, M.R. Antimicrobial and anti- oxidant activities of edible coatings enriched with natural plant extracts: in vitro and in vivo studies. Postharvest Biology and Technology 49:2 (2008) $294-300$.

Ramos-García, M., Bosquez-Molina, E., Hernández-Romano, J., Zavala-Padilla, G., Terrés-Rojas, E., Alia-Tejacal, I., Barrera-Necha, L., Hernández-López, M., Bautista-Baños, S. Use of chitosan-based edible coatings in combination with other natural compounds, to control Rhizopus 
stolonifer and Escherichia coli DH5 $\alpha$ in fresh tomatoes. Crop Protection 38 (2012) $1-6$.

Randazzo, W., Jiménez Belenguer, A., Settanni, L., Perdones, A., Moschetti, M., Palazzolo, E., Guarrasi, V., Vargas, M., Germanà, M.A., Moschetti, G. Antilisterial effect of citrus essential oils and their performance in edible films formulations. Food Control 59 (2016) 750 - 758.

Reddy, M. B., Arul, J., Ait-Barka, E., Angers, P., Richard, C., Castaigne, F. Effect of Chitosan on Growth and Toxin Production by Alternaria alternata f. sp. lycopersici. Biocontrol Science and Technology, 8:1 (1998) $33-43$.

Regnier, T., Combrinck, S., Du Plooy, W., Botha, B. Evaluation of Lippia scaberrima essential oil and some pure terpenoid constituents as postharvest mycobiocides for avocado fruit. Postharvest Biology and Technology 57:3 (2010) 176-182.

Rinaudo, M. Chitin and chitosan: Properties and applications. Progress in Polymer Science 31:7 (2006) $603-632$.

Rivera Calo, J., Crandall, P.G., O'Bryan, C.A., Ricke, S. C. Essential oils as antimicrobials in food systems $-A$ review. Food Control 54 (2015) $111-119$.

Roselló, J., Sempere, F., Sanz-Berzosa, I., Chiralt, A., Santamarina, P. Antifungal activity and potential use of essential oils against Fusarium culmorum and Fusarium verticillioides. Journal of Essential Oil Bearing Plants, 18:2 (2015) $359-367$.

Rota, M.C., Herrera, A., Martínez, R.M., Sotomayor, J.A., Jordán, M.J. Antimicrobial activity and chemical composition of Thymus vulgaris, Thymus zygis and Thymus hyemalis essential oils. Food Control 19:7 (2008) $681-687$.

Ruiz-Navajas, Y., Viuda-Martos, M., Sendra, E., Pérez-Alvarez, J.A., Fernández-López, J. In vitro antibacterial and antioxidant properties of chitosan edible films incorporated with Thymus moroderi or Thymus piperella essential oils. Food Control 30:2 (2013) 386 - 392. 
Sánchez-González, L., González-Martínez, C., Chiralt, A., Cháfer, M. Physical and antimicrobial properties of chitosan-tea tree essential oil composite films. Journal of Food Engineering 98:4 (2010a) 443 - 452.

Sánchez-González, L., Cháfer, M., Chiralt, A., González-Martínez, C. Physical properties of edible chitosan films containing bergamot essential oil and their inhibitory action on Penicillium italicum. Carbohydrates Polymers 82:5 (2010b) $277-283$.

Sánchez-González, L., Chiralt, A., González-Martínez, C., Cháfer, M. Effect of essential oils on properties of film forming emulsion and films based on hydroxypropylmethylcellulose and chitosan. Journal of Food Engineering 105:2 (2011a) $246-253$.

Sánchez-González, L., Vargas, M., González-Martínez, C., Chiralt, A., Cháfer, M. Use of essential oils in bioactive edible coatings. Food Engineering Reviews 3:1 (2011b) 1 - 16.

Sánchez-González, L., Cháfer, M., Hernández, M., Chiralt, A., González-Martínez, C. Antimicrobial activity of polysaccharide films containing essential oils. Food Control, 22:8 (2011c) $1302-1310$.

Sánchez-González, L., Cháfer, M., González-Martínez, C., Chiralt, A., Desobry, S. Study of the release of limonene present in chitosan films enriched with bergamot oil in food stimulants. Journal of Food Engineering 105:1 (2011d) $138-143$.

Sánchez-González, L., Pastor, C., Vargas, M., Chiralt, A., González-Martínez, C., Cháfer, M. Effect of HPMC and Chitosan coatings with and without bergamot essential oil on quality and safety of cold stored grapes. Postharvest Biology and Technology 60:1 (2011e) 57-63.

Seiichi, T., Yoshiaki, M., Masayoshi, J., Norio, N., Shin-Ichiro, N. Induction of drug specific antibody and the controlled release of drug by 6-O-carboxymethyl-chitin. Journal of Controlled Release 28:1 (1994) $235-241$.

Serrano, M., Martínez-Romero, D., Castillo, S., Guillen, F., Valero, D. The use of antifungal compounds improves the beneficial effect of map in sweet 
cherry storage. Innovative Food Science and Emerging Technologies 6:1 (2005) $115-123$.

Shahidi, F., Arachchi, J.K.V., Jeon, Y.J. Food applications of chitin and chitosans. Trends in Food Science and Technology 10:2 (1999) 37 - 51.

Shahidi, F., Abuzaytoun, R. Chitin, chitosan and co-products: chemistry, production, applications and health effects. Advances in Food and Nutrition Research 49 (2005) $93-135$.

Singh, G., Maurya, S., deLampasona, M.P., Catalan, C.A.N. A comparison of chemical, antioxidant and antimicrobial studies of cinnamon leaf and bark volatile oils, oleoresins and their constituents. Food and Chemical Toxicology 45:9 (2007) 1650 - 1661.

Sivakumar, D., Bautista-Baños, S. A review on the use of essential oils for postharvest decay control and maintenance of fruit quality during storage. Crop Protection 64 (2014) $27-37$.

Sorlier, P., Viton, C., Domard, A. Relation between solution properties and degree of acetylation of chitosan: role of aging. Biomacromolecules 3:6 (2002) $1136-1342$.

Talens, P., Pérez-Masiá, R., Fabra, M.J., Vargas, M., Chiralt, A. Application of edible coatings to partially dehydrated pineapple for use in fruit-cereal products. Journal of Food Engineering 112:1 (2012) 86-93.

Tampieri, M.P., Galuppi, R., Macchioni, F., Carelle, M.S., Falcioni, L., Cioni, P.L., Morelli, I. The inhibition of Candida albicans by selected essential oils and their major components. Mycopathologia 159:3 (2005) 339-345.

Tiwari, B.K., Valdramidis, V.P., O'Donnell, C.P., Muthukumarappan, K., Bourke, P., Cullen, P.J. Application of natural antimicrobials for food preservation. Journal of Agricultural and Food Chemistry 57:14 (2009) $5987-6000$.

Tzortzakis, N.G. Maintaining postharvest quality of fresh produce with volatile compounds. Innovative Food Science and Emerging Technologies $8: 1$ (2007a) $111-116$. 
Tzortzakis, N.G. Methyl jasmonate-induced suppression of anthracnose rot in tomato fruit. Crop Protection 26:10 (2007b) 1507 - 1513.

Tzortzakis, N. G. Impact of cinnamon oil-enrichment on microbial spoilage of fresh produce. Innovative Food Science and Emerging Technologies 10:1 (2009) $97-102$.

Valencia-Chamorro, S. A., Palou, L., Del Río, M.A., Pérez-Gago, M.B. Antimicrobial edible films and coatings for fresh and minimally processed fruits and vegetables: a review. Critical Reviews in Food Science and Nutrition 51:9 (2011) $872-900$.

Vargas, M., Albors, A., Chiralt, A., González-Martínez, C. Quality of cold-stored strawberries as affected by chitosan-oleic acid edible coatings. Postharvest Biology and Technology 41:2 (2006) 164 - 171.

Vargas, M., Pastor, C., Chiralt, A., McClements, D.J., González-Martínez, C. Recent advances in edible coatings for fresh and minimally-processed fruits. Critical Reviews in Food Science and Nutrition 48:6 (2008) 496 - 511.

Vargas, M., Albors, A., Chiralt, A., González-Martínez, C. Characterization of chitosan-oleic acid composite films. Food Hydrocolloids, 23:2 (2009a) $536-547$.

Vargas, M., Chiralt, A., Albors, A., González-Martínez, C. Effect of chitosan-based edible coatings applied by vacuum impregnation on quality preservation of fresh-cut carrots. Postharvest Biology and Technology 51:2 (2009b) $263-271$.

Vargas, M., González-Martínez, C. Recent patents on food applications of chitosan. Recent Patents on Food, Nutrition and Agriculture 2:2 (2010) $121-128$.

Vargas, M., Albors, A., Chiralt, A., González-Martínez, C. Water interactions and microstructure of chitosan-methylcellulose composite films as affected by ionic concentration. LWT - Food Science and Technology 44:10 (2011a) $2290-2295$.

Vargas, M., Perdones, A., Chiralt, Cháfer, M., González-Martínez, C. Effect of homogenization conditions on physicochemical properties of 
chitosan-based film-forming dispersions and films. Food Hydrocolloids 25:5 (2011b) $1158-1165$.

Vaughn, S.F., Spencer, G.F. Volatile monoterpenes inhibit potato tuber sprouting. American Potato Journal 68:12 (1991) 821 - 831.

Wilson, C.L., El Ghaouth, A., Upchurch, B., Stevens, C., Khan, V., Droby, S., Chalutz, E. Using an online UV-C apparatus to treat harvested fruit for controlling postharvest decay. HortTechnology 7:3 (1997a) 278- 282.

Wilson, C.L., Solar, J.M., Ghaouth, A.E.L., Wisniewski, M.E. Rapid evaluation of plant extracts and essential oils for antifungal activity against Botrytis cinerea. Plant Disease 81:2 (1997b) $204-210$.

Xing, Y., Li, X., Xu, Q., Yun, J., Lu, Y., Tang, Y. Effects of chitosan coating enriched with cinnamon oil on qualitative properties of sweet pepper (Capsicum annuum L.). Food Chemistry 124:4 (2011) 1443 - 1450.

Yoksan, R., Chirachanchai, S. Silver nanoparticle-loaded chitosan-starch based films: Fabrication and evaluation of tensile, barrier and antimicrobial properties. Materials Science and Engineering: C 30:6 (2010) 891 - 897.

Zivanovic, S., Chi, S., Draughon, A.F. Antimicrobial activity of chitosan films enriched with essential oils. Journal of food science 70:1 (2005) M45-M51. 


\section{OBJECTIVES}

The general objective of the thesis was to develop and characterize antifungal chitosan films or coatings for fruit preservation, taking into account the polymer antimicrobial properties and the encapsulation of different essential oils into the polymer matrix to enhance the active properties of the material. Films were obtained by casting method (extension and drying) of the chitosan-essential oil emulsions. Oleic acid was also included in the film formulations in order to reduce the film hygroscopic character and to facilitate the essential oil emulsification and retention in the films.

For this purpose, several specific objectives were defined:

1 To analyse the effect of the homogenization treatments on the physicochemical properties of the chitosan-oleic acid film-forming emulsions and functional properties of the films. The impact of emulsion properties on the film functionality was analysed.

2 To evaluate the effect of chitosan-lemon essential oil coatings, obtained by using different homogenization treatments, on the preservation of strawberries in terms of different quality aspects: physicochemical parameters, aroma profile, senesce and fungal decay.

3 To analyse the effect of the incorporation of oleic acid in the chitosan-essential oil (basil, cinnamon leaf and thyme) formulations in terms of the properties of the film-forming emulsions and the films. The film or coating potential to prevent fungal decay was also analysed through in vitro or in vivo studies.

4 To evaluate the effect of preharvest and postharvest applications of film-forming dispersions based on chitosan and methylcellulose containing oregano essential oil in tomato plant and fruit.

5 To quantify the retention of oregano essential oil in the chitosan-methylcellulose films during the film drying step and to analyse the compound release of the encapsulated essential oil into different food simulants. 



\section{CHAPTERS}

CHAPTER 1. EFFECT OF HOMOGENIZATION CONDITIONS ON PHYSICOCHEMICAL PROPERTIES OF CHITOSAN-BASED FILM-FORMING DISPERSIONS AND FILMS

CHAPTER 2. APPLICATION OF CHITOSAN FILMS CONTAINING ESSENTIAL OILS IN PRESERVATION OF STRAWBERRIES

EFFECT OF CHITOSAN-LEMON ESSENTIAL OIL COATINGS ON STORAGE-KEEPING QUALITY OF STRAWBERRY

EFFECT OF CHITOSAN-LEMON ESSENTIAL OIL COATINGS ON AROMA PROFILE OF STRAWBERRIES

CHAPTER 3. EFFECT OF OLEIC ACID ON THE ESSENTIAL OIL PERFORMANCE IN CHITOSAN MATRIX

PROPERTIES OF FILM-FORMING DISPERSIONS AND FILMS BASED ON CHITOSAN CONTAINING BASIL AND THYME ESSENTIAL OILS

PHYSICAL AND ANTIMICROBIAL PROPERTIES OF CINNAMON LEAF ESSENTIAL OIL FILMS AS AFFECTED BY OLEIC ACID

CHAPTER 4. EFFECT OF CHITOSAN COATINGS CONTAINING ESSENTIAL OILS ON TOMATO PLANTS AND FRUITS

EFFECT ON TOMATO PLANT AND FRUIT OF THE APPLICATION OF BIOPOLYMER-OREGANO ESSENTIAL OILS COATINGS

CHAPTER 5. RETENTION AND MIGRATION OF ESSENTIAL OILS IN CHITOSAN FILMS

RETENTION AND MIGRATION OF OREGANO ESSENTIAL OIL IN CHITOSAN BASED FILMS 



\section{CHAPTER 1}

\section{EFFECT OF HOMOGENIZATION \\ CONDITIONS ON PHYSICOCHEMICAL \\ PROPERTIES OF CHITOSAN-BASED \\ FILM-FORMING DISPERSIONS AND \\ FILMS}

Maria Vargas*, Ángela Perdones, Amparo Chiralt, Maite Cháfer, Chelo González-Martínez

Food Hydrocolloids 25:5 (2011) $1158-1164$

Department of Food Technology-Institute of Food Engineering for Development, Universitat Politècnica de València, Camino de Vera s/n, 46022 Valencia, Spain.

*Telephone: 0034963877000 Ext.73642 Fax: 0034963877369

e-mail:mavarco@tal.upv.es 


\section{ABSTRACT}

Film-forming dispersions (FFD) based on high molecular weight chitosan $(\mathrm{CH})$ alone or in combination with oleic acid $(\mathrm{OA})$ were prepared under different homogenization conditions (rotor-stator or rotor-stator together with microfluidization at different pressures). Film-forming dispersions (FFD) were characterized in terms of particle size distribution, rheological properties, distribution and $\zeta$-potential. In order to study the impact of the properties of the FFD on the casted films, the water vapour permeability, mechanical properties and microstructure of the dry films were evaluated. Results showed that microfluidization promoted significant changes in the size and surface charge of the FFD particles, which in turn had an impact on the rheological properties of the FFD. The changes were more marked with the increase in microfluidization pressure. As regards film properties, the higher the microfluidization pressure in the FFD, the lower the water vapour permeability values and the stiffer the $\mathrm{CH}$ :OA composite films. These results were explained by film microstructure, which was observed by SEM.

Keywords: microfluidization, particle size, $\zeta$-potential, rheological properties, water vapour permeability, microstructure. 


\section{INTRODUCTION}

Polysaccharides and lipids are commonly mixed in order to obtain composite films or coatings to take advantage of the special functional characteristics of each group, thus diminishing their drawbacks (Greener and Fennema, 1994). Lipids contribute to the improvement of the water vapour resistance of the films, whereas hydrocolloids confer selective permeability to $\mathrm{O}_{2}$ and $\mathrm{CO}_{2}$, durability, structural cohesion and integrity (Krochta and De-Mulder-Johnston, 1997). The way in which lipids are emulsified (emulsion structure) and the emulsion stability directly affects the film structure and thus, its properties. During film drying, the solvent is evaporated and the effective lipid concentration increases, in line with flocculation phenomena, coalescence and creaming, depending on the physical state of the lipid, the composition of the continuous phase and the drying conditions. Small particles and a high emulsion stability (exhibited during the film drying) will give rise to a homogeneous distribution of the lipid particles in the film, which in turn contributes to a more efficient control of water transfer (Debeaufort, Martin-Polo and Voilley 1993).

Emulsion stability depends on the complex mechanisms, but it is well known that some of the key aspects are the average fat globule size and their size distribution pattern which, in turn, affect the stability, colour, and rheological properties of the FFD, among other factors (Becher, 2001). Rotor-stator systems are also often used in the food industry to homogenize different media and high viscosity immiscible liquids (Schubert, 1997), reaching particle sizes in the range of $1 \mu \mathrm{m}$ (Urban, Wagner, Schaffner, Roglin and Ulrich, 2006). To reduce the size of the lipid particles, homogenizers that use pressures of up to 500 bar have been commonly used, giving rise to particles much smaller than $1 \mu \mathrm{m}$. Nowadays, high pressure homogenizers such as microfluidizers can produce pressures in the range of 1,000 bar or higher. Although the use of such pressures leads to finer emulsions, the average particle size only reduces slightly (Perrier-Cornet, Marie and Gervais, 2005). The greatest effect is observed on the particle size distribution, which becomes narrower when compared with that obtained by low pressure homogenization (Paquin, 1999). Microfluidization can provide dispersions and emulsions 
with narrower particle size distributions due to the high shear stresses developed in the microchannels of the interaction chamber, and has been used in the pharmaceutical industry (Pinnamaneni, Das and Das, 2003; Strawbridge, Ray, Hallett, Tosh and Dalgleish, 1995). However, there are few studies into the effect of microfluidization on the properties of the film-forming dispersions used to obtain edible films and coatings.

On the other hand, some studies have also pointed out that high homogenization pressures can affect not only fat globules but also other food constituents, such as proteins (Lee, Lefèvre, Subirade and Paquin, 2009) and polysaccharides (Kasaai, Charlet, Paquin and Arul, 2003; Paquin, 1999), modifying their functional properties. This modification may not only lead to a change in the degree of aggregation but also to irreversible disruption of the biopolymer conformation.

The aim of this work was to analyse the effect of homogenization treatments on the physicochemical properties of chitosan-oleic acid film-forming dispersions such as the particle size, $\zeta$-potential and rheological properties. Some relevant properties of the films obtained with such FFD, like water vapour permeability, microstructure and mechanical properties, were also characterized and related with the characteristics of the FFD.

\section{MATERIALS AND METHODS}

\subsection{Materials}

Film-forming dispersions (FFD) were prepared with high molecular weight chitosan (CH) with a deacetylation degree of $75.6 \%$ (CAS Number 9012-76-4, Batch 10305DD, Sigma-Aldrich, USA, viscosity in 1 wt. \% glacial acetic acid solution: $1.406 \mathrm{~Pa} \cdot \mathrm{s}$ ), $98 \%$ glacial acetic acid (CAS Number 64-19-7, Panreac, Spain) and oleic acid (OA) (CAS Number 112-80-1, Panreac, Spain). 


\subsection{Preparation of the film-forming dispersions}

Chitosan $(0.5 \% \mathrm{w} / \mathrm{w})$ was dispersed in an aqueous solution of glacial acetic acid $(0.25 \% \mathrm{v} / \mathrm{w})$. After $12 \mathrm{~h}$ of stirring, this dispersion was homogenized by means of a rotor-stator homogenizer (DI25 Yellow Line, IKA ${ }^{\circledR}$, Germany) at 20,500 rpm for $4 \mathrm{~min}$. To prepare CH:OA FFD, chitosan $(0.5 \% \mathrm{w} / \mathrm{w})$ was dispersed in an aqueous solution of glacial acetic acid $(0.25 \% \mathrm{v} / \mathrm{w})$ and, after $12 \mathrm{~h}$ of stirring, oleic acid was added to reach a final concentration of $0.5 \%(\mathrm{w} / \mathrm{w})$. The mixture was emulsified using the rotor-stator homogenizer (DI25 Yellow Line, IKA ${ }^{\circledR}$, Germany) at 20,500 rpm for 4 min. Subsequently, FFD were submitted to a second homogenization at high pressure in a single pass by using a Microfluidizer ${ }^{\circledR}$ (M110-P, Microfluidics, Newton, MA, USA) at different pressures: 9,000, 12,000, 18,000 and 24,000 psi (62, 83, 124 and $165 \mathrm{MPa}$, respectively). Pure $\mathrm{CH}$ dispersions were also submitted to different pressures ( 83 and $165 \mathrm{MPa}$ ) in the microfluidizer after the rotor-stator homogenization. Table 1.1 shows the composition and homogenization conditions for each FFD.

Table 1.1 Composition of the film-forming dispersions (FFD) and homogenization conditions.

\begin{tabular}{cccl}
\hline FFD & $\mathrm{CH}(\% \mathrm{w} / \mathrm{w})$ & $\mathrm{OA}(\% \mathrm{w} / \mathrm{w})$ & Homogenization conditions \\
\hline \multirow{3}{*}{$\mathrm{CH}$} & 0.5 & - & $\mathrm{RS}$ \\
& 0.5 & - & $\mathrm{RS}+12(\mathrm{MF}$ at $93 \mathrm{MPa})$ \\
& 0.5 & - & $\mathrm{RS}+24$ (MF at 165 MPa) \\
\hline \multirow{2}{*}{$\mathrm{CH}: \mathrm{OA}$} & 0.5 & 0.5 & $\mathrm{RS}$ \\
& 0.5 & 0.5 & $\mathrm{RS}+9(\mathrm{MF}$ at $62 \mathrm{MPa})$ \\
& 0.5 & 0.5 & $\mathrm{RS}+12(\mathrm{MF}$ at $83 \mathrm{MPa})$ \\
& 0.5 & 0.5 & $\mathrm{RS}+18(\mathrm{MF}$ at 124 MPa) \\
& 0.5 & 0.5 & $\mathrm{RS}+24(\mathrm{MF}$ at 165 MPa) \\
\hline
\end{tabular}

RS: Rotor-stator homogenization, MF: Microfluidization, $\mathrm{CH}$ : chitosan, OA: oleic acid.

\subsection{Characterization of the film-forming dispersions}

\subsubsection{Particle size and $\zeta$-potential measurements}

The analysis of the particle size of $\mathrm{CH}$ :OA FFD was carried out by using a laser diffractometer (MasterSizer 2000, Malvern Instruments, UK). 
The samples were diluted in a sodium acetate buffer solution (175 mM) under the appropriate solvent conditions $(\mathrm{pH}=4.8)$ at 2,000 rpm until an obscuration rate of $10 \%$ was obtained. The Mie theory was applied by considering the following optical properties for OA droplets: a refractive index of 1.46 and absorption of 0.00 . Three samples of each FFD were measured in triplicate. In order to carry out $\zeta$-potential measurements, FFD were diluted to a droplet concentration of $0.02 \%$ using a sodium acetate buffer solution ( $175 \mathrm{mM})$ at $\mathrm{pH} 4.8$. $\zeta$-potential was determined by using a ZetaSizer (Nano-Z, Malvern Instruments, UK). The Smoluchowsky mathematical model was used to convert the electrophoretic mobility measurements into $\zeta$-potential values.

\subsubsection{Rheological behaviour}

The rheological behaviour of film-forming dispersions was analysed in triplicate at $25^{\circ} \mathrm{C}$ by means of a rotational rheometer (Haake Rheostress 1 , Thermo Electric Corporation, Germany) with a type Z34DIN Ti sensor system of coaxial cylinders. Rheological curves were obtained after a stabilization time of $5 \mathrm{~min}$ at $25^{\circ} \mathrm{C}$. The shear stress $(\sigma)$ was measured as a function of shear rate $(\dot{\gamma})$ from 0 to $512 \mathrm{~s}^{-1}$ in the following way: $5 \mathrm{~min}$ to reach the maximum shear rate and $5 \mathrm{~min}$ to attain zero shear rate. The power law model (Eq. 1.1) was applied to determine the consistency index $(K)$ and the flow behaviour index $(n)$ of the FFD. Apparent viscosities were calculated at $100 \mathrm{~s}^{-1}$.

$$
\sigma=K \cdot \dot{\gamma}^{n}
$$

\subsection{Preparation of films}

Films were obtained by casting. FFD were poured onto a framed and levelled polytetrafluorethylene (PTFE) plate $(\phi=15 \mathrm{~cm})$ and were dried at room temperature for $48 \mathrm{~h}$. Films were prepared by pouring the amount of FFD that will provide a polymer surface density in the dry films of $56 \mathrm{~g} / \mathrm{m}^{2}$. Dry films were peeled off from the casting surface and preconditioned in desiccators at $20^{\circ} \mathrm{C}$ and $54 \%$ relative humidity $(\mathrm{RH})$ during two weeks prior to performing all the tests. Film thickness was measured using a hand-held digital micrometre (Palmer-Comecta, Spain, $\pm 0.001 \mathrm{~mm}$ ). The thickness of 
each film was measured five times and the mean values were used in water vapour permeability calculations.

\subsection{Characterization of the films}

\subsubsection{Water vapour permeability}

Samples of dry films $(\phi=4 \mathrm{~cm})$ were stored in desiccators at $54.4 \% \mathrm{RH}$ and $20{ }^{\circ} \mathrm{C}$ for at least 15 days prior to the evaluation of the water vapour transmission rate. Water vapour permeability (WVP) was measured, in quintuplicate, according to the "water method" of the ASTM E-96-95 (ASTM, 1995), using Payne permeability cups (Elcometer SPRL, Hermelle/s Argenteau, Belgium). De-ionised water was used inside the testing cup to achieve $100 \% \mathrm{RH}$ on one side of the film, while an oversaturated magnesium nitrate solution was used to control the relative humidity on the other side of the film: $54.4 \%$. During WVP testing, the side of the film in contact with the PTFE plate was placed in contact with the part of the test cup having the highest $\mathrm{RH}$. A fan placed on the top of the cup was used to promote convection. Water vapour transmission rate (WVTR) measurements were taken at $20^{\circ} \mathrm{C}$. To calculate WVTR (Eq. 1.2), the slopes of the steady state period of the curves of weight loss as a function of time were determined by linear regression. For each type of film, WVP measurements (Eq. 1.3) were carried out in triplicate.

$$
\begin{gathered}
W V T R=J / A \\
W V P=\frac{W V T R}{P_{w 1}-P_{w 2}} \cdot L
\end{gathered}
$$

Where WVTR is the water vapour transmission rate $\left(g \cdot h^{-1} \cdot \mathrm{m}^{-2}\right), J$ is the slope of the plotting of weight loss vs. time $\left(g \cdot h^{-1}\right), A$ is the area of the film $\left(\mathrm{m}^{2}\right)$, $P_{w 1}$ is the partial pressure of water vapour on the film's underside $(\mathrm{Pa}), P_{w 2}$ is the partial pressure of water on the film's upper surface $(P a), L$ is the film thickness $(m)$.

\subsubsection{Mechanical properties}

Mechanical properties were measured by using a Texture Analyser TA-XT-plus (Stable Micro Systems, Surrey, UK), with a $50 \mathrm{~N}$ load cell 
equipped with tensile grips (A/TG model). Sample films were cut into $25.4 \mathrm{~mm}$ wide and $100 \mathrm{~mm}$ long strips, according to the ASTM D-882 standard (ASTM, 2001). Grip separation was set at $50 \mathrm{~mm}$ and cross-head speed was $50 \mathrm{~mm} / \mathrm{min}$. Tensile strength (TS) and percentage of elongation (E) at break, and elastic modulus (EM) were evaluated in eight samples from each type of film.

\subsubsection{Scanning electron microscopy}

Dried films were stored in desiccators with $\mathrm{P}_{2} \mathrm{O}_{5}$ for at least 15 days. A microstructural analysis of cross-sections of the films was carried out using Scanning Electron Microscopy (SEM) technique in a JEOL JSM-5410 (Japan) electron microscope. Pieces of $5 \times 1 \mathrm{~mm}$ were cut from films, cryofractured and mounted in copper stubs. Samples were gold coated and observed using an accelerating voltage of $10 \mathrm{kV}$.

\subsection{Statistical analysis}

Results were analysed by a multifactor analysis of variance with $95 \%$ significance level using Statgraphics ${ }^{\circledR}$ Plus 5.1. Multiple comparisons were performed through $95 \%$ LSD intervals.

\section{RESULTS AND DISCUSSION}

\subsection{Physicochemical properties of chitosan-based film-forming dispersions}

The typical particle size distribution of $\mathrm{CH}$ :OA FFD is plotted in Figure 1.1. FFD homogenized by the rotor-stator (RS) showed a bimodal particle size distribution, with two overlapped populations with mean particle sizes of between 0.1 and $4 \mu \mathrm{m}$. This distribution changed drastically when the FFD were submitted to microfluidization at all pressures, leading to monomodal particle size distributions, with particle sizes ranging between 0.03 and $1 \mu \mathrm{m}$. The higher the microfluidization pressure, the smaller the particle and the narrower the obtained distributions. 
Table 1.2 shows the average particle size $(D[4,3]$ and $D[3,2])$ and $\zeta$-potential values for the FFD. Microfluidizing FFD promoted a significant decrease in their average particle size $(p<0.05)$, which in turn was significantly affected by the applied pressure. In addition, the differences between the $D[4,3]$ and $D[3,2]$ values for every FFD diminished with the increase in the homogenization pressure.

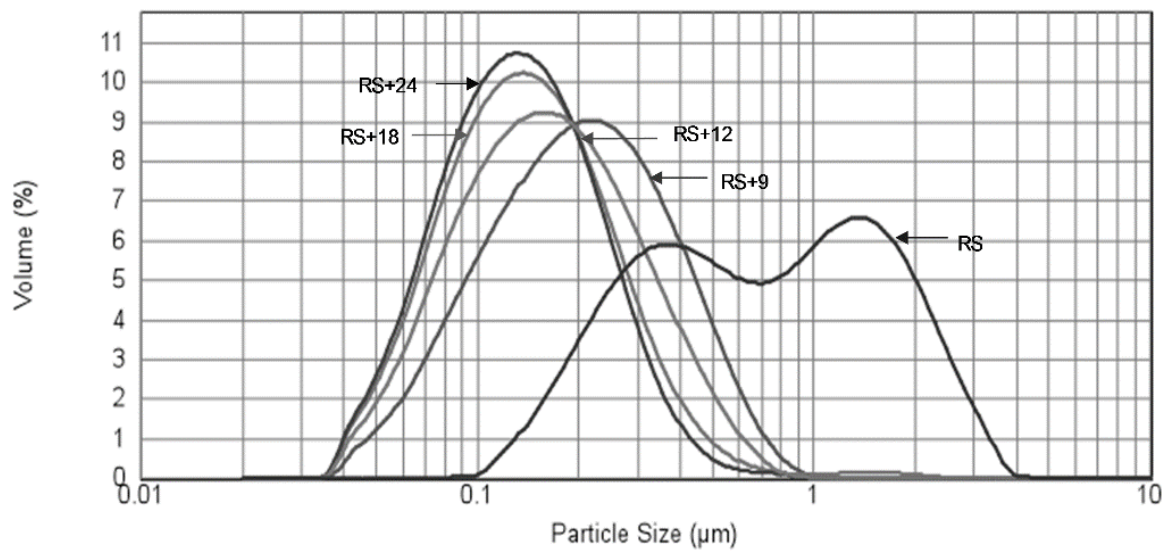

Figure 1.1 Typical particle size distribution for $\mathrm{CH}$ :OA film-forming dispersions. RS: rotor-stator, +9: microfluidization at 9,000 psi, +12: microfluidization at 12,000 psi, +18: microfluidization at 18,000 psi, +24 : microfluidization at 24,000 psi. CH: chitosan, OA: oleic acid.

Small and spherical particles are measured through $D[3,2]$ values, whereas $D[4,3]$ is more sensitive to big, irregular-shaped particles, such as flocks and aggregates (McClements, 2005). Thus, the tendency observed in these average values indicates that the particles tend to be smaller when the homogenization pressure increases, which permits the separation of clusters into individual particles. Similar results have been obtained by Cruz et al., (2007) and Pereda, Ferragut, Quevedo, Guamis and Trujillo (2007) when applying similar homogenization pressures to soymilk and cow milk systems, respectively.

$\zeta$-potential values of the FFD are shown in Table 1.2. At the $\mathrm{pH}$ of the FFD (4.8), the amino group of chitosan ( $\mathrm{pKa} \mathrm{NH}^{+3} / \mathrm{NH}_{2} \approx 6.5$ ) is positively charged and is able to interact with the carboxylate function of oleic acid ( $\mathrm{pKa} \mathrm{COOH} / \mathrm{COO}^{-} \approx 4.8$ ), which is negatively charged (Ham-Pichavant, Sèbe, Pardon and Coma, 2005), leading to positively charged dispersed particles. 
These values coincide with those obtained for $\mathrm{CH}$ :OA FFD dispersed by means of a RS (Vargas, Albors, Chiralt and González-Martínez, 2009). The increase in homogenization pressure caused a decrease in the surface charge of the particles, which was significant $(p<0.05)$ for pressures above $83 \mathrm{MPa}(\mathrm{RS}+18$ and RS+24). The latter can be explained by the promotion of electrostatic interactions between the oleic acid micelles and chitosan, leading to a decrease in the net surface electrical charge of $\mathrm{CH}: \mathrm{OA}$ particles due to microfluidization. In this sense, Lee, Lefèvre, Subirade and Paquin (2009) found that high pressure homogenization promoted more interactions between the lipid phase and proteins in emulsions, by means of providing further energy to induce additional changes in the structure of the polymer and in their interactions.

Table 1.2 Mean values and (standard deviation) of $D[4,3], D[3,2]$ and $\zeta$-potential of $\mathrm{CH}: \mathrm{OA} F F D$ as affected by homogenization conditions (HC).

\begin{tabular}{lccc}
\hline HC & $D[4,3](\mu \mathrm{m})$ & $D[3,2](\mu \mathrm{m})$ & $\zeta$-Potential $(\mathrm{mV})$ \\
\hline RS & $0.94(0.01)^{\mathrm{a}}$ & $0.499(0.006)^{\mathrm{a}}$ & $73.7(1.4)^{\mathrm{a}}$ \\
$\mathrm{RS}+9$ & $0.238(0.002)^{\mathrm{b}}$ & $0.159(0.001)^{\mathrm{b}}$ & $72(2)^{\mathrm{a}}$ \\
$\mathrm{RS}+12$ & $0.196(0.002)^{\mathrm{c}}$ & $0.133(0.002)^{\mathrm{c}}$ & $71(2)^{\mathrm{a}}$ \\
$\mathrm{RS}+18$ & $0.166(0.003)^{\mathrm{d}}$ & $0.118(0.0004)^{\mathrm{d}}$ & $68(2)^{\mathrm{b}}$ \\
$\mathrm{RS}+24$ & $0.154(0.001)^{\mathrm{e}}$ & $0.113(0.001)^{\mathrm{e}}$ & $67.2(0.9)^{\mathrm{b}}$ \\
\hline
\end{tabular}

$a, b, c, d, e$ Different superscripts in the same column indicate significant differences $(p<0.05)$. HC: homogenization conditions, RS: rotor-stator, +9: microfluidization at 9,000 psi, +12: microfluidization at 12,000 psi, +18: microfluidization at 18,000 psi, +24: microfluidization at 24,000 psi. CH: chitosan, OA: oleic acid.

The typical flow curves for $\mathrm{CH}$ and $\mathrm{CH}$ :OA FFD are shown in Figure 1.2a and Figure $1.2 b$, respectively. Flow curves were fitted to the Power Law and the parameters of the model are shown in Table 1.3, together with apparent viscosity values calculated at $100 \mathrm{~s}^{-1}$, which is the typical shear rate of different unit operations, such as flow through a pipe, stirring or mastication (McClements, 2005).

Chitosan-based FFD behaved in a shear-thinning, non-time dependent rheological way when homogenized by the RS. However, microfluidization led to changes in the rheological behaviour of the FFD, since all of them became Newtonian. 
As deduced from the shape of the flow curves, microfluidization led to significant changes in the flow behaviour index (n), which showed values near to 1 at all homogenization pressures. This trend has also been observed by other authors when using similar homogenization pressures in different hydrocolloid-lipid systems (Cruz et al., 2007; Floury, Desrumaux and Lardières, 2000; Perrechil and Cunha, 2010).
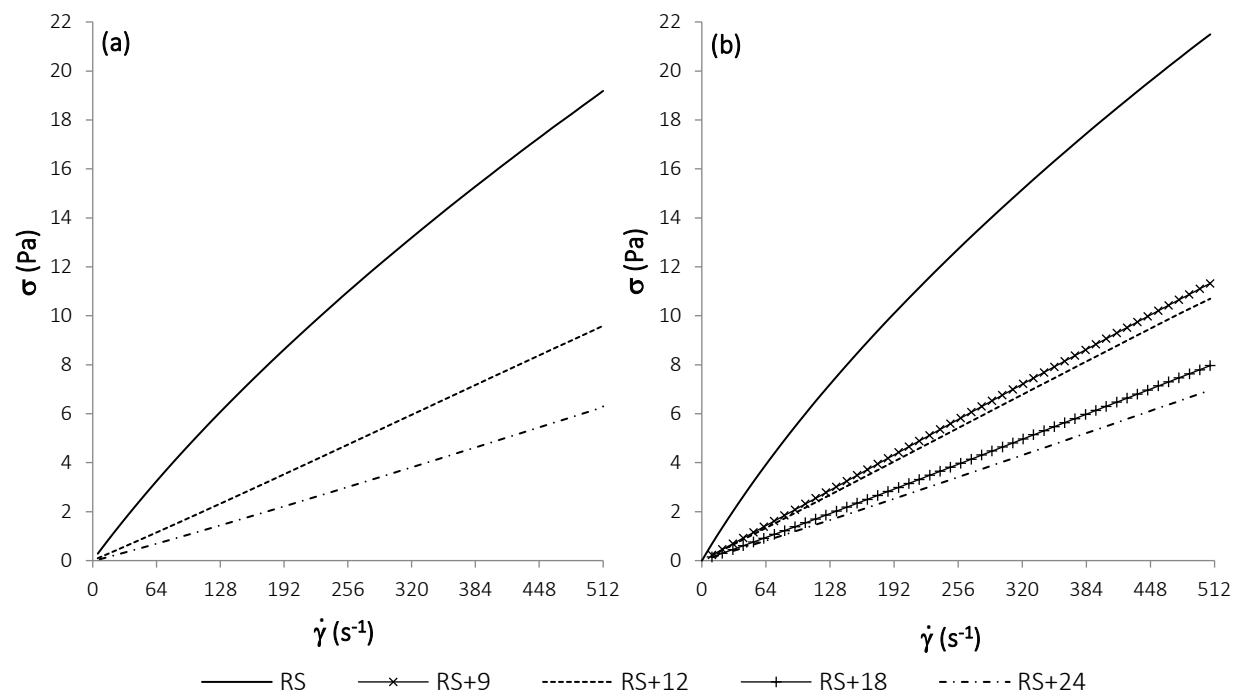

Figure 1.2 Flow curves of (a) $\mathrm{CH}$ (b) $\mathrm{CH}$ :OA film-forming dispersions at $25^{\circ} \mathrm{C}$. $\mathrm{RS}$ : rotor-stator, +9: microfluidization at 9,000 psi, +12: microfluidization at 12,000 psi, +18: microfluidization at 18,000 psi, +24: microfluidization at 24,000 psi. CH: chitosan, OA: oleic acid.

As regards consistency index $(\mathrm{K})$ and apparent viscosity values, the results showed that, as expected, the addition of OA to the FFD led to a significant increase in both parameters under the same homogenization conditions. On the other hand, both pure $\mathrm{CH}$ and $\mathrm{CH}: \mathrm{OA}$ FFD showed a significant decrease in $\mathrm{K}$ and apparent viscosity values when the homogenization pressure increased. The main factors that determine the rheological properties of emulsions are associated with the characteristics of both the dispersed phase (volume concentration, distribution, size, shape and electrical charge of the particles) and the continuous phase (viscosity, chemical composition, and concentration of electrolytes), together with the presence of surfactants and thickening agents (McClements, 2005). In the present study, microfluidization affects the rheology pattern of both phases by decreasing the size and diminishing the number of clusters 
formed in the dispersed phase and also by decreasing the viscosity of the continuous phase, which leads to a decrease in the viscosity of the FFD (Table 1.3). In fact, as shown in Table 1.3, the viscosity of chitosan-based film-forming dispersions significantly decreased $(p<0.05)$ when the homogenization pressure increased. The latter could be explained not only by the changes in the degree of polymer aggregation but also by the fragmentation of the polymer and the subsequent decrease in its molecular weight due to high pressure, as was observed in chitosan-acetic acid solutions (Kasaai, Charlet, Paquin and Arul, 2003) and xanthan gum systems (Paquin, 1999) submitted to microfluidization at similar homogenization pressures.

Table 1.3 Power Law parameters and apparent viscosity values at $100 \mathrm{~s}^{-1}$ for $\mathrm{CH}$ and $\mathrm{CH}: \mathrm{OA}$ film-forming dispersions (FFD) at $25^{\circ} \mathrm{C}$. Mean values and (standard deviation).

\begin{tabular}{ccccc}
\hline \multirow{2}{*}{ FFD } & $\mathrm{HC}$ & \multicolumn{3}{c}{$0 \leq \gamma \leq 512 \mathrm{~s}^{-1}$} \\
\cline { 3 - 5 } & & $\mathrm{n}$ & $\mathrm{K}(\mathrm{Pa} \cdot \mathrm{s})$ & $\eta_{\mathrm{ap}}(\mathrm{Pa} \cdot \mathrm{s})$ \\
\hline \multirow{2}{*}{$\mathrm{RS}$} & $\mathrm{RS}+12$ & $1.024(0.003)^{\mathrm{bx}}$ & $0.016(0.001)^{\mathrm{bx}}$ & $0.0181(0.0001)^{\mathrm{bx}}$ \\
& $\mathrm{RS}+24$ & $1.051(0.001)^{\mathrm{cx}}$ & $0.009(0.001)^{\mathrm{cx}}$ & $0.0111(0.0004)^{\mathrm{cx}}$ \\
\hline & $\mathrm{RS}$ & $0.838(0.002)^{\mathrm{ay}}$ & $0.123(0.001)^{\mathrm{ay}}$ & $0.0585(0.0001)^{\mathrm{ay}}$ \\
& $\mathrm{RS}+9$ & $1.001(0.001)^{\mathrm{b}}$ & $0.022(0.001)^{\mathrm{b}}$ & $0.0224(0.0001)^{\mathrm{b}}$ \\
$\mathrm{CH}: \mathrm{OA}$ & $\mathrm{RS}+12$ & $1.009(0.001)^{\mathrm{cy}}$ & $0.020(0.001)^{\mathrm{by}}$ & $0.0209(0.0006)^{\mathrm{by}}$ \\
& $\mathrm{RS}+18$ & $1.030(0.003)^{\mathrm{d}}$ & $0.013(0.001)^{\mathrm{c}}$ & $0.0149(0.0012)^{\mathrm{c}}$ \\
& $\mathrm{RS}+24$ & $1.042(0.002)^{\mathrm{ey}}$ & $0.011(0.001)^{\mathrm{cy}}$ & $0.0128(0.0004)^{\mathrm{dy}}$ \\
\hline
\end{tabular}

$a, b, c, d$, e Different superscripts in the same column indicate significant differences $(p<0.05)$ due to treatments for the same FFD. ${ }^{x}, y$ Different superscripts in the same column indicate significant differences $(p<0.05)$ due to the addition of oleic acid for the same homogenization conditions. HC: homogenization conditions, RS: rotor-stator, +9: microfluidization at 9,000 psi, +12: microfluidization at $12,000 \mathrm{psi},+18$ : microfluidization at 18,000 psi, +24 : microfluidization at 24,000 psi. CH: chitosan, OA: oleic acid.

The rheological parameters and apparent viscosity at $100 \mathrm{~s}^{-1}$ for pure chitosan FFD are in the range of those reported for non-microfluidized chitosan solutions and non-microfluidized chitosan-oleic acid dispersions 
(Vargas, Albors, Chiralt and González-Martínez, 2009). The observed differences could be explained by the different source, molecular weight, and deacetylation degree of the chitosan used.

\subsection{Characteristics of chitosan-based films}

The films' microstructure is affected by the organization of the different components of the FFD and by how they interact during the drying process. Their microstructure provides information about the arrangement of the ingredients of the FFD and allows us a better understanding of water vapour transmission mechanisms and mechanical properties. Figure 1.3 shows the cross-sections of pure chitosan films obtained from FFD submitted to different homogenization pressures, where the differing treatments gave rise to no observed differences. When these structures are compared with the cross-sections of the films that incorporate oleic acid (Figure 1.4), lipid particles (or their voids) that are embedded in the polymer matrix are observed. These particles (or voids) interrupt the chitosan matrix producing discontinuities in the polymer network.
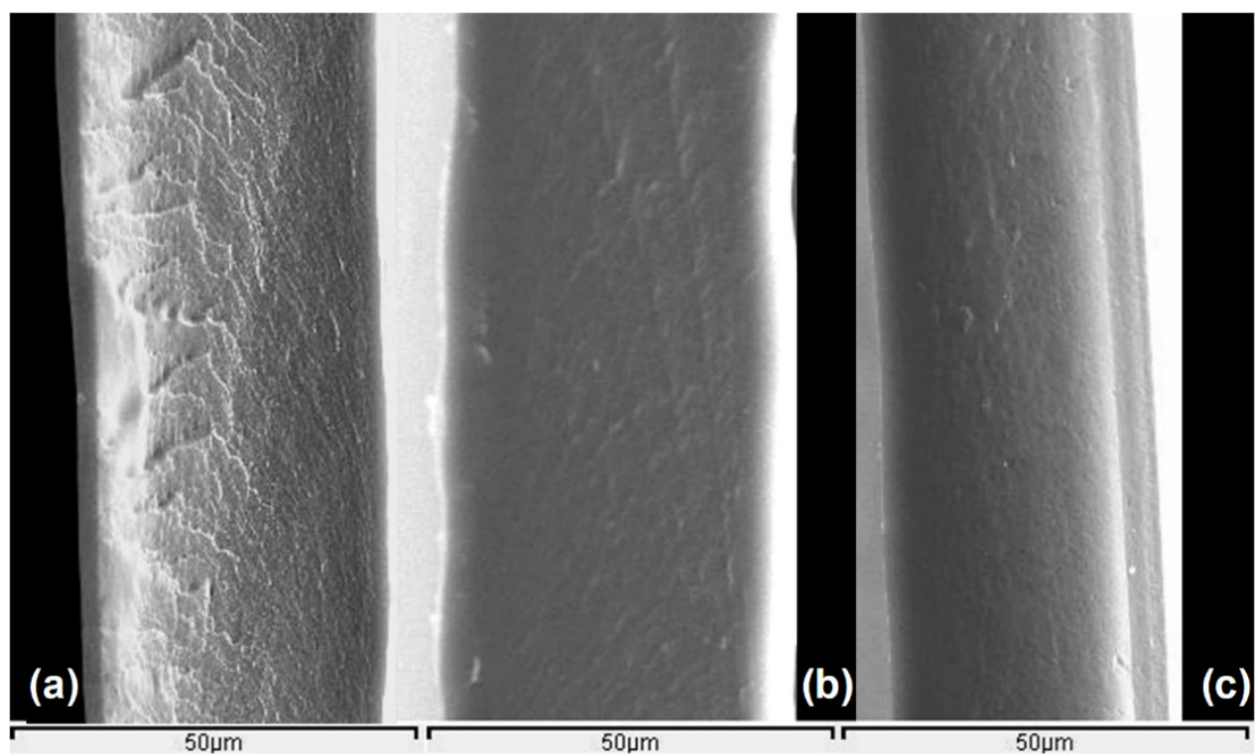

$50 \mu \mathrm{m}$

Figure 1.3 SEM micrographs of the cross-sections of pure chitosan films.

(a) RS, (b) RS+12, (c) RS +24. Magnification is 1000x. RS: rotor-stator,

+9: microfluidization at 9,000 psi, +12: microfluidization at 12,000 psi,

+18: microfluidization at 18,000 psi, +24: microfluidization at 24,000 psi. 


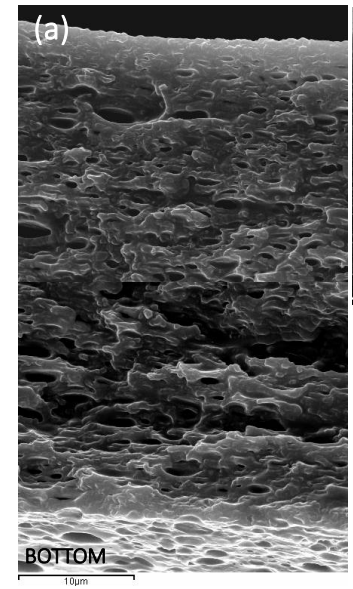

TOP

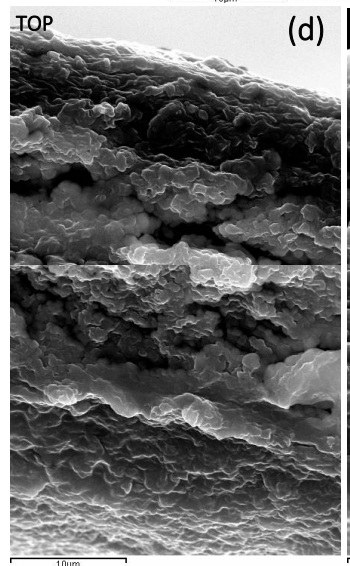

(d) (c)
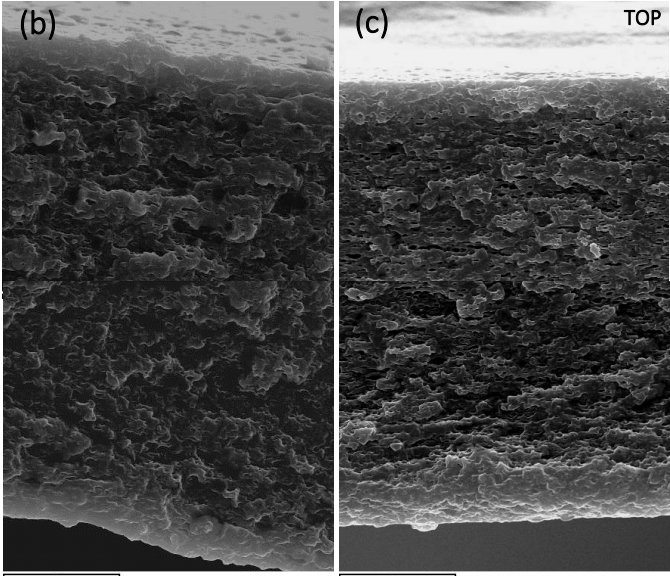

(e)

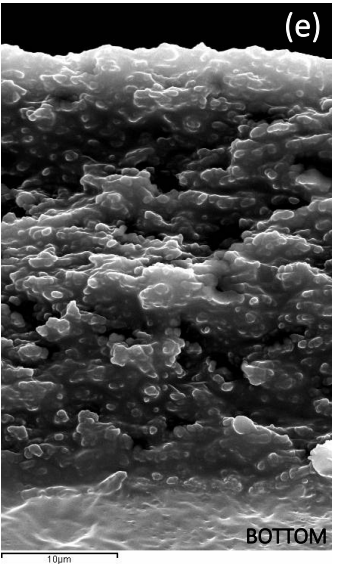

Figure 1.4 SEM micrographs of the cross-sections of $\mathrm{CH}: \mathrm{OA}$ composite films.

(a) RS; (b) RS+9, (c) RS+12, (d) RS+18, (e) RS+24. Magnification is 3000x.

RS: rotor-stator, +9: microfluidization at 9,000 psi, +12 : microfluidization at

$12,000 \mathrm{psi},+18$ : microfluidization at $18,000 \mathrm{psi},+24$ : microfluidization at 24,000 psi. CH: chitosan, OA: oleic acid.

The application of high pressure homogenization promoted relevant changes in the film microstructure even at the lowest pressure used, since after the application of microfluidization, differences between both phases became less marked. Lipid particles become embedded in the network and the smaller particles made them more closely connected with the polymer. When using the higher microfluidization pressures (124 and $165 \mathrm{MPa}$ ), more irregularities were observed in the film structure due to the lipid particle aggregation phenomena which developed during film drying. In this sense, Jafari, Assadpoor, He and Bhandari (2008) pointed out that if the process pressures are too high, they tend to make dispersed particles more 
susceptible to flocculation phenomena due to the fact that there is no complete coating of the generate interfacial surface with the stabilizing polymer, giving rise to bridging flocculation. In these cases, a second homogenization step, at lower pressure, is usually recommended.

The measurement of the water vapour permeability of the films (WVP) provides useful information as regards the feasibility of applying the FFD as a food coating. In the present study, the WVP was measured at a $\mathrm{RH}$ gradient of $100 / 54$, to simulate the usual gradient that is established when the FFD are applied to the surface of fresh-cut foods. Table 1.4 shows WVP values of pure and composite films. WVP values obtained for non-microfluidized films were lower than those found by Vargas, Albors, Chiralt and González-Martínez (2009) in CH:OA films, but the differences can be explained by the fact that a different temperature was used in the measurements.

Table 4 Water vapour permeability (WVP) of the films at $20^{\circ} \mathrm{C}$ and $\mathrm{RH}$ gradient of 100/54, elastic modulus (EM), elongation at break (E) and tensile strength (TS). Mean values and (standard deviation).

\begin{tabular}{|c|c|c|c|c|c|}
\hline FFD & $\mathrm{HC}$ & $\begin{array}{c}\text { WVP } \times 10^{11} \\
\left(\mathrm{~g} \cdot \mathrm{Pa}^{-1} \cdot \mathrm{s}^{-1} \cdot \mathrm{m}^{-1}\right)\end{array}$ & $\begin{array}{c}\mathrm{EM} \\
(\mathrm{MPa}) \\
\end{array}$ & $\begin{array}{c}E \\
(\%)\end{array}$ & $\begin{array}{c}\text { TS } \\
(\mathrm{MPa})\end{array}$ \\
\hline \multirow{3}{*}{$\mathrm{CH}$} & RS & $112(8)^{x}$ & $2556(117)^{\mathrm{ax}}$ & $4.6(0.7)^{\mathrm{ax}}$ & $81(5)^{a x}$ \\
\hline & $\mathrm{RS}+12$ & $120(3)^{x}$ & $2429(114)^{b x}$ & $4.7(1)^{b x}$ & $85(8)^{b x}$ \\
\hline & $R S+24$ & $109(9)^{x}$ & $2297(148)^{c x}$ & $4.4(0.5)^{\mathrm{ax}}$ & $71(7)^{c x}$ \\
\hline \multirow{5}{*}{$\mathrm{CH}: \mathrm{OA}$} & RS & $63.99(1.05)^{\text {ay }}$ & $1117(25)^{\text {ay }}$ & $10(5)^{\text {ay }}$ & $37(3)^{\text {ay }}$ \\
\hline & $\mathrm{RS}+9$ & $54(4)^{b}$ & $1103(43)^{a}$ & $9(3)^{a b}$ & $38(3)^{a}$ \\
\hline & $\mathrm{RS}+12$ & $51(1.4)^{\mathrm{bcy}}$ & $1172(36)^{\text {by }}$ & $8(3)^{\mathrm{abcy}}$ & $39(3)^{\text {ay }}$ \\
\hline & $\mathrm{RS}+18$ & $49.3(1.5)^{c}$ & $1197(14)^{b}$ & $4.9(1.7)^{b}$ & $36(1)^{a}$ \\
\hline & $\mathrm{RS}+24$ & $61(2)^{\text {ay }}$ & $1331(56)^{c y}$ & $6(2)^{\mathrm{bcy}}$ & $43(4)^{b y}$ \\
\hline
\end{tabular}

$a, b, c, d, e$ Different superscripts in the same column indicate significant differences $(p<0.05)$ due to treatments for the same FFD. ${ }^{x}, y$ Different superscripts in the same column indicate significant differences $(p<0.05)$ due to the addition of oleic acid for the same homogenization conditions. HC: homogenization conditions, RS: rotor-stator, +9: microfluidization at 9,000 psi, +12 : microfluidization at $12,000 \mathrm{psi},+18$ : microfluidization at $18,000 \mathrm{psi},+24$ : microfluidization at 24,000 psi. CH: chitosan, OA: oleic acid.

As expected, for the same homogenization conditions, the addition of OA led to a significant decrease in the WVP of the films. Nevertheless, 
microfluidization led to different results depending on the film composition. In pure chitosan films, the WVP was not affected by homogenization conditions. However, the application of microfluidization led to a significant decrease in the WVP of $\mathrm{CH}$ :OA films $(p<0.05)$. The decrease in particle size observed in these FFD (higher number of dispersed particles in the matrix), increased the tortuosity factor for water transfer in the continuous matrix, thus decreasing the WVP. This tortuosity factor is greater when the oil phase ratio increases or when the oil particle size is reduced (Morillon, Debeaufort, Blond, Capelli and Volley, 2002; Pérez-Gago and Krochta, 2001). Similar results were obtained by Fabra (2010) in OA-sodium caseinate films. The reduction observed in the WVP values of $\mathrm{CH}$ :OA composite films was not significant for the films obtained from the FFD homogenized at the highest pressure, which could be explained by the different microstructure which is developed during drying, as commented on above. Thus, we can conclude that only when microfluidization leads to a better distribution of the lipid particles in the dry film does the control of water transfer become more efficient.

Measuring the mechanical properties of the film allows us to predict their mechanical response during application and handling (Tanaka, Ishizaki, Suzuki and Takai, 2001). Table 1.4 shows elastic modulus (EM), percentage of elongation at break (E) and tensile strength (TS) of the films equilibrated at $20{ }^{\circ} \mathrm{C}$ and $54 \% \mathrm{RH}$. For every homogenization condition, the addition of OA led to a significant decrease (around $50 \%$ ) in EM and TS values due to the presence of OA particles which interrupt the polymer matrix, as has been previously observed in the micrographs of the cross-sections of the films and which is coherent with previous studies (Fabra, 2010; Vargas, Albors, Chiralt and González-Martínez, 2009).

The effect of the different homogenization conditions depended on the composition of the FFD and the pressure level. In pure chitosan films, EM and TS decreased when the homogenization pressure rose. Some authors have shown that there is a positive correlation between the molecular weight of chitosan and the mechanical resistance of the films (Park, Marsh and Rhim, 2002). From the obtained results, it seems that when increasing the homogenization pressure the molecular weight of the polymer was reduced, which had a significant effect on the mechanical properties of the dry film. In composite films, on the other hand, the use of microfluidization promoted an increase in $\mathrm{EM}$ and $\mathrm{TS}$ values and a reduction 
in the elongation at break, producing harder and less extensible films. The formation of a high number of structural interactions between $\mathrm{OA}$ and $\mathrm{CH}$ molecules as a consequence of the use of microfluidization (commented on above) could explain the better mechanical response of these films. Similar results were found by Fabra (2010) in OA-sodium caseinate based films. 


\section{CONCLUSIONS}

The application of different homogenization conditions to chitosan-based film-forming dispersions led to significant changes in their physicochemical properties. The use of microfluidization led to a significant decrease in the apparent viscosity of the FFD and modified their rheological behaviour, which changed from shear-thinning to Newtonian with the rise in homogenization pressure. In $\mathrm{CH}: \mathrm{OA} \mathrm{FFD}$, microfluidization led to a significant decrease in particle size and to monomodal, narrower particle size distributions, which in turn affect the properties of the dry films. The use of high homogenization pressures decreases the water vapour permeability of the composite films and leads to milder changes in the mechanical properties that occur when oleic acid is incorporated into the chitosan matrix, while seeming to promote structural links between $O A$ and $\mathrm{CH}$. The use of microfluidization treatments appears to be a suitable approach to the production of chitosan-based film-forming dispersions with different particle sizes, surface charge and rheological behaviour in order to develop edible films adapted to a specific target application.

\section{Acknowledgements}

The authors acknowledge the financial support provided by Universitat Politècnica de València (PAID-06-09-2834), Conselleria de Empresa, Universidad y Ciencia (GV/2010/082), and Ministerio de Educación y Ciencia (Project AGL2007-65503). Ángela Perdones also thanks the Universitat Politècnica de València for the FPI grant. 


\section{REFERENCES}

ASTM. Standard test methods for water vapor transmission of materials. Standard Designations: E96-95. In ASTM, Annual Book of ASTM (pp. 406 - 413). ASTM (Philadelphia) 1995.

ASTM. Standard test method for tensile properties of thin plastic sheeting. Standard D882. In ASTM, Annual Book of ASTM, (pp. 162-170). ASTM (Philadelphia) 2001.

Becher, P. Emulsions: theory and practice. Oxford University Press (Oxford) 2001.

Cruz, N., Capellas, M.M., Hernández, M., Trujillo, A.J., Guamis, B., Ferragut, $V$. Ultra-high pressure homogenization of soymilk: microbial, physicochemical and microstructural characteristics. Food Research International 40:6 (2007) $725-732$.

Debeaufort, F., Martin-Polo, M., Voilley, A. Polarity, homogeneity and structure affect water vapour permeability of model edible films. Journal of Food Science; 58:2 (1993) 426 - 429, 434.

Fabra, M.J. Edible coatings based on sodium caseinate. PhD Thesis. Universitat Politècnica de València (Valencia) 2010.

Floury, J., Desrumaux, A, Lardières, J.L. Effect of high-pressure homogenization on droplet size distributions and rheological properties of model oil-in-water emulsions. Innovative Food Science and Emerging Technologies, 1:2 (2000) 127-134.

Greener, I.K., Fennema, O.R. Edible films and coatings: Characteristics, formation, definitions, and testing methods. In J.M. Krochta, E.A. Baldwin, M.O. Nísperos-Carriedo (Eds.). Edible coatings and films to improve food quality (pp. 1 - 24). Technomic Publishing Company, Inc. (Lancaster) 1994. 
Ham-Pichavant, F., Sèbe, G., Pardon, P., Coma, V. Fat resistance properties of chitosan-based paper packaging for food applications. Carbohydrate Polymers 61:3 (2005) $259-265$.

Jafari, S.M., Assadpoor, E., He, Y., Bhandari, B. Re-coalescence of emulsion droplets during high-energy emulsification. Food Hydrocolloids 22:7 (2008) $1191-1202$.

Kasaai, M.R., Charlet, G., Paquin, P., Arul, J. Fragmentation of chitosan by microfluidization process. Innovative Food Science and Emerging Technologies 4:4 (2003) $403-413$.

Krochta, J.M., De-Mulder-Johnston, C. Edible and biodegradable polymer films: challenges and opportunities. Food Technology 51:2 (1997) 61 - 74.

Lee, S., Lefèvre, T., Subirade, M., Paquin, P. Effects of ultra-high pressure homogenization on the properties and structure of interfacial protein layer in whey protein-stabilized emulsion. Food Chemistry 113:1 (2009) $191-195$.

McClements, D.J. Food emulsions: principles, practice, and techniques (pp. 341 - 388). CRC Press LLC, Boca Raton (Florida) 2005.

Morillon, V., Debeaufort, F., Blond, G., Capelli, M., Volley, A. Factors affecting the moisture permeability of lipid-based edible films: $A$ review. Critical Reviews in Food Science and Nutrition 42:1 (2002) 67 - 89.

Paquin, P. Technological properties of high pressure homogenizers: the effect of fat globules, milk proteins, and polysaccharides. International Dairy Journal 9:3 (1999) $329-335$.

Park, S.Y., Marsh, K.S., Rhim, J.W. Characteristics of Different Molecular Weight Chitosan Films Affected by the Type of Organic Solvents. Journal of Food Science, 67:1 (2002) 194-197.

Pereda, J., Ferragut, V., Quevedo, M., Guamis, B., Trujillo, A.J. Effects of ultra-high pressure homogenization on microbial and physicochemical shelf life of milk. Journal of Dairy Science 90:3 (2007) 1081 - 1093. 
Pérez-Gago, M.B., Krochta, J.M. Lipid particle size effect on water vapor permeability and mechanical properties of whey protein/beeswax emulsion films. Journal of Agriculture and Food Chemistry 49:2 (2001) 996 - 1002.

Perrechil, F.A., Cunha, R.L. Oil-in-water emulsions stabilized by sodium caseinate: Influence of $\mathrm{pH}$, high-pressure homogenization and locust bean gum addition. Journal of Food Engineering 97:4 (2010) $441-448$.

Perrier-Cornet, J.M., Marie, P., Gervais, P. Comparison of emulsification efficiency of protein-stabilized oil-in-water emulsions using jet, high pressure and colloid mill homogenization. Journal of Food Engineering 66 (2005) $211-217$.

Pinnamaneni, S., Das, N.G., Das, S.K. Comparison of oil-in-water emulsions manufactured by microfluidization and homogenization. Die Pharmazie - An International Journal of Pharmaceutical Sciences 58:8 (2003) $554-558$.

Schubert, $H$. Advances in the mechanical production of food emulsions. In R. Jowitt (Ed.), Engineering and Food (pp. 82). Sheffield Academic Press (Shelffield) 1997.

Strawbridge, K.B., Ray, E., Hallett, F.R., Tosh, S.M., Dalgleish, D.G. Measurement of particle-size distributions in milk homogenized by a microfluidizer-estimation of populations of particles with radii less than $100 \mathrm{Nm}$. Journal of Colloid and Interface Science 171:2 (1995) 392 - 398.

Tanaka, M., Ishizaki, S., Suzuki, T., Takai, R. Water vapour permeability of edible films prepared from fish water soluble proteins as affected by lipid type. Journal of Tokyo University of Fisheries 87 (2001) 31 - 37.

Urban, K., Wagner, G., Schaffner, D., Röglin, D., Ulrich, J. Rotor-stator and disc systems for emulsification processes. Chemical Engineering and Technology 29:1 (2006) 24-31.

Vargas, M., Albors, A., Chiralt, A., González-Martínez, C. Characterization of chitosan-oleic acid composite films. Food Hydrocolloids 23:2 (2009) $536-547$. 



\section{CHAPTER 2}

\section{APPLICATION OF CHITOSAN FILMS CONTAINING ESSENTIAL OILS IN PRESERVATION OF STRAWBERRIES}

EFFECT OF CHITOSAN-LEMON ESSENTIAL OIL COATINGS ON STORAGE-KEEPING QUALITY OF STRAWBERRY

EFFECT OF CHITOSAN-LEMON ESSENTIAL OIL COATINGS ON VOLATILE PROFILE OF STRAWBERRIES DURING STORAGE 



\section{EFFECT OF CHITOSAN-LEMON ESSENTIAL OIL COATINGS ON STORAGE-KEEPING QUALITY OF STRAWBERRY}

Ángela Perdones ${ }^{1}$, Laura Sánchez-González ${ }^{1,2}$, Amparo Chiralt $^{1}$, Maria Vargas ${ }^{1^{*}}$

Postharvest Biology and Technology 70 (2012) 32 - 41

\footnotetext{
${ }^{1}$ Instituto Universitario de Ingeniería de Alimentos para el Desarrollo, Departamento de Tecnología de Alimentos, Universitat Politècnica de València, Camino de Vera s/n, 46022 Valencia, Spain

${ }^{2}$ Institut National Polytechnique de Lorraine (INPL), ENSAIA 2, Avenue de la Forêt de Haye, Boîte Postale 172, 54505 Vandoeuvre-lès-Nancy Cedex, France

*Telephone: 0034963877000 Ext. 73642 Fax: 0034963877369 e-mail:mavarco@tal.upv.es
} 


\section{ABSTRACT}

Film-forming dispersions (FFD) were prepared with $1 \%$ high molecular weight chitosan and $3 \%$ lemon essential oil and were submitted to two different homogenization treatments. The particle size and viscosity of the FFD were evaluated and stand-alone coatings were characterized in terms of water vapour permeability (WVP) and antimicrobial activity. The FFD were applied to cold-stored strawberries, cv. Camarosa, and the physicochemical properties, fungal decay and respiration rate of strawberries were determined throughout cold storage at $5{ }^{\circ} \mathrm{C}$. The use of microfluidization to prepare chitosan-based FFD led to a significant reduction in the particle size and apparent viscosity of the dispersions, with no significant effect on the decrease in the WVP of the stand-alone coatings. Chitosan coatings did not show a significant effect in terms of the acidity, $\mathrm{pH}$ and soluble solid content of strawberries throughout storage. In contrast, coatings slowed down the respiration rate of samples when lemon essential oil was added to the FFD. Adding lemon essential oil enhanced the chitosan antifungal activity both in in vitro tests and during cold storage in strawberries inoculated with a spore suspension of Botrytis cinerea.

Keywords: coating, chitosan, strawberry, microfluidization, lemon essential oil, water vapour resistance, respiration rate, sensory profile. 


\section{INTRODUCTION}

Strawberry is a highly perishable fruit with a short postharvest life which is mainly due to fungal decay. The shelf-life of cold-stored $\left(0-4{ }^{\circ} \mathrm{C}\right)$ fresh strawberries is around 5 days. In order to extend fruit shelf life, the use of low temperatures combined with controlled or modified atmospheres has been studied (Holcroft and Kader, 1999; Pérez and Sanz, 2001; Sanz, Pérez, Olías and Olías, 1999). Edible coatings are thin layers of material made from biodegradable ingredients that can be consumed as a part of the food product and can act as a selective barrier to gas transport (Vargas, Pastor, Chiralt, McClements and González-Martínez, 2008). In this way, edible film technology is an alternative method with which to extend the commercial shelf life of coated products by modifying their internal atmosphere (Park, 1999).

Chitosan is a biodegradable cationic hydrocolloid with antimicrobial activity and film-forming ability (Cuero, 1999; Jung, Kim, Choi, Lee and Kim, 1999; No, Park, Lee and Meyers, 2002; Tharanathan and Kittur, 2003; Vargas and González-Martínez, 2010; Zheng and Zhu, 2003). Chitosan films have relatively high water vapour permeability (Vargas, Albors, Chiralt and González-Martínez, 2009), which is a major drawback since adequate water vapour barrier properties are desirable in order to avoid dehydration processes during fruit storage. The addition of lipid materials to chitosan-based films can improve their moisture barrier properties. For instance, Wong, Gastineau, Gregorski, Tillin and Pavlath (1992) added saturated fatty acids and fatty acid esters to chitosan-based films, obtaining a higher resistance to water vapour transmission when lauric and butyric acids were incorporated. Vargas, Albors, Chiralt and González-Martínez (2009) developed chitosan-oleic acid composite films with improved water vapour barrier properties, which at the same time have proven to be effective at extending the shelf life of cold-stored strawberries (Vargas, Albors, Chiralt and González-Martínez, 2006). The application of chitosan-based films (alone or in combination with other compounds such as vitamin) was also effective at controlling the decay of cold-stored strawberries (El Ghaouth, Arul, Ponnampalam and Boulet, 1991; Han, Zhao, Leonard and Traber, 2004; Zhang and Quantick, 1998). 
Chitosan coatings applied to strawberries, stored at room temperature, led to an improvement of fruit firmness, reduced visual fungal decay and delayed changes in external colour (Hernández-Muñoz, Almenar, Ocio and Gavara, 2006). In a similar study, Hernández-Muñoz, Almenar, del Valle, Vélez and Gavara (2008), reported a reduction in respiration rate and weight loss for cold-stored strawberries when chitosan coating was applied. Moreover, the addition of calcium gluconate to the chitosan solution increased the strawberry firmness and nutritional value without altering the fruit visual appearance, which was correlated with the lower dehydration and darkening levels during storage. Ribeiro, Vicente, Teixeira and Miranda (2007) showed reduced microbial growth rates in cold-stored strawberries coated with chitosan solutions applied by spraying. The potential of chitosan coatings in maintaining strawberry flavour and aroma during cold storage has been also shown by Almenar, Hernández-Muñoz and Gavara (2009). In this study, a reduction in acetaldehyde and ethanol formation was reported in chitosan-coated strawberry samples, which may be a positive indicator of prolonged shelf-life. A recent study (Kerch, Sabovics, Kruma, Kampuse and Straumite, 2011) indicated that coatings of chitosan and chitooligosaccharides applied to strawberries led to an improvement in fruit firmness and to a reduction in Vitamin C and anthocyanin content. Campaniello, Bevilacqua, Ainigaglia and Corboet (2008) used chitosan coatings to control spoilage and browning of fresh-cut strawberries in combination with other preservation factors, such as low temperature and modified atmosphere packaging.

Essential oils (EO) are natural antioxidant and antimicrobial lipidic substances extracted from fruits and vegetables. Most of them consist of a mixture of terpens, terpenoids and other aromatic and aliphatic constituents (Bakkali, Averbeck, Averbeck and Idaomar, 2008), but their composition can vary markedly depending on the specific oil. For instance, lemon essential oil, which is extracted from Citrus lemon, has limonene, valencene and ocimene as major components (Moufida and Marzouk, 2003). Limonene, which has the GRAS status of the U.S. FDA (US EPA, 1994), is used as a food additive or flavouring agent, and is known to have fungicidal properties, including activity against Botrytis cinerea and Aspergillus niger (Sharma and Tripathi, 2008; Wilson, Solar, El Ghaouth and Wisniewski, 1997). The use of EO in food preservation is often limited because of their application costs and other drawbacks, such as their 
intense aroma and potential toxicity. An interesting approach to reduce the doses of essential oils while maintaining their effectiveness could be to incorporate these compounds into the formulation of edible coatings. In this sense, Sánchez-González, Cháfer, Hernández, Chiralt and González-Martínez (2011a) developed antibacterial composite films based on chitosan or hydroxypropylmethylcellulose and different EO (lemon, tea tree or bergamot), which were applied on the surface of inoculated agar plates, which were used as a model of a solid food system. In this study, an inhibition of the growth of bacteria (E. coli, L. monocytogenes and S. aureous) was observed for chitosan films that incorporated essential oils. The antibacterial activity of the chitosan films was enhanced when the added EO were more effective than the polymer, like in the case of Gram-positive bacteria.

Chitosan-essential oil edible coatings have proven to be effective at extending the shelf-life of some fruits and vegetables, such as sweet pepper (Xing et al., 2011) and table grapes (Sánchez-González et al., 2011b). The antifungal effect of bioactive coatings prepared with modified chitosan and limonene or peppermint essential oil on the fungal decay of cold-stored strawberries has recently been evaluated (Vu, Hollingsworth, Leroux, Salmieri and Lacroix, 2011). Nevertheless, there are no studies published into the effect of chitosan-lemon essential oil composite coatings on the postharvest quality of cold-stored strawberry.

When developing hydrocolloid-based film-forming dispersions (FFD), such as chitosan-essential oil systems, the way in which lipids are emulsified determines the emulsion stability, which directly affects the coating's final structure and thus, its properties. The stability of the FFD depends on complex mechanisms, but some of the key aspects are the average fat globule size and their size distribution pattern which, in turn, both affect the stability, colour, and rheological properties of the FFD, among other factors (Becher, 2001). Rotor-stator systems are also often used in the food industry to homogenize different media and high viscosity immiscible liquids, reaching particle sizes in the range of $1 \mu \mathrm{m}$ (Urban, Wagner, Schaffner, Röglin and Ulrich, 2006). To reduce the size of the dispersed particles and obtain narrower particle size distributions, high pressure homogenizers, such as microfluidizers, capable of producing pressures in the range of 1,000 bar or higher, can be used (Paquin, 1999). 
Microfluidization has been extensively used by the pharmaceutical industry (Pinnamaneni, Das and Das, 2003; Strawbridge, Ray, Hallet, Tosh and Dalgleish, 1995) and it has recently been applied to produce hydrocolloid-based FFD (Fabra, Pérez-Masiá, Talens and Chiralt, 2011; Vargas, Perdones, Chiralt, Cháfer and González-Martínez, 2011a). However, to the best of our knowledge, there are no studies published into using such coatings to extend the shelf-life of fruits or vegetables.

The purpose of the present study was to evaluate the effect of chitosan-lemon essential oil coatings, prepared using different homogenization treatments, on the physicochemical quality, fungal decay and respiration rate of cold-stored strawberries, cv. Camarosa.

\section{MATERIALS AND METHODS}

\subsection{Materials}

Strawberries (Fragaria $x$ ananassa) cv. Camarosa, obtained from organic farming, were transported in cold to the laboratory and coating experiments were carried out on the same day. Strawberries of uniform size, shape and colour and without any signs of mechanical damage or fungal decay were selected and washed in $10 \mathrm{mg} / \mathrm{L}$ sodium hypochlorite solution prior to coating. A total amount of 530 fruits was used for conducting all experiments.

High molecular weight chitosan $(\mathrm{CH})$, with a deacetylation degree of $75.6 \%$ (CAS Number 9012-76-4, Batch 10305DD, Sigma-Aldrich, USA, viscosity in 1 wt. \% glacial acetic acid solution: $1.406 \mathrm{~Pa} \cdot \mathrm{s})$, and $98 \%$ glacial acetic acid, were used to prepare the FFD.

\subsection{Preparation and characterization of the film-forming dispersions}

Chitosan ( $1 \% \mathrm{w} / \mathrm{w})$ was dispersed in an aqueous solution of glacial acetic acid $(0.5 \% \mathrm{v} / \mathrm{w})$. This FFD was named as $\mathrm{CH}$. To prepare chitosan-essential oil FFD, chitosan was dissolved as described above and lemon essential oil was added to reach a final concentration of $3 \%(w / w)$. The mixture was 
emulsified using a rotor-stator homogenizer (DI25 Yellow Line, IKA ${ }^{\circledR}$, Germany) at 20,500 rpm for $4 \mathrm{~min}$. This film-forming dispersion was named as $\mathrm{CH}$.L. This coarse emulsion was submitted to a second homogenization at $165 \mathrm{MPa}$ in a single pass by using microfluidization (Microfluidizer ${ }^{\circledR}$, M110-P, Microfluidics, Newton, MA, USA) to obtain CH.LM FFD. An aqueous solution of glacial acetic acid $(0.5 \% \mathrm{v} / \mathrm{v})$, was used for the immersion of a control sample (control).

The particle size of CH-L FFD was measured by using a laser diffractometer (MasterSizer 2000, Malvern Instruments, UK). The FFD were diluted in a sodium acetate buffer solution under the appropriate solvent conditions at $2,000 \mathrm{rpm}$ until an obscuration rate of $10 \%$ was obtained. The Mie theory was applied by considering the following optical properties for dispersed droplets: a refractive index of 1.52 and absorption of 0.00 . Three samples of each FFD were measured in triplicate. The rheological behaviour of FFD was analysed in triplicate after one day of storage at $25^{\circ} \mathrm{C}$ by means of a rotational rheometer (Haake Rheostress1, Thermo Electric Corporation, Germany) with a type Z34DIN Ti sensor system of coaxial cylinders. Rheological curves were obtained after a stabilization time of $5 \mathrm{~min}$ at $25{ }^{\circ} \mathrm{C}$. The shear stress $(\sigma)$ was measured as a function of shear rate $(\dot{\gamma})$ from 0 to $512 \mathrm{~s}^{-1}$. The power law model was applied to determine the consistency $(\mathrm{K})$ and the flow behaviour $(\mathrm{n})$ indexes of the FFD. Apparent viscosity values were calculated at $100 \mathrm{~s}^{-1}$, which could be a typical gradient generated during the sample coating application process with the FFD.

\subsection{Preparation and characterization of the stand-alone coatings}

Stand-alone coatings (films) were obtained by casting. FFD were poured onto a framed and levelled polytetrafluorethylene (PTFE) plate and were dried at room temperature for $48 \mathrm{~h}$. Films were prepared by pouring the amount of FFD that will provide a solids surface density of $56 \mathrm{~g} / \mathrm{m}^{2}$ in the dry films. Dry coatings were peeled off from the casting surface and preconditioned in desiccators at $5{ }^{\circ} \mathrm{C}$ and $59 \%$ relative humidity $(\mathrm{RH})$ prior to testing. Film thickness was measured in quintuplicate using a hand-held digital micrometer (Palmer-Comecta, Spain, $\pm 0.001 \mathrm{~mm}$ ) and the average value was used in water vapour permeability (WVP) calculations. WVP was measured, in quintuplicate, following the "water method" of the ASTM E-96-95 (ASTM, 1995), using Payne permeability cups (Elcometer SPRL, Hermelle/s Argenteau, Belgium). De-ionised water was used inside 
the testing cup to achieve $100 \% \mathrm{RH}$ on one side of the film, while an oversaturated magnesium nitrate solution was used to control the relative humidity on the other side of the film: $58.9 \% \mathrm{RH}$. During WVP testing, the side of the film in contact with the PTFE plate was placed in contact with the part of the test cup having the highest $\mathrm{RH}$. A fan placed on the top of the cup was used to promote convection. The water vapour transmission rate (WVTR) was measured in triplicate at $5{ }^{\circ} \mathrm{C}$ for each type of film. The WVP was determined from WVTR values, as described by Vargas, Albors, Chiralt and González-Martínez (2009).

The microstructural analysis of the cross sections of the dry films (previously conditioned in desiccators with $\mathrm{P}_{2} \mathrm{O}_{5}$ for at least 15 days) was carried out following the SEM technique using a JEOL JSM-5410 (Japan) electron microscope. Pieces of $5 \times 1 \mathrm{~mm}^{2}$ were cut from films and mounted in copper stubs. Samples were gold coated and observed using an accelerating voltage of $10 \mathrm{kV}$.

The methodology followed for the determination of the antimicrobial effectiveness of the stand-alone coatings was adapted from Kristo, Koutsoumanis and Biliaderis (2008). Stock culture of Botrytis cinerea (CECT 20516), supplied by Colección Española de Cultivos Tipo (CECT, Burjassot, Spain), was kept frozen $\left(-25^{\circ} \mathrm{C}\right)$ in Potato Dextrose Agar (Scharlab, Barcelona, Spain) supplemented with $30 \%$ glycerol (Panreac, Barcelona, Spain). The fungus was inoculated on potato dextrose agar (PDA) and incubated at $25{ }^{\circ} \mathrm{C}$ until sporulation. The cells were counted in a haemocytometer and diluted to a concentration of $10^{5}$ spores per $\mathrm{mL}$, which is the recommended concentration for the evaluation of moulds in postharvest treatments (Sánchez-González, Cháfer, Chiralt and González-Martínez, 2010). Aliquots of PDA (20 g) were poured into Petri dishes. After the culture medium solidified, diluted spore solution was inoculated on the surface. The different coatings, with the same diameter as the Petri dishes, were placed on the inoculated surfaces. Inoculated and non-coated PDA Petri dishes were used as control. Plates were then covered with parafilm to avoid dehydration and stored for 12 days at $20^{\circ} \mathrm{C}$. Microbial counts on PDA plates were examined both immediately after the inoculation and periodically during the storage period. To this end, the agar was removed aseptically from the Petri dishes and placed in a sterile plastic bag with $100 \mathrm{~mL}$ of tryptone phosphate water (Scharlab, Barcelona, Spain). 
The bag was homogenized for 2 min in a Stomacher blender (Bag Mixer 400 , Interscience). Serial dilutions were made and then poured onto PDA plates that were incubated for 5 days at $25^{\circ} \mathrm{C}$ before colonies were counted. All the tests were run in triplicate.

\subsection{Application of the coatings}

Selected strawberries were dipped in the FFD for $1 \mathrm{~min}$. A total amount of 120 strawberries were coated with each FFD. Samples were dried by natural convection for $1 \mathrm{~h}$ at $20^{\circ} \mathrm{C}$ and were stored on PET trays ( $\sim 10$ strawberries per tray), where the pieces did not come into direct contact with each other. The trays were kept at $4 \pm 1{ }^{\circ} \mathrm{C}$ and $90 \%$ relative humidity in a climate chamber (EC1400, Radiber, Barcelona, Spain). Physicochemical analyses of control (non-coated) and coated samples were performed in quintuplicate after 0, 4, 7, 11 and 15 storage days.

\subsubsection{Surface solid density and water vapour resistance}

The mean value of the coating thickness was calculated in ten samples of each formulation by quantifying the surface solid density (SSD) (Eq. 2.1.1).

$$
S S D=\frac{M_{F a} \cdot X_{s}}{A_{s}}
$$

The average sample surface area $\left(A_{s}\right)$ was estimated by considering strawberry geometry as a cone with a known height (measured in triplicate using a digital calliper) and volume (measured with a pycnometer, by using water as reference liquid). Samples were weighed before and after coating, to determine the mass of coating solution adhered to the strawberry surface $\left(M_{F a}\right)$. The mass fraction of solids $\left(X_{s}\right)$ of each film-forming solution was also considered to calculate SSD.

The water vapour resistance of strawberries was determined in ten samples per coating formulation and in ten non-coated samples that were kept in desiccators at $59 \% \mathrm{RH}$, which was generated by using oversaturated magnesium nitrate solution. The desiccators were kept in an incubator Hot-Cold M4000668 (P-Selecta, Barcelona, Spain) at $5{ }^{\circ} \mathrm{C}$. Water vapour resistance (WVR) was calculated using a modified equation of Fick's First 
Law (Eq. 2.1.2), as described by Avena-Bustillos, Krochta, Saltveit, Rojas-Villegas and Sauceda-Pérez (1994).

$$
W V R=\frac{a_{w}-\frac{\% R H}{100} \cdot P_{w v}}{R \cdot T} \times \frac{A_{s}}{J}
$$

Where $J$ is the slope of the weight loss curve in stationary conditions, $A_{s}$ sample area, $a_{w}$ water activity of samples, $P_{w v}$ saturated water vapour pressure, $T$ absolute temperature and $R$ the universal constant of gasses.

\subsubsection{Acidity, $\mathrm{pH}$, soluble solids and maturity index}

Five samples per coating formulation and five non-coated control samples were independently ground using an Ultraturrax at 8,500 rpm for $1 \mathrm{~min}$. Acidity was analysed following method AOAC 942.15 (AOAC, 1995), and was expressed as $\mathrm{g}$ of citric acid per $100 \mathrm{~g}$ of fruit. Measurement of $\mathrm{pH}$ was carried out by means of a pH-meter (GLP 21+, Crison, Barcelona, Spain). Total soluble solids were measured by a 3 T ABBE refractometer (ATAGO Co Ltd, Japan) at $22{ }^{\circ} \mathrm{C}$. Maturity index (MI) was calculated as the quotient between soluble solids and acidity.

\subsubsection{Colour measurement}

The colour was determined using a CM-3600d spectrocolorimeter (Minolta Co, Tokyo, Japan) with a $10 \mathrm{~mm}$ diameter window. The measurements were taken in five samples per formulation before and after coating and at each time of storage. To avoid the effects of heterogeneity on the fruit surface, measurements were always carried out in the same previously marked sample zone of each fruit. CIE-L ${ }^{*}{ }^{*} b^{*}$ coordinates, hue $\left(h^{*}{ }_{a b}\right)$ and chroma $\left(C^{*} a b\right)(C I E, 1986)$ were obtained from the reflection spectra of the samples using D65 illuminant $/ 10^{\circ}$ observer.

\subsubsection{Mechanical properties}

The mechanical properties were measured by using a TA-XT-plus Texture Analyser (Stable Micro Systems, Surrey, UK), with a $500 \mathrm{~N}$ load cell, using a $10 \mathrm{~mm}$ diameter cylindrical probe. The strawberry samples were cut longitudinally and $95 \%$ compressed at a $0.2 \mathrm{~mm} / \mathrm{s}$ deformation rate. Force and distance at the failure point were used as mechanical 
parameters. Measurements were carried out in five fruits (10 halves) per coating formulation and in five non-coated strawberries (10 halves).

\subsubsection{Fungal decay}

To enable the comparison with the results obtained in the in vitro studies, 50 strawberries per coating formulation were inoculated with Botrytis cinerea $\left(10^{5}\right.$ spores $\left./ \mathrm{mL}\right)$ by sample immersion in a spore suspension before applying the coating. 50 non-coated inoculated strawberries were used as control. The strawberries that showed any sign of surface mycelia development were considered decayed. Results were expressed as percentage of infected strawberries. Two replicates were performed.

\subsubsection{Respiration rate}

In order to measure the respiration rate, a closed system was used (Castelló, Fito and Chiralt, 2006). At each time of storage, strawberry samples (about $150 \mathrm{~g}$ ) were placed in $0.847 \mathrm{~L}$ hermetic glass jars with a septum in the lid for sampling the gas in the headspace at different times for $10 \mathrm{~h}$. The jars were stored in a climate chamber (EC1400, Radiber, Barcelona, Spain) at $5{ }^{\circ} \mathrm{C}$. Gas sampling was carried out every $30 \mathrm{~min}$ by means of a needle connected to a gas analyser (CheckMate $9900 \mathrm{PBI}$ Dansensor, Ringsted, Denmark). This head space gas analyser is based on an electrochemical sensor for recording the $\mathrm{O}_{2}$ content and a mini-IR spectrophotometer for the $\mathrm{CO}_{2}$ content (Rocculi, Romani and Dalla Rosa, 2005). Three replicates were performed for each formulation.

The experimental points considered were in the time range in which a linear relationship was observed between gas concentration and time. This means that no changes in the respiration pathway of the samples occurred in this period and so changes in the headspace composition did not produce any notable alterations in their metabolism. The respiration rate $\left(R R_{i}, \mathrm{~mL} \cdot \mathrm{kg}^{-1} \cdot \mathrm{h}^{-1}\right)$ of the samples, in terms of $\mathrm{CO}_{2}$ generation and $\mathrm{O}_{2}$ consumption, was determined from the slope of the fitted linear equation, as described by Fonseca, Oliveira and Brecht (2002). 


\subsubsection{Sensory analysis}

Sensory evaluation was carried out by means of a difference-from-control test with a seven-point scale (Meilgaard, Civille and Carr, 1999). This test has a twofold objective: (1) to determine whether a difference exists between the different samples and the control sample and (2) to measure the size of these differences. In all cases, judges compare a coded sample with a reference sample (non-coated sample) in different attributes and they evaluate the size of the differences between these samples against a seven-point scale. All coated and non-coated samples were compared with a reference sample. The following sensory parameters were evaluated by 30 non-trained panellists: brightness, strawberry aroma and flavour, acidity, astringency and overall preference.

\subsection{Statistical analysis}

The results were analysed by a multifactor analysis of variance (ANOVA) with a $95 \%$ significance level using Statgraphics ${ }^{\circledR}$ Plus 5.1. Multiple comparisons were performed through $95 \%$ Fisher's LSD intervals.

\section{RESULTS AND DISCUSSION}

\subsection{Characterization of FFD and the stand-alone coatings}

The particle size distribution of the FFD is shown in Figure 2.1.1. Both distributions were bimodal. The application of microfluidization led to a significant reduction in the particle size $(p<0.05)$, as has been previously observed for $\mathrm{CH}$-oleic acid dispersions (Vargas, Perdones, Chiralt and González-Martínez, 2011a), and enhanced the bimodal character of the size distribution. The occurrence of the bimodal distribution may be attributed to the formation of smaller droplets when $\mathrm{CH}$ was adsorbed at the oil-water interface and bigger droplets when the droplets are not completely covered and bridging flocculation can occur, giving rise to greater aggregates (McClements, 2005). The high ratio essential oil-CH could explain the fact that there was insufficient polymer to cover the complete droplet surface, mainly when droplet sizes were reduced by microfluidization. 
The interfacial adsorption of $\mathrm{CH}$ on the surface of essential oil droplets has previously been observed through the $\zeta$-potential values (Sánchez-González, Chiralt, González-Martínez and Cháfer, 2011c).

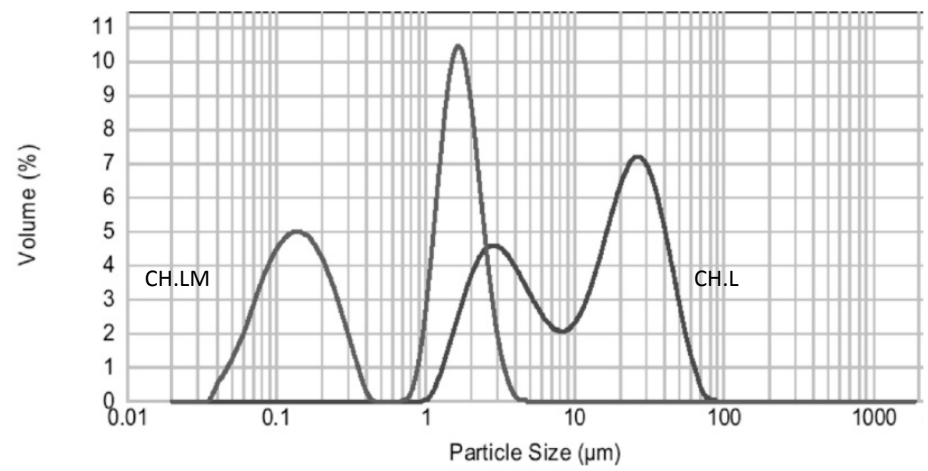

Figure 2.1.1 Typical Particle size distribution of CH.L and CH.LM film-forming dispersions. $\mathrm{CH}$ : chitosan, L: lemon essential oil, $\mathrm{M}$ : microfluidized.

The different droplet size distribution in the FFD had a great impact on the final microstructure of the stand-alone coatings, as can be observed in Figure 2.1.2, where the SEM-micrographs of the cross-sections of the films are shown. The smaller particles and more uniform size distribution can be observed for coatings containing essential oil when FFD were submitted to microfluidization.

(a) (b)

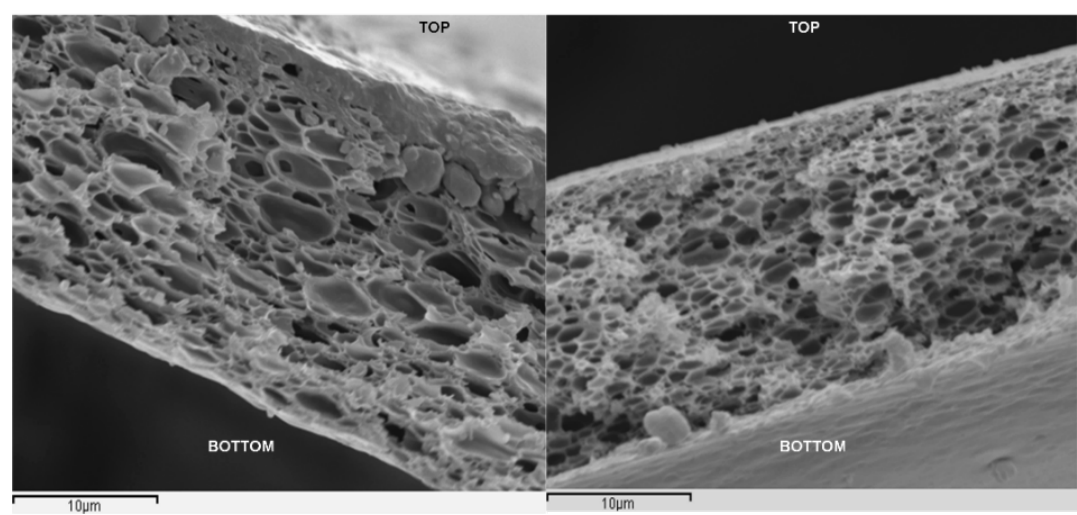

Figure 2.1.2 SEM micrographs of the cross-sections (top: film drying surface, bottom: film surface in contact with the plate) of the stand-alone coatings containing lemon essential oil: (a) CH.L, chitosan-lemon essential oil (b) CH.LM, microfluidized chitosan-lemon essential oil. 
Pure chitosan FFD showed shear-thinning behaviour ( $\mathrm{n}=0.63, \mathrm{~K}=1.1 \mathrm{~Pa} \cdot \mathrm{s}$ ). When lemon EO was incorporated by means of rotor-stator homogenization, the rheological behaviour was very similar $(n=0.62$, $\mathrm{K}=1.6$ ) to that obtained for pure $\mathrm{CH}$. This coincides with the results reported by Bonilla, Atarés, Vargas and Chiralt (2012) and Sánchez-González, Chiralt, González-Martínez and Cháfer (2011c) for chitosan FFD containing essential oils. The use of high-pressure homogenization led to greater changes in the rheological behaviour of FFD, which become more Newtonian ( $n=0.893, K=0.114$ ), and to a significant reduction in the apparent viscosity values, as shown in Table 2.1.1. Similar results were found in chitosan-based FFD prepared with basil or thyme essential oils (Bonilla, Atarés, Vargas and Chiralt, 2012). The main factors that determine the rheological properties of emulsions are associated with the characteristics of both the dispersed phase (volume concentration, distribution, size, shape and electrical charge of the particles) and the continuous phase (viscosity, chemical composition, and concentration of electrolytes), together with the presence of surfactants and thickening agents (McClements, 2005).

Table 2.1.1 Apparent viscosity values at $100 \mathrm{~s}^{-1}$ of the film-forming dispersions (FFD), water vapour permeability (WVP) of the stand-alone coatings at $5{ }^{\circ} \mathrm{C}$ and 100/59 \% RH gradient, surface solid density (SSD) and water vapour resistance (WVR) in coated strawberry samples. Mean values and (standard deviation).

\begin{tabular}{lccccc}
\hline FFD & $\begin{array}{c}\eta_{\text {ap }} \\
(\mathrm{Pa} \cdot \mathrm{s}) \\
\mathrm{n}=3\end{array}$ & $\begin{array}{c}\text { Thickness } \\
(\mu \mathrm{m}) \\
\mathrm{n}=6\end{array}$ & $\begin{array}{c}\text { WVP } \times 10^{11} \\
\left(\mathrm{~g} \cdot \mathrm{Pa}^{-1} \cdot \mathrm{s}^{-1} \cdot \mathrm{m}^{-1}\right) \\
\mathrm{n}=6\end{array}$ & $\begin{array}{c}\text { SSD } \\
\left(\mathrm{g} / \mathrm{m}^{2}\right) \\
\mathrm{n}=10\end{array}$ & $\begin{array}{c}\text { WVR } \\
(\mathrm{s} / \mathrm{cm}) \\
\mathrm{n}=10\end{array}$ \\
\hline $\mathrm{CH}$ & $0.242(0.001)^{\mathrm{a}}$ & $54(3)^{\mathrm{a}}$ & $35(3)^{\mathrm{a}}$ & $1.5(0.3)^{\mathrm{a}}$ & $34(13)^{\mathrm{a}}$ \\
CH.L & $0.247(0.003)^{\mathrm{a}}$ & $37(4)^{\mathrm{b}}$ & $19.7(1.9)^{\mathrm{b}}$ & $4.3(1.2)^{\mathrm{b}}$ & $28(5)^{\mathrm{a}}$ \\
CH.LM & $0.064(0.002)^{\mathrm{b}}$ & $38(6)^{\mathrm{b}}$ & $22.4(1.1)^{\mathrm{c}}$ & $4.3(1.1)^{\mathrm{b}}$ & $30(11)^{\mathrm{a}}$ \\
\hline Non-coated & - & & - & - & $30(5)^{\mathrm{a}}$
\end{tabular}

$a, b, c$ Different superscripts indicate significant differences according to ANOVA test $(p<0.05)$. $\mathrm{CH}$ : chitosan, L: lemon essential oil, M: microfluidized.

Microfluidization affects the rheology of both phases by decreasing the size and diminishing the number of clusters formed in the dispersed phase and also by modifying the viscosity of the continuous phase; all of this contributes to a decrease in the viscosity of the FFD. Vargas, Perdones, 
Chiralt, Cháfer and González-Martínez (2011a) reported that the viscosity of chitosan-based film-forming dispersions significantly decreased when the homogenization pressure increased, which was explained by the changes in the degree of polymer aggregation and the fragmentation of the polymer chains due to high pressure.

The thickness values of the stand-alone coatings are shown in Table 2.1.1, where a significant decrease was observed when oil was incorporated into the formulation. This has been observed in other $\mathrm{CH}$ films containing essential oils (Sánchez-González, Chiralt, González-Martínez and Cháfer, 2011c) and was attributed to the loss of volatile compounds during the film drying, which reduces the total solid remaining in the plate after film drying. The water vapour permeability values of the stand-alone coatings are shown in Table 2.1.1. The addition of lemon essential oil led to a significant reduction $(p<0.05)$ in the WVP. The use of microfluidization to prepare chitosan-lemon essential oil FFD did not improve the water barrier properties of the films, despite the increase in the tortuosity factor for water molecule diffusion in the matrix which, as reported by other authors (Pérez-Gago and Krochta, 2001), can imply an increase in the characteristic diffusion time. The scarce effect of microfluidization on WVP was also observed by Bonilla, Atarés, Vargas and Chiralt (2012) in chitosan-based films containing basil or thyme essential oils and was justified by the increased contact between $\mathrm{CH}$ molecules and the essential oil compounds in the micro-fluidized samples, which, in turn, makes the $\mathrm{CH}$ chain aggregation forces weaker, contributing to a decrease in the cohesion forces of the polymer network. This makes the polymer matrix more open and mass transfer is favoured despite the more tortuous path introduced by smaller droplets.

The development of the fungal growth in the in vitro tests is shown in Figure 2.1.3 for both the control plates and those coated with $\mathrm{CH}, \mathrm{CH} . \mathrm{L}$ and $\mathrm{CH}$.LM films. The use of pure chitosan film led to a reduction in the growth of Botrytis cinerea, thus showing a certain degree of antifungal activity. This antifungal activity of chitosan films was enhanced by the addition of lemon essential oil, although in the CH.L formulation, the power of inhibition of the films decreases after two storage days. This decrease was also reported for chitosan-bergamot essential oil films and was explained by considering the changes in the availability of the antimicrobials, 
controlled by the rate of diffusion of the active compounds to the surface of the agar medium throughout the storage period and the progressive evaporation of volatiles (Sánchez-González, Cháfer, Chiralt and González-Martínez, 2010). However, using microfluidization to prepare the FFD leads to a longer-lasting antimicrobial activity of the coating, as no fungal growth was observed in plates coated with CH.LM films. This could be due to the fact that the diffusion of active compounds to the agar medium is easier or to the fact that the antimicrobials lost through evaporation during the whole storage period is limited, since the matrix structure is different and the mass transfer process will occur in a different way.

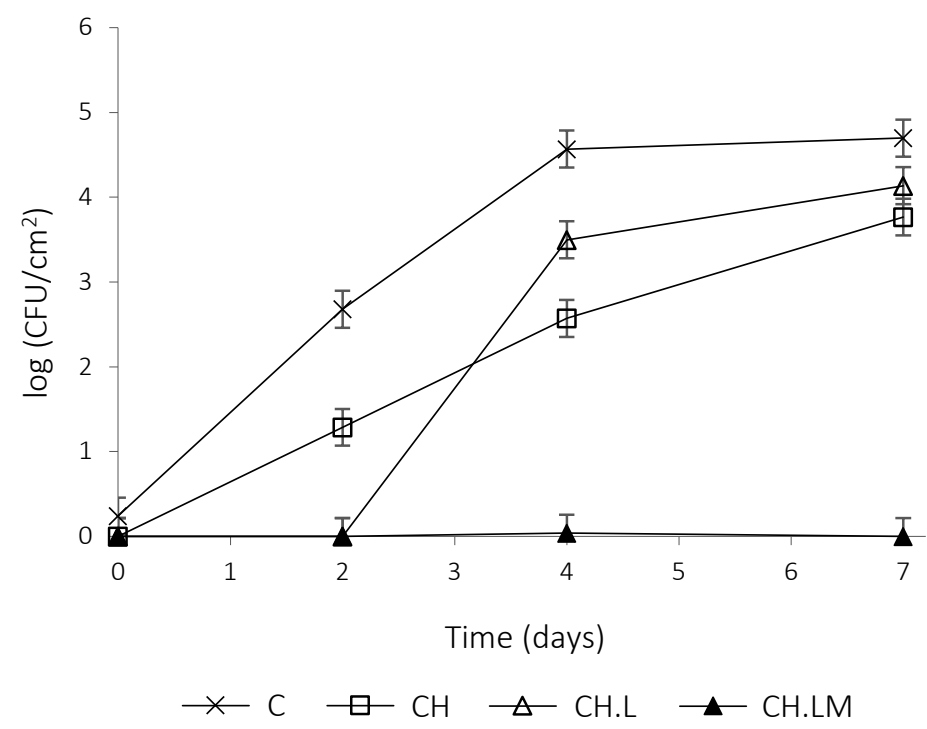

Figure 2.1.3 Effect of chitosan-based coatings on the growth and survival of Botrytis cinerea on PDA medium stored at $20^{\circ} \mathrm{C}$. Mean values and $95 \%$ Fisher's LSD intervals according to ANOVA test $(n=3)$. C: non-coated, $\mathrm{CH}$ : chitosan, L: lemon essential oil, M: microfluidized. 


\subsection{Characterization of strawberries}

\subsubsection{Surface solid density and water vapour resistance}

Surface solid density values and water vapour resistance of non-coated and coated strawberries are shown in Table 2.1.1. Surface solid density, which can be used as an estimation of coating thickness, significantly increased $(p<0.05)$ in line with the increase in the mass fraction of solids in the film-forming dispersion and no significant effect of the apparent viscosity values was observed on the amount of FFD adhered to the samples, as reported by other authors (Villalobos-Carvajal, Hernández-Muñoz, Albors and Chiralt, 2009), since strawberries coated with microfluidized FFD (CH.LM) did not show significantly different SSD values with respect to those coated with non-microfluidized CH.L dispersion.

Coatings did not significantly improve the WVR of samples, in agreement with the high permeability values of chitosan-based films, especially at high relative humidity (90\%) when the films are highly plasticized and barrier properties are greatly reduced (Vargas, Albors, Chiralt and González-Martínez, 2011b). The low WVR of coated samples explains the weight loss trend of samples throughout cold storage, where no significant effect of the coating application was detected (Table 2.1.2).

\subsubsection{Physicochemical properties}

Soluble solids, acidity, $\mathrm{pH}$, maturity index, and resistance to fracture of coated and non-coated strawberries during cold storage are shown in Table 2.1.2.

Soluble solid content, $\mathrm{pH}$ and maturity index increased throughout the storage in agreement with the progress of the ripening process. Samples coated with FFD containing lemon essential oil showed significantly lower maturity index and $\mathrm{pH}$ values at the end of storage $(\mathrm{p}<0.05)$, which points to the possible effect of essential oil components on the fruit metabolic activity. Some authors reported interactions of this kind of compounds with cell membranes (Sánchez-González, Vargas, González-Martínez and Cháfer, 2011d), which can affect the fruit metabolic pathway and senescence. 
Table 2.1.2 Soluble solids (\%), acidity (g citric acid/100 g), pH, maturity index, weight loss (\%) and resistance to fracture (F/D, N/mm) of non-coated (C) and coated strawberries. Mean values and (standard deviation).

\begin{tabular}{|c|c|c|c|c|c|c|c|}
\hline Coating & $\begin{array}{l}\text { Time } \\
\text { (days) }\end{array}$ & $\begin{array}{c}\text { Soluble solids } \\
\qquad n=5\end{array}$ & $\begin{array}{c}\text { Acidity } \\
n=5\end{array}$ & $\begin{array}{c}\mathrm{pH} \\
n=5\end{array}$ & $\begin{array}{c}\text { Maturity Index } \\
\quad n=5\end{array}$ & $\begin{array}{l}\text { Weight loss } \\
n=5\end{array}$ & $\begin{array}{c}F / D \\
n=10\end{array}$ \\
\hline \multirow{4}{*}{ C } & 0 & $7.8(0.1)^{\mathrm{ax}}$ & $0.9(0.05)^{\mathrm{ax}}$ & $3.64(0.04)^{a x}$ & $8.7(0.6)^{\mathrm{ax}}$ & $11(3)^{a x}$ & $1.73(0.5)^{\mathrm{ax}}$ \\
\hline & 7 & $9.3(0.2)^{\mathrm{bx}}$ & $1.17(0.08)^{b x}$ & $3.64(0.05)^{a x}$ & $7.9(0.4)^{\mathrm{ax}}$ & $21(5)^{b x}$ & $1.18(0.14)^{b x}$ \\
\hline & 11 & - & - & - & - & $30(6)^{c x}$ & - \\
\hline & 15 & $13.1(1.0)^{c x}$ & $1.15(0.05)^{b x}$ & $3.91(0.07)^{b x}$ & $12.5(1.4)^{b x}$ & $40(7)^{\mathrm{dx}}$ & $0.7(0.4)^{c x}$ \\
\hline \multirow{4}{*}{$\mathrm{CH}$} & 0 & $7.8(0.7)^{\mathrm{ax}}$ & $0.91(0.05)^{a x}$ & $3.68(0.07)^{\text {ay }}$ & $8.6(0.6)^{\mathrm{ax}}$ & $11(2)^{a x}$ & $1.6(0.3)^{\mathrm{ax}}$ \\
\hline & 7 & $10.6(1.1)^{\text {by }}$ & $1.07(0.09)^{b x}$ & $3.76(0.01)^{\text {ay }}$ & $9.8(0.3)^{\text {ay }}$ & $20(5)^{b x}$ & $0.9(0.3)^{b x}$ \\
\hline & 11 & - & - & - & - & $27(3)^{b x}$ & - \\
\hline & 15 & $15.0(0.9)^{c y}$ & $1.21(0.05)^{c x}$ & $3.95(0.02)^{\text {by }}$ & $12.4(0.8)^{b x}$ & $35(4)^{c x}$ & $0.9(0.4)^{c x}$ \\
\hline \multirow{4}{*}{ CH.L } & 0 & $7.6(0.8)^{\mathrm{ax}}$ & $0.88(0.06)^{\mathrm{ax}}$ & $3.54(0.13)^{a x}$ & $8.7(0.5)^{\mathrm{ax}}$ & $10(2)^{a x}$ & $1.4(0.3)^{\text {ay }}$ \\
\hline & 7 & $9.2(0.1)^{\mathrm{bx}}$ & $1.12(0.02)^{b x}$ & $3.67(0.05)^{a x}$ & $8.29(0.09)^{a x}$ & $20(4)^{b x}$ & $0.5(0.2)^{\text {by }}$ \\
\hline & 11 & - & - & - & - & $30(7)^{c x}$ & - \\
\hline & 15 & $14.1(0.8)^{c x y}$ & $1.32(0.08)^{c y}$ & $3.86(0.06)^{b x}$ & $10.7(0.9)^{\text {by }}$ & $41(9)^{d x}$ & $0.5(0.3)^{c y}$ \\
\hline \multirow{4}{*}{ CH.LM } & 0 & $7.8(0.8)^{\mathrm{ax}}$ & $0.89(0.05)^{a x}$ & $3.70(0.05)^{a x}$ & $8.8(1.1)^{\mathrm{ax}}$ & $9.4(1.8)^{a x}$ & $1.6(0.5)^{\mathrm{axy}}$ \\
\hline & 7 & $9.3(0.7)^{b x}$ & $1.12(0.03)^{b x}$ & $3.67(0.06)^{\mathrm{ax}}$ & $8.2(0.4)^{a b x}$ & $20(3)^{b x}$ & $0.9(0.4)^{\text {bxy }}$ \\
\hline & 11 & - & - & - & - & $29(5)^{c x}$ & - \\
\hline & 15 & $11.8(0.2)^{\mathrm{cz}}$ & $1.22(0.02)^{c x}$ & $3.81(0.08)^{b x}$ & $9.6(0.3)^{\text {ay }}$ & $40(7)^{\mathrm{dx}}$ & $0.53(0.19)^{c x y}$ \\
\hline
\end{tabular}

a, b, c Different superscripts within a column indicate significant differences due to storage time according to ANOVA test ( $p<0.05)$. $x, y$ Different superscripts within a column indicate significant differences among coating formulations according to ANOVA test ( $p<0.05)$. $\mathrm{CH}$ : chitosan, $\mathrm{L}$ : lemon essential oil, M: microfluidized. 
The ratio force-deformation at the break point (F/D) is shown in Table 2.1.2. This parameter, which is related to the resistance to fracture of the product, significantly decreased during cold storage. These changes in the mechanical response of the samples are attributed to changes in the structure of the cellular tissue during ripening and senescence where the cell union forces through the middle lamellae are greatly weakened (Chiralt et al., 2001). The reduction in the sample water content, and the subsequent loss of cell turgor, also contributes to a decrease in the F/D values. No effect of coating application was observed on the mechanical response development and no benefits of lemon essential oil were appreciated in terms of preservation of fruit mechanical properties. On the contrary, a slightly more marked decrease in the F/D parameter was observed when essential oil is present in the coating formulation, which again suggests that the essential oil compounds affect the metabolic pattern of the fruit. On the contrary, other authors (Hernández-Muñoz, Almenar, del Valle, Vélez and Gavara, 2008) reported slight beneficial effects on fruit mechanical behaviour of cold-stored strawberries (at lower relative humidity conditions, $70 \%$, than those used in the present study) coated with chitosan, as compared with non-coated samples. In this case, the moisture equilibration will lead to a more dried coating with improved water vapour barrier properties at the same time that the non-coated sample weight losses are promoted.

Figure 2.1.4 shows lightness $\left(\mathrm{L}^{*}\right)$, hue $\left(\mathrm{h}^{*} \mathrm{ab}\right)$ and chroma $\left(\mathrm{C}^{*}{ }_{\mathrm{ab}}\right)$ of strawberries before and after coating application, as well as the mean colour total difference induced by coatings. ANOVA did not reflect significant differences for the colour parameters of the uncoated sample groups used for each treatment, which ratified the sample selection to observe the effect of treatments on colour. Coatings did not significantly affect the $L^{*}$ values, although hue became significantly redder (lower

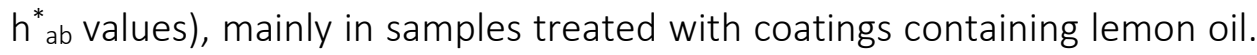
Samples coated with pure $\mathrm{CH}$ reached a slightly more vivid colour ( $\mathrm{C}^{*}$ ab increased) whereas the opposite occurs when coatings contained essential oil. Nevertheless, the mean total colour difference induced by the different coatings showed similar values, in the range of $6-7$ units, which are in the order of the usual colour tolerance, taking into account the natural variability in the fruits. 

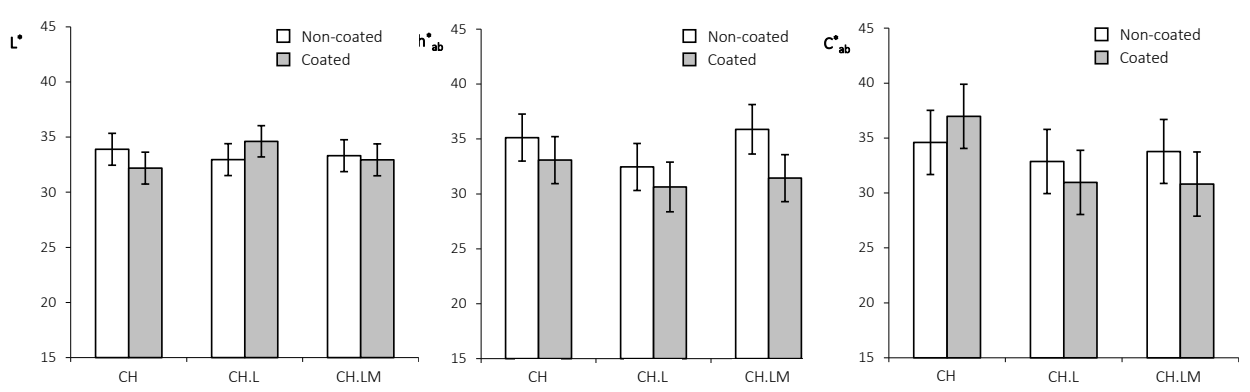

Figure 2.1.4 Lightness $\left(\mathrm{L}^{*}\right)$, hue $\left(\mathrm{h}^{*} \mathrm{ab}\right)$ and chroma $\left(\mathrm{C}^{*}{ }_{\mathrm{ab}}\right)$ of strawberries before and after coating. Mean values and 95\% Fisher's LSD intervals according to ANOVA test $(n=3)$. CH: chitosan, L: lemon essential oil, M: microfluidized.

Changes of colour parameters $\mathrm{L}^{*}, \mathrm{~h}^{*}{ }_{\mathrm{ab}}$ and $\mathrm{C}^{*}$ ab of uncoated and coated samples throughout storage are plotted in Figure 2.1.5. Lightness decreased throughout storage in non-coated samples (control) and in coated ones, as a consequence of surface moisture loss, which could be responsible for the observed darker colour. However, this decrease was less marked in samples coated with films containing lemon essential oil, which showed the highest lightness values at the end of storage. This effect has also been described for strawberries coated with chitosan-oleic acid edible coatings (Vargas, Albors, Chiralt and González-Martínez, 2006). The sample hue remained practically constant throughout the storage time and only significantly decreased between 11 and 14 storage days.

At the end of storage, samples treated with coatings containing essential oil were significantly redder (lower $\mathrm{h}^{*}$ ab values) than control and pure $\mathrm{CH}$ coated samples. The $\mathrm{C}^{*}$ ab values progressively decreased throughout storage from 4 days onwards and the different samples did not show significant differences in $C^{*}$ ab values at the end of storage. To sum up, throughout storage, samples became darker, redder and less vivid. The coatings did not have a notable effect on this development, except those containing lemon essential oil which gave rise to slightly lighter and redder samples at the end of storage. 

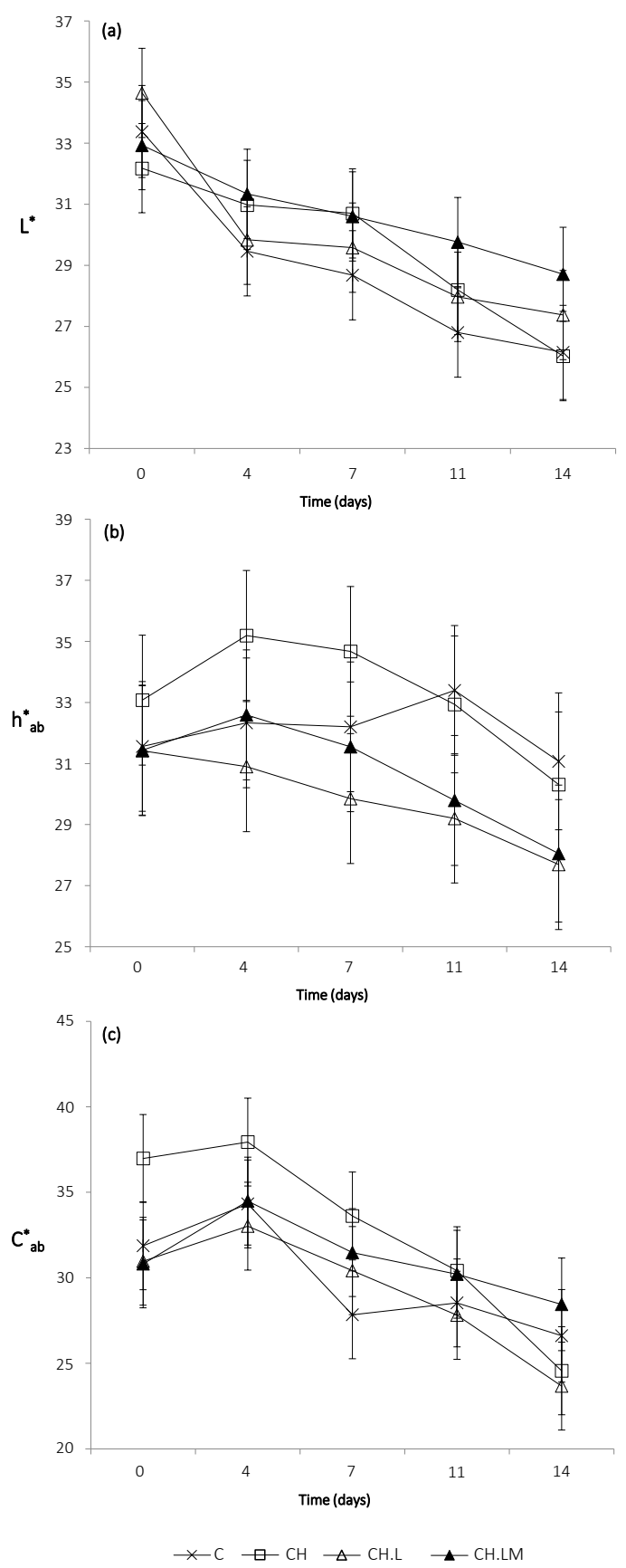

Figure 2.1.5 Lightness (a), hue (b) and chroma (c) of cold-stored strawberries as a function of storage time. Mean values and 95\% Fisher's LSD intervals according to ANOVA test $(n=3)$. CH: chitosan, L: lemon essential oil, M: microfluidized. 


\subsubsection{Fungal decay}

Figure 2.1.6 shows the development of fungal decay of inoculated strawberries during cold storage, expressed as the percentage of visibly infected samples out of the total amount of stored samples. Chitosan coatings reduced the percentage of infected strawberries as compared to non-coated ones (control) after three storage days. Pure chitosan coatings have previously been reported to have antifungal effect when applied to cold stored strawberries (El Ghaouth, Arul, Ponnampalam, Boulet, 1991; Vargas, Albors, Chiralt and González-Martínez, 2006).

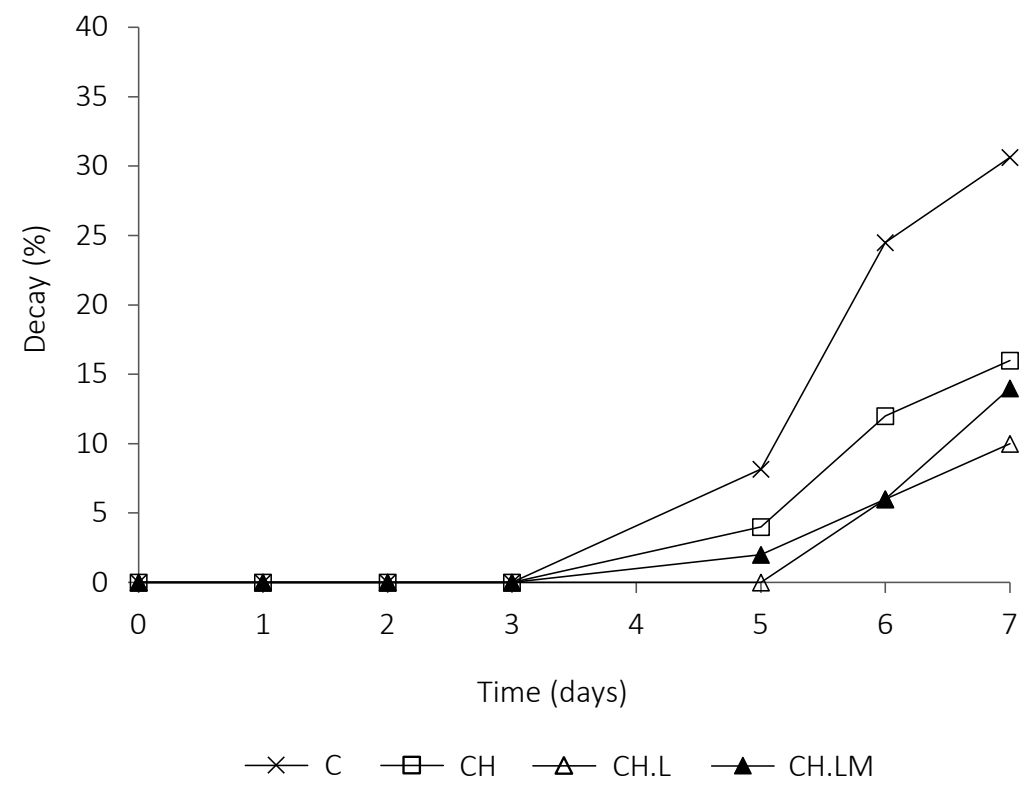

Figure 2.1.6 Fungal decay of infected non-coated (C) and coated strawberries

throughout storage at $5{ }^{\circ} \mathrm{C}$. Mean values. 95\% Fisher's LSD intervals $=2.1$, according to ANOVA test. CH: chitosan, L: lemon essential oil, M: microfluidized.

Chitosan antifungal activity was enhanced by the addition of lemon essential oil, and no significant differences were shown due to microfluidization of the FFD, despite what was observed in the in vitro study, where chitosan coatings with lemon essential oil prepared by means of microfluidization (CH.LM) exhibited a high anti-Botrytis effect. No clear explanation for this fact was found, although interactions between the coating components and the fruit surface can lead to divergent behaviour with respect to that observed in the in vitro studies (Antunes and 
Cabaco, 2010; Gutiérrez, Barry-Ryan and Bourke, 2008). In this sense, Vu, Hollingsworth, Leroux, Salmieri and Lacroix (2011) reported a higher antifungal effect of limonene than peppermint essential oil, encapsulated in coatings of modified chitosan, when applied to cold-stored strawberries, although the in vitro antifungal effect of the free (non-encapsulated) oils showed the opposite trend.

\subsubsection{Respiration rate}

The development of the respiration rate (RR) of samples during cold storage is shown in Figure 2.1.7. At time 0 (immediately after coating), no notable differences were observed for $\mathrm{O}_{2}$ consumption and $\mathrm{CO}_{2}$ generation among the different samples, although coatings with essential oil seem to slightly increase the $\mathrm{CO}_{2}$ rate. A significant effect of both sample treatment and storage time was observed on RR, but interactions between the two factors were more significant. Oxygen consumption greatly decreased during the first 3 storage days in all cases. Nevertheless, no subsequent decrease was observed for control and pure $\mathrm{CH}$ coated samples, whereas a progressive decrease occurs for samples treated with coatings containing essential oil.

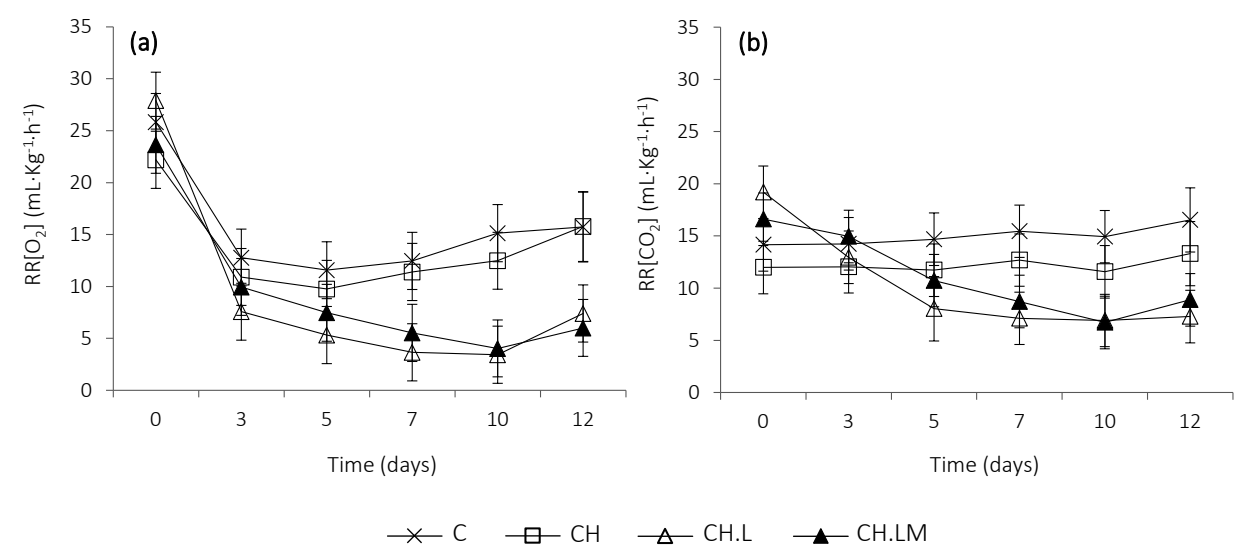

Figure 2.1.7 Respiration rate in terms of $\mathrm{O}_{2}(\mathrm{a})$ and $\mathrm{CO}_{2}(\mathrm{~b})$ as a function of storage time and coating formulation. Mean values and 95\% Fisher's LSD intervals according to ANOVA test $(n=3)$. CH: chitosan, L: lemon essential oil, M: microfluidized.

In terms of $\mathrm{CO}_{2}$, a practically constant rate was observed throughout storage for control and pure $\mathrm{CH}$ coated samples. However, the use of essential oil in coatings provoked a progressive reduction of RR up to about 
7 storage days, when it stabilized at very low RR values. Likewise, slightly lower RR values were observed for pure $\mathrm{CH}$ coated samples than for control ones. The decrease in respiration rate promoted by the use of pure chitosan coatings was also observed by El Ghaouth, Arul, Ponnampalam, Boulet (1991), Hernández-Muñoz, Almenar, del Valle, Vélez and Gavara (2008) and Vargas, Albors, Chiralt and González-Martínez (2006) in cold-stored strawberries. The use of microfluidization for obtaining the FFD did not induce any additional effect on the sample respiration pattern.

The obtained results seem to suggest that $\mathrm{CH}$ films could reduce the gas permeability in the fruit surface, thus affecting the gas exchange during fruit respiration, but lemon essential oil in the coatings affects the metabolic pattern of strawberries, thus modifying the respiration pattern. Nevertheless, the induced changes were not great during the observed storage period.

\subsubsection{Sensory analysis}

Results of the sensory evaluation of strawberries non-coated and coated with $\mathrm{CH}$ and $\mathrm{CH} . \mathrm{L}$ are plotted in Figure 2.1.8, where the sensory profile of the different samples is shown. Judges evaluated CH.L as being less glossy than samples coated with pure $\mathrm{CH}$, although the overall differences considering the non-coated samples were not significant. Han, Lederer, McDaniel and Zhao (2005) also reported a loss of surface glossiness in chitosan-coated strawberries when Vitamin E was incorporated in the coating. Typical strawberry aroma and flavour of samples coated with CH.L was considered to show a significant decrease with respect to $\mathrm{CH}$-coated and non-coated samples (more marked in aroma than in flavour), probably by the masking effect of the lemon oil aroma compounds. Chitosan shows astringent attributes when dissolved in an acidic medium as a result of a rise in amine protonated groups, which would augment the salivary protein-binding affinity (Rodríguez, Albertengo, Vitale and Agulló, 2003). These astringency properties, related with a slightly bitter and astringent taste, have been detected in sensory evaluations of strawberries carried out immediately after film application (Vargas, Albors, Chiralt and González-Martínez, 2006). However, this was not detected by the panellists in the present study performed after 24 hours of cold storage. The changes in flavour and aroma provoked by CH.L coatings were associated with a significant $(p<0.05)$ decrease in the sample preference. In this sense, as 
recommended by Gammariello, Conte, Del Nobile (2010), further studies should be carried out in order to obtain a good compromise between the antimicrobial effectiveness of the active compounds and their sensory impact.

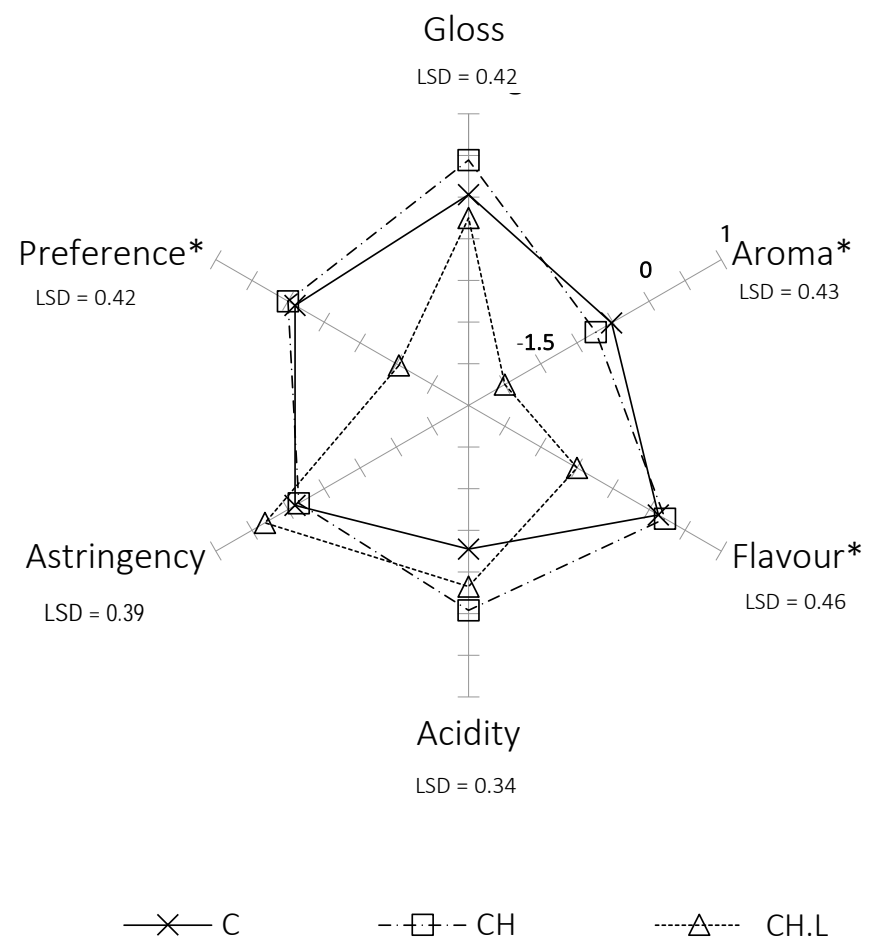

Figure 2.1.8 Sensory profile of strawberries. C: non-coated sample; $\mathrm{CH}$ : sample coated with chitosan; CH.L: sample coated with chitosan and lemon essential oil.

*Indicates 95\% significant differences according to ANOVA test $(n=30)$. 


\section{CONCLUSION}

Chitosan-based edible coatings did not promote significant changes in the physicochemical quality of strawberries throughout cold storage, although they seem to slightly affect the metabolic pattern of the fruit when they contain lemon essential oil, as deduced by some differences induced in the respiration behaviour and some colour and mechanical properties. Nevertheless, they induce a better preservation of the fruit in terms of fungal decay, especially when lemon essential oil is incorporated in the coating. According to these results, chitosan-lemon essential oil coatings can be an alternative method with which to extend strawberry shelf-life. Nevertheless, lemon oil should be incorporated at a lesser concentration in the film (lower than 1:3, CH:L ratio) to minimize its impact on the olfactory perception.

\section{Acknowledgements}

The authors acknowledge the financial support provided by Conselleria de Empresa, Universidad y Ciencia (project GV/2010/082), Universitat Politècnica de València (project PAID-06-09-2834) and Ministerio de Economía y Competitividad (project AGL2010-20694). Ángela Perdones also thanks the Universitat Politècnica de València for the FPI grant. 


\section{REFERENCES}

Almenar, E., Hernández-Muñoz, P., Gavara, R. Evolution of selected volatiles in chitosan-coated strawberries (Fragaria $x$ ananassa) during refrigerated storage. Journal of agricultural and food chemistry 57:3 (2009) $974-980$.

Antunes, M.D.C., Cavaco, A.M. The use of essential oils for postharvest decay control. A review. Flavour and fragrance journal 25:5 (2010) $351-366$.

ASTM. Standard test methods for water vapor transmission of materials. Standard Designations: E96-95. In: ASTM, Annual Book of ASTM (pp. 406 - 413). ASTM (Philadelphia) 1995.

AOAC. Official Methods of Analysis, 17 th Ed. Association of Analytical Chemists International (Washington, D.C) 1995.

Avena-Bustillos, R.J., Krochta, J.M., Saltveit, M.E., Rojas-Villegas, R.J., Sauceda-Pérez, J. Optimization of edible coating formulations on zucchini to reduce water loss. Journal of Food Engineering 21:2 (1994) 197 - 214.

Bakkali, F., Averbeck, S., Averbeck, D., Idaomar, M. Biological effects of essential oils - a review. Food and Chemical Toxicology 46:2 (2008) $446-475$.

Becher, P. Emulsions: theory and practice, third ed. Oxford University Press, Oxford (2001).

Bonilla, J., Atarés, L., Vargas, M., Chiralt, A. Effect of essential oils and homogenization conditions on properties of chitosan based films. Food Hydrocolloids 26:1 (2012) 9-16.

Campaniello, D., Bevilacqua, A., Ainigaglia, M., Corboet, M.R. Chitosan: Antimicrobial activity and potential applications for preserving minimally processed strawberries. Food Microbiology 25:8 (2008) $992-1000$. 
Castelló, M.L., Fito, P.J., Chiralt, A. Effect of osmotic dehydration and vacuum impregnation on respiration rate of cut strawberries. LWT - Food Science and Technology 39:10 (2006) 1171-1179.

Chiralt, A., Martínez-Navarrete, N., Martínez-Monzo, J., Talens, P., Moraga, G., Ayala, A., Fito, P. Changes in mechanical properties throughout osmotic processes: Cryoprotectant effect. Journal of Food Engineering 49:2 (2001) $129-135$.

CIE, Commission Internationale de L'Eclairage. Colorimetry $2^{\text {nd }}$ Ed. Pub no 15-2 (Paris) 1986.

Cuero, R.G. Antimicrobial action of exogenous chitosan. In Jollés, P., Muzzarelli, R.A.A. (Eds.), Chitin and Chitinases. (p. 315 -333). Birkhäuser Verlag, 1999.

El Ghaouth, A., Arul, J., Ponnampalam, R., Boulet, M. Chitosan coating effect on storability and quality of fresh strawberries. Journal of food science 12:6 (1991) $1618-1632$.

Fabra, M.J., Pérez-Masiá, R., Talens, P., Chiralt, A. Influence of the homogenization conditions and lipid self-association on properties of sodium caseinate based films containing oleic and stearic acids. Food Hydrocolloids 25:5 (2011) 1112 - 1121.

Fonseca, S.C., Oliveira, F.A.R., Brecht, J.K. Modelling respiration rate of fresh fruits and vegetables for modified atmosphere packages: a review. Journal of Food Engineering 52:2 (2002) 99 - 119.

Gammariello, D., Conte, A., Del Nobile, M.A. Assessment of chitosan and extracts of lemon and sage as natural antimicrobial agents during Fior di latte cheesemaking. International Journal of Dairy Technology 63:4 (2010) $530-537$.

Gutierrez, J., Barry-Ryan, C. Bourke, P. The anti-microbial efficacy of plant essential oil combinations and interactions with food ingredients. International journal of food microbiology 124:1 (2008) 91 - 97.

Han, C., Zhao, Y., Leonard, S.W., Traber, M.G. Edible coatings to improve storability and enhance nutritional value of fresh and frozen strawberries 
(Fragaria $x$ ananassa) and raspberries (Rubus idaeus). Postharvest Biology and Technology 33:1 (2004) $67-78$.

Han, C., Lederer, C., McDaniel, M., Zhao, Y. Sensory evaluation of fresh strawberries (Fragaria ananassa) coated with chitosan-based edible coatings. Journal of Food Science 70:3 (2005) 172 - 180.

Hernández-Muñoz, P., Almenar, E., Ocio, M.J, Gavara, R. Effect of calcium dips and chitosan coatings on postharvest life of strawberries (Fragaria $x$ ananassa). Postharvest Biology and Technology 39:3 (2006) $247-253$.

Hernández-Muñoz, P., Almenar, E., Del Valle, V., Vélez, D. Gavara, R. Effect of chitosan coating combined with postharvest calcium treatment on strawberry (Fragaria $x$ ananassa) quality during refrigerated storage. Food Chemistry 110:2 (2008) 428-435.

Holcroft, D.M., Kader, A.A. Controlled atmosphere-induced changes in $\mathrm{pH}$ and organic acid metabolism may affect color of stored strawberry fruit. Postharvest Biology and Technology 17:1 (1999) $19-32$.

Jung, B.O, Kim, C.H., Choi, K.S., Lee, Y.M., Kim, J.J. Preparation of amphiphilic chitosan and their antimicrobial activities. Journal of Applied Polymer Science 72:3 (1999) 1713 - 1719.

Kerch, G., Sabovics, M., Kruma, Z., Kampuse, S., Straumite, E. Effect of chitosan and chitooligosaccharide on vitamin $C$ and polyphenols contents in cherries and strawberries during refrigerated storage. European Food Research and Technology 233:2 (2011) $351-358$.

Kristo, E., Koutsoumanis, K.P., Biliaderis, C.G. Thermal, mechanical and water vapor barrier properties of sodium caseinate films containing antimicrobials and their inhibitory action on Listeria monocytogenes. Food Hydrocolloids 22:3 (2008) 373 - 386.

McClements, D.J. Food emulsions: principles, practice, and techniques (pp. 341 - 388). CRC Press LLC, Boca Raton (Florida) 2005.

Meilgaard, M., Civille, G.V., Carr, B.T. Sensory evaluation and techniques. CRC Press LLC, Boca Raton (Florida) 1999. 
Moufida, S., Marzouk, B. Biochemical characterization of blood orange, sweet orange, lemon, bergamot and bitter orange. Phytochemistry 62:8 (2003) $1283-1289$.

No, H.K., Park, N.Y., Lee, S.H., Meyers, S.P. Antibacterial activity of chitosans and chitosan oligomers with different molecular weights. International Journal of Food Microbiology 74:1 (2002) 65 - 72.

Paquin, P. Technological properties of high pressure homogenizers: the effect of fat globules, milk proteins, and polysaccharides. International Dairy Journal 9:3 (1999) 329-335.

Park, H.J. Development of advanced edible coatings for fruits. Trends in Food Science and Technology 10:8 (1999) 254-260.

Pérez, A.G., Sanz, C. Effect of high-oxygen and high-carbon-dioxide atmospheres on strawberry flavor and other quality traits. Journal of Agricultural and Food Chemistry 49:5 (2001) 2370 - 2375.

Pérez-Gago, M.B., Krochta, J.M. Lipid particle size effect on water vapour permeability and mechanical properties of whey protein-beeswax emulsion films. Journal of agricultural and food chemistry 49:2 (2001) $996-1002$.

Pinnamaneni, S., Das, N.G., Das, S.K. Comparison of oil-in-water emulsions manufactured by microfluidization and homogenization. Die Pharmazie - An International Journal of Pharmaceutical Sciences 58:8 (2003) $554-558$.

Ribeiro, C., Vicente, A.A., Teixeira, J.A., Miranda, C. Optimization of edible coating composition to retard strawberry fruit senescence. Postharvest Biology and Technology 44:1 (2007) $63-70$.

Rocculi, P., Romani, S., Dalla Rosa, M. Effect of MAP with argon and nitrous oxide on quality maintenance of minimally processed kiwifruit. Postharvest Biology and Technology 35:3 (2005) 319 - 328.

Rodríguez, M.S., Albertengo, L.A., Vitale, I., Agulló, E. Relationship between astringency and chitosan-saliva solutions turbidity at different $\mathrm{pH}$. Journal of food science 68:2 (2003) $665-667$. 
Sánchez-González, L., Cháfer M., Chiralt, A., González-Martínez, C. Physical properties of edible chitosan films containing bergamot essential oil and their inhibitory action on Penicillium italicum. Carbohydrate Polymers 82:2 (2010) $277-283$.

Sánchez-González, L., Cháfer M., Hernández, M., Chiralt, A., González-Martínez, C. Antimicrobial activity of polysaccharide films containing essential oils. Food Control 22:8 (2011a) 1302-1310.

Sánchez-González, L., Pastor, C., Vargas, M., Chiralt, A., González-Martínez, C., Cháfer, M. Effect of hydroxypropylmethylcellulose and chitosan coatings with and without bergamot essential oil on quality and safety of cold-stored grapes. Postharvest Biology and Technology 60:1 (2011b) $57-63$.

Sánchez-González, L., Chiralt, A., González-Martínez, C., Cháfer M. Effect of essential oils on properties of film forming emulsions and films based on hydroxypropylmethylcellulose and chitosan. Journal of Food Engineering 105:2 (2011c) $246-253$.

Sánchez-González, L., Vargas, M., González-Martínez, C., Chiralt, A., Cháfer, M. Use of Essential Oils in Bioactive Edible Coatings: A Review. Food Engineering Reviews 3:1 (2011d) $1-16$.

Sanz, C., Pérez, A.G, Olías, R., Olías, J. M. Quality of strawberries packed with perforated polypropylene. Journal of Food Science 64:4 (1999) 748 - 752.

Sharma, N., Tripathi, A. Effects of Citrus sinensis (L.) Osbeck epicarp essential oil on growth and morphogenesis of Aspergillus niger (L.) Van Tieghem. Microbiological Research 163:3 (2008) 337 - 344.

Strawbridge, K.B., Ray, E., Hallett, F.R., Tosh, S.M., Dalgleish, D.G. Measurement of particle-size distributions in milk homogenized by a microfluidizer-estimation of populations of particles with radii less than 100 Nm. Journal of Colloid and Interface Science 171:2 (1995) 392 - 398.

Tharanathan, R.N., Kittur, F.S. Chitin - The undisputed biomolecule of great potential. Critical Reviews in Food Science and Nutrition 43:1 (2003) $61-87$. 
Urban, K., Wagner, G., Schaffner, D., Röglin, D., Ulrich, J. Rotor-stator and disc systems for emulsification processes. Chemical Engineering and Technology 29:1 (2006) 24-31.

US EPA. Registration eligibility decision (RED): Limonene. (Washington D.C) 1994.

Vargas, M., Albors, A., Chiralt, A., González-Martínez, C. Quality of cold-stored strawberries as affected by chitosan-oleic acid edible coatings. Postharvest Biology and Technology 41:2 (2006) $164-171$.

Vargas, M., Pastor, C., Chiralt, A., McClements, D.J., González-Martínez, C. Recent advances in edible coatings for fresh and minimally processed fruits. Critical Reviews in Food Science and Nutrition 48:6 (2008) 496 - 511.

Vargas, M., Albors, A., Chiralt, A., González-Martínez, C. Characterization of chitosan-oleic acid composite films. Food Hydrocolloids 23:2 (2009) $536-547$.

Vargas, M., González-Martínez, C. Recent patents on Food Applications of Chitosan. Recent Patents on Food, Nutrition and Agriculture 2:2 (2010) $121-128$.

Vargas, M., Perdones, A., Chiralt, A., Cháfer, M., González-Martínez, C. Effect of homogenization conditions on physicochemical properties of chitosan-based film-forming dispersions and films. Food Hydrocolloids 25:5 (2011a) $1158-1164$.

Vargas, M., Albors, A., Chiralt, A., González-Martínez, C. Water interactions and microstructure of chitosan-methylcellulose composite films as affected by ionic concentration. LWT - Food Science and Technology 44:10 (2011b) $2290-2295$.

Villalobos-Carvajal, R., Hernández-Muñoz, P., Albors, A., Chiralt, A. Barrier and optical properties of edible hydroxypropyl methylcellulose coatings containing surfactants applied to fresh cut carrot slices. Food Hydrocolloids $23: 2$ (2009) $526-535$.

Vu, K.D., Hollingsworth, R.G., Leroux, E., Salmieri, S., Lacroix, M. Development of edible bioactive coating based on modified chitosan for 
increasing the shelf life of strawberries. Food Research International 44:1 (2011) $198-203$.

Wilson, C.L., Solar, J.M., El Ghaouth, A., Wisniewski, M.E. Rapid evaluation of plant extracts and essential oils for antifungal activity against Botrytis cinerea. Plant Disease 81:2 (1997) $204-210$.

Wong, D., Gastineau, F., Gregorski, K.S., Tillin, S.J., Pavlath, A.E. Chitosan-Lipid films. Microstructure and surface energy. Journal of Agricultural and Food Chemistry 40:4 (1992) 540 - 544.

Xing, Y., Li, X., Xu, Q., Yun, J., Lu, Y., Tang, Y. Effects of chitosan coating enriched with cinnamon oil on qualitative properties of sweet pepper (Capsicum annuum L.). Food Chemistry 124:4 (2011) 1443 - 1450.

Zhang, D., Quantick, P.C. Antifungal effect of chitosan coating on fresh strawberries and raspberries during storage. Journal of Horticultural Science and Biotechnology 73:6 (1998) 763 - 767.

Zheng, L.Y., Zhu, J.F. Study on antimicrobial activity of chitosan with different molecular weights. Carbohydrate Polymers 54:4 (2003) 527 - 530. 



\section{EFFECT OF CHITOSAN-LEMON ESSENTIAL OIL COATINGS ON VOLATILE PROFILE OF STRAWBERRIES DURING STORAGE}

Ángela Perdones, Isabel Escriche, Amparo Chiralt, Maria Vargas*

Food Chemistry (2015). In Press, Accepted Manuscript.

Department of Food Technology-Institute of Food Engineering for Development, Universitat Politècnica de València, Camino de Vera s/n, 46022 Valencia, Spain.

*Telephone: 0034963877000 Ext.73642 Fax: 0034963877369 e-mail:mavarco@tal.upv.es 


\section{ABSTRACT}

Chitosan coatings containing lemon essential oils were described as effective at controlling fruit fungal decay at $20^{\circ} \mathrm{C}$ during 7 days. In this work, the GC-MS was used to characterise the volatile compounds of strawberries during cold storage in order to analyse the influence of fruit coatings with chitosan, containing or not containing lemon essential oil, on the volatile profile of the fruits. The coatings affected the metabolic pathways and volatile profile of the fruits. Pure chitosan promoted the formation of esters and dimethyl furfural in very short time after coating, while coatings containing lemon essential oil incorporated terpenes (limonene, $\gamma$-terpinene, $p$-cymene and $\alpha$-citral) to the fruit volatiles and enhanced the fermentative process, modifying the typical fruit aroma composition. No effect of chitosan coatings was sensorially perceived, the changes induced by lemon essential oil were notably appreciated.

Keywords: biopolymer, film, volatile, storage, postharvest, essential oil, Fragaria $x$ ananassa. 


\section{INTRODUCTION}

Nowadays, essential oils (EO) are increasingly applied in food preservation due to the interest of consumers in natural food additives. Essential oils are natural oily liquids obtained from plant material. These natural substances and their constitutive compounds have antimicrobial (Bakkali, Averbeck, Averbeck and Idaomar, 2008; Burt, 2004; Rivera Calo, Crandall, O'Bryan and Ricke, 2015) and antioxidant properties (Perdones, Vargas, Atarés and Chiralt, 2014; Xing et al., 2005). Lemon essential oil is citrus oil from Citrus limon, rich in volatile compounds, such as limonene and $\gamma$-terpinene (Caccioni, Guizzardi, Biondi, Renda and Ruberto, 1998; Moufida and Marzouk, 2003). Limonene, which is the main compound of lemon essential oil, has the GRAS status of the US FDA (US EPA, 1994) and is used as a food additive or flavouring agent. Moreover, limonene exhibits fungicidal properties, including activity against common postharvest fungal pathogens of fruit (Combrick, Regnier and Kamatou, 2011; Sharma and Tripathi, 2008; Wilson, Solar, El Ghaouth and Wisniewski, 1997). The use of EO in food preservation is often limited because of their application costs and other disadvantages, e.i. their intense aroma and potential toxicity. An interesting approach to reduce the doses of essential oils while maintaining their effectiveness could be to incorporate these compounds into the formulation of edible coatings. Chitosan is one of the film-forming biopolymers with great compatibility with citrus essential oils (Sánchez-González, Chiralt, González-Martínez and Cháfer, 2011a). Chitosan is a cationic polysaccharide obtained from chitin by deacetylation in the presence of alkali that itself shows antimicrobial activity (Vargas and González-Martínez, 2010; Zheng and Zhu, 2003). Chitosan-based edible coatings were used to improve the postharvest quality and shelf-life of strawberries (Gol, Patel and Ramana Rao, 2013; Hernández-Muñoz, Almenar, Del Valle, Vélez and Gavara, 2008; Vargas, Albors, Chiralt and González-Martínez, 2006; Wang and Gao, 2013). The ability of chitosan-based coatings to act as protective gas-barriers and modify the fruit's internal atmosphere may affect the fruit flavour and aroma. In this sense, previous studies showed that pure chitosan coatings can be used to maintain strawberry flavour during storage and to delay the production of off-flavours (Almenar, Hernández-Muñoz and Gavara, 2009). 
Lemon essential oil was also incorporated into chitosan-based coatings in order to improve their antimicrobial properties (Perdones, Sánchez-González, Chiralt and Vargas, 2012) and both the development of the physicochemical quality of the fruit and the fungal decay of cold-stored strawberries as affected by coating application were reported. Chitosan coatings containing lemon essential oil induced a better preservation of the fruit in terms of fungal decay, although the oil impacted on the olfactory perception of the fruit.

The aim of this work was to study the influence of chitosan and chitosan-lemon essential oil coatings on the volatile profile of strawberry throughout cold storage, in order to discover the persistency of oil volatiles in the fruit and the influence of both the coating and the essential oil components on the development of the profile of volatile compounds in strawberry throughout cold storage.

\section{MATERIALS AND METHODS}

\subsection{Materials}

Organically grown strawberries (Fragaria $x$ ananassa cv. Camarosa), harvested at the same day, were selected according to shape, uniform size and colour as well as the absence of physical damage or fungal infection. Before coating, strawberries were washed with a solution of sodium hypochlorite $(10 \mathrm{mg} / \mathrm{L})$. A total of 200 fruits were used to conduct all the experiments.

To obtain coating-forming dispersions (CFD), high molecular weight chitosan (acetylation degree: $24.4 \%$, viscosity in $1 \%(\mathrm{w} / \mathrm{w})$ glacial acetic acid solution: $1.406 \mathrm{~Pa} \cdot \mathrm{s}$ ), $98 \%$ acetic acid (Panreac Química, S.A., Castellar del Vallés, Barcelona, Spain) and lemon essential oil (Herbes del Molí, Alicante, Spain) were used.

Gas chromatography reference standards (corresponding to volatiles of Table 2.2.4) were purchased from Sigma-Aldrich Corp. (St. Louis, MO). Absolute ethanol, used for lemon essential oil dilution, was from VWR (Barcelona, Spain). 


\subsection{Preparation of the coating-forming dispersions}

Three different coating-forming dispersions were prepared. $1 \%(\mathrm{w} / \mathrm{w})$ chitosan was dispersed in an aqueous solution of acetic acid $0.5 \%(\mathrm{v} / \mathrm{w})$. Following overnight agitation at $25^{\circ} \mathrm{C}$, lemon essential oil ( $\mathrm{L}$ ) was added to the chitosan solution $(\mathrm{CH})$ in a $\mathrm{CH}: \mathrm{L}$ ratio of $1: 3$. Both $\mathrm{CH}$ and $\mathrm{CH} . \mathrm{L}$ dispersions were homogenized using a rotor-stator homogenizer (Ultraturrax DI25 Yellow Line, IKA ${ }^{\circledR}$, Germany) at 20,500 rpm for $4 \mathrm{~min}$. After vacuum degasification at room temperature, $\mathrm{CH}$.L CFD was submitted to a second homogenization by means of a Microfuidizer $^{\circledR}$ (M110-P, Microfluidics, Newton, MA, USA) in a single pass at $165 \mathrm{MPa}$ to obtain CH.LM coating.

\subsection{Application of coatings and sample preparation}

Selected strawberries were randomly distributed into four groups of 50 strawberries each. One group was used as a control, whose samples were immersed in an aqueous solution of glacial acetic acid $0.5 \%(\mathrm{v} / \mathrm{v})$ for $1 \mathrm{~min}$, and the other three were treated with each one of the coatings $(\mathrm{CH}, \mathrm{CH} . \mathrm{L}$ and CH.LM). Strawberry samples were dipped in the corresponding CFD for $1 \mathrm{~min}$, allowed to dry at room temperature for $1 \mathrm{~h}$ and, afterwards, cold-stored on PET trays in a climate chamber (EC1400, Radiber, Barcelona, Spain) at $4 \pm 1{ }^{\circ} \mathrm{C}$ and $90 \%$ relative humidity (RH). The weight of the wet coating in the samples was determined through their mass difference before and after coating in order to evaluate the losses in lemon essential oil during the drying of the coating and fruit storage. After 0,7 and 15 days of storage, 5 strawberries per formulation were randomly removed from the chamber and minced using an Ultraturrax homogenizer at 8,500 rpm for $1 \mathrm{~min}$. $60 \mathrm{~g}$ of the obtained purée were placed in propylene tubes and frozen at $-20^{\circ} \mathrm{C}$ until the volatile analyses were carried out.

2.4 Characterization of the maturity index (MI) and respiration rate of strawberries

In the sample purée, maturity index was also determined through the measurement of the total soluble solids and acidity. Soluble solids were measured by means of a refractometer (3 T ABBE, ATAGO Co Ltd., Japan) at $22{ }^{\circ} \mathrm{C}$. Acidity (expressed as g of citric acid per $100 \mathrm{~g}$ of fruit) was 
measured following the method AOAC 942.15 (AOAC, 1995). Maturity index was calculated as the quotient of total soluble solids and acidity. The respiration rate of the strawberries was evaluated at $5{ }^{\circ} \mathrm{C}$ during storage following the methodology described by Vargas, Albors, Chiralt and González-Martínez (2006). Strawberry samples (about 150 g) were placed in $0.847 \mathrm{~L}$ hermetic glass jars with a septum in the lid for sampling gas in the headspace at different times. Gas sampling was carried out every 30 min by means of a needle connected to a gas analyser (CheckMate 9900 PBI Dansensor, Ringsted, Denmark). Three replicates were performed for each formulation. Experimental points were considered in the time range where a linear relationship was observed between gas concentration and time. This means that no changes in the respiration pathway of the samples occurred in this period. Respiration rate of the samples was determined from the slope of the fitted linear equation.

\subsection{Volatile analysis}

Volatile compounds were extracted by purge and trap thermal desorption (Peinado, Rosa, Heredia, Escriche and Andrés, 2013). $500 \mu \mathrm{L}$ of the internal standard 2-pentanol $(10 \mathrm{mg} / \mathrm{L})$ and $10 \mathrm{~g}$ of strawberry purée were placed into a purging flask and kept in a water bath at $45^{\circ} \mathrm{C}$ for $20 \mathrm{~min}$. Throughout this time, purified nitrogen $(100 \mathrm{~mL} / \mathrm{min}$ ) was forced through a glass frit placed at the bottom of the flask. The volatile compounds were collected by the stream of bubbles, which passed through the sample and were trapped in a $100 \mathrm{mg}$ porous polymer (Tenax ${ }^{\circledR} \mathrm{TA}, 20$ - 35 mesh) packed into a glass tube placed at the end of the system. The same procedure was used to characterize the volatile profile of lemon essential oil. To this end, $10 \mathrm{~g}$ of lemon essential oil dilution in water $(1: 1000)$ of a $3 \%(w / v)$ ethanol absolute solution were used.

The aromatic extract was thermally desorbed by a direct thermal desorber (TurboMatrix TD, Perkin-Elmer TM, CT-USA). Desorption was performed under a $10 \mathrm{~mL} / \mathrm{min}$ helium flow at $220^{\circ} \mathrm{C}$ for $10 \mathrm{~min}$, and the volatiles were cryofocused in a cold trap at $-30^{\circ} \mathrm{C}$. After $1 \mathrm{~min}$, the cold trap was heated up to $250^{\circ} \mathrm{C}$ (at a rate of $99^{\circ} \mathrm{C}$ ) and volatiles were directly transferred onto the head of the capillary column.

GC-MS analysis was performed using a Finnigan TRACETM MS (ThermoQuest, Austin, USA). Volatile compounds were separated using a 
DB-WAX capillary column ( $1.0 \mu \mathrm{m} \times 0.32 \mathrm{~mm} \times 60 \mathrm{~m}$, SGE, Australia). Helium was used as the carrier gas at a constant flow rate of $1 \mathrm{~mL} / \mathrm{min}$. The oven was kept at an initial temperature of $40^{\circ} \mathrm{C}$ for $2 \mathrm{~min}$. Then, the temperature was increased to $190^{\circ} \mathrm{C}$ at a rate of $4{ }^{\circ} \mathrm{C} / \mathrm{min}$, maintained for $5 \mathrm{~min}$ and finally increased to $230{ }^{\circ} \mathrm{C}$ at $10^{\circ} \mathrm{C} / \mathrm{min}$. The $\mathrm{MS}$ interface and source temperatures were 250 and $200{ }^{\circ} \mathrm{C}$, respectively. Electron impact mass spectra were recorded in impact ionisation mode at $70 \mathrm{eV}$ and with a mass range of $\mathrm{m} / \mathrm{z} 33-433$. A total of 3 extracts were obtained for each sample.

The identification of isolated volatile compounds was tentatively carried out by comparing their mass spectra $(\mathrm{m} / \mathrm{z}$ values of the most important ions) with spectral data from the National Institute of Standards and Technology 2002 library as well as published retention indices and spectral data. A solution of the homogenous series of normal alkanes (C8 - C20 by Fluka Buchs, Schwiez, Switzerland) was used to determine the Kovats retention indices.

The quantification of the 23 selected volatile compounds, selected on the basis of their ratio and contribution to the aroma perception (Forney, Kalt and Jordan, 2000; Jetti, Yang, Kurnianta, Finn and Quian, 2007; Larsen and Poll, 1992), was performed after calibration by the standard addition method, in order to avoid the food matrix composition effect. $10 \mathrm{~g}$ of thawed strawberry purée, $500 \mu \mathrm{L}$ of internal standard 2-pentanol $(10 \mathrm{~mL} / \mathrm{L})$ and 10 different concentrations of the standards or of the essential oil (limonene, $\gamma$-terpinene and $p$-cymene) were analysed in triplicate following the procedure already described.

\subsection{Sensory evaluation}

Sensory evaluation was performed by a difference-from-control test with a seven-point $(-3$ to +3$)$ numerical category scale (Meilgaard, Civile and Carr, 1999). This test is classified as an overall difference test and is used to determine if there is a difference between one or more test samples and a control sample, while the size of the differences can be quantified (score 0 means that there is no difference with respect to the control). The sensory parameters (strawberry aroma and flavour) were evaluated by 30 untrained panellists. Judges compared a coded sample with a control sample (non-coated strawberry) and they evaluated the size of the 
differences against a seven-point scale. All the coated and non-coated (blind) samples were compared with the control (non-coated) sample.

\subsection{Statistical analysis}

The results were analysed by a multifactor analysis of variance (ANOVA) with a $95 \%$ significance level using Statgraphics ${ }^{\circledR}$ Plus Centurion VII. Multiple comparisons were performed through 95 \% Fisher's LSD intervals. Furthermore, a Principal Component Analysis (PCA) was applied to describe the relationships between the quantified volatile compound and the different treatments during storage, using Unscrambler 10.X software.

\section{RESULTS AND DISCUSSION}

The volatile compounds identified in non-coated (control) strawberry samples before storage are shown in Table 2.2.1, together with the Retention Index. A total of 57 esters, 16 alcohols, 7 aldehydes, 3 ketones, 2 terpenes, 1 aromatic hydrocarbon and 2,5-dimethyl-4-methoxy-3(2H) furanone (DMF) were identified in the strawberry volatile profile. Taking into account the relative area of the different peaks in the chromatograms with respect to that of the internal standard, the weight percentage of each compound family was estimated; as followed $76.85 \%$ for esters, $11.4 \%$ for alcohols and $8.85 \%$ for aldehydes (Table 2.2.2). The rest of the compounds, including DMF, were in minority. Similar volatile profiles were reported for strawberries of the same variety by different authors (Jetti, Yang, Kurnianta, Finn and Quian, 2007; Peinado, Rosa, Heredia, Escriche and Andrés, 2013). In every case, the esters were found to be the major compounds.

The main compounds of the used lemon essential oil (Table 2.2.2) were D-limonene $(51 \pm 2 \%), \gamma$-terpinene $(15.0 \pm 0.7 \%), \beta$-pinene $(4.7 \pm 1.0 \%)$, myrcene $(3.8 \pm 0.3 \%)$, p-cymene $(3.1 \pm 0.5 \%)$, sabinene $(2.6 \pm 0.5 \%)$ and $\alpha$-citral $(2.4 \pm 0.2 \%)$, coinciding with that reported by other authors (Caccioni, Guizzardi, Biondi, Renda and Ruberto, 1998; Espina et al., 2011). For D-limonene and $\alpha$-citral antimicrobial properties were reported (Burt, 2004). Some of the identified volatile of lemon essential oil were also present as minor compounds in non-coated strawberry samples; in particular, the aldehyde nonanal and the monoterpene $\beta$-linalool. 
Table 2.2.1 Identified volatile compounds in strawberry samples and Retention Index (RI). Compounds have been ordered within each category according to the ratio Areacompund/Areatotal.

\begin{tabular}{|c|c|c|c|}
\hline Compounds & RI & Compounds & $\mathrm{RI}$ \\
\hline Esters $76.85 \%$ & & ethyl benzoate & 1,708 \\
\hline ethyl acetate & 915 & butyl butanoate & 1,234 \\
\hline methyl butanoate & 1,010 & hexyl butanoate & 1,433 \\
\hline 2-hexenyl acetate & 1,354 & methyl methacrylate & 1,133 \\
\hline ethyl 2-methyl butanoate & 1,073 & ethyl pentanoate & 1,151 \\
\hline ethyl hexanoate & 1,250 & octyl butanoate & 1,635 \\
\hline hexyl acetate & 1,290 & pentyl butanoate & 1,281 \\
\hline ethyl propanoate & 980 & benzyl acetate & 1,768 \\
\hline isoamyl acetate & 1,139 & 2-hexenyl isovalerate (E) & 1,498 \\
\hline butyl acetate & 1,095 & hexyl 2-methyl butanoate & 1,442 \\
\hline ethyl butanoate & 1,059 & methyl 2-methylene butanoate & 1,216 \\
\hline 4-hexenyl acetate & 1,338 & butyl 3-methyl hexanoate & 1,475 \\
\hline methyl acetate & 858 & hexyl 3-methyl butanoate & 1,661 \\
\hline ethyl 2-methyl propanoate & 987 & methyl 2-methyl propanoate & 945 \\
\hline ethyl 3-methyl butanoate & 1,089 & 3-methyl-2-butenyl acetate & 1,275 \\
\hline ethyl 2-butenoate (Z) & 1,187 & methyl heptanoate & 1,319 \\
\hline methyl hexanoate & 1,205 & ethyl 3-octenoate (Z) & 1,513 \\
\hline methyl propanoate & 931 & methyl 2-hexenoate & 1,316 \\
\hline ethyl 1-methyl acetate & 922 & methyl octanoate & 1,408 \\
\hline propyl acetate & 999 & ethyl decanoate & 1,656 \\
\hline propyl 2-methyl acetate & 1,033 & Aldehydes $11.4 \%$ & \\
\hline methyl 3-methyl butanoate & 1,040 & 2-hexenal (E) & 1,249 \\
\hline octyl acetate & 1,493 & hexanal & 1,106 \\
\hline methyl 2-methyl butanoate & 1,033 & acetaldehyde & 646 \\
\hline S-methyl thioacetate & 1,077 & nonanal & 1,417 \\
\hline 3-hexenyl acetate & 1,328 & 2-nonenal & 1,568 \\
\hline 2-pentenyl acetate (Z) & 1,245 & decanal & 1,524 \\
\hline ethyl 2-hexenoate (E) & 1,368 & octanal & 1,311 \\
\hline pentyl acetate & 1,191 & Alcohols $8.85 \%$ & \\
\hline ethyl 2-methylthio acetate & 1,479 & ethanol & 959 \\
\hline ethyl 2-methyl-2-butenoate & 1,260 & 1-hexanol & 1,372 \\
\hline ethyl octanoate & 1,452 & 1-butanol, 3-methyl & 1,229 \\
\hline methyl 3-hexenoate & 1,323 & 2-hexen-1-ol (E) & 1,427 \\
\hline octyl 2-methyl butanoate & 1,644 & 1-penten-3-ol & 1,183 \\
\hline
\end{tabular}


Table 2.2.1 (Continued)

\begin{tabular}{lllr}
\hline Compounds & RI & Compounds & $\mathrm{RI}$ \\
\hline Alcohols 8.85 \% (Continued) & & Ketones 2.11\% & \\
1-butanol & 1,170 & 2-pentanone & 1,005 \\
1-octanol & 1,575 & 2-propanone & 848 \\
1-propanol, 2-methyl & 1,119 & 6-methyl-5-heptene-2-one & 1,363 \\
3-hexen-1-ol (Z) & 1,407 & Monoterpenes 0.57\% & \\
2-penten-1-ol (Z) & 1,342 & B-linalool & 1,564 \\
1-pentanol & 1,271 & Furans 0.11\% & \\
& 1,506 & 2,5-dimethyl-4-methoxy-3(2H) & 1,632 \\
1-hexanol, 2-ethyl & 1,556 & Aromatic hydrocarbons 0.06\% & \\
2-octen-1-ol (E) & 1,385 & ethyl benzene & 1,285 \\
1,5-pentanediol, 3-methyl & 1,596 & & \\
2-undecanol & 950 & & \\
2-propanol & & & \\
\hline
\end{tabular}

Strawberries, prior to coating, showed an average maturity index (MI) of $8.7 \pm 0.8$. Both storage and the type of coating influenced how much this value increased throughout cold storage. The highest increase was observed in non-coated samples (control) and in those coated with $\mathrm{CH}$; the average $\mathrm{MI}$ values for these treatments was $12 \pm 1.2$ at 15 storage days. The addition of lemon essential oil to $\mathrm{CH}$ coatings promoted a delay in ripening, especially in samples coated with $\mathrm{CH} . \mathrm{LM}$, which reached a $\mathrm{MI}$ value of $9.6 \pm 0.3$ after 15 days of storage. The detected ripening patterns correspond well with the respiratory behaviour reported in Table 2.2.3, where a significantly lower respiration rate both in terms of oxygen and carbon dioxide production was detected in samples with coatings containing lemon essential oil. Moreover, the addition of lemon essential oil to the coatings led to a significant increase in the respiratory quotient of the samples, which reached the highest values at 7 storage days, whereas no significant effect of coating with $\mathrm{CH}$ was observed on the respiration pattern of the samples. Coherently, the levels of acetaldehyde and ethanol, which are volatile compounds related with a fermentative metabolism, were also higher at 7 storage days in samples treated with lemon essential oil, although they decreased after 15 storage days (Table 2.2.3). At the end of the storage period, the concentration level of ethyl acetate was significantly lower in these samples as compared to uncoated or $\mathrm{CH}$ coated samples. This behaviour suggests that the physiological pathways of the 
plant cells could be notably affected by the contact with the essential oil compounds, which may also influence the volatile biosynthesis and aroma profile, regardless of the incorporation of new volatiles passing from the lemon essential oil to the samples. The effect of the cellular stress provoked by different treatments such as, osmotic treatments, on the volatile profile of strawberries has been demonstrated in previous studies (Talens, Escriche, Martínez-Navarrete and Chiralt, 2002). A relevant role of enzyme activity in syntheses of volatiles in strawberries has been also reported (Zabetakis and Holden, 1997). In fact, no modifications in the volatile profile were observed in previously blanched strawberry samples submitted to different treatments (Moreno, Chiralt, Escriche and Serra, 2000). In this sense, active coatings can provoke changes in the cellular synthesis of volatiles, associated with the chitosan or essential oil interactions with the plant cells, which will induce cellular stress and changes in enzyme activity.

Table 2.2.4 shows the amount (expressed as $\mathrm{mg} / \mathrm{kg}$ of strawberry) of some selected volatile compounds present in the strawberry profile for the different treatments and storage time. In general, a decrease in the concentration of esters and aldehydes during storage was observed for all treatments. Alcohols decreased during storage for all treatments, except 1-hexanol and 3-hexen-1-ol whose concentration increased when coatings containing lemon essential oil were applied. Nevertheless, no relevant impact of these alcohols on the strawberry flavour has been reported. The concentration of DMF notably increased in all the samples during storage, especially in the $\mathrm{CH}$-coated strawberries, but this hardly occurred in samples treated with lemon essential oil. This occurs in line with the different ripening behaviour observed for the different samples: $\mathrm{CH}$ coating did not significantly affect the ripening index whereas coatings with lemon essential oil slowed down the cell respiration while promoting the fermentative process, thus reflecting the influence of lemon essential oil compounds on the cell physiological pathways.

The concentration of monoterpenes, which mainly came from lemon essential oil, decreased during storage, thus indicating that a progressive loss of the exogenous volatile compounds of strawberry occurred throughout the storage time. Likewise, their concentration was much lower than that expected from the initial concentration in the CFD. 
Table 2.2 .5 shows the estimated losses of the lemon essential oil components during the coating formation, determined both from the concentration value in the newly coated samples ( 0 storage days) and that deduced from the mass of the wet coating of each sample and the lemon essential oil compound concentration in the CFD. The latter was estimated from the wt. \% of lemon essential oil in the CFD and its concentration of volatiles commented on above. In the same way, the losses of these compounds after 7 and 15 days storage times were evaluated and shown in Table 2.2.5. A high percentage loss was obtained in every case due to the volatility of the compounds and their simultaneous evaporation with water during the coating drying step. The smallest loss was detected for limonene, although no significant differences were detected among treatments for the four evaluated compounds. CH.LM coatings led to significantly higher essential oil losses in terms of the 4 evaluated volatiles $(p<0.05)$. The lower viscosity of the CH.LM coating-forming dispersion (64 $\mathrm{mPa} \cdot \mathrm{s}$, Perdones, Sánchez-González, Chiralt and Vargas, 2012) as compared to CH.L (247 mPa·s, Perdones, Sánchez-González, Chiralt and Vargas, 2012) could facilitate the diffusion of lemon essential oil to the coating surface and its subsequent evaporation during the drying step of the coating (Sánchez-González, Cháfer, González-Martínez, Chiralt and Desobry, 2011b).

Limonene, $\boldsymbol{\gamma}$-terpinene and $\mathrm{p}$-cymene losses progressed during storage, reaching final average loss values of $93 \%$, whereas all $\alpha$-citral was completely lost after 7 days of storage. Despite these high lemon essential oil losses, the remaining amount $(38 \pm 5 \mathrm{mg}$ lemon essential oil $/ \mathrm{Kg}$ strawberry) was enough to control fungal decay in strawberries (Perdones, Sánchez-González, Chiralt and Vargas, 2012), and to alter the physiological pathways in strawberries, as previously stated. 
Table 2.2.2 Identified volatile compounds in the lemon essential oil and Retention index (RI). Compounds have been ordered within each category according to the ratio Area $_{\text {compund }} /$ Areatotal. $_{\text {Con }}$

\begin{tabular}{|c|c|c|c|}
\hline Compound & $\mathrm{RI}$ & Compound & $\mathrm{RI}$ \\
\hline Monoterpenes $95.45 \%$ & & Sesquisterpenes $2.51 \%$ & \\
\hline limonene & 1.218 & $\beta$-bisabolene & 1.751 \\
\hline$\gamma$-terpinene & 1.264 & isocaryophyllene & 1.633 \\
\hline$\beta$-pinene & 1.122 & valencene & 1.756 \\
\hline myrcene & 1.174 & $\beta$-farnesene & 1.713 \\
\hline p-cymene & 1.293 & $\alpha$-caryophyllene & 1.708 \\
\hline sabinene & 1.134 & $\beta$-bisabolol & 1.639 \\
\hline$\alpha$-citral & 1.768 & & \\
\hline geranyl acetate & 1.778 & Ketones $1.26 \%$ & \\
\hline neryl acetate & 1.748 & 2-pentanone & 1.005 \\
\hline$\beta$-citral & 1.717 & 5-hepten-2-one, 6 methyl & 1.363 \\
\hline$\alpha$-bergamotene & 1.608 & 3-buten, 2-one & 976 \\
\hline$\beta$-phellandrene & 1.227 & & \\
\hline terpinolene & 1.303 & Aldehydes $0.62 \%$ & \\
\hline trans- $\beta$-Ocimene & 1.248 & decanal & 1.524 \\
\hline$\beta$-linalool & 1.564 & nonanal & 1.417 \\
\hline$\alpha$-thujene & 1.043 & octanal & 1.311 \\
\hline camphene & 1.115 & hexanal & 1.106 \\
\hline cis-limonene oxide & 1.479 & & \\
\hline$\alpha$-pinene & 1.038 & Esters $0.26 \%$ & \\
\hline$\beta$-citronellal & 1.505 & citronellyl acetate & 1.680 \\
\hline eucalyptol & 1.229 & & \\
\hline trans-limonene oxide & 1.491 & Aromatic hydrocarbons $0.16 \%$ & \\
\hline$\alpha$-terpinene & 1.195 & 4-mehylstyrene & 1.389 \\
\hline$\alpha$-terpineol & 1.726 & & \\
\hline cis- $\beta$-terpineol & 1.575 & Alcohols $0.03 \%$ & \\
\hline 4-terpineol & 1.488 & 2-nonanol & 1.429 \\
\hline 3-carene & 1.079 & & \\
\hline$\alpha$-phellandrene & 1.179 & & \\
\hline 2,6-dimethyl-3,5,7-octatriene-2-ol (E) & 1.472 & & \\
\hline
\end{tabular}


Table 2.2.3 Evolution of the respiration rate $\left(R R, \mathrm{mg} \cdot \mathrm{kg}^{-1} \cdot \mathrm{h}^{-1}\right)$ and respiratory quotient (RQ) of strawberry samples and of the content of volatiles related with fermentative metabolism during storage $\left(\mathrm{mg} \cdot \mathrm{kg}^{-1}\right)$. Mean values and (standard deviation).

\begin{tabular}{|c|c|c|c|c|c|c|c|}
\hline FFD & Time (days) & $\operatorname{RR}\left[\mathrm{O}_{2}\right]$ & $\mathrm{RR}\left[\mathrm{CO}_{2}\right]$ & $\mathrm{RQ}$ & Acetaldehyde & ethyl acetate & Ethanol \\
\hline \multirow{3}{*}{ Control } & 0 & $26(4)^{\mathrm{ab} 2}$ & $14.1(0.5)^{\mathrm{ab} 1}$ & $0.55(0.06)^{a 1}$ & $6.8(0.8)^{\mathrm{a} 1}$ & $11(2)^{a 1}$ & $18.8(0.3)^{\mathrm{a} 1}$ \\
\hline & 7 & $12.5(1.2)^{\mathrm{b} 2}$ & $15.45(1.09)^{\mathrm{b} 1}$ & $1.24(0.06)^{\mathrm{a} 2}$ & $9.4(1.0)^{a 12}$ & $26(4)^{\mathrm{b} 2}$ & $13.24(0.13)^{a 1}$ \\
\hline & 15 & $16(3)^{\mathrm{b} 1}$ & $17(2)^{\mathrm{b} 1}$ & $1.07(0.09)^{b 2}$ & $15.4(1.6)^{\mathrm{a} 2}$ & $23.5(1.4)^{\mathrm{b} 2}$ & $40(3)^{\mathrm{a} 2}$ \\
\hline \multirow{3}{*}{$\mathrm{CH}$} & 0 & $22(2)^{\mathrm{a} 3}$ & $12(1.3)^{\mathrm{a} 1}$ & $0.54(0.02)^{\mathrm{a} 1}$ & $20(4)^{b 1}$ & $13.7(0.5)^{\mathrm{a} 1}$ & $46(12)^{b 1}$ \\
\hline & 7 & $11.4(1.2)^{\mathrm{b} 2}$ & $12.7(1.4)^{\mathrm{b} 1}$ & $1.112(0.012)^{\mathrm{a} 2}$ & $14.4(1.6)^{\mathrm{ab} 1}$ & $19.1(1.3)^{\mathrm{a} 2}$ & $32.5(1.6)^{b 1}$ \\
\hline & 15 & $16(4)^{b 1}$ & $13(3)^{b 1}$ & $0.85(0.03)^{\mathrm{a} 3}$ & $14(7)^{a 1}$ & $22.6(0.9)^{\mathrm{ab} 2}$ & $46(4)^{a 1}$ \\
\hline \multirow{3}{*}{ CH.L } & 0 & $28(4)^{b 2}$ & $19(2)^{c 2}$ & $0.69(0.05)^{\mathrm{a} 1}$ & $18(7)^{\mathrm{bc} 1}$ & $11(2)^{a 1}$ & $32(13)^{\mathrm{ab} 1}$ \\
\hline & 7 & $3.7(1.2)^{\mathrm{a} 2}$ & $7(2)^{a 1}$ & $2(0.2)^{c 2}$ & $19.6(1.4)^{\mathrm{bc} 1}$ & $23(2)^{\mathrm{ab} 2}$ & $43(8)^{\mathrm{b} 1}$ \\
\hline & 15 & $7(3)^{\mathrm{a} 1}$ & $7.3(0.2)^{\mathrm{a} 1}$ & $1.6(0.2)^{c 3}$ & $15.28(0.02)^{\mathrm{a} 1}$ & $18(3)^{a^{2}}$ & $47(15)^{\mathrm{a} 1}$ \\
\hline \multirow{3}{*}{ CH.LM } & 0 & $24(2)^{a b 2}$ & $16.6(0.3)^{\mathrm{bc} 2}$ & $0.71(0.06)^{\mathrm{a} 1}$ & $10.93(0.15)^{\mathrm{a} 1}$ & $12(3)^{a 1}$ & $20(3)^{a 1}$ \\
\hline & 7 & $5.5(0.3)^{\mathrm{a} 2}$ & $8.7(1.3)^{\mathrm{a} 1}$ & $1.57(0.14)^{b 2}$ & $25(3)^{c 2}$ & $22.1(1.3)^{\mathrm{ab} 2}$ & $41(4)^{\mathrm{b} 2}$ \\
\hline & 15 & $6(2)^{\mathrm{a} 1}$ & $9(3)^{\mathrm{a} 1}$ & $1.5(2)^{c 2}$ & $16(7)^{c 1}$ & $14.9(0.8)^{\mathrm{a} 1}$ & $36.8(0.7)^{\mathrm{a} 2}$ \\
\hline
\end{tabular}


Table 2.2.4 Concentration ( $\mathrm{mg} \cdot \mathrm{Kg}^{-1}$ strawberry) of the different volatile compounds quantified in strawberry samples as a function of storage time for samples uncoated (control) and coated with chitosan (CH), chitosan-lemon essential oil (CH.L) and the microfluidized chitosan-lemon essential oil (CH.LM). Mean values and (standard deviation).

\begin{tabular}{|c|c|c|c|c|c|}
\hline Compound & Time (days) & Control & $\mathrm{CH}$ & CH.L & CH.LM \\
\hline \multicolumn{6}{|l|}{ Esters } \\
\hline ethyl propanoate & $\begin{array}{c}0 \\
7 \\
15\end{array}$ & $\begin{array}{c}0.72(0.07)^{\mathrm{a} 2} \\
0.50(0.04)^{\mathrm{ab} 12} \\
0.17(0.03)^{\mathrm{a} 1}\end{array}$ & $\begin{array}{c}2.1(0.6)^{\mathrm{c3}} \\
1.18(0.05)^{\mathrm{c} 2} \\
0.210(0.012)^{\mathrm{a} 1}\end{array}$ & $\begin{array}{c}1.6(0.2)^{\mathrm{b} 2} \\
0.42(0.08)^{\mathrm{a} 1} \\
0.036(0.003)^{\mathrm{a} 1}\end{array}$ & $\begin{array}{c}0.81(0.08)^{\mathrm{a} 2} \\
0.930(0.108)^{\mathrm{bc} 2} \\
0.030(0.004)^{\mathrm{a} 1}\end{array}$ \\
\hline methyl butanoate & $\begin{array}{c}0 \\
7 \\
15\end{array}$ & $\begin{array}{c}2.58(0.03)^{\mathrm{a} 2} \\
1.88(0.08)^{\mathrm{b} 2} \\
0.103(0.012)^{\mathrm{a} 1}\end{array}$ & $\begin{array}{c}3.7(0.9)^{\mathrm{a} 3} \\
1.52(0.06)^{\mathrm{b} 2} \\
0.06(0.03)^{\mathrm{a} 1}\end{array}$ & $\begin{array}{l}2.797(0.012)^{\mathrm{a} 2} \\
0.213(0.015)^{\mathrm{a} 1} \\
0.020(0.010)^{\mathrm{a} 1}\end{array}$ & $\begin{array}{c}2.56(0.07)^{\mathrm{b} 2} \\
0.685(0.016)^{\mathrm{a} 1} \\
0.0214(0.0015)^{\mathrm{a} 1}\end{array}$ \\
\hline ethyl butanoate & $\begin{array}{c}0 \\
7 \\
15\end{array}$ & $\begin{array}{c}1.63(0.05)^{\mathrm{a} 2} \\
1.69(0.12)^{\mathrm{a} 2} \\
0.8(0.3)^{\mathrm{a} 1}\end{array}$ & $\begin{array}{l}1.92(0.15)^{\mathrm{ab} 2} \\
3.22(0.12)^{\mathrm{c3}} \\
0.95(0.04)^{\mathrm{a} 1}\end{array}$ & $\begin{array}{c}2.17(0.17)^{\mathrm{b} 2} \\
2.2(0.4)^{\mathrm{b} 2} \\
0.24(0.06)^{\mathrm{b} 1}\end{array}$ & $\begin{array}{c}2.3(0.3)^{\mathrm{b} 2} \\
3.1(0.2)^{\mathrm{c} 3} \\
0.27(0.06)^{\mathrm{b} 1}\end{array}$ \\
\hline methyl hexanoate & $\begin{array}{c}0 \\
7 \\
15\end{array}$ & $\begin{array}{c}0.18(0.04)^{\mathrm{a} 2} \\
0.103(0.000)^{\mathrm{a} 12} \\
0.0343(0.0017)^{\mathrm{a} 1}\end{array}$ & $\begin{array}{c}0.53(0.09)^{\mathrm{c} 2} \\
0.064(0.003)^{\mathrm{a} 1} \\
0.0101(0.0018)^{\mathrm{a} 1}\end{array}$ & $\begin{array}{c}0.27(0.05)^{\mathrm{ab} 2} \\
0.016(0.007)^{\mathrm{a} 1} \\
0.007(0.003)^{\mathrm{a} 1}\end{array}$ & $\begin{array}{c}0.34(0.15)^{\mathrm{b} 2} \\
0.046(0.009)^{\mathrm{a} 1} \\
0.007(0.003)^{\mathrm{a} 1}\end{array}$ \\
\hline ethyl hexanoate & $\begin{array}{c}0 \\
7 \\
15\end{array}$ & $\begin{array}{c}0.96(0.02)^{\mathrm{a} 1} \\
0.514(0.014)^{\mathrm{a} 1} \\
0.45(0.16)^{\mathrm{a} 1}\end{array}$ & $\begin{array}{c}6.0(0.6)^{\mathrm{d} 2} \\
0.71(0.12)^{\mathrm{ab} 1} \\
0.26(0.03)^{\mathrm{a} 1}\end{array}$ & $\begin{array}{c}4.0(0.7)^{\mathrm{c} 2} \\
0.63(0.03)^{\mathrm{ab} 1} \\
0.1262(0.0103)^{\mathrm{a} 1}\end{array}$ & $\begin{array}{c}2.6(0.4)^{\mathrm{b} 3} \\
1.3(0.2)^{\mathrm{b} 2} \\
0.143(0.018)^{\mathrm{a} 1}\end{array}$ \\
\hline hexyl acetate & $\begin{array}{c}0 \\
7 \\
15\end{array}$ & $\begin{array}{c}0.916(0.015)^{\mathrm{a}} \\
0.55(0.06)^{\mathrm{be}} \\
0.20(0.08)^{\mathrm{a}}\end{array}$ & $\begin{array}{c}1.58(0.05)^{\mathrm{b}} \\
0.74(0.09)^{\mathrm{c}} \\
0.122(0.014)^{\mathrm{a}}\end{array}$ & $\begin{array}{c}0.88(0.18)^{\mathrm{a}} \\
0.10(0.10)^{\mathrm{a}} \\
0.024(0.003)^{\mathrm{a}}\end{array}$ & $\begin{array}{c}0.7(0.3)^{\mathrm{a}} \\
0.31(0.09)^{\mathrm{ab}} \\
0.02(0.03)^{\mathrm{a}}\end{array}$ \\
\hline
\end{tabular}


Table 2.2.4 (Continued)

\begin{tabular}{|c|c|c|c|c|c|}
\hline Compound & Time (days) & Control & $\mathrm{CH}$ & CH.L & CH.LM \\
\hline \multicolumn{6}{|l|}{ Aldehydes } \\
\hline \multirow{3}{*}{ hexanal } & 0 & $0.69(0.16)^{\mathrm{b} 2}$ & $0.8(0.4)^{\mathrm{b} 2}$ & $0.059(0.009)^{\mathrm{a} 1}$ & $0.10(0.06)^{\mathrm{a} 12}$ \\
\hline & 7 & $0.88(0.04)^{\mathrm{b} 2}$ & $0.83(0.03)^{\mathrm{b} 2}$ & $0.22(0.11)^{\mathrm{a} 1}$ & $0.34(0.08)^{\mathrm{a} 2}$ \\
\hline & 15 & $0.25(0.04)^{\mathrm{a} 1}$ & $0.12(0.04)^{\mathrm{a} 1}$ & $0.056(0.006)^{\mathrm{a} 1}$ & $0.0336(0.0009)^{a 1}$ \\
\hline \multirow{3}{*}{ 2-hexenal } & 0 & $2.0(0.2)^{\mathrm{a} 2}$ & $4.9(1.0)^{\mathrm{b} 3}$ & $1.62(0.01)^{\mathrm{a} 2}$ & $1.5(0.5)^{\mathrm{a} 3}$ \\
\hline & 7 & $2.0(0.3)^{\mathrm{b} 2}$ & $2.9(0.4)^{c 2}$ & $0.61(0.18)^{\mathrm{a} 1}$ & $0.77(0.10)^{\mathrm{a} 2}$ \\
\hline & 15 & $0.54(0.03)^{\mathrm{a} 1}$ & $0.25(0.07)^{\mathrm{a} 1}$ & $0.18(0.04)^{\mathrm{a} 1}$ & $0.14(0.06)^{\mathrm{a} 1}$ \\
\hline \multirow{3}{*}{ nonanal** } & 0 & $0.068(0.008)^{\mathrm{a} 12}$ & $0.0463(0.0009)^{\mathrm{a} 1}$ & $0.241(0.015)^{\mathrm{b} 2}$ & $0.053(0.014)^{\mathrm{a} 12}$ \\
\hline & 7 & $0.0447(0.0006)^{\mathrm{a} 2}$ & $0.078(0.004)^{\mathrm{b} 2}$ & $0.0513(0.0018)^{a 1}$ & $0.070(0.011)^{\mathrm{ab} 2}$ \\
\hline & 15 & $0.08(0.03)^{\mathrm{b} 1}$ & $0.038(0.003)^{\mathrm{a} 1}$ & $0.034(0.009)^{\mathrm{a} 1}$ & $0.0347(0.0015)^{a 1}$ \\
\hline \multicolumn{6}{|l|}{ Alcohols } \\
\hline \multirow{3}{*}{ 1-penten-3-ol } & 0 & $0.28(0.05)^{\mathrm{b} 2}$ & $0.442(0.009)^{c 2}$ & $0.066(0.015)^{\mathrm{a} 1}$ & $0.107(0.009)^{\mathrm{a} 1}$ \\
\hline & 7 & $0.141(0.004)^{b 1}$ & $0.21(0.02)^{c 1}$ & $0.068(0.008)^{\mathrm{a} 1}$ & $0.12(0.04)^{b 1}$ \\
\hline & 15 & $0(0)^{\mathrm{a} 3}$ & $0(0)^{\mathrm{a} 3}$ & $0(0)^{\mathrm{a} 2}$ & $0(0)^{\mathrm{a} 2}$ \\
\hline \multirow{3}{*}{ 2-penten-1-ol (Z) } & 0 & $0.049(0.013)^{\mathrm{b} 3}$ & $0.017(0.009)^{\mathrm{a} 2}$ & $0.0074(0.0006)^{a 1}$ & $0.0067(0.0002)^{\mathrm{a} 2}$ \\
\hline & 7 & $0.015(0.006)^{\mathrm{bc} 2}$ & $0.026(0.005)^{c 2}$ & $0(0)^{\mathrm{a} 1}$ & $0.011(0.002)^{\mathrm{b} 12}$ \\
\hline & 15 & $0(0)^{\mathrm{a} 1}$ & $0(0)^{\mathrm{a} 1}$ & $0(0)^{\mathrm{a} 1}$ & $0(0)^{\mathrm{a} 1}$ \\
\hline \multirow{3}{*}{ 1-hexanol } & 0 & $0.6(0.2)^{c 2}$ & $0.33(0.11)^{\mathrm{b} 1}$ & $0.06(0.03)^{\mathrm{a} 1}$ & $0.049(0.002)^{\mathrm{a} 2}$ \\
\hline & 7 & $0.131(0.012)^{\mathrm{a} 1}$ & $0.491(0.006)^{b 2}$ & $0.12(0.04)^{\mathrm{a} 1}$ & $0.27(0.06)^{\mathrm{a} 1}$ \\
\hline & 15 & $0.164(0.003)^{\mathrm{a} 1}$ & $0.23(0.03)^{\mathrm{a} 1}$ & $0.174(0.007)^{\mathrm{a} 1}$ & $0.137(0.011)^{\mathrm{a} 12}$ \\
\hline \multirow{3}{*}{ 3-hexen-1-ol (Z) } & 0 & $0.065(0.013)^{c 2}$ & $0.0295(0.0013)^{\mathrm{b} 3}$ & $0.006(0.003)^{\mathrm{a} 1}$ & $0.010(0.002)^{a 1}$ \\
\hline & 7 & $0.0086(0.0009)^{\mathrm{ab} 1}$ & $0.0170(0.0009)^{\mathrm{b} 2}$ & $0.0053(0.0019)^{\mathrm{a} 1}$ & $0.0095(0.0003)^{\mathrm{ab} 1}$ \\
\hline & 15 & $0.00230(0.00006)^{\mathrm{a} 1}$ & $0.005(0.002)^{\mathrm{a} 1}$ & $0.0026(0.0004)^{\mathrm{a} 1}$ & $0.0026(0.0005)^{a 1}$ \\
\hline \multirow{3}{*}{ 2-hexen-1-ol (E) } & 0 & $0.93(0.03)^{c 2}$ & $0.5(0.3)^{\mathrm{b} 2}$ & $0.07(0.03)^{\mathrm{a} 1}$ & $0.09(0.05)^{\mathrm{a} 1}$ \\
\hline & 7 & $0.11(0.02)^{\mathrm{a} 1}$ & $0.37(0.02)^{\mathrm{b} 2}$ & $0.06(0.04)^{\mathrm{a} 1}$ & $0.143(0.004)^{\mathrm{a} 1}$ \\
\hline & 15 & $0(0)^{\mathrm{a} 1}$ & $0(0)^{a 1}$ & $0(0)^{\mathrm{a} 1}$ & $0(0)^{a 1}$ \\
\hline
\end{tabular}


Table 2.2.4 (Continued)

\begin{tabular}{|c|c|c|c|c|c|}
\hline Compound & Time (days) & Control & $\mathrm{CH}$ & CH.L & CH.LM \\
\hline \multicolumn{6}{|l|}{ Monoterpenes } \\
\hline \multirow{3}{*}{ limonene* } & 0 & - & - & $160(40)^{\mathrm{a} 2}$ & $71(15)^{b 1}$ \\
\hline & 7 & - & - & $91(6)^{\mathrm{a} 1}$ & $59(4)^{\mathrm{a} 1}$ \\
\hline & 15 & - & - & $47(4)^{a 1}$ & $35(8)^{a 1}$ \\
\hline \multirow{3}{*}{$\gamma$-terpinene* } & 0 & - & - & $39(8)^{\mathrm{a} 3}$ & $19(5)^{\mathrm{b} 2}$ \\
\hline & 7 & - & - & $21.1(0.8)^{\mathrm{a} 2}$ & $14.8(0.7)^{\mathrm{a} 1}$ \\
\hline & 15 & - & - & $8.5(0.9)^{\mathrm{a} 1}$ & $7(2)^{a 1}$ \\
\hline \multirow{3}{*}{ p-cymene* } & 0 & - & - & $6.7(1.8)^{\mathrm{b} 3}$ & $3.3(0.7)^{\mathrm{a} 2}$ \\
\hline & 7 & - & - & $4.3(0.4)^{\mathrm{a} 2}$ & $2.6(0.4)^{\mathrm{a} 12}$ \\
\hline & 15 & - & - & $1.3(0.2)^{\mathrm{a} 1}$ & $1.2(0.4)^{\mathrm{a} 1}$ \\
\hline \multirow{3}{*}{$\beta$-linalool** } & 0 & $0.29(0.09)^{a 1}$ & $0.68(0.17)^{\mathrm{a} 2}$ & $1.3(0.6)^{\mathrm{b} 1}$ & $0.72(0.03)^{a 12}$ \\
\hline & 7 & $0.05(0.02)^{\mathrm{a} 1}$ & $0.169(0.010)^{\mathrm{a} 1}$ & $1.5(0.4)^{\mathrm{b} 1}$ & $1.2(0.3)^{\mathrm{b} 2}$ \\
\hline & 15 & $0.066(0.004)^{\mathrm{a} 1}$ & $0.096(0.006)^{\mathrm{a} 1}$ & $0.220(0.014)^{\mathrm{a} 2}$ & $0.27(0.03)^{\mathrm{a} 1}$ \\
\hline \multirow{3}{*}{$\alpha$-citral* } & 0 & - & - & $3.1(1.1)^{\mathrm{a} 2}$ & $1.31(0.12)^{\mathrm{b} 2}$ \\
\hline & 7 & - & - & $0(0)^{\mathrm{a} 1}$ & $0(0)^{a 1}$ \\
\hline & 15 & - & - & $0(0)^{\mathrm{a} 1}$ & $0(0)^{a 1}$ \\
\hline \multicolumn{6}{|l|}{ Furans } \\
\hline \multirow{3}{*}{ DMF } & 0 & $7.5(1.1)^{a 1}$ & $4.7(0.9)^{\mathrm{a} 1}$ & $6.6(1.2)^{\mathrm{a} 1}$ & $2.9(0.9)^{\mathrm{a} 1}$ \\
\hline & 7 & $5.13(0.18)^{a 1}$ & $5.8(0.3)^{\mathrm{a} 1}$ & $6.7(1.9)^{\mathrm{a} 1}$ & $6.5(1.8)^{\mathrm{a} 12}$ \\
\hline & 15 & $11(3)^{\mathrm{a} 2}$ & $25(3)^{\mathrm{b} 2}$ & $8(5)^{\mathrm{a} 1}$ & $10(3)^{\mathrm{a} 2}$ \\
\hline
\end{tabular}

$\overline{a, b, c, d}$ Different superscripts indicate significant differences among coating treatment at a given storage time according to ANOVA test ( $p<0.05) .{ }^{1,2,3}$ Different superscripts indicate significant differences due to storage time for a given coating treatment according to ANOVA test $(p<0.05) . *$ Compound also identified in lemon essential oil. ** Compound identified in both lemon essential oil and in strawberry samples. CH: chitosan, L: lemon essential oil, M: microfluidized. 
Table 2.2.5 Loss of essential oil compounds (wt. \%) during coating formation and storage.

\begin{tabular}{cccccc}
\hline FFD & $\begin{array}{c}\text { Time } \\
(\text { days })\end{array}$ & $\begin{array}{c}\text { Limonene } \\
\left(T_{\mathrm{b}}=176^{\circ} \mathrm{C}\right)\end{array}$ & $\begin{array}{c}\gamma \text {-terpinene } \\
\left(\mathrm{T}_{\mathrm{b}}=183^{\circ} \mathrm{C}\right)\end{array}$ & $\begin{array}{c}\mathrm{p} \text {-cymene } \\
\left(\mathrm{T}_{\mathrm{b}}=178{ }^{\circ} \mathrm{C}\right)\end{array}$ & $\begin{array}{c}\alpha \text {-citral } \\
\left(\mathrm{T}_{\mathrm{b}}=229^{\circ} \mathrm{C}\right)\end{array}$ \\
\hline \multirow{3}{*}{ CH.L } & 0 & $63(10)^{\mathrm{a} 1}$ & $65(9)^{\mathrm{a} 1}$ & $70(8)^{\mathrm{a} 1}$ & $83(5)^{\mathrm{a} 1}$ \\
& 7 & $78(6)^{\mathrm{a} 2}$ & $81(5)^{\mathrm{a} 2}$ & $81(5)^{\mathrm{a} 2}$ & $100(0)^{\mathrm{a} 2}$ \\
& 15 & $89(3)^{\mathrm{a} 3}$ & $92(2)^{\mathrm{a} 3}$ & $94.3(1.6)^{\mathrm{a} 3}$ & $100(0)^{\mathrm{a} 2}$ \\
\hline \multirow{2}{*}{ CH.LM } & 0 & $83(3)^{\mathrm{b} 1}$ & $84(3)^{\mathrm{b} 1}$ & $86(3)^{\mathrm{b} 1}$ & $92.9(1.4)^{\mathrm{b} 1}$ \\
& 7 & $86(3)^{\mathrm{b} 12}$ & $87(3)^{\mathrm{b} 1}$ & $89(2)^{\mathrm{b} 1}$ & $100(0)^{\mathrm{a} 2}$ \\
& 15 & $91.7(1.6)^{\mathrm{a} 2}$ & $93.6(1.3)^{\mathrm{a} 2}$ & $94.98(0.99)^{\mathrm{a} 2}$ & $100(0)^{\mathrm{a} 2}$ \\
\hline
\end{tabular}

$\bar{a}, \mathrm{~b}$ Different superscripts in a column indicate significant differences among coating treatments at a determined time according to ANOVA test $(p<0.05)$. 1, 2, 3 Different superscripts in a column indicate significant differences due to storage time for a given treatment according to ANOVA test $(p<0.05)$. L: lemon essential oil, M: microfluidized.

In order to properly analyse the relationship between volatile composition and coating application during storage, a Principal Component Analysis was carried out, taking into account all the quantified volatiles (Table 2.2.3 and Table 2.2.4). Figure 2.2 .1 shows the typical plot where the two functions, PC-1 and PC-2, explained $67 \%$ of the total variability, PC-1 explaining a greater percentage. The location of the different treatments-times in the plot shows a good grouping of the treatments and times, exhibiting marked differences among the different samples due to both coating treatment and storage time. Likewise, plotting the different compounds allows us to find the compound group, which has greater weight in the volatile profile of the different samples. In this sense, it is remarkable that, after 15 storage days, all the samples appeared as only one wide group, near ethyl acetate, which indicates that the most characteristic volatile compounds in each one notably disappeared throughout time, giving rise to a similar final profile in every case. However, marked differences were observed for newly coated samples, which appeared in well separated groups, in terms of both PC-1 and PC-2 functions. PC-1 mainly separates samples treated with lemon essential oil, both microfluidized and non-microfluidized, which are located nearer to the terpenes coming from the lemon essential oil. Likewise, samples coated with $\mathrm{CH}$ are nearer the location of ester, in agreement with the higher concentration of these compounds.

Differences in the volatile profile of the samples submitted to the different treatments persisted after 7 storage days, although they all migrate in the 
plot towards a position near to that of the final time. At 7 days of storage, the samples treated with CFD containing lemon essential oil were closer to the acetaldehyde and ethanol coordinates. This is in agreement with the fermentative process that is promoted by the essential oil, as previously commented on.

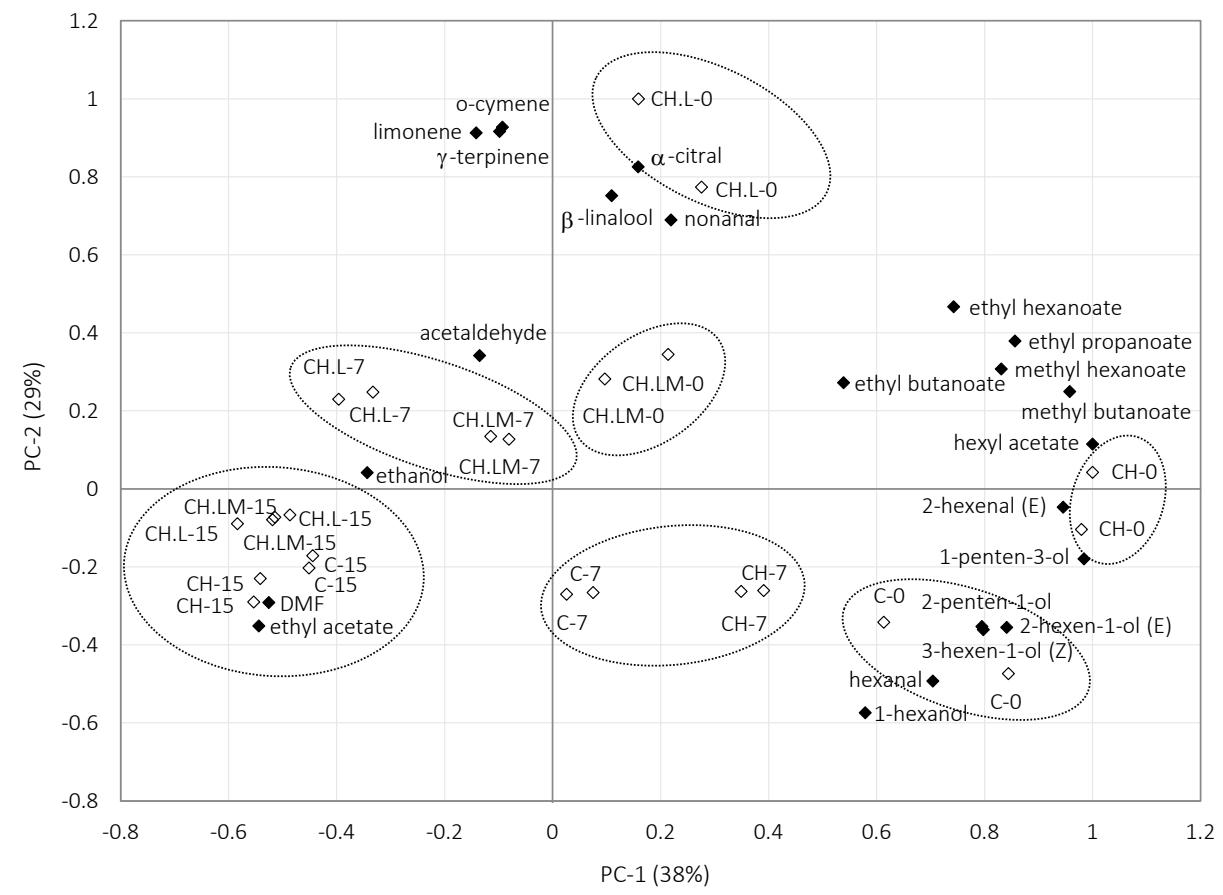

Figure 2.2.1 Principal Component analysis of strawberry quantified volatile compounds and treatments (coating-storage time). C: control (non-coated),

$\mathrm{CH}$ : chitosan coating, CH.L: chitosan coating with lemon essential oil, CH.LM: microfluidized coating containing lemon essential oil.

The sensory test revealed a significantly different perception of the panellists regarding the aroma and flavour of samples treated with coatings containing essential oils as compared to non-coated and $\mathrm{CH}$ coated samples. However, the panellists did not differentiate between the non-coated and $\mathrm{CH}$ coated samples in terms of these attributes. As deduced from the analysis of volatiles, differences in the aroma and flavour perception must be attributed not only to the presence of lemon essential oil compounds in the strawberry fruit, but also to the different development of the characteristic volatiles of strawberry in line with the physiological alterations in the fruit. 


\section{CONCLUSION}

Chitosan coatings, with and without lemon essential oil, affected the strawberry volatile profile which, in turn, had an impact on the perception of the fruit aroma and flavour. The coatings affected the metabolic pathways of the fruit. Particularly, pure chitosan promoted ester and 2,5-dimethyl-4-methoxy-3(2H) furanone formation in very short time after coating, which could enhance the aroma perception. However, the addition of lemon essential oil to the coatings not only incorporated the lemon essential oil terpenes into the fruit volatiles, but also promoted changes in the cell physiology, enhancing the fermentative process, thus modifying the typical fruit volatile composition. Whereas the effect of chitosan coatings was not sensorially perceived, probably because the differences were within the range of consumer tolerance, the changes induced by lemon essential oil were notably appreciated. Therefore, although lemon essential oil contributed to the prevention of fungal decay, the impact of its application was negative from the point of view of the quality of the fruit's aroma.

\section{Acknowledgements}

The authors acknowledge the financial support provided by Ministerio de Economía y Competividad (AGL2013-42989-R). Ángela Perdones also thanks the Universitat Politècnica de València for the FPI grant. 


\section{REFERENCES}

Almenar, E., Hernández-Muñoz, P., Gavara, R. Evolution of selected volatiles in chitosan-coated strawberries (Fragaria $x$ ananassa) during refrigerated storage. Journal of Agricultural and Food Chemistry, 57:3 (2009) $974-980$.

AOAC. Official methods of analysis. (17 th Ed.). Association of Analytical Chemists International, (Washington DC) 1995.

Bakkali, F., Averbeck, S., Averbeck, D., Idaomar, M. Biological effects of essential oils-A review. Food and Chemical Toxicology 46:2 (2008) $446-475$.

Burt, S. Essential oils: their antibacterial properties and potential applications in foods - a review. International Journal of Food Microbiology 94:3 (2004) $223-253$.

Caccioni, D. R. L., Guizzardi, M., Biondi, D. M., Renda, A., Ruberto, G. Relationship between volatile components of citrus fruit essential oils and antimicrobial action on Penicillium digitatum and Penicillium italicum. International Journal of Food Microbiology 43:1 (1998) 73 - 79.

Combrick, S., Regnier, T., Kamatou, G.P.P. In vitro activity of eighteen essential oils and some major components against common postharvest fungal pathogens of fruit. Industrial Crops and Products 33:2 (2011) $344-349$.

Espina, L., Somolinos, M., Lorán, S., Conchello, P., García, D., Pagán, R. Chemical composition of commercial citrus fruit essential oils and evaluation of their antimicrobial activity acting alone or in combined processes. Food Control 22:6 (2011) 896 - 902.

Forney, C. F., Kalt, W., \& Jordan, M. A. The composition of strawberry aroma is influenced by cultivar, maturity, and storage. HortScience 35:6 (2000) $1022-1026$. 
Gol, N. B., Patel, P. R., Ramana Rao, T. V. Improvement of quality and shelf-life of strawberries with edible coatings enriched with chitosan. Postharvest Biology and Technology 85 (2013) 185 - 195.

Hernández-Muñoz, P., Almenar, E., Del Valle, V., Vélez, D., Gavara, R. Effect of chitosan coating combined with postharvest calcium treatment on strawberry (Fragaria $x$ ananassa) quality during refrigerated storage. Food Chemistry 110:2 (2008) 428-435.

Jetti, R.R., Yang, E., Kurnianta, A., Finn, C., Qian, M.C. Quantification of selected aroma-active compounds in strawberries by headspace solid-phase microextraction gas chromatography and correlation with sensory descriptive analysis. Journal of Food Science 72:7 (2007) S487 - S496.

Larsen, M., Poll, L. Odour thresholds of some important aroma compounds in strawberries. Zeitschrift für Lebensmittel-Untersuchung und Forschung 195:2 (1992) $120-123$.

Meilgaard, M., Civille, G.V., Carr, B.T. Sensory evaluation and techniques. CRC Press LLC, Boca Raton (Florida) 1999.

Moreno, J., Chiralt, A., Escriche, I., Serra, J.A. Effect of blanching/osmotic dehydration combined methods on quality and stability of minimally processed strawberries. Food Research International, 33:7 (2000) $609-616$.

Moufida, S., Marzouk, B. Biochemical characterization of blood orange, sweet orange, lemon, bergamot and bitter orange. Phytochemistry 62:8 (2003) $1283-1289$.

Peinado, I., Rosa, E., Heredia, A., Escriche, I., Andrés, A. Influence of processing on the volatile profile of strawberry spreads made with isomaltulose. Food Chemistry 138:1 (2013) 621 - 629.

Perdones, A., Sánchez-González, L., Chiralt, A., Vargas, M. Effect of chitosan-lemon essential oil coatings on storage-keeping quality of strawberry. Postharvest Biology and Technology 70 (2012) $32-41$.

Perdones, A., Vargas, M., Atarés, L., Chiralt, A. Physical, antioxidant and 
antimicrobial properties of chitosan-cinnamon leaf oil films as affected by oleic acid. Food Hydrocolloids 36 (2014) 256 - 264.

Rivera Calo, J., Crandall, P.G., O'Bryan, C.A., Ricke, S.C. Essentials oils as antimicrobials in food systems -A review. Food Control 54 (2015) $111-119$.

Sánchez-González, L., Chiralt, A., González-Martínez, C., Cháfer, M. Effect of essential oils on properties of film forming emulsions and films based on hydroxypropylmethylcellulose and chitosan. Journal of Food Engineering 105:2 (2011a) $246-253$.

Sánchez-González, Cháfer, M., González-Martínez, C., Chiralt, A., Desobry, S. Study of the release of limonene present in chitosan films enriched with bergamot oil in food simulants. Journal of Food Engineering 105:1 (2011b) $138-143$.

Sharma, N., Tripathi, A. Effects of Citrus sinensis (L.) Osbeck epicarp essential oil on growth and morphogenesis of Aspergillus niger (L.) Van Tieghem. Microbiological Research 163:3 (2008) 337 - 344.

Talens, P., Escriche, I., Martínez-Navarrete, N., Chiralt, A. Study of the Influence of Osmotic Dehydration and Freezing on the Volatile Profile of Strawberries. Journal of Food Science 67:5 (2002) 1649 - 53.

US EPA. Registration eligibility decision (RED): Limonene. (Washington D.C) 1994.

Vargas, M., Albors, A., Chiralt, A., González-Martínez, C. Quality of cold-storage strawberries as affected by chitosan-oleic acid edible coatings. Postharvest Biology and technology 41:2 (2006) $164-171$.

Vargas, M., González-Martínez, C. Recent patents on food applications of chitosan. Recent Patents on Food, Nutrition and Agriculture 2:2 (2010) $121-128$.

Wang, S. Y., Gao, H. Effect of chitosan-based edible coating on antioxidants, antioxidant enzyme system, and postharvest fruit quality of strawberries (Fragaria $x$ ananassa Duch.). LWT - Food Science and Technology 52:2 (2013) $71-79$. 
Wilson, C.L., Solar, J.M., El Ghaouth, A., Wisniewski, M.E. Rapid evaluation of plant extracts and essential oils for antifungal activity against Botrytis cinerea. Plant Disease 81:2 (1997) $204-210$.

Xing, R., Liu, S., Guo, Z., Yu, H., Wang, P., Li, C., Li, Z., Li, P. Relevance of molecular weight of chitosan and its derivatives and their antioxidant activities in vitro. Bioorganic and Medicinal Chemistry 13:5 (2005) $1573-1577$.

Zabetakis, I., Holden, M.A. Strawberry flavour: Analysis and biosynthesis. Journal of the Science of Food and Agriculture, 74:4 (1997) $424-434$.

Zheng, L.Y., Zhu, J.F. Study on antimicrobial activity of chitosan with different molecular weights. Carbohydrates Polymers 54:4 (2003) $527-530$. 


\section{CHAPTER 3}

\section{EFFECT OF OLEIC ACID ON THE ESSENTIAL OIL PERFORMANCE IN CHITOSAN MATRIX}

PROPERTIES OF FILM-FORMING DISPERSIONS AND FILMS BASED ON CHITOSAN CONTAINING BASIL AND THYME ESSENTIAL OILS

PHYSICAL AND ANTIMICROBIAL PROPERTIES OF CHITOSAN-CINNAMON LEAF ESSENTIAL OIL FILMS AS AFFECTED BY OLEIC ACID 



\section{PROPERTIES OF FILM-FORMING DISPERSIONS AND FILMS BASED ON CHITOSAN CONTAINING BASIL AND THYME ESSENTIAL OILS}

Ángela Perdones, Maria Vargas*, Amparo Chiralt

Submitted to Food Hydrocolloids.

Department of Food Technology-Institute of Food Engineering for Development, Universitat Politècnica de València, Camino de Vera s/n, 46022 Valencia, Spain.

*Telephone: 0034963877000 Ext.73642 Fax: 0034963877369 e-mail:mavarco@tal.upv.es 


\section{ABSTRACT}

Film-forming emulsions and films of chitosan containing basil and thyme essential oils, with and without oleic acid were characterized as to the emulsion stability (particle size, $\zeta$-potential and rheological behaviour) and barrier, mechanical and optical properties of the films. The losses of the essential oil during the film formation were also quantified as well as the antifungal effect of the films against Aspergillus niger, Botrytis cinerea and Rhizopus stolonifer.

The retention of essential oil in the films was greatly dependent on the stability of the film-forming emulsion. The addition of oleic acid (OA) to the chitosan-essential oil formulations enhanced the emulsion stability and oil retention in the film at the same time that it improved the water vapour barrier properties of the films. Lipids reduced the film stretchability but when OA was present in the formulation, this reduction was mitigated, as well as the changes in colour provoked by the essential oils, whereas OA reduced the film transparency. Chitosan films with basil or thyme essential oils did not inhibit the growth of the tested fungi.

Keywords: basil, thyme, essential oil, emulsion stability, oil retention, antifungal activity. 


\section{INTRODUCTION}

Chitosan-based films can encapsulate essential oils (EO) so that these natural compounds can be used in food preservation. In order to achieve effective antimicrobial activity, high concentrations of essential oils are generally needed. The incorporation of essential oils into edible films can be a useful strategy to improve coating functionality in terms of the enhancement of antimicrobial properties of chitosan at the same time that the matrix hygroscopic character can be reduced. Likewise, reduction of the cost of applying EO and minimization of their intense aroma perception could be achieved (Sánchez-González, Vargas, González-Martínez, Chiralt and Cháfer, 2011a).

The release rate of the encapsulated essential oil from the polymer matrix could be controlled, thus enlarging their antimicrobial action on the product by both direct contact or through the head space of the packaging due to the volatile nature of these components. One way to encapsulate essential oil into the polymer matrix consists of their emulsification in the aqueous film-forming dispersions of polymer and subsequent casting and drying processes under controlled conditions. Nevertheless, previous studies have shown notable losses of the essential oils during the film formation step by casting process (Sánchez-González, Cháfer, González-Martínez, Chiralt and Desobry, 2011b).

Solvent evaporation in the casting plate occurs overlapped with destabilisation phenomena of the film-forming emulsion: droplet flocculation, coalescence and creaming to the liquid surface. On this surface, water and essential oil components form immiscible blends which evaporate at lower temperature than pure compounds (steam distillation process). To minimize this negative effect, the enhancing of the stabilization factors of the initial emulsions (reduction of particle size, increase of the viscosity of the continuous phase or incorporation of emulsifiers) is key.

Thyme essential oil contains more than 60 compounds, most of them show antioxidant and antimicrobial properties against a broad spectrum of Gram-negative or Gram-positive bacteria (Baranauskiene, Venskutoni, Viskelis and Dambrauskiene, 2003; Burt and Reinders, 2003; Gaysinsky, 
Davidson, Bruce and Weiss, 2005; Singh, Falahee and Adams, 2001). The most important active compounds of thyme EO are the phenols thymol, rosmarinic acid and carvacrol (Di Pasqua, Hoskins, Betts and Mauriello, 2006; Shan, Cai, Sun and Corke, 2005). Similarly, basil essential oil consists of more than 30 compounds; the main constituent being estragol (Baratta et al., 1998; Bozin, Mimica-Dukic, Simin and Anackov, 2006; Tampieri et al., 2005). Basil EO has been proven to exhibit antimicrobial effect against different bacteria such as Enterobacteraerogenes, Enterobacter aglomerans, Escherichia coli, Listeria innocua, Literia monocytogenes and Salmonella typhimurium (Wan, Wilcock and Coventry, 1998) and against different fungi, such as Aspergillus niger, Botryodiplodia theobromae, Rhizopus solani, Botrytis cinerea, Fusarium solani, Mucor mucedo (Hussain, Anwar, Sherazi and Przybylski, 2008; Wilson, Solar, El Ghaouth and Wisniewski, 1997). Incorporation of these EO into chitosan films could be an interesting option to obtain controlled release active films which could be used in preservation of foods were the aroma of EO are compatible such as meat or vegetable products.

The aim of this work was to characterize relevant physicochemical properties of film-forming dispersions and films based on chitosan containing basil or thyme essential oils and to assess the effect of oleic acid addition, as emulsifier, on the final retention of essential oil in the films and on the film properties. Antifungal effect of the films containing EO was also tested.

\section{MATERIALS AND METHODS}

\subsection{Reagents}

High molecular weight chitosan $(\mathrm{CH})$ with a viscosity of $1.2 \mathrm{~Pa} \cdot \mathrm{s}$ at $1 \% \mathrm{w} / \mathrm{w}$ in $1 \% \mathrm{w} / \mathrm{w}$ glacial acetic acid (Batch MKBD1916V, Sigma-Aldrich Química, Madrid, Spain, $78 \%$ deacetylation degree), glacial acetic acid, oleic acid (OA) and magnesium nitrate-6-hydrate (Panreac Química, S.A., Castellar del Vallés, Barcelona, Spain), basil (BO) and thyme (TO) essential oil (Herbes del 
Molí, Alicante, Spain) were used to prepare the film-forming dispersions (FFD).

\subsection{Preparation and characterization of the film-forming dispersions}

$\mathrm{CH}(1 \% \mathrm{w} / \mathrm{w})$ was dispersed in an aqueous solution of glacial acetic acid ( $1 \% \mathrm{v} / \mathrm{w}$ ) at $25^{\circ} \mathrm{C}$ for $12 \mathrm{~h}$. Basil essential oil, thyme essential oil, oleic acid, or a mixture of essential oil and oleic acid, were added at different concentrations as described in Table 3.1.1. FFD were prepared by means of a rotor-stator homogenizer (Ultraturrax DI25 Yellow Line, IKA ${ }^{\circledR}$, Germany) at 20,500 rpm for $4 \mathrm{~min}$. After homogenization, the formulations were degassed with a vacuum pump (Wertheim, Germany).

Table 3.1.1 Composition of the Film-forming dispersions (FFD).

\begin{tabular}{lcccc}
\hline FFD & $\begin{array}{c}\mathrm{CH} \\
(\mathrm{g} / 100 \mathrm{~g})\end{array}$ & $\begin{array}{c}\mathrm{OA} \\
(\mathrm{g} / 100 \mathrm{~g})\end{array}$ & $\begin{array}{c}\mathrm{EO} \\
(\mathrm{g} / 100 \mathrm{~g})\end{array}$ & $\begin{array}{c}\text { TOTAL LIPID } \\
(\mathrm{g} / 100 \mathrm{~g})\end{array}$ \\
\hline $\mathrm{CH}_{1}$ & 1 & - & - & - \\
$\mathrm{CH}_{1}: \mathrm{BO}_{0.5}$ & 1 & - & 0.5 & 0.5 \\
$\mathrm{CH}_{1}: \mathrm{TO}_{0.5}$ & 1 & - & 0.5 & 0.5 \\
$\mathrm{CH}_{1}: \mathrm{OA}_{0.25}: \mathrm{BO}_{0.25}$ & 1 & 0.25 & 0.25 & 0.5 \\
$\mathrm{CH}_{1}: \mathrm{OA}_{0.25}: \mathrm{TO}_{0.25}$ & 1 & 0.25 & 0.25 & 0.5 \\
$\mathrm{CH}_{1}: \mathrm{OA}_{0.5}$ & 1 & 0.5 & - & 0.5 \\
$\mathrm{CH}_{1}: \mathrm{BO}_{1}$ & 1 & - & 1 & 1 \\
$\mathrm{CH}_{1}: \mathrm{TO}_{1}$ & 1 & - & 1 & 1 \\
$\mathrm{CH}_{1}: \mathrm{OA}_{0.5}: \mathrm{BO}_{0.5}$ & 1 & 0.5 & 0.5 & 1 \\
$\mathrm{CH}_{1}: \mathrm{OA}_{0.5}: \mathrm{TO}_{0.5}$ & 1 & 0.5 & 0.5 & 1 \\
$\mathrm{CH}_{1}: \mathrm{OA}_{0.75}: \mathrm{BO}_{0.25}$ & 1 & 0.75 & 0.25 & 1 \\
$\mathrm{CH}_{1}: \mathrm{OA}_{0.75}: \mathrm{TO}_{0.25}$ & 1 & 0.75 & 0.25 & 1 \\
$\mathrm{CH}_{1}: \mathrm{OA}_{1}$ & 1 & 1 & - & 1 \\
\hline
\end{tabular}

$\mathrm{CH}$ : chitosan, OA: oleic acid, EO: essential oil, BO: basil essential oil, TO: thyme essential oil. Subscripts indicate the ratio of film components.

\subsubsection{Particle size distribution, $\zeta$-potential and rheological behaviour}

The particle size of the FFD was measured by using a laser diffractometer (MasterSizer 2000, Malvern Instruments, UK). The FFD were diluted in a glacial acetic acid solution $(\mathrm{pH}=4.8)$ at 2,000 rpm until an obscuration rate 
of $10 \%$ was obtained. The Mie theory was applied considering a refractive index of 1.338 and 0 absorption. Three samples of each FFD were measured in quintuplicate. $\zeta$-potential was measured in quintuplicate by Laser-Doppler electrophoresis performed with a Zetasizer nano-Z (Malvern Instruments, Worcestershire, UK). The electrophoretic mobility of the droplets was transformed into $\zeta$-potential values using the Smoluchowsky model. The samples were diluted to a droplet concentration of $0.02 \%$ with a glacial acetic acid solution ( $\mathrm{pH}$ 4.8). The rheological behaviour of FFD was analysed in triplicate at $25^{\circ} \mathrm{C}$ by means of a rotational rheometer (Haake Rheostress1, Thermo Electric Corporation, Germany) with a type Z34DIN Ti sensor system of coaxial cylinders. Rheological curves were obtained after a stabilization time of $5 \mathrm{~min}$ at $25^{\circ} \mathrm{C}$. The shear stress $(\sigma)$ was measured as a function of shear rate $(\dot{\gamma})$ from 0 to $512 \mathrm{~s}^{-1}$, taking $5 \mathrm{~min}$ to reach the maximum shear rate and another $5 \mathrm{~min}$ to attain zero shear rate. The power law model was applied to determine the consistency $(K)$ and the flow behaviour ( $n$ ) indexes of the FFD. Apparent viscosity values were calculated at $100 \mathrm{~s}^{-1}$.

\subsection{Preparation and characterization of the films}

The films were obtained by casting technique. FFD were poured onto a framed and levelled Teflon ${ }^{\circledR}$ plate $(\phi=15 \mathrm{~cm})$ and were dried at room temperature for $48 \mathrm{~h}$. Films were prepared by pouring a constant amount of FFD that will provide a constant $\mathrm{CH}$ surface density in the dry films of $28 \mathrm{~g} / \mathrm{m}^{2}$. Dry films were peeled off the casting surface and preconditioned in desiccators at $5{ }^{\circ} \mathrm{C}$ and $59 \%$ relative humidity $(\mathrm{RH})$ for one week prior to performing all the tests. Film thickness was measured using a Palmer digital micrometer (Comecta, Barcelona, Spain $\pm 0.001 \mathrm{~mm}$ ) at 5 minimum different points of the same sample. Losses of the essential oil during the film formation were estimated from the difference between weight of the initial solid extended in the casting plate and the final weight of the dried film. Results were expressed as wt. \% with respect to the initial amount of essential oil.

\subsubsection{Water vapour permeability}

The water vapour permeability (WVP) was measured gravimetrically at $5{ }^{\circ} \mathrm{C}$ and $59-100 \%$ relative humidity $(\mathrm{RH})$ gradient, using a modification of the ASTM E96-95 gravimetric method (ASTM, 1995) for hydrophilic films 
(Gennadios, Weller and Gooding, 1994). Payne permeability cups (Elcometer SPRL, Hermelle/s Argenteau, Belgium) were filled with $5 \mathrm{~mL}$ of deionized water $(100 \% \mathrm{RH})$. The films were secured and the cups were placed in pre-equilibrated cabinets fitted with a fan, at $5{ }^{\circ} \mathrm{C}$. The $\mathrm{RH}$ of the cabinets was held at $59 \% \mathrm{RH}$ using oversaturated solutions of $\mathrm{Mg}\left(\mathrm{NO}_{3}\right)_{2}$. WVP was calculated with the equations described by Vargas, Perdones, Chiralt, Cháfer and González-Martínez (2011). Six replicates per formulation were made.

\subsubsection{Optical and mechanical properties}

Mechanical properties were measured by using a Texture Analyser TA-XT-plus (Stable Micro Systems, UK), with a $50 \mathrm{~N}$ load cell equipped with tensile grips (A/TG model). Sample films were cut according to the ASTM D-882 standard (ASTM, 2001). Grip separation was set at $50 \mathrm{~mm}$ and cross-head speed was $50 \mathrm{~mm} / \mathrm{min}$. Tensile strength (TS) and percentage of elongation (E) at break, and elastic modulus (EM) were evaluated in nine samples from each formulation.

The gloss of the films was measured with a flat surface glossmeter (Multi Gloss 268, Minolta, Germany) using a black matte background and at an incidence angle of $60^{\circ}$ (ASTM, 1999). Nine replicates were made per formulation. Results were expressed as gloss units, relative to a highly polished surface of black glass standard with a gloss value close to 100 .

The transparency of the films was determined through the surface reflectance spectra with a spectrocolorimeter CM-3600d (Minolta Co, Japan). Measurements were taken from nine replicates per formulation by using both a white and a black background and the Kubelka-Munk theory for multiple scattering was applied to the sample reflection spectra. The internal transmittance (Ti) was calculated from the reflectance of the sample backed by a known reflectance and the reflectance of the film on an ideal black background (Hutchings, 1999). Moreover, the ClE-L"a* ${ }^{*}{ }^{*}$ coordinates (CIE, 1986) were obtained by the infinite reflection spectra of the samples, using a D65 illuminant $/ 10^{\circ}$ observer in order to calculate the whiteness index (WI) of the samples. 


\subsubsection{Antifungal tests}

Antifungal effect of the films containing essential oils was tested through measuring the growth inhibition halo for three fungi (Aspergillus niger, Botrytis cinerea and Rhizopus stolonifer) by both contact and head space methods (Perdones, Vargas, Atarés and Chiralt, 2014). To this end, potato dextrose agar was used as culture media. Film circles $(\phi=2.5 \mathrm{~cm})$ were put on the agar media (contact method) or fixed to the plate cover (head space method). Incubation of the plates was carried out at $25^{\circ} \mathrm{C}$ for 14 days. The inhibition area (percentage) in the plate was measured after 1 and 7 days. The antimicrobial tests was also carried out with pure EO embedded in a filter paper circle $(\phi=2.5 \mathrm{~cm})$ by using different amounts of oils per culture plate $(3.5$ and $7.0 \mathrm{mg} /$ plate).

\subsection{Statistical analysis}

The results were analysed by means of a multifactor analysis of variance with a $95 \%$ significance level using Statgraphics Centurion ${ }^{\circledR}$. Multiple comparisons were performed through $95 \%$ least significant difference intervals (LSD). Pearson correlation was also analysed for the emulsion stability parameters and for the loss of the essential oil.

\section{RESULTS AND DISCUSSION}

\subsection{Properties of film-forming dispersions}

As seen in Figure 3.1.1, all CH:Lipid FFD showed a monomodal and polydisperse particle size distribution with particle sizes ranging between 0.04 and $0.6 \mu \mathrm{m}$ for $0.5 \%$ total lipid content (TLC), and 0.07 and $1.3 \mu \mathrm{m}$ for $1 \%$ TLC. Mean diameters for each formulation are given in Table 3.1.2. In terms of both $D[4,3]$ and $D[3,2]$ values, the particle size was significantly affected by TLC $(p<0.05)$; the higher the lipid ratio, the bigger the particles. Likewise, for a given TLC, droplets of pure BO were bigger than those of TO. The addition of $\mathrm{OA}$ to the lipid mixture led to a significant decrease $(p<0.05)$ in the droplet size as compared to $\mathrm{CH}$-basil or $\mathrm{CH}$-thyme 
emulsions, in agreement with the emulsifying role of OA. Pure OA emulsions exhibited the smallest droplets at a given TLC, according to its amphiphilic nature which favours its dispersion in aqueous media.

The values of $\zeta$-potential (Table 3.1.2) were positive in all samples, which suggest that $\mathrm{CH}$ molecules adsorbed at the lipid droplet surface, thus giving rise to highly charged positive particles, the extend different depending on the samples.
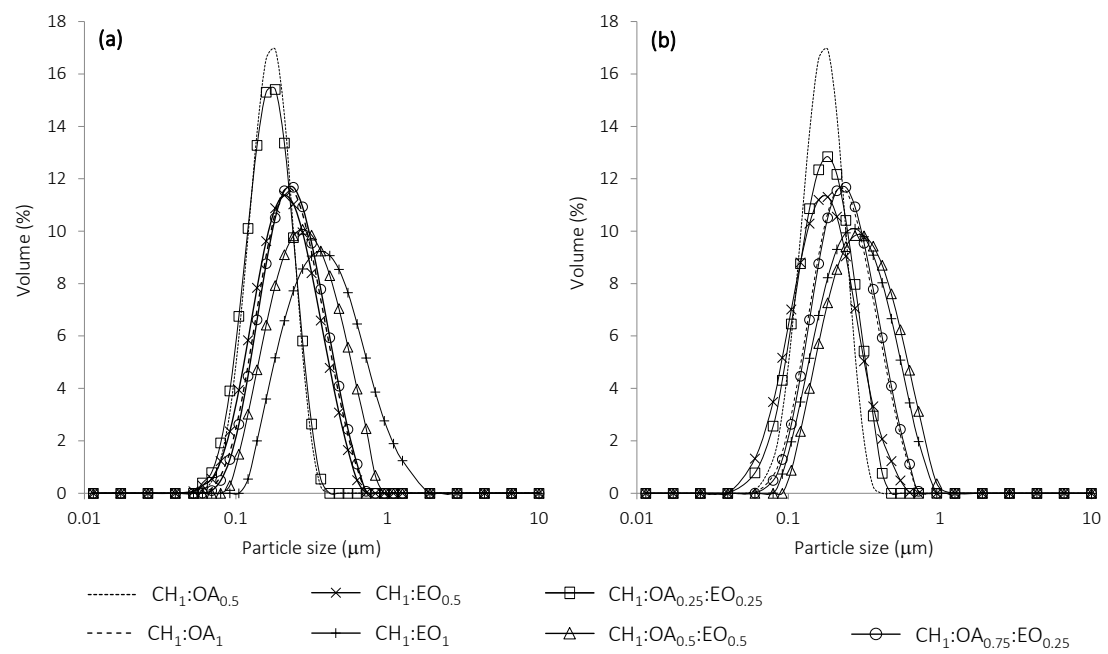

Figure 3.1.1 Particle size distribution of the film-forming dispersion containing (a) basil essential oil and (b) thyme essential oil analysed at $25^{\circ} \mathrm{C}$. $\mathrm{CH}$ : chitosan, EO: essential oil. Subscripts indicate the ratio of film components.

In general, the increase of the OA ratio in the FFD implied greater values of the $\zeta$-potential, which suggests that this compound favours the $\mathrm{CH}$ adsorption at the droplet interface, thus contributing to the emulsion stabilization. The amphiphilic nature of oleic acid led us to hypothesize that the EO droplets would be surrounded by oleic acid molecules, which, in turn, would interact with $\mathrm{CH}$ molecules through the formation of bonds between the carboxyl groups of the $\mathrm{OA}$ and the polar groups of $\mathrm{CH}$. These interfacial effects favour the emulsion formation (low droplet size) and stability through the high values of $\zeta$-potential (electrostatic stabilization) and the adsorption of the polymer (steric stabilization) (McClements, 2005). The higher values of $\zeta$-potential of pure BO droplets suggest a greater surface adsorption of chitosan in these oil spheres, which could also contribute to the observed slightly higher values of the droplet 
size. In the same way, it is also remarkable that $\zeta$-potential values for a same oil composition decreased when the TLC arise from 0.5 to $1 \%$. This can be explained by the high increase in the total surface area of the interface and the limited amount of chitosan, which would cause a lesser surface density of chitosan on the droplet surfaces.

As concerns the viscous stabilization of the film-forming emulsions, pure $\mathrm{CH}$ at $1 \%$ showed shear thinning behaviour with a high viscosity (Table 3.1.2), which would reduce the flocculation and creaming rates of oil droplets during film formation. Figure 3.1.2 shows the flow curves for all samples where a shear-thinning behaviour can be observed for all film-forming emulsions. Non-time dependent flow behaviour was detected in any case from the comparison of the up and down curves. The observed rheological behaviour was the result of two contributions: the remaining concentration of chitosan in the aqueous phase and the concentration of the lipid dispersed phase. However, a decrease in the shear stress values of chitosan solution when lipids were added was observed, except for sample containing pure $\mathrm{OA}$ at $1 \%$. This also points out that a part of the chitosan molecules were adsorbed at the droplet surface, thus decreasing chitosan effective concentration at the continuous phase with the subsequent reduction of its thickening effect, but enhancing steric stabilization of the emulsions.
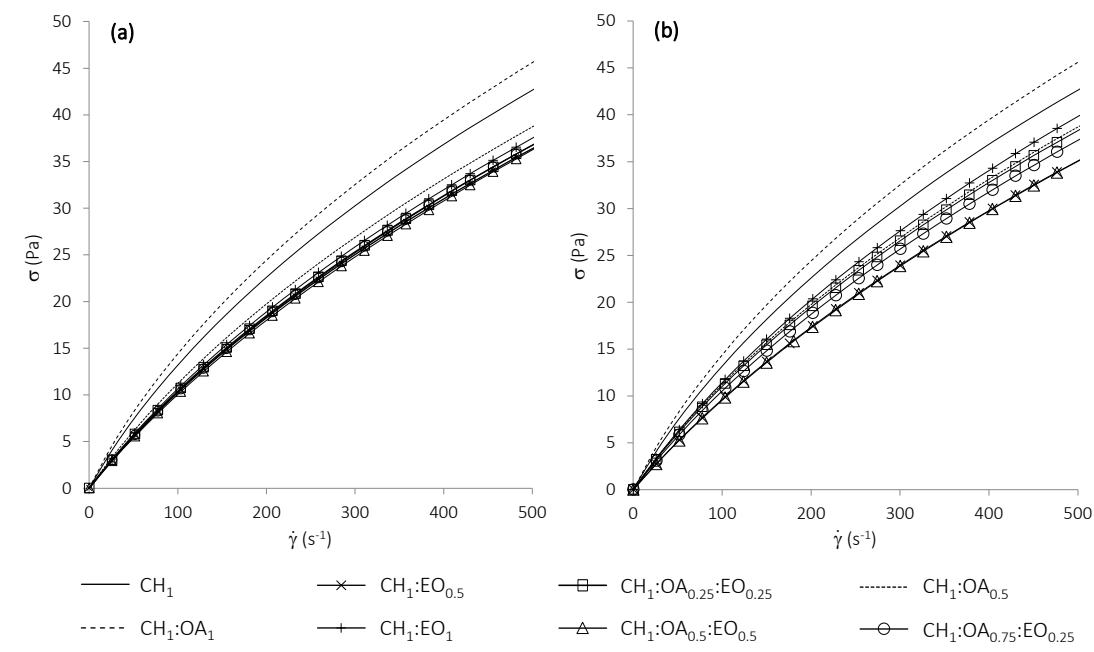

Figure 3.1.2 Typical flow curves of the film-forming dispersion containing (a) basil essential oil and (b) thyme essential oil analysed at $25^{\circ} \mathrm{C}$. CH: chitosan, OA: oleic acid, EO: essential oil. Subscripts indicate the ratio of film components. 
Table 3.1.2 Particle size, $\zeta$-potential and rheological properties of the film-forming dispersions (FFD). Mean values and (standard deviations).

\begin{tabular}{|c|c|c|c|c|c|c|}
\hline \multirow{2}{*}{ FFD } & \multicolumn{2}{|c|}{ Particle Size $(\mu \mathrm{m})$} & \multirow{2}{*}{$\begin{array}{c}\text { ל-Potential } \\
(\mathrm{mV})\end{array}$} & \multirow{2}{*}{$\mathrm{n}$} & \multirow{2}{*}{$\begin{array}{c}\mathrm{K} \\
(\mathrm{Pa} \cdot \mathrm{s})\end{array}$} & \multirow{2}{*}{$\begin{array}{c}\eta_{\text {ap at } 100 \mathrm{~s}^{-1}} \\
(\mathrm{~Pa} \cdot \mathrm{s})\end{array}$} \\
\hline & $D[4,3]$ & $D[3,2]$ & & & & \\
\hline $\mathrm{CH}_{1}$ & - & - & $*$ & $0.7219(0.0015) \mathrm{b}$ & $0.4918(0.0006) j$ & $0.1047(0.0004) j$ \\
\hline $\mathrm{CH}_{1}: \mathrm{BO}_{0.5}$ & $0.21900(0.00105)^{c}$ & $0.176(0.004)^{f}$ & $70.3(1.8)^{\mathrm{e}}$ & $0.7786(0.0003)^{\mathrm{e}}$ & $0.2925(0.0009)^{\mathrm{e}}$ & $0.08556(0.00008)^{d}$ \\
\hline $\mathrm{CH}_{1}: \mathrm{TO}_{0.5}$ & $0.17720(0.00103)^{b}$ & $0.1425(0.0005)^{b}$ & $65(4)^{c}$ & $0.792(0.003)^{h}$ & $0.257(0.004)^{b}$ & $0.0830(0.0019)^{b}$ \\
\hline $\mathrm{CH}_{1}: \mathrm{OA}_{0.25}: \mathrm{BO}_{0.25}$ & $0.16300(0.00105)^{a}$ & $0.146(0.002)^{c}$ & $71.0(1.5)^{\mathrm{e}}$ & $0.774(0.002)^{d}$ & $0.303(0.003)^{f}$ & $0.0865(0.0005)^{\mathrm{e}}$ \\
\hline $\mathrm{CH}_{1}: \mathrm{OA}_{0.25}: \mathrm{TO}_{0.25}$ & $0.17490(0.00099)^{b}$ & $0.1483(0.0007)^{d}$ & $71.9(1.7)^{\mathrm{e}}$ & $0.7664(0.0005)^{c}$ & $0.3321(0.0013)^{h}$ & $0.090926(0.000105)^{\mathrm{g}}$ \\
\hline $\mathrm{CH}_{1}: \mathrm{OA}_{0.5}$ & $0.161643(0.001008)^{a}$ & $0.109(0.000)^{a}$ & $80(4)^{g}$ & $0.7080(0.0006)^{a}$ & $0.3006(0.0019)^{f}$ & $0.09107(0.00102)^{h}$ \\
\hline $\mathrm{CH}_{1}: \mathrm{BO}_{1}$ & $0.4088(0.0015)^{j}$ & $0.305(0.002)^{\prime}$ & $60(2)^{b}$ & $0.7748(0.0006)^{d}$ & $0.30844(0.00105)^{\mathrm{g}}$ & $0.08849(0.00004)^{f}$ \\
\hline $\mathrm{CH}_{1}: \mathrm{TO}_{1}$ & $0.2858(0.0008)^{g}$ & $0.2272(0.0004)^{i}$ & $53(3)^{\mathrm{a}}$ & $0.7685(0.0012)^{c}$ & $0.343027(0.001009)^{i}$ & $0.0950(0.0005)^{i}$ \\
\hline $\mathrm{CH}_{1}: \mathrm{OA}_{0.5}: \mathrm{BO}_{0.5}$ & $0.2973(0.0008)^{h}$ & $0.23587(0.00106)^{j}$ & $60.2(1.3)^{b}$ & $0.788848(0.001095)^{g}$ & $0.274(0.002)^{c}$ & $0.08482(0.00017)^{c}$ \\
\hline $\mathrm{CH}_{1}: \mathrm{OA}_{0.5}: \mathrm{TO}_{0.5}$ & $0.3205(0.0008)^{i}$ & $0.2525(0.0013)^{\mathrm{k}}$ & $53.3(0.8)^{\mathrm{a}}$ & $0.8004(0.0006)^{i}$ & $0.2466(0.0003)^{\mathrm{a}}$ & $0.08149(0.00017)^{\mathrm{a}}$ \\
\hline $\mathrm{CH}_{1}: \mathrm{OA}_{0.75}: \mathrm{BO}_{0.25}$ & $0.2405(0.0005)^{e}$ & $0.19800(0.00105)^{g}$ & $65.2(0.8)^{c d}$ & $0.7840(0.00018)^{a}$ & $0.286(0.005)^{d}$ & $0.0862(0.0007)^{d}$ \\
\hline $\mathrm{CH}_{1}: \mathrm{OA}_{0.75}: \mathrm{TO}_{0.25}$ & $0.2515(0.0016)^{f}$ & $0.2005(0.0005)^{h}$ & $57.8(0.8)^{\mathrm{b}}$ & $0.7889(0.0008)^{g}$ & $0.2734(0.0004)^{c}$ & $0.0848(0.0002)^{c}$ \\
\hline $\mathrm{CH}_{1}: \mathrm{OA}_{1}$ & $0.2343(0.0005)^{d}$ & $0.1629(0.0003)^{\mathrm{e}}$ & $75.1(1.4)^{f}$ & $0.7835(0.0007)^{f}$ & $0.567(0.004)^{k}$ & $0.1123(0.0004)^{k}$ \\
\hline
\end{tabular}

$* \zeta$-potential $\mathrm{CH}_{\text {Lipid }=0.5 \%}=68(4)^{\mathrm{d}} \mathrm{CH}_{\text {Lipid }=1 \%}=63(4)^{\mathrm{c}}$.

$a, b, c, d, e, f, g, h, i, j, k, I$ Different superscripts in the same column indicate $95 \%$ significant differences among FFD. CH: chitosan, OA: oleic acid, BO: basil essential oil, TO: thyme essential oil. Subscripts indicate the ratio of film components. 
Rheological data was fitted to the Ostwald de Waele model and the model parameters $(n, K)$ are shown in Table 3.1.2, together with the apparent viscosity values $\left(\eta_{a p}\right)$ at a shear rate of $100 \mathrm{~s}^{-1}$. Rheological parameters of $\mathrm{CH}$ dispersions were significantly affected by the incorporation of the lipid phase in line with the previously commented effect on the stress values. These changes depended on the kind of lipid and concentration. Apparent viscosity values increased when OA was present in the emulsions at $0.5 \%$ TLC which could be due to the increase in $\zeta$-potential and the subsequent promotion of the electroviscous effects. At $1 \%$ TLC, with lower $\zeta$-potential values, this was not observed, except for the OA emulsions which showed the greatest $\zeta$-potential and viscosity values, exceeding those of pure $\mathrm{CH}$ solution.

According to the obtained results, EO emulsions with OA and lower TLC were the more stable systems which could affect EO retention in the dried films.

\subsection{Characterization of the films}

\subsubsection{Physicochemical properties of the films}

Table 3.1.3 shows the values of the average thickness of the films, together with their WVP and mechanical parameters. The EO losses, in percentage with respect to the added amount, were also included. The $\mathrm{CH}-\mathrm{OA}$ films became significantly thicker $(p<0.05)$ as the OA content increased, which is in accordance with their higher surface solid density in the casting plate. However, in $\mathrm{CH}-\mathrm{BO}$ and $\mathrm{CH}-\mathrm{TO}$ films, this was not observed in line with the losses of volatile compounds during film drying. For the same TLC, $\mathrm{CH}-\mathrm{BO}-\mathrm{AO}$ and $\mathrm{CH}-\mathrm{TO}-\mathrm{AO}$ films were significantly $(\mathrm{p}<0.05)$ thicker than $\mathrm{CH}-\mathrm{BO}$ and $\mathrm{CH}-\mathrm{TO}$ films, which suggests lower losses of volatiles. These values are coherent with the losses quantified gravimetrically that are shown in Table 3.1.3. For films with OA, the EO losses were about $30 \%$ when equivalent amounts of $O A$ and $E O$ were used and decreased to about $25 \%$ when OA:EO ratio was 3:1. In contrast, losses of EO in formulations without OA were about $40 \%$. 
Table 3.1.3 Thickness, essential oil loss, water vapour permeability (WVP) and elastic modulus (EM), elongation (E) and tensile strength (TS) at break of the films. Mean values and (standard deviation).

\begin{tabular}{|c|c|c|c|c|c|c|}
\hline Film & $\begin{array}{c}\text { Thickness } \\
(\mu \mathrm{m})\end{array}$ & $\begin{array}{c}\text { EO loss } \\
\text { wt. } \% \\
\end{array}$ & $\begin{array}{c}\text { WVP } \times 10^{11} \\
\left(\mathrm{~g} \cdot \mathrm{m}^{-1} \cdot \mathrm{s}^{-1} \cdot \mathrm{Pa}^{-1}\right)\end{array}$ & $\begin{array}{c}\mathrm{EM} \\
(\mathrm{MPa}) \\
\end{array}$ & $\begin{array}{c}\mathrm{TS} \\
(\mathrm{MPa}) \\
\end{array}$ & $\begin{array}{c}E \\
(\%) \\
\end{array}$ \\
\hline $\mathrm{CH}_{1}$ & $42.2(1.5)^{a}$ & - & $274(87)^{\mathrm{e}}$ & $\begin{array}{l}1375 \\
(49)^{d}\end{array}$ & $45(5)^{c}$ & $21(4)^{g}$ \\
\hline $\mathrm{CH}_{1}: \mathrm{BO}_{0.5}$ & $45(4)^{a b}$ & $\begin{array}{c}38.5 \\
(0.4)^{\mathrm{g}}\end{array}$ & $234(60)^{\text {de }}$ & $\begin{array}{l}1833 \\
(96)^{f}\end{array}$ & $51(4)^{d}$ & $\begin{array}{c}5.7 \\
(1.9)^{\mathrm{a}}\end{array}$ \\
\hline $\mathrm{CH}_{1}: \mathrm{TO}_{0.5}$ & $48.0(1.9)^{\mathrm{cd}}$ & $\begin{array}{c}41.5 \\
(0.2)^{\mathrm{h}}\end{array}$ & $224(43)^{c d}$ & $\begin{array}{l}1843 \\
(53)^{\mathrm{fg}}\end{array}$ & $52(3)^{d}$ & $6(4)^{\mathrm{ab}}$ \\
\hline $\mathrm{CH}_{1}: \mathrm{OA}_{0.25}: \mathrm{BO}_{0.25}$ & $49(3)^{c d}$ & $\begin{array}{c}28.3 \\
(0.7)^{c}\end{array}$ & $175(50)^{\mathrm{ab}}$ & $\begin{array}{l}1542 \\
(56)^{\mathrm{e}}\end{array}$ & $45(3)^{c}$ & $9(3)^{\mathrm{bcd}}$ \\
\hline $\mathrm{CH}_{1}: \mathrm{OA}_{0.25}: \mathrm{TO}_{0.25}$ & $54(2)^{e}$ & $\begin{array}{c}30.4 \\
(0.8)^{d}\end{array}$ & $184(30)^{\mathrm{abc}}$ & $\begin{array}{l}1494 \\
(44)^{\mathrm{e}}\end{array}$ & $\begin{array}{c}43.3 \\
(1.9)^{c}\end{array}$ & $\begin{array}{c}7.1 \\
(0.3)^{\mathrm{abc}}\end{array}$ \\
\hline $\mathrm{CH}_{1}: \mathrm{OA}_{0.5}$ & $60(4)^{f}$ & - & $213(37)^{\mathrm{bcd}}$ & $\begin{array}{l}1324 \\
(61)^{c}\end{array}$ & $42(2)^{c}$ & $10(2)^{\mathrm{cd}}$ \\
\hline $\mathrm{CH}_{1}: \mathrm{BO}_{1}$ & $46(3)^{b c}$ & $\begin{array}{l}52.2 \\
(0.2)^{i}\end{array}$ & $236(70)^{\text {de }}$ & $\begin{array}{l}1895 \\
(61)^{\mathrm{g}}\end{array}$ & $\begin{array}{c}52.5 \\
(1.8)^{d}\end{array}$ & $\begin{array}{c}5.4 \\
(1.6)^{\mathrm{ab}}\end{array}$ \\
\hline $\mathrm{CH}_{1}: \mathrm{TO}_{1}$ & $50(2)^{d}$ & $\begin{array}{l}53.1 \\
(0.2)^{i}\end{array}$ & $212(52)^{\mathrm{bcd}}$ & $\begin{array}{l}1816 \\
(31)^{f}\end{array}$ & $\begin{array}{c}51.75 \\
(1.04)^{d}\end{array}$ & $\begin{array}{c}6.3 \\
(1.5)^{\mathrm{abc}}\end{array}$ \\
\hline $\mathrm{CH}_{1}: \mathrm{OA}_{0.5}: \mathrm{BO}_{0.5}$ & $67(6)^{g h}$ & $\begin{array}{c}32.3 \\
(0.5)^{\mathrm{e}}\end{array}$ & $165(29)^{a}$ & $\begin{array}{l}1111 \\
(52)^{b}\end{array}$ & $37(2)^{b}$ & $13(3)^{e f}$ \\
\hline $\mathrm{CH}_{1}: \mathrm{OA}_{0.5}: \mathrm{TO}_{0.5}$ & $64(3)^{\mathrm{g}}$ & $\begin{array}{c}34.2 \\
(0.9)^{f}\end{array}$ & $189(24)^{\mathrm{abc}}$ & $\begin{array}{l}1154 \\
(24)^{b}\end{array}$ & $39(5)^{b}$ & $16(5)^{f}$ \\
\hline $\mathrm{CH}_{1}: \mathrm{OA}_{0.75}: \mathrm{BO}_{0.25}$ & $67(4)^{g h}$ & $\begin{array}{c}24.4 \\
(0.4)^{a}\end{array}$ & $163(25)^{\mathrm{a}}$ & $\begin{array}{l}1049 \\
(44)^{a}\end{array}$ & $33(3)^{a}$ & $9(3)^{\mathrm{abcd}}$ \\
\hline $\mathrm{CH}_{1}: \mathrm{OA}_{0.75}: \mathrm{TO}_{0.25}$ & $70(7)^{\mathrm{hi}}$ & $\begin{array}{c}26.5 \\
(0.3)^{b}\end{array}$ & $153(40)^{\mathrm{a}}$ & $\begin{array}{c}972 \\
(26)^{e}\end{array}$ & $30(4)^{a}$ & $8(4)^{\mathrm{abcd}}$ \\
\hline $\mathrm{CH}_{1}: \mathrm{OA}_{1}$ & $72(3)^{i}$ & - & $171(29)^{a}$ & $\begin{array}{c}971 \\
(27)^{\mathrm{e}}\end{array}$ & $33(4)^{a}$ & $11(5)^{\text {de }}$ \\
\hline
\end{tabular}

$a, b, c, d, e, f, g, h, i, j, k, I$ Different superscripts in the same column indicate $95 \%$ significant differences among films. $\mathrm{CH}$ : chitosan, OA: oleic acid, BO: basil essential oil, TO: thyme essential oil. Subscripts indicate the ratio of film components.

These results indicate a better encapsulation of the essential oil in the polymer matrix resulting from the addition of $\mathrm{OA}$ by the subsequent promotion of the emulsion stability. In fact, good correlation coefficients were obtained for the EO losses and the stability parameters of the FFD as shown in Table 3.1.4. The obtained coefficients indicate that the EO losses increased when the droplet particle size rose and when $\zeta$-potential decreased according to the lower stability of the emulsions. Likewise, the EO losses increased when the apparent viscosity values rose. This seems an 
apparent contradiction with the stabilizing viscous effect, but in this case, the decrease in viscosity was associated with greater adsorption of chitosan at the interface, which promotes steric stabilization of the emulsion. Thus, the enhancement of the emulsion stability, by decreasing droplet size or by the interfacial adsorption of amphiphilic molecules, is a good strategy to increase the EO retention in the final film.

Table 3.1.4 Pearson product moment correlations between each pair of variables $(D[4,3], \zeta$-potential, apparent viscosity and essential oil losses).

\begin{tabular}{lcccc}
\hline & $\begin{array}{c}D[4,3] \\
(\mu \mathrm{m})\end{array}$ & $\begin{array}{c}\zeta \text {-potential } \\
(\mathrm{mV})\end{array}$ & $\begin{array}{c}\eta_{100} \\
(\mathrm{~Pa} \cdot \mathrm{s})\end{array}$ & $\begin{array}{c}\text { EO loss } \\
(\%)\end{array}$ \\
\hline$D[4,3](\mu \mathrm{m})$ & 1 & & & \\
$\zeta$-potential $(\mathrm{mV})$ & $-0.67^{* *}$ & 1 & & \\
$\eta_{100}(\mathrm{~Pa} \cdot \mathrm{s})$ & -0.05 & 0.01 & 1 & \\
EO loss $(\%)$ & $0.45^{* *}$ & $-0.40^{*}$ & $0.44^{*}$ & 1 \\
\hline
\end{tabular}

"Superscript indicates statistically significant non-zero correlations at the $95 \%$ confidence level. *** Superscript indicates statistically significant non-zero correlations at the $99 \%$ confidence level.

As expected, the incorporation of the oil phase in the $\mathrm{CH}$ matrices led to an improvement in their water barrier properties (Table 3.1.4). OA was more effective than EO at reducing WVP values for a determined TLC. So, EO-OA blends reduced WVP to a greater extent than pure EO. This can be explained by the higher lipid retention and better dispersion in the film, which contributes to increase the tortuosity factor for transport of water molecules through the film. The WVP significantly decreased as the OA content increased in chitosan films, as shown in previous studies (Vargas, Albors, Chiralt and González-Martínez, 2009; Vargas, Perdones, Chiralt, Cháfer and González-Martínez and, 2011).

The typical curves for film mechanical behaviour are shown in Figure 3.1.3. Lipids reduced the film stretchability in all cases and promoted changes in the film strength depending on the composition and ratio. Pure EO promoted film stiffness and brittleness whereas pure OA mainly decrease the film extensibility. This indicates that lipid molecules also interact to certain extent with $\mathrm{CH}$, thus modifying the chain aggregation pattern in the matrix, additionally to the introduction of discontinuities (lipid droplets) which also affect mechanical response of the films. Table 3.1.3 shows the 
values of mechanical parameters where the effect of lipid addition can be observed. $\mathrm{CH}-\mathrm{BO}$ and $\mathrm{CH}-\mathrm{TO}$ films showed higher elasticity modulus and tensile strength at break than $\mathrm{CH}$ or $\mathrm{CH}-\mathrm{OA}$ films $(\mathrm{p}<0.05)$. OA addition to $\mathrm{CH}-\mathrm{BO}$ and $\mathrm{CH}-\mathrm{TO}$ films led to a significant decrease in the stiffness $(p<0.05)$ and to an increase in the stretchability of the films.
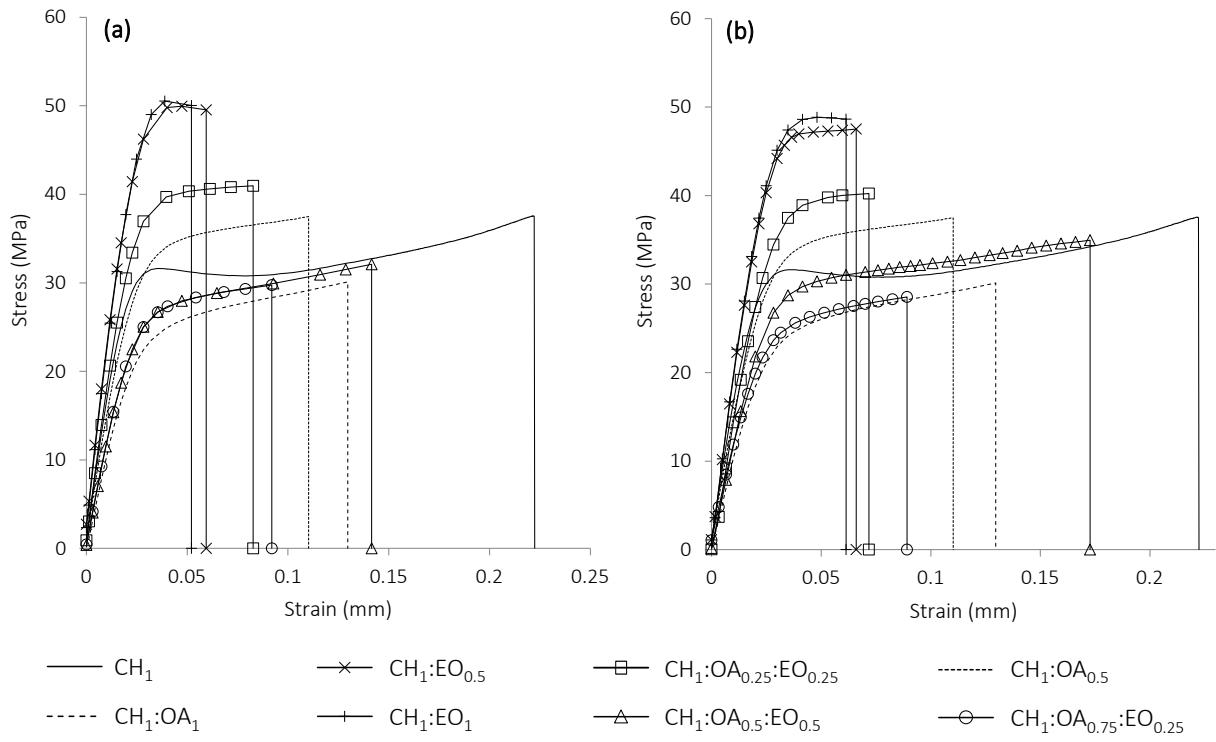

Figure 3.1.3 Typical Stress vs. strain curves of the films containing (a) basil essential oil and (b) thyme essential oil. CH: chitosan, OA: oleic acid, EO: essential oil. Subscripts indicate the ratio of film components.

The internal transmittance spectra of the films are plotted in Figure 3.1.4. The shape of the spectra was not affected by the TLC. The addition of OA led to a decrease in the internal transmittance of the films. According to the shape of internal transmittance spectra, Ti values at $450 \mathrm{~nm}$ are shown in Table 3.1.4. Lipid addition significantly decreased $(p<0.05)$ the $T i$ of the films, in concordance with the OA content; the higher the $\mathrm{OA}$ concentration, the lower the Ti values. Likewise, the addition of the lipid phase also provoked a significant decrease in gloss for every formulation, except $\mathrm{CH}_{0.5}: \mathrm{TO}_{0.5}$, whose value remained the same as $\mathrm{CH}_{1}$ (Table 3.1.4). OA led to a significant reduction in gloss when it was incorporated with TO. 
(a)

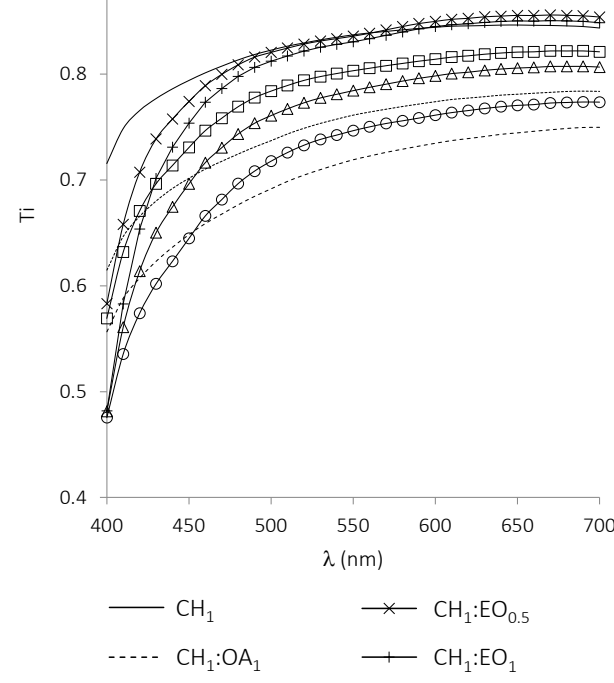

(b)

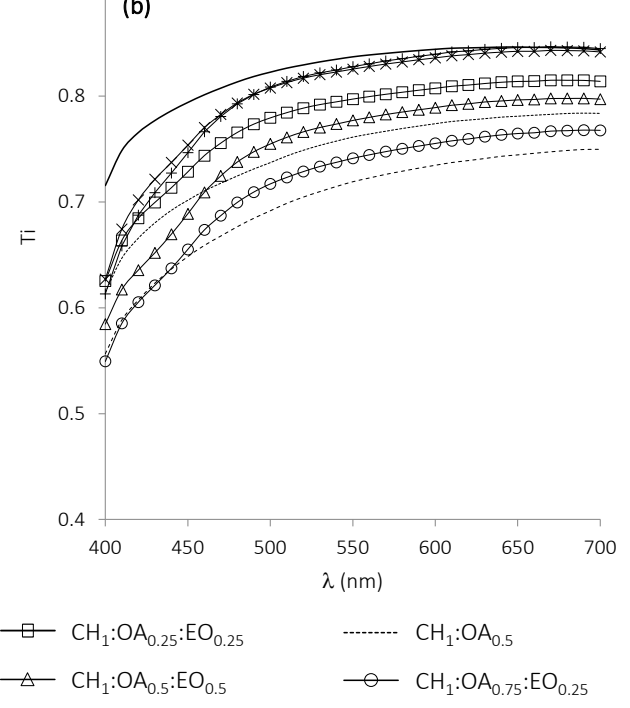

Figure 3.1.4 Spectral distribution on internal transmittance (Ti) of the films containing (a) basil essential oil and (b) thyme essential oil. CH: chitosan, OA: oleic acid, EO: essential oil. Subscripts indicate the ratio of film components.

Colour parameters of the films: lightness $\left(L^{*}\right)$, hue $\left(h^{*}{ }_{a b}\right)$ and chroma $\left(C^{*}{ }_{a b}\right)$, the whiteness index (WI) and the total colour difference as compared to a pure $\mathrm{CH}$ film $(\triangle \mathrm{E})$ are shown in Table 3.1.5. $\mathrm{CH}_{1}$ : $\mathrm{OA}_{1}$ films showed higher $\mathrm{L}^{*}$ and $\mathrm{WI}$ than pure $\mathrm{CH}$ films $(\mathrm{p}<0.05)$. The incorporation of increasing amounts of BO or TO led to a significant reduction $(p<0.05)$ in the $\mathrm{WI}$ and $L^{*}$ values of $\mathrm{CH}$ films. These changes in $\mathrm{WI}$ were significantly reduced $(p<0.05)$ by the addition of OA. The incorporation of BO or TO into the $\mathrm{CH}$ matrix yielded films with lower hue $(p<0.05)$ and a more saturated colour (higher chroma). Regardless of the total lipid content, the addition of $\mathrm{OA}$ reduced the described changes in colour parameters and the total colour difference with respect to pure $\mathrm{CH}$ films $(p<0.05)$. 
Table 3.1.5 Gloss values at $60^{\circ}$, internal transmittance $(T i)$ at $450 \mathrm{~nm}$, lightness $\left(\mathrm{L}^{*}\right)$, chroma $\left(\mathrm{C}^{*}{ }_{\mathrm{ab}}\right)$ and hue $\left(\mathrm{h}^{*}{ }_{\mathrm{ab}}\right)$, the whiteness index $(\mathrm{WI})$ and the total colour difference $(\triangle \mathrm{E})$ as regards $\mathrm{CH}$ films. Mean values and (standard deviations).

\begin{tabular}{|c|c|c|c|c|c|c|c|}
\hline Film & Gloss & $T_{i}$ & $L^{*} a b$ & $\mathrm{~h}^{*}{ }_{\mathrm{ab}}$ & $\mathrm{C}_{\mathrm{ab}}^{*}$ & WI & $\Delta \mathrm{E}$ \\
\hline $\mathrm{CH}_{1}$ & $\begin{array}{l}67 \\
(3)^{\mathrm{e}}\end{array}$ & $\begin{array}{c}0.782 \\
(0.005)^{f}\end{array}$ & $\begin{array}{l}79.8 \\
(0.6)^{\mathrm{e}}\end{array}$ & $\begin{array}{c}90.7 \\
(0.4)^{\mathrm{fg}}\end{array}$ & $\begin{array}{c}19.1 \\
(0.2)^{b}\end{array}$ & $\begin{array}{c}72.24 \\
(0.19)^{\mathrm{g}}\end{array}$ & - \\
\hline $\mathrm{CH}_{1}: \mathrm{BO}_{0.5}$ & $\begin{array}{c}63 \\
(12)^{\text {de }}\end{array}$ & $\begin{array}{c}0.774 \\
(0.009)^{f}\end{array}$ & $\begin{array}{c}77.6 \\
(0.8)^{c d}\end{array}$ & $\begin{array}{l}83.3 \\
(0.9)^{a}\end{array}$ & $\begin{array}{l}21.5 \\
(0.3)^{d}\end{array}$ & $\begin{array}{c}69.1 \\
(0.8)^{\text {cde }}\end{array}$ & $\begin{array}{c}4.2 \\
(0.7)^{d}\end{array}$ \\
\hline $\mathrm{CH}_{1}: \mathrm{TO}_{0.5}$ & $\begin{array}{l}66 \\
(8)^{\mathrm{e}}\end{array}$ & $\begin{array}{c}0.754 \\
(0.016)^{\mathrm{e}}\end{array}$ & $\begin{array}{c}78.15 \\
(0.98)^{c d}\end{array}$ & $\begin{array}{l}90.16 \\
(1.04)^{\mathrm{ef}}\end{array}$ & $\begin{array}{c}22.1 \\
(1.4)^{\mathrm{de}}\end{array}$ & $\begin{array}{c}68.9 \\
(1.5)^{c d}\end{array}$ & $\begin{array}{c}4.2 \\
(0.9)^{d}\end{array}$ \\
\hline $\mathrm{CH}_{1}: \mathrm{OA}_{0.25}: \mathrm{BO}_{0.25}$ & $\begin{array}{c}44 \\
(16)^{c}\end{array}$ & $\begin{array}{c}0.7306 \\
(0.0113)^{d}\end{array}$ & $\begin{array}{l}79.4 \\
(0.4)^{\mathrm{e}}\end{array}$ & $\begin{array}{l}91.5 \\
(0.4)^{\mathrm{h}}\end{array}$ & $\begin{array}{l}20.3 \\
(0.7)^{c}\end{array}$ & $\begin{array}{l}71.1 \\
(0.7)^{\dagger}\end{array}$ & $\begin{array}{c}1.4 \\
(0.7)^{\mathrm{a}}\end{array}$ \\
\hline $\mathrm{CH}_{1}: \mathrm{OA}_{0.25}: \mathrm{TO}_{0.25}$ & $\begin{array}{c}44 \\
(18)^{c}\end{array}$ & $\begin{array}{c}0.728 \\
(0.005)^{d}\end{array}$ & $\begin{array}{l}75.5 \\
(0.5)^{\mathrm{a}}\end{array}$ & $\begin{array}{l}93.6 \\
(0.9)^{i}\end{array}$ & $\begin{array}{l}17.5 \\
(0.6)^{\mathrm{a}}\end{array}$ & $\begin{array}{l}69.9 \\
(0.5)^{\mathrm{e}}\end{array}$ & $\begin{array}{c}4.7 \\
(0.4)^{d}\end{array}$ \\
\hline $\mathrm{CH}_{1}: \mathrm{OA}_{0.5}$ & $\begin{array}{c}56 \\
(7)^{\text {cde }}\end{array}$ & $\begin{array}{c}0.688 \\
(0.014)^{c}\end{array}$ & $\begin{array}{l}78.42 \\
(1.02)^{d}\end{array}$ & $\begin{array}{c}91.3 \\
(0.5)^{\mathrm{gh}}\end{array}$ & $\begin{array}{l}17.0 \\
(0.3)^{\mathrm{a}}\end{array}$ & $\begin{array}{c}72.52 \\
(0.98)^{\mathrm{g}}\end{array}$ & $\begin{array}{c}2.5 \\
(0.2)^{b c}\end{array}$ \\
\hline $\mathrm{CH}_{1}: \mathrm{BO}_{1}$ & $\begin{array}{c}54 \\
(15)^{c d}\end{array}$ & $\begin{array}{c}0.754 \\
(0.009)^{\mathrm{e}}\end{array}$ & $\begin{array}{c}77.30 \\
(1.13)^{\mathrm{bc}}\end{array}$ & $\begin{array}{l}85.5 \\
(0.8)^{\mathrm{b}}\end{array}$ & $\begin{array}{l}24.4 \\
(0.6)^{g}\end{array}$ & $\begin{array}{c}66.68 \\
(1.17)^{b}\end{array}$ & $\begin{array}{c}6.27 \\
(1.04)^{\mathrm{e}}\end{array}$ \\
\hline $\mathrm{CH}_{1}: \mathrm{TO}_{1}$ & $\begin{array}{l}60 \\
(8)^{\text {de }}\end{array}$ & $\begin{array}{c}0.746 \\
(0.009)^{\mathrm{e}}\end{array}$ & $\begin{array}{l}76.6 \\
(0.5)^{b}\end{array}$ & $\begin{array}{l}87.9 \\
(0.4)^{c}\end{array}$ & $\begin{array}{l}24.9 \\
(0.4)^{g}\end{array}$ & $\begin{array}{l}65.8 \\
(0.6)^{a}\end{array}$ & $\begin{array}{c}6.8 \\
(0.5)^{\mathrm{e}}\end{array}$ \\
\hline $\mathrm{CH}_{1}: \mathrm{OA}_{0.5}: \mathrm{BO}_{0.5}$ & $\begin{array}{c}45 \\
(22)^{c}\end{array}$ & $\begin{array}{c}0.70 \\
(0.02)^{c}\end{array}$ & $\begin{array}{c}79.51 \\
(1.03)^{\mathrm{e}}\end{array}$ & $\begin{array}{l}89.4 \\
(1.2)^{\mathrm{d}}\end{array}$ & $\begin{array}{l}23.0 \\
(0.8)^{f}\end{array}$ & $\begin{array}{c}69.4 \\
(1.5)^{\mathrm{de}}\end{array}$ & $\begin{array}{c}4.1 \\
(0.8)^{d}\end{array}$ \\
\hline $\mathrm{CH}_{1}: \mathrm{OA}_{0.5}: \mathrm{TO}_{0.5}$ & $\begin{array}{c}30 \\
(13)^{\mathrm{ab}}\end{array}$ & $\begin{array}{c}0.689 \\
(0.015)^{c}\end{array}$ & $\begin{array}{l}75.6 \\
(1.6)^{\mathrm{a}}\end{array}$ & $\begin{array}{l}93.6 \\
(0.9)^{i}\end{array}$ & $\begin{array}{l}20.5 \\
(1.3)^{c}\end{array}$ & $\begin{array}{c}68.4 \\
(1.4)^{c}\end{array}$ & $\begin{array}{c}4.375 \\
(1.109)^{\mathrm{d}}\end{array}$ \\
\hline $\mathrm{CH}_{1}: \mathrm{OA}_{0.75}: \mathrm{BO}_{0.25}$ & $\begin{array}{l}25 \\
(8)^{a}\end{array}$ & $\begin{array}{c}0.64 \\
(0.02)^{\mathrm{a}}\end{array}$ & $\begin{array}{c}79.4 \\
(1.2)^{\mathrm{e}}\end{array}$ & $\begin{array}{l}93.2 \\
(1.2)^{i}\end{array}$ & $\begin{array}{l}22.5 \\
(1.6)^{\text {ef }}\end{array}$ & $\begin{array}{l}69.50 \\
(1.15)^{\text {de }}\end{array}$ & $\begin{array}{c}3.0 \\
(0.6)^{\mathrm{bc}}\end{array}$ \\
\hline $\mathrm{CH}_{1}: \mathrm{OA}_{0.75}: \mathrm{TO}_{0.25}$ & $\begin{array}{c}28 \\
(15)^{\mathrm{a}}\end{array}$ & $\begin{array}{c}0.67 \\
(0.02)^{b}\end{array}$ & $\begin{array}{c}77.42 \\
(1.02)^{\mathrm{bc}}\end{array}$ & $\begin{array}{l}93.4 \\
(0.6)^{\mathrm{i}}\end{array}$ & $\begin{array}{l}17.9 \\
(0.5)^{\mathrm{a}}\end{array}$ & $\begin{array}{l}71.15 \\
(1.19)^{f}\end{array}$ & $\begin{array}{c}3.1 \\
(0.6)^{c}\end{array}$ \\
\hline $\mathrm{CH}_{1}: \mathrm{OA}_{1}$ & $\begin{array}{c}43 \\
(5)^{b c}\end{array}$ & $\begin{array}{c}0.65 \\
(0.02)^{a}\end{array}$ & $\begin{array}{l}82.0 \\
(0.8)^{f}\end{array}$ & $\begin{array}{c}89.6 \\
(0.6)^{\text {de }}\end{array}$ & $\begin{array}{l}19.0 \\
(0.5)^{b}\end{array}$ & $\begin{array}{l}73.9 \\
(0.9)^{\mathrm{e}}\end{array}$ & $\begin{array}{c}2.3 \\
(0.7)^{\mathrm{b}}\end{array}$ \\
\hline
\end{tabular}

$a, b, c, d, e, f, g, h, i, j, k, l$ Different superscripts in the same column indicate $95 \%$ significant differences among films. $\mathrm{CH}$ : chitosan, OA: oleic acid, BO: basil essential oil, TO: thyme essential oil. Subscripts indicate the ratio of film components. 


\subsubsection{Antimicrobial properties of the films}

The results of the growth inhibition halo by contact or at the head space of the inoculated agar plates gave rise to no detected effects on the development of fungi (Aspergillus niger, Botrytis cinerea and Rhizopus stolonifer) since no inhibition occured, as shown in Figure 3.1.5 for Aspergillus niger at 7 incubation days, where the amount of encapsulated EO in the disk film is indicated for each formulation. This result could be explained by the lack of antifungal activity of the tested oils against the fungi considered or by the good encapsulation of the remaining essential oils in the film matrix and their limited release in the agar plate. Further studies are required to analyse the antifungal activity of the free oils and their release kinetics to the media from the film matrix.

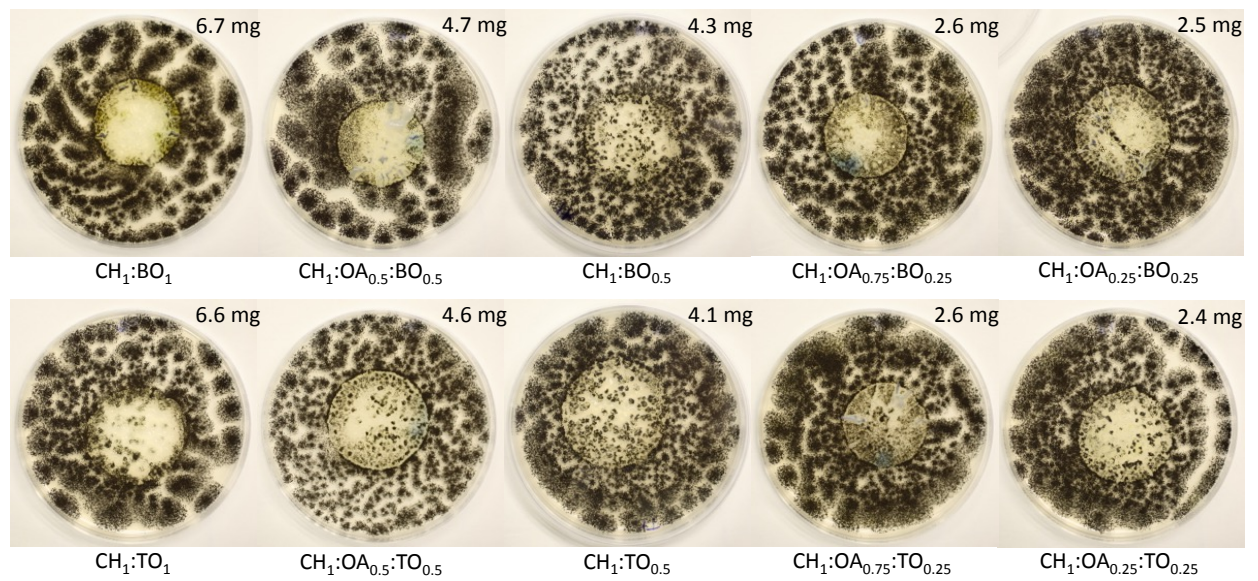

Figure 3.1.5 Growth of Aspergillus niger after 7 days of incubation at $25^{\circ} \mathrm{C}$ with disks $(\phi=2.5 \mathrm{~cm}$ ) of the different film formulation containing basil or thyme essential oils in contact with the agar media. The amount of the EO in each plate, according to its content in the film, is shown. $\mathrm{CH}$ : chitosan, OA: oleic acid, BO: basil essential oil, TO: thyme essential oil. Subscripts indicate the ratio of film components. 


\section{CONCLUSIONS}

The essential oil retention in the chitosan films was greatly dependent on the stability of the film-forming emulsion during film formation. The addition of oleic acid to the chitosan-essential oil formulations enhanced the emulsion stability and oil retention in the film at the same time that it improved the film water vapour barrier properties. Lipids reduced the film stretchability but when oleic acid was present in the formulation, this reduction was mitigated, as well as the changes in colour caused by the essential oils. However oleic acid reduced the film transparency to a greater extent than pure essential oils. Chitosan films with basil or thyme essential oils did not inhibit the growth of Aspergillus niger, Botrytis cinerea or Rhizopus stolonifer in an in vitro test.

\section{Acknowledgements}

The authors acknowledge the financial support provided by the Universitat Politècnica de València (UPPTE/2012/183) and the Ministerio de Ciencia e Innovación (AGL2010-20694). Ángela Perdones also thanks the Universitat Politècnica de València for the FPI grant. 


\section{REFERENCES}

ASTM. Standard test methods for water vapor transmission of materials. Standard Designations: E96-95. In ASTM, Annual Book of ASTM (pp. 406 - 413). ASTM (Philadelphia) 1995.

ASTM. Standard test method for specular gloss. Standard designation D523. In Annual Book of ASTM Standards (Vol.06.01). ASTM (Philadelphia) 1999.

ASTM. Standard test method for tensile properties of thin plastic sheeting. Standard D882. In Annual Book of ASTM Standards (pp. 162-170). ASTM (Philadelphia) 2001.

Baranauskiene, R., Venskutoni, S.P.R., Viskelis, P., Dambrauskiene, E. Influence of nitrogen fertilizers on the yield and composition of thyme (Thymus vulgaris). Journal of Agricultural and Food chemistry 51:26 (2003) $7751-7758$.

Baratta, M.T., Dorman, H.J.D., Deans, S.G., Figueiredo, A.C., Barroso, J.G., Ruberto, G. Antimicrobial and antioxidant properties of some commercial essential oils. Flavour and Fragrance Journal 13:4 (1998) 235 - 244.

Bozin, B., Mimica-Dukic, N., Simin, N., Anackov, G. Characterization of the volatile composition of essential oils of some Lamiaceae spices and the antimicrobial and antioxidant activities of the entire oils. Journal of Agricultural and Food Chemistry 54:5 (2006) 1822 - 1828.

Burt, S.A., Reinders, R.D. Antibacterial activity of selected plant essential oils against Escherichia coli 0157:H7. Letters in Applied Microbiology 36:3 (2003) $162-167$.

CIE. Colorimetry. (2 ${ }^{\text {nd }}$ Ed.). (Technical Report CIE 15.2) Commission Internationale de L'Eclairage (Paris) 1986.

Di Pasqua, R., Hoskins, N., Betts, G., Mauriello, G. Changes in membrane fatty acids composition of microbial cells induced by addiction of thymol, 
carvacrol, limonene, cinnamaldehyde and eugenol in the growing media. Journal of Agricultural and Food Chemistry 54:7 (2006) 2745 - 2749.

Gaysinsky, S., Davidson, P. M., Bruce, B. D., Weiss, J. Growth inhibition of E. Coli O157:H7 and Listeria monocytogenes by carvacrol and eugenol encapsulated in surfactant micelles. Journal of Food Protection 68:12 (2005) $2559-2566$.

Gennadios, A., Weller, C.L., Gooding, C.H. Measurements errors in water vapour permeability of highly permeable, hydrophilic edible films. Journal of Food Engineering 21:4 (1994) 395 - 409.

Hussain, A.I., Anwar, F., Sherazi, S.T.H., Przybylski, R. Chemical composition, antioxidant and antimicrobial activities of basil (Ocimum basilicum) essential oils depends on seasonal variations. Food Chemistry 108:3 (2008) $986-995$.

Hutchings, J.B. Food and colour appearance. ( $2^{\text {nd }}$ Ed.). Aspen Publication (Gaithersburg) 1999.

McClements, D.J. Food emulsions: principles, practice, and techniques (pp. 341 - 388). CRC Press LLC, Boca Raton (Florida) 2005.

Perdones, A., Vargas, M., Atarés, L., Chiralt, A. Physical, antioxidant and antimicrobial properties of chitosan-cinnamon leaf oil films as affected by oleic acid. Food Hydrocolloids 36 (2014) 256 - 264.

Sánchez-González, L., Vargas, M., González-Martínez, C., Chiralt, A., Cháfer, M. Use of Essential Oils in Bioactive Edible Coatings: A Review. Food Engineering Reviews 3:1 (2011a) 1- 16.

Sánchez-González, L., Cháfer, M., González-Martínez, C., Chiralt, A., Desobry, S. Study of the release of limonene present in chitosan films enriched with bergamot oil in food stimulants. Journal of Food Engineering 105:1 (2011b) $138-143$.

Shan, B., Cai, Y. Z., Sun, M., Corke, H. Antioxidant capacity of 26 spice extracts and characterization of their phenolic constituents. Journal of Agricultural and Food Chemistry 53:20 (2005) 7749 - 7759. 
Singh, B., Falahee, M.B., Adams, M.R. Synergistic inhibition of Listeria monocytogenes by nisin and garlic extract. Food Microbiology 18:2 (2001) $133-139$.

Tampieri, M.P., Galuppi, R., Macchioni, F., Carelle, M.S., Falcioni, L., Cioni, P.L., Morelli, I. The inhibition of Candida albicans by selected essential oils and their major components. Mycopathologia 159:3 (2005) $339-345$.

Vargas, M., Albors, A., Chiralt, A., González-Martínez, C. Characterization of chitosan-oleic acid composite films. Food Hydrocolloids 23:2 (2009) $536-547$.

Vargas, M., Perdones, A., Chiralt, A., Cháfer, M., González-Martínez, C. Effect of Homogenization Conditions on Physicochemical Properties of Chitosan-Based Film-Forming Dispersions and Films. Food Hydrocolloids 25:5 (2011) $1158-1164$.

Wan, J., Wilcock, A., Coventry, M.J. The effect of essential oils of basil on the growth of Aeromonas hydrophila and Pseudomonas fluorescens. Journal of Applied Microbiology 84:2 (1998) 152 - 158.

Wilson, C.L., Solar, J.M., El Ghaouth, A., Wisniewski, M.E. Rapid evaluation of plant extracts and essential oils for antifungal activity against Botrytis cinerea. Plant Disease 81:2 (1997) $204-210$. 


\section{PHYSICAL AND ANTIMICROBIAL}

PROPERTIES OF

CHITOSAN-CINNAMON LEAF

ESSENTIAL OIL FILMS AS AFFECTED

BY OLEIC ACID

Ángela Perdones, Maria Vargas*, Lorena Atarés, Amparo Chiralt

Food Hydrocolloids 36 (2014) $256-264$

Department of Food Technology-Institute of Food Engineering for Development, Universitat Politècnica de València, Camino de Vera s/n, 46022 Valencia, Spain.

*Telephone: 0034963877000 Ext.73642 Fax: 0034963877369

e-mail:mavarco@tal.upv.es 


\section{ABSTRACT}

The physical, antioxidant and antimicrobial properties of chitosan $(\mathrm{CH})$-cinnamon leaf essential oil (C) films, containing or not oleic acid (OA), were evaluated. The addition of OA led an increase in surface charge and particle size of the film-forming dispersions. This is in agreement with a greater $\mathrm{CH}$ adsorption on the droplets containing $\mathrm{OA}$ and the entrapment of $\mathrm{C}$ compounds in the non-polar core of the OA molecule associations. OA contributed to a better retention of $C$ in the film during its drying, diminished the changes in colour parameters provoked by $\mathrm{C}$ addition and reduced the film transparency. Water vapour permeability of $\mathrm{CH}$ films was reduced by $\mathrm{OA}$ incorporation while it increased when they contained only $C$. Every film containing $C$ showed antioxidant and antifungal properties, depending on the $\mathrm{C}$ content (the higher the $\mathrm{C}$ content, the greater the effect). OA reduced the antifungal effectiveness of $\mathrm{C}$ containing films in line with its encapsulating effect on $\mathrm{C}$ compounds. All the coatings were effective in extending the shelf-life of cold-stored strawberries, mainly when $\mathrm{CH}$ was combined with $\mathrm{C}$ at the ratio 1:0.5. 


\section{INTRODUCTION}

Chitosan is a biopolymer that has film-forming ability and shows antimicrobial activity (No, Park, Lee and Meyers, 2002; Tharanathan and Kittur, 2003). One of the most important drawbacks to the application of chitosan films to fresh food products is their poor water vapour barrier properties (Vargas, Sánchez-González, Chiralt, Cháfer and González-Martínez, 2012), which can be improved by the incorporation of lipid compounds, such as oleic acid (Vargas, Pastor, Chiralt, McClements and González-Martínez, 2008).

Essential oils (EO) are natural antioxidant and antimicrobial substances, extracted from vegetables. Most of them consist of a mixture of terpens, terpenoids and other aromatic and aliphatic compounds (Bakkali, Averbeck, Averbeck and Idaomar, 2008), but their composition can vary markedly depending on the origin. Cinnamon leaf essential oil has shown not only antifungal and antibacterial properties against a broad spectrum of food spoilage microorganisms but also antioxidant activity (Singh, Maurya, deLampasona and Catalan, 2007). The main compound of cinnamon leaf essential oil is eugenol (70-95\%), followed by cinnamaldehyde which can be present in a proportion of 1 to $5 \%$ (Vangalapati, Satya, Prakash and Avanigadda, 2012).

The use of EO in food preservation is often limited because of their application costs and other drawbacks, such as their intense aroma and potential toxicity. An interesting approach to reduce the doses of essential oils, while maintaining their effectiveness, could be to incorporate these compounds into the formulation of edible coatings (Sánchez-González, Vargas, González-Martínez, Chiralt and Cháfer, 2011a). In this sense, Sánchez-González, Cháfer, Chiralt and González-Martínez (2011b) developed antibacterial composite films based on chitosan and different EO (lemon, tea tree or bergamot), which were proved to inhibit the growth of bacteria (E. coli, L. monocytogenes and S. aureous) in an in vitro study. Wang et al., (2011) prepared chitosan films incorporated with cinnamon, clove and anise essential oils. Cinnamon oil-chitosan films exhibited a 
synergistic effect, which was related to the constant release of cinnamon essential oil.

The antifungal effect of bioactive coatings prepared with chitosan and essential oils, such as peppermint and lemon, on the fungal decay of cold-stored strawberries has recently been evaluated (Perdones, Sánchez-González, Chiralt and Vargas, 2012; Vu, Hollingsworth, Leroux, Salmieri and Lacroix, 2011). Nevertheless, there are no published studies on the antifungal effect of chitosan-cinnamon leaf essential oil composite coatings applied to strawberry. In addition, the studies into film development based on chitosan and cinnamon leaf essential oil are scarce.

The aim of this work was to characterize the film-forming dispersions and physical, antioxidant and antimicrobial properties of chitosan-cinnamon leaf essential oil films, containing or not oleic acid. The potential application of such coatings to control the fungal decay of strawberries was also evaluated.

\section{MATERIALS AND METHODS}

\subsection{Reagents}

High molecular weight chitosan (Batch MKBD1916V, $0.8 \mathrm{~Pa} \cdot \mathrm{s}$ viscosity, at $1 \% \mathrm{w} / \mathrm{w}$ in $1 \% \mathrm{w} / \mathrm{w}$ glacial acetic acid, acetylation degree: $22 \%)$, ABTS (2,2'-azinobis(3-ethylbenzothiazoline-6-sulfonic acid) diammonium salt), Trolox (6-hydroxy-2,5,7,8-tetramethylchroman-2-carboxylic acid) and potassium persulfate was provided by Sigma-Aldrich Química (Madrid, Spain). Cinnamon leaf essential oil was supplied by Herbes del Molí (Alicante, Spain). Acetic acid, oleic acid and magnesium nitrate were purchased from Panreac Química, S.A. (Castellar del Vallés, Barcelona, Spain).

\subsection{Preparation and characterization of the film-forming dispersions}

Chitosan (CH) was dispersed at $1 \mathrm{wt}$ \% in an aqueous solution of acetic acid $(1 \% \mathrm{v} / \mathrm{w})$ and Tween $80(0.1 \% \mathrm{w} / \mathrm{w})$. After at least $8 \mathrm{~h}$ of magnetic stirring, 
chitosan solution was vacuum-filtered. Cinnamon leaf essential oil (C) or oleic acid (OA) or both compounds were added at different concentrations as described in Table 3.2.1. Film-forming dispersions (FFD) were prepared by means of a rotor-stator homogenizer (Ultraturrax DI 25 basic-Yellowline, Janke and Kunkel, Staufen, Germany). After homogenization, the formulations were degassed at room temperature and at 7 mbar with a vacuum pump (Wertheim, Germany).

Table 3.2.1 Composition of the Film-forming dispersions (FFD).

\begin{tabular}{lcccc}
\hline FFD & $\begin{array}{c}\text { Chitosan } \\
(\% \text { w.b. })\end{array}$ & $\begin{array}{c}\text { Oleic Acid } \\
(\% \text { w.b. })\end{array}$ & $\begin{array}{c}\text { Cinnamon Leaf EO } \\
(\% \text { w.b. })\end{array}$ & $\begin{array}{c}\text { TOTAL LIPID } \\
\text { (\% w.b.) }\end{array}$ \\
\hline $\mathrm{CH}_{1}$ & 1 & - & - & - \\
$\mathrm{CH}_{1}: \mathrm{OA}_{0.25}: \mathrm{C}_{0.25}$ & 1 & 0.25 & 0.25 & 0.5 \\
$\mathrm{CH}_{1}: \mathrm{C}_{0.5}$ & 1 & - & 0.5 & 0.5 \\
$\mathrm{CH}_{1}: \mathrm{OA}_{0.5}: \mathrm{C}_{0.5}$ & 1 & 0.5 & 0.5 & 1 \\
$\mathrm{CH}_{1}: \mathrm{C}_{1}$ & 1 & - & 1 & 1 \\
$\mathrm{CH}_{1}: \mathrm{OA}_{1}$ & 1 & 1 & - & 1 \\
\hline
\end{tabular}

$\mathrm{CH}$ : chitosan, OA: oleic acid, C: Cinnamon leaf essential oil. Subscripts indicate the ratio of film components.

\subsubsection{Particle size distribution, $\zeta$-potential and rheological behaviour}

The particle size analysis of the FFD was carried out by means of a laser diffractometer (Mastersizer 2000, Malvern Instruments, Worcestershire, UK). The samples were diluted in the acetic acid solution $(\mathrm{pH}=4.8)$ at $2,000 \mathrm{rpm}$ until an obscuration rate of $10 \%$ was obtained. Mie theory was applied considering a refractive index of 1.47 and 1.50 for $C$ and $O A$, respectively, and 0 absorption in both cases. Three replications performulation were made. $\zeta$-potential was measured in triplicate by Laser-Dopler electrophoresis performed with a Zetasizer nano-Z (Malvern Instruments, Worcestershire, UK). The electrophoretic mobility of the droplets was transformed into $\zeta$-potential values using the Smoluchowsky model. The samples were diluted to a droplet concentration of $0.02 \%$ with an acetic acid solution ( $\mathrm{pH} 4.8$ ).

The rheological behaviour of FFD was analysed in triplicate at $25^{\circ} \mathrm{C}$ using a rotational rheometer (HAAKE Rheostress 1, Thermo Electric Corporation, Karlsruhe, Germany) with a sensor system of coaxial cylinders, type 
Z34DIN Ti. Samples were left to rest for 5 min before the measurements were taken. The shear stress $(\dot{\gamma})$ was obtained as a function of shear rate $(\sigma)$ between 0 and $512 \mathrm{~s}^{-1}$, taking $5 \mathrm{~min}$ for each (up and down) cycle. Experimental data were fitted to the Ostwald de Waele model (Eq. 3.2.1) in order to determine the consistency $(K)$ and the flow behaviour indexes $(n)$.

$$
\sigma=K \cdot \dot{\gamma}^{n}
$$

\subsection{Preparation and characterization of the films}

FFD were casted in Teflon ${ }^{\circledR}$ plates $(\phi=15 \mathrm{~cm})$, so as to keep $\mathrm{CH}$ amount constant in the dry films $\left(28 \mathrm{~g} / \mathrm{m}^{2}\right)$. The films were dried at room temperature and $60 \%$ relative humidity $(\mathrm{RH})$ and were conditioned in desiccators with an oversaturated salt solution of magnesium nitrate at $20{ }^{\circ} \mathrm{C}$ or $5{ }^{\circ} \mathrm{C}$. Film thickness was determined with a Palmer digital micrometre (Comecta, Barcelona, Spain) to the nearest $\pm 0.001 \mathrm{~mm}$.

\subsubsection{Microstructure}

Microstructure was observed by SEM in cross-sectioned cryofractured film specimens, using a JEOL JSM-5410 (Japan) electron microscope. The films (2 samples per formulation) were equilibrated in $\mathrm{P}_{2} \mathrm{O}_{5}$ to eliminate water, cryofractured by immersion in liquid nitrogen, and then mounted on copper stubs perpendicularly to their surface. After gold coating, the images were captured using an accelerating voltage of $10 \mathrm{kV}$.

\subsubsection{Optical and mechanical properties}

Gloss of the films was measured with a gloss meter (Multi Gloss 268, Minolta, Germany) on their shiny side, using a black matte background and at an incidence angle of $60^{\circ}$ (ASTM D523, 1999). Nine replicates were made per each formulation. Results were expressed as gloss units, relative to a highly polished surface of black glass standard with a gloss value near to 100.

Colour of the films was determined through the surface reflectance spectra with a spectrocolorimeter CM-3600d (Minolta Co, Tokyo, Japan) with a $10 \mathrm{~mm}$ illuminated sample area. Measurements were taken from nine replicates per formulation by using both a white and a black background 
and Kubelka-Munk theory for multiple scattering was applied to the sample reflection spectra. Internal transmittance (Ti) was calculated from the reflectance of the sample layer backed by a known reflectance and the reflectance of the film on an ideal black background (Hutchings, 1999). Moreover, CIE-L ${ }^{*}{ }^{*}{ }^{*}{ }^{*}$ coordinates, (CIE, 1986) were obtained by the infinite reflection spectra of the samples, using D65 illuminant/10 observer in order to calculate the whiteness index (WI) of the samples (Eq. 3.2.2).

$$
\left.W I=100-\left(\left(100-L^{*}\right)^{2}+a^{* 2}+b^{* 2}\right)\right)^{0.5}
$$

Mechanical properties were analysed by means of tensile tests (ASTM D882, 2001), to obtain the true stress ( $\alpha$ ) vs. Hencky strain $\left(\varepsilon_{H}\right)$ curves. The mechanical parameters: elastic modulus (EM), tensile strength at break (TS) and elongation percentage at break (E) were obtained. A Universal Testing Machine (TA.XT plus model, Stable Micro Systems, Haslemere, England) with a $50 \mathrm{~N}$ load cell was used to perform the tests. Film specimens were mounted in the film-extension grips and stretched at $50 \mathrm{~mm} \cdot \mathrm{min}^{-1}$ until breakage. Nine to twelve replicates of each formulation were tested.

\subsubsection{Water vapour and oxygen permeability}

Water vapour permeability (WVP) was determined gravimetrically at $5{ }^{\circ} \mathrm{C}$ and $20{ }^{\circ} \mathrm{C}$ and $59-100 \%$ and $54-100 \%$, RH gradient, using a modification of the ASTM E96-95 gravimetric method (ASTM, 1995) for hydrophilic films (Gennadios, 1994). Payne permeability cups of $3.5 \mathrm{~cm}$ in diameter (Elcometer SPRL, Hermelle/s Argenteau, Belgium) were filled with $5 \mathrm{~mL}$ of distilled water $(100 \% \mathrm{RH})$. The films were secured and the cups were placed in pre-equilibrated cabinets fitted with a fan, at $5{ }^{\circ} \mathrm{C}$ or $20{ }^{\circ} \mathrm{C}$. The $\mathrm{RH}$ of the cabinets was held constant at $59 \%$ or $54 \% \mathrm{RH}$ using oversaturated solutions of $\mathrm{Mg}\left(\mathrm{NO}_{3}\right)_{2}$. The cups were weighted periodically after the steady state had been reached. WVP was calculated with the equations described by Vargas, Perdones, Chiralt, Cháfer and GonzálezMartínez (2011). Six replicates per formulation were made.

The oxygen permeability (OP) was measured according to the ASTM D3985-05 (2002). The oxygen barrier performance of the films was evaluated by measuring the oxygen transference rate with an Ox-Tran 1/50 system (Mocon, Minneapolis, USA) at $10{ }^{\circ} \mathrm{C}$ or $20^{\circ} \mathrm{C}$. One side of the film 
was exposed to pure nitrogen and the other to pure oxygen flow. The tests were performed in continuous mode at $59 \%$ or $54 \% \mathrm{RH}$, depending on the temperature. OP was calculated by dividing the oxygen transmission rate by the difference in oxygen partial pressure between the two sides of the film, and multiplying by the average film thickness. Two replicates per formulation were made.

\subsubsection{Antioxidant activity}

The Trolox Equivalent Antioxidant Capacity (TEAC) of cinnamon leaf essential oil and chitosan-based films was determined using a modification of the original TEAC method (Re et al., 1999). Trolox (6-hydroxy-2,5,7,8-tetramethylchroman-2-carboxylic acid), which is a vitamin $E$ analogue, was used as a standard of antioxidant capacity. A $7 \mathrm{mM}$ aqueous solution of ABTS (2,2'-azinobis(3-ethylbenzothiazoline-6-sulfonic acid) diammonium salt) was allowed to react with a $2.45 \mathrm{mM}$ potassium persulfate solution in the dark, for $16 \mathrm{~h}$. During this period, ABTS radical cation $\left(\mathrm{ABTS}^{\bullet+}\right)$, a blue chromophore, was produced. The tests were performed with aqueous dilutions of the ABTS ${ }^{\bullet+}$ solution whose absorbance at $734 \mathrm{~nm}$ was 0.70 ( \pm 0.02$)$. The films $(0.075 \mathrm{~g})$ were diluted in $25 \mathrm{~mL}$ of an acetic solution $(1 \% \mathrm{v} / \mathrm{w})$ prior to the determination. This dilution was adjusted so that the addition of a $10 \mu \mathrm{L}$ aliquot to $990 \mu \mathrm{L}$ of $\mathrm{ABTS}^{\bullet+}$ dilution would produce a $20-80 \%$ absorbance decrease within 6 min. Absorbance at $734 \mathrm{~nm}$ was registered every minute during the test. For calibration, Trolox standards of between 60 and $500 \mathrm{mg} / \mathrm{L}$ were prepared following the procedure described above. The TEAC of cinnamon leaf essential oil and film samples was determined by comparing the corresponding percentage of absorbance reduction to the concentration-response curve and was expressed as $\mu \mathrm{g}$ of sample that show the same antioxidant activity as $1 \mathrm{mM}$ of Trolox. All the determinations were carried out at least six times using a spectrophotometer (Beckman Coulter DU 730, England) and distilled water as the blank.

\subsection{Antifungal assays}

The antifungal effect of the stand-alone films and the FFD was evaluated in vitro and in vivo against Aspergillus niger (CECT20156), Botrytis cinerea (CECT20516) and Rhizopus stolonifer (CECT2344) which were supplied by Colección Española de Cultivos Tipo (Burjasot, Spain). The stock culture 
were kept frozen $\left(-25^{\circ} \mathrm{C}\right)$ in Potato Dextrose Agar (Scharlab, Barcelona, Spain) supplemented with $30 \%$ glycerol (Panreac, Barcelona, Spain) and was inoculated on potato dextrose agar (PDA) and incubated at $25^{\circ} \mathrm{C}$ until sporulation.

To perform the in vitro assays, the surface of PDA plates was seeded with $0.1 \mathrm{~mL}$ of a spores suspension $\left(10^{4}\right.$ spores $\left./ \mathrm{mL}\right)$. Pieces of film (diameter $=2.4 \mathrm{~cm}$ ) were placed at the centre of the PDA plates, which were incubated at $25{ }^{\circ} \mathrm{C}$ for 6 days (A. niger and R. stolonifer) or 14 days (B. cinerea). The diameter of the zone of growth inhibition was measured at different incubation times with a digital calliper to the nearest $0.01 \mathrm{~mm}$. The activity of cinnamon leaf essential oil was evaluated by diluting the oil with dimethyl sulphoxide (Sigma-Aldrich Química, Madrid, Spain) to obtain different oil concentrations as described by Sacchetti et al., (2005). A constant amount of the serial diluted essential oil solutions was deposited on sterile paper discs (diameter $=2.4 \mathrm{~cm}$ ) that were placed in the centre of the inoculated Petri dishes as described above.

The in vivo studies were carried out using 25 strawberries per formulation, which were inoculated with $R$. stolonifer by sample immersion in a spore suspension $\left(10^{5} \mathrm{spores} / \mathrm{mL}\right)$. Experiments were performed in duplicate. Inoculated and non-inoculated samples were dipped in the FFD for $1 \mathrm{~min}$. FFD containing the highest lipid proportion were not tested to avoid the possible phytotoxic effects of cinnamon leaf essential oil. Samples were dried by natural convection for $1 \mathrm{~h}$ at $20^{\circ} \mathrm{C}$ and were stored on perforated plastic trays, where the pieces did not come into direct contact with each other. Non-coated inoculated strawberries were used as control treatment. The trays were kept at $10{ }^{\circ} \mathrm{C}-70 \% \mathrm{RH}$ or $20{ }^{\circ} \mathrm{C}-80 \% \mathrm{RH}$ in a storage chamber (EC1400, Radiber, Barcelona, Spain). The strawberries that showed any sign of surface mycelia development were considered decayed. Results were expressed as percentage of infected strawberries. Total aerobial, moulds and yeasts and coliforms counts of strawberries inoculated with spore suspension of $R$. stolonifer and stored at $10{ }^{\circ} \mathrm{C}-70 \% \mathrm{RH}$ were also determined as a function of storage time. 


\section{RESULTS AND DISCUSSION}

\subsection{Properties of film-forming dispersions}

Film-forming dispersions (FFD) showed monomodal particle size distributions. Mean particle sizes $(D[4,3]$ and $D[3,2])$ are shown in Table 3.2.2. Very small particles were obtained for all formulations, but their mean size increased for $1 \%$ lipid content when $C$ was present. When $\mathrm{OA}-\mathrm{C}$ blends were incorporated, an increase in the particle size was observed with respect to those containing only $\mathrm{C}$. However, $\mathrm{CH}_{1}: \mathrm{OA}_{1}$ exhibited relatively small particles. This different behaviour could be due to the surfactant properties of OA which will lead to the formation of micellar structures in aqueous media, which does not occur for $C$ compounds. These could be included in the non-polar core of the OA micelles, thus leading to an increase in their size, mainly when the amount of $C$ increases in the blend.

All the FFD had high positive values of $\zeta$-potential, in accordance with the values detected for chitosan-based solutions in acid media (Vargas, Albors, Chiralt and González-Martínez, 2009). Every sample containing OA showed the same value of $\zeta$-potential, suggesting that interactions of surfactant molecules with $\mathrm{CH}$ on the droplet surface lead to a similar degree of polymer adsorption, which is responsible for the positive charge. When OA was not present, $\zeta$-potential values were lower, mainly for the greater ratio of $\mathrm{C}$. This suggests that, in this case, $\mathrm{CH}$ adsorption on the droplet surface was more in agreement with the different lipid composition and affinity with $\mathrm{CH}$ chains.

FFD showed shear-thinning, non-time dependent rheological behaviour. Flow curves were fitted to the Power Law model and rheological parameters are shown in Table 3.2.2. Apparent viscosities ranged between 90 and $148 \mathrm{mPa} \cdot \mathrm{s}$ depending on their composition. $\mathrm{CH}_{1}: \mathrm{OA}_{1}$ was the most viscous and showed the lowest flow behaviour index (Perdones, Sánchez-González, Vargas and Chiralt, 2012; Vargas, Albors, Chiralt and González-Martínez, 2009), while samples $\mathrm{CH}_{1}: \mathrm{C}_{1}$ are the least viscous with the higher flow behaviour index. Differences in flow behaviour can be explained in terms of the differences in total volume of dispersed phase, 
particle size distribution and droplet surface charge (McClements, 2005). In this sense, it is remarkable that dispersions with $1 \%$ lipid were more viscous when they showed higher $\zeta$-potential, while the opposite effect was observed for $0.5 \%$ lipid.

Table 3.2.2 Particle size, $\zeta$-potential and rheological properties of the film-forming dispersions (FFD). Mean values and (standard deviations).

\begin{tabular}{|c|c|c|c|c|c|c|}
\hline \multirow{2}{*}{ FFD } & \multicolumn{2}{|c|}{ Particle Size $(\mu \mathrm{m})$} & \multirow{2}{*}{$\begin{array}{c}\zeta \text {-Potential } \\
(\mathrm{mV})\end{array}$} & \multirow{2}{*}{$\mathrm{n}$} & \multirow{2}{*}{$\begin{array}{c}\mathrm{K} \\
(\mathrm{Pa} \cdot \mathrm{s})\end{array}$} & \multirow{2}{*}{$\begin{array}{l}\eta_{100 s^{-1}} \\
(\mathrm{~Pa} \cdot \mathrm{s})\end{array}$} \\
\hline & $D[4,3]$ & $D[3,2]$ & & & & \\
\hline $\mathrm{CH}_{1}$ & - & - & $63.4(0.6)^{a}$ & $\begin{array}{c}0.722 \\
(0.002)^{\mathrm{a}}\end{array}$ & $\begin{array}{c}0.488 \\
(0.007)^{a}\end{array}$ & $\begin{array}{c}0.1355 \\
(0.0012)^{a}\end{array}$ \\
\hline $\mathrm{CH}_{1}: \mathrm{OA}_{0.25}: \mathrm{C}_{0.25}$ & $\begin{array}{c}0.222 \\
(0.006)^{\mathrm{a}}\end{array}$ & $\begin{array}{c}0.158 \\
(0.004)^{a}\end{array}$ & $75.9(0.4)^{d}$ & $\begin{array}{c}0.77010 \\
(0.00106)^{b}\end{array}$ & $\begin{array}{c}0.317 \\
(0.003)^{b}\end{array}$ & $\begin{array}{c}0.1098 \\
(0.0004)^{b}\end{array}$ \\
\hline $\mathrm{CH}_{1}: \mathrm{C}_{0.5}$ & $\begin{array}{c}0.178 \\
(0.004)^{b}\end{array}$ & $\begin{array}{c}0.127 \\
(0.002)^{b}\end{array}$ & $72(2)^{c}$ & $\begin{array}{c}0.726623 \\
(0.001004)^{c}\end{array}$ & $\begin{array}{c}0.473 \\
(0.005)^{c}\end{array}$ & $\begin{array}{c}0.1342 \\
(0.0009)^{\mathrm{ac}}\end{array}$ \\
\hline $\mathrm{CH}_{1}: \mathrm{OA}_{0.5}: \mathrm{C}_{0.5}$ & $\begin{array}{c}0.479 \\
(0.002)^{c}\end{array}$ & $\begin{array}{c}0.393 \\
(0.002)^{c}\end{array}$ & $76(2)^{d}$ & $\begin{array}{c}0.7373 \\
(0.0013)^{d}\end{array}$ & $\begin{array}{c}0.443 \\
(0.008)^{d}\end{array}$ & $\begin{array}{c}0.132 \\
(0.002)^{c}\end{array}$ \\
\hline $\mathrm{CH}_{1}: \mathrm{C}_{1}$ & $\begin{array}{c}0.402 \\
(0.005)^{d}\end{array}$ & $\begin{array}{c}0.327 \\
(0.004)^{d}\end{array}$ & $66(2)^{b}$ & $\begin{array}{c}0.8228 \\
(0.0008)^{e}\end{array}$ & $\begin{array}{c}0.2039 \\
(0.0011)^{e}\end{array}$ & $\begin{array}{c}0.0902 \\
(0.0002)^{d}\end{array}$ \\
\hline $\mathrm{CH}_{1}: \mathrm{OA}_{1}$ & $\begin{array}{c}0.2297 \\
(0.0006)^{a}\end{array}$ & $\begin{array}{c}0.1627 \\
(0.0006)^{\mathrm{a}}\end{array}$ & $75.1(0.6)^{d}$ & $\begin{array}{c}0.7080 \\
(0.0006)^{f}\end{array}$ & $\begin{array}{c}0.488 \\
(0.007)^{f}\end{array}$ & $\begin{array}{c}0.1477 \\
(0.0006)^{\mathrm{e}}\end{array}$ \\
\hline
\end{tabular}

a, b, c Different superscripts in the same column indicate 95\% significant differences among FFD. $\mathrm{CH}$ : chitosan, OA: oleic acid, C: Cinnamon leaf essential oil. Subscripts indicate the ratio of film components.

The observed differences in the FFD properties will affect the stability of the systems during the film formation. The water loss during film drying could lead to droplet flocculation, coalescence and creaming phenomena which in turn will affect the final microstructure of dry film. In this sense, the FFD with higher $\zeta$-potential, lower particle size and greater viscosity will be the most stable during film drying step. From the obtained values, $\mathrm{CH}_{1}: \mathrm{C}_{1}$ FFD could suffer destabilization phenomena to a greater extent.

\subsection{Properties of the stand-alone films}

\subsubsection{Microstructure and thickness}

SEM images of the cross-sections of films are shown in Figure 3.2.1. Pure $\mathrm{CH}$ film was homogenous with a compact and regular continuous matrix. When $\mathrm{C}, \mathrm{OA}$ or $\mathrm{OA}-\mathrm{C}$ blends are incorporated to the $\mathrm{CH}$ matrix, lipid 
particles can be distinguished and a coarse microstructure can be appreciated, especially at the highest lipid content. Samples containing $1 \%$ of lipid (OA or OA-C blend) showed the coarsest matrix. Samples with 1 \% C showed finer structure probably due to a great loss of essential oil during the film drying step, which lead to a less rich lipid film than that expected from the initial ratios. Similar results were observed in chitosan-bergamot essential oil films (Sánchez-González, Cháfer, González-Martínez, Chiralt and Desobry, 2011c). The partial loss of cinnamon leaf essential oil seems to be limited in the OA-C blends, which is coherent with the values of the film thickness (Table 3.2.3); for the same theoretical surface solid density, thickness was lower when OA was not present in the formulation.
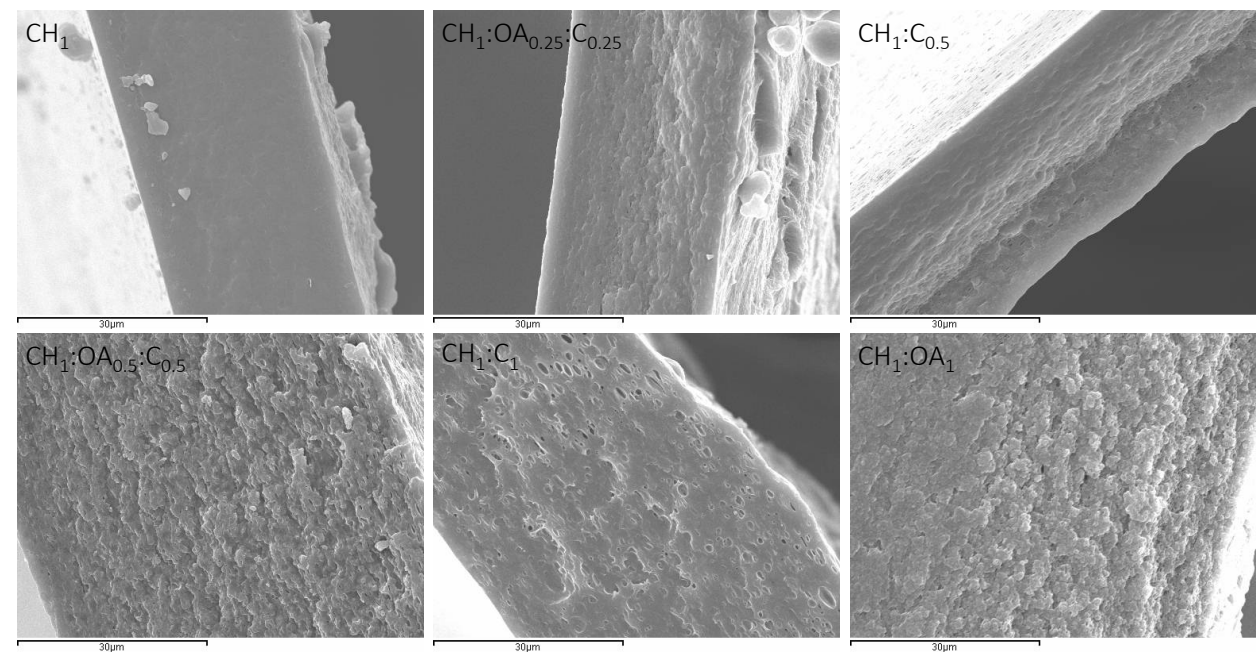

Figure 3.2.1 SEM micrographs of cross-sections of the films. Magnification is 2000x. CH: chitosan, OA: oleic acid, C: Cinnamon leaf essential oil. Subscripts indicate the ratio of the components in the film.

The thickness of the films is shown in Table 3.2.3. All composite films were thicker than $\mathrm{CH}$ films, which is coherent with their greater solid content per surface unit, since all the films were prepared by keeping the amount of polymer per surface area constant. $\mathrm{CH}_{1}: \mathrm{C}_{1}$ films were significantly thinner than $\mathrm{CH}_{1}: \mathrm{OA}_{1}$, which points to the partial evaporation of the volatile compounds of the essential oil during film drying and coincides with that observed by Sánchez-González, Cháfer, Chiralt and González-Martínez (2010). The addition of OA seems to contribute to retain a greater amount of cinnamon leaf EO into the film matrix. In fact, although the detected differences were not statistically significant, a clear tendency was observed: 
$\mathrm{CH}-\mathrm{OA}-\mathrm{C}$ films were thicker than $\mathrm{CH}-\mathrm{C}$ for the same total lipid amount. The quantification of $\mathrm{C}$ losses during film drying trough gravimetric balance reveals losses of: $39 \%, 46 \%, 37 \%, 33 \%$ with respect the initial added amount for $\mathrm{CH}_{1}: \mathrm{C}_{1}, \mathrm{CH}_{1}: \mathrm{C}_{0.5}, \mathrm{CH}_{1}: \mathrm{OA}_{0.5}: \mathrm{C}_{0.5}, \mathrm{CH}_{1}: \mathrm{OA}_{0.25}: \mathrm{C}_{0.25}$ films, respectively. The corresponding losses referred per $100 \mathrm{~g}$ of dry chitosan (constant basis in all films) were $39 \%, 23 \%, 18 \%, 8 \%$. The results showed that the addition of higher amount of $\mathrm{C}$ led to higher absolute losses during film drying. Nevertheless, when comparing films with the same amount of $C$ with or without oleic acid, a greater retention of cinnamon leaf EO in the film matrix was observed, which pointed out to a certain degree of encapsulation effect of OA.

Table 3.2.3 Thickness, elastic modulus (EM), and elongation (E) and tensile strengtn (TS) at break of the films. Mean values and (standard deviation).

\begin{tabular}{lcccc}
\hline Film & $\begin{array}{c}\text { Thickness } \\
(\mu \mathrm{m})\end{array}$ & $\begin{array}{c}\text { TS } \\
(\mathrm{MPa})\end{array}$ & $\begin{array}{c}\mathrm{E} \\
(\%)\end{array}$ & $\begin{array}{c}\mathrm{EM} \\
(\mathrm{MPa})\end{array}$ \\
\hline $\mathrm{CH}_{1}$ & $42(12)^{\mathrm{a}}$ & $44(6)^{\mathrm{a}}$ & $20(5)^{\mathrm{a}}$ & $1674(49)^{\mathrm{a}}$ \\
$\mathrm{CH}_{1}: \mathrm{OA}_{0.25}: \mathrm{C}_{0.25}$ & $51(5)^{\mathrm{b}}$ & $43(9)^{\mathrm{a}}$ & $21(6)^{\mathrm{ac}}$ & $1421(80)^{\mathrm{b}}$ \\
$\mathrm{CH}_{1}: \mathrm{C}_{0.5}$ & $48(4)^{\mathrm{b}}$ & $37(3)^{\mathrm{b}}$ & $17(3)^{\mathrm{ad}}$ & $1455(89)^{\mathrm{b}}$ \\
$\mathrm{CH}_{1}: \mathrm{OA}_{0.5}: \mathrm{C}_{0.5}$ & $64(3)^{\mathrm{c}}$ & $39(4)^{\mathrm{ab}}$ & $29(5)^{\mathrm{b}}$ & $1047(161)^{\mathrm{c}}$ \\
$\mathrm{CH}_{1}: \mathrm{C}_{1}$ & $60(3)^{\mathrm{c}}$ & $38(6)^{\mathrm{ab}}$ & $27(4)^{\mathrm{bc}}$ & $962(68)^{\mathrm{cd}}$ \\
$\mathrm{CH}_{1}: \mathrm{OA}_{1}$ & $74(3)^{\mathrm{d}}$ & $33(4)^{\mathrm{b}}$ & $11(5)^{\mathrm{d}}$ & $848(24)^{\mathrm{d}}$
\end{tabular}

a, b, c, d, e Different superscripts in the same column indicate 95\% significant differences among film formulations. CH: chitosan, OA: oleic acid, C: Cinnamon leaf essential oil. Subscripts indicate the ratio of film components.

\subsubsection{Mechanical properties}

As shown in Table 3.2.3, the addition of OA or C promoted a decrease in tensile strength at break and elastic modulus, as compared with pure $\mathrm{CH}$ films, as previously reported for other films containing lipids (Perdones, Sánchez-González, Chiralt and Vargas, 2012; Sánchez-González, Cháfer, Chiralt and González-Martínez, 2011b; Vargas, Albors, Chiralt and González-Martínez, 2009). This has been related with the presence of discontinuities in the polymer matrix which reduce the matrix cohesion forces, thus implying a loss of mechanical resistance. In the case of pure OA, a significant reduction of the film extensibility was obtained, which seems 
to indicate that essential oil contribute to plasticize the polymer matrix, thus inhibiting the usual brittleness effect that the lipid discontinuities of the matrix cause. At both total lipid concentrations, the presence of OA led to an increase in the elongation and tensile strength at break, although the effects were not significant. EM values were not significantly affected by $\mathrm{OA}$ addition.

\subsubsection{Optical properties}

Optical properties of the films are shown in Table 3.2.4.

Table 3.2.4 Gloss values at $60^{\circ}$, colour coordinates: lightness $\left(\mathrm{L}^{*}\right)$, chroma $\left(\mathrm{C}^{*} \mathrm{ab}\right)$ and hue $\left(\mathrm{h}_{\mathrm{ab}}^{*}\right)$, whiteness index $(\mathrm{WI})$ and total colour difference $(\Delta \mathrm{E})$ with respect to $\mathrm{CH}$ films of the obtained films. Mean values and (standard deviations).

\begin{tabular}{lcccccc}
\hline Film & Gloss 60 & $\mathrm{L}^{*}{ }_{\mathrm{ab}}$ & $\mathrm{h}^{*}{ }_{\mathrm{ab}}$ & $\mathrm{C}^{*}{ }_{\mathrm{ab}}$ & $\mathrm{Wl}$ & $\Delta \mathrm{E}$ \\
\hline $\mathrm{CH}_{1}$ & $67(5)^{\mathrm{a}}$ & $79.6(0.6)^{\mathrm{a}}$ & $91.0(0.3)^{\mathrm{a}}$ & $19.0(0.4)^{\mathrm{a}}$ & $72.1(0.2)^{\mathrm{a}}$ & - \\
$\mathrm{CH}_{1}: \mathrm{OA}_{0.25}: \mathrm{C}_{0.25}$ & $61(11)^{\mathrm{a}}$ & $75(1)^{\mathrm{b}}$ & $81.4(0.2)^{\mathrm{b}}$ & $28(2)^{\mathrm{a}}$ & $63.8(0.6)^{\mathrm{b}}$ & $9.6(0.4)^{\mathrm{a}}$ \\
$\mathrm{CH}_{1}: \mathrm{C}_{0.5}$ & $69(12)^{\mathrm{a}}$ & $74(1)^{\mathrm{c}}$ & $79.3(0.4)^{\mathrm{c}}$ & $32(2)^{\mathrm{b}}$ & $59(1)^{\mathrm{c}}$ & $14(1)^{\mathrm{b}}$ \\
$\mathrm{CH}_{1}: \mathrm{OA}_{0.5}: \mathrm{C}_{0.5}$ & $28(10)^{\mathrm{b}}$ & $72(1)^{\mathrm{d}}$ & $78.8(0.7)^{\mathrm{d}}$ & $31.1(0.8)^{\mathrm{c}}$ & $58.1(0.9)^{\mathrm{d}}$ & $15.3(0.9)^{\mathrm{c}}$ \\
$\mathrm{CH}_{1}: \mathrm{C}_{1}$ & $68(15)^{\mathrm{a}}$ & $69(1)^{\mathrm{d}}$ & $76.6(0.4)^{\mathrm{e}}$ & $35.6(0.6)^{\mathrm{c}}$ & $53.0(0.8)^{\mathrm{e}}$ & $20.6(0.7)^{\mathrm{d}}$ \\
$\mathrm{CH}_{1}: \mathrm{OA}_{1}$ & $46(4)^{\mathrm{c}}$ & $81.9(0.8)^{\mathrm{e}}$ & $89.9(0.6)^{\mathrm{f}}$ & $18.9(0.5)^{\mathrm{d}}$ & $73.8(0.9)^{\mathrm{f}}$ & $2.4(0.7)^{\mathrm{e}}$ \\
\hline $\mathrm{a}, \mathrm{b}, \mathrm{c}$, d, e Different superscripts in the same column indicate $95 \%$ significant differences among films. \\
$\mathrm{CH}$ : chitosan, OA: oleic acid, C: Cinnamon leaf essential oil. Subscripts indicate the ratio of film \\
components.
\end{tabular}

Gloss of the films containing lipids did not significantly differ from that of the $\mathrm{CH}$ films, except for the samples $\mathrm{CH}_{1}: \mathrm{OA}_{0.5}: \mathrm{C}_{0.5}$ and $\mathrm{CH}_{1}: \mathrm{OA}_{1}$ which showed a significant decrease. Film gloss is related with its surface roughness which, in turn, is affected by the progress of coalescence and creaming phenomenon of the lipids to the film surface. In this sense, it is remarkable that samples containing the greater amount of total lipid (except $\mathrm{CH}_{1}: \mathrm{C}_{1}$ which loss a great ratio of lipid during film drying) in the film were the less glossy, in agreement with the greater progress of the destabilization phenomena during film formation.

The internal transmittance $(T i)$ spectra of the films are plotted in Figure 3.2.2. Pure $\mathrm{CH}$ and $\mathrm{CH}-\mathrm{OA}$ spectra were similar in shape, although $\mathrm{OA}$ provoked a decrease in the internal transmittance of films. Cinnamon leaf essential oil promoted a selective decrease in the film internal 
transmittance between 460 and $520 \mathrm{~nm}$ due to the selective absorption of the coloured components of cinnamon leaf essential oil.

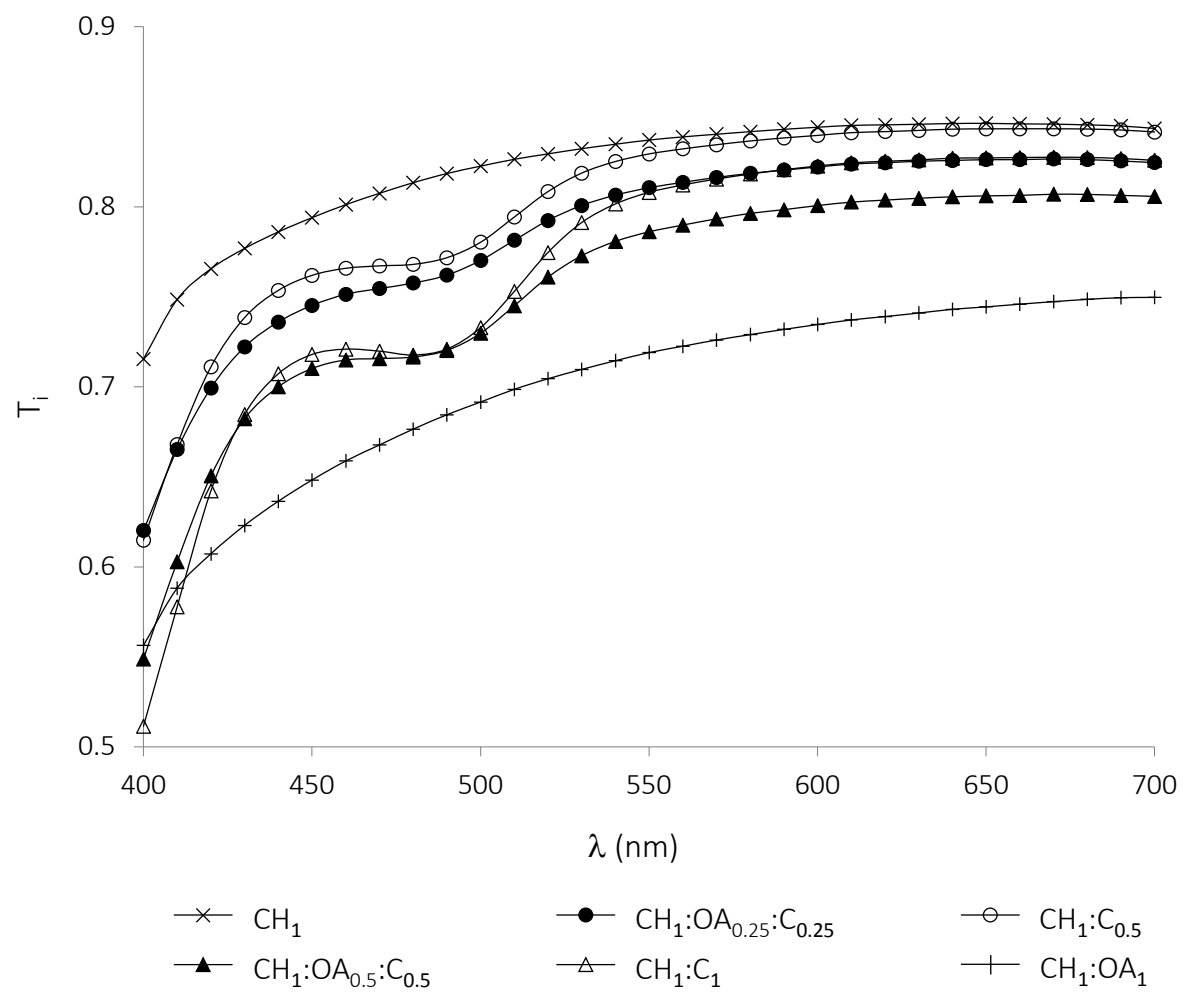

Figure 3.2.2 Average internal transmittance (Ti) spectra of the films conditioned at $20{ }^{\circ} \mathrm{C}-54 \% \mathrm{RH}$. $\mathrm{CH}$ : chitosan, OA: oleic acid, C: Cinnamon leaf essential oil. Subscripts indicate the ratio of the components in the film.

Ti curves of samples containing only $\mathrm{C}$ at different ratios are almost parallel, as occurs with samples containing C-OA blends. In both films, the higher the lipid ratio, the lower the Ti values. Nevertheless, it is remarkable that, for the same total lipid content, the lipid blend provoked a greater $\mathrm{Ti}$ decrease than pure $C$, which points to a greater capacity of OA to reduce film transparency. In fact, the lowest internal transmittance was detected for $\mathrm{CH}_{1}: \mathrm{OA}_{1}$ films.

From the reflectance spectra of an infinite thickness film, lightness $\left(\mathrm{L}^{*}\right)$, hue $\left(h^{*}{ }_{a b}\right)$, chroma $\left(C^{*}{ }_{a b}\right)$ and whiteness index $(W I)$ of each film were obtained as well as the total colour difference with respect to the pure $\mathrm{CH}$ film $(\triangle \mathrm{E})$ (Table 3.2.4). $\mathrm{CH}_{1}: \mathrm{OA}_{1}$ films showed higher lightness and $\mathrm{WI}$ than 
pure $\mathrm{CH}$ films, coherent with their lower internal transparency. The incorporation of increasing amounts of $\mathrm{C}$ led to a significant reduction of $\mathrm{WI}$ and lightness values, which was mitigated by OA addition. $\mathrm{C}$ yielded films with a yellower, more saturated colour (lower hue values and higher chroma). At both total lipid contents, the addition of OA reduced the colour changes induced by $\mathrm{C}$ and the total colour difference with respect to pure $\mathrm{CH}$ films.

\subsubsection{Equilibrium moisture content and barrier properties}

Equilibrium moisture content (EMC), WVP and OP values of films at $5{ }^{\circ} \mathrm{C}$ and $20^{\circ} \mathrm{C}$ are shown in Table 3.2.5. As expected, the increase in EMC with the decrease in temperature was observed, which is in agreement with the endothermic nature of the adsorption phenomenon. Changes in temperature could also affect the crystallization degree of polymer chains due to differences in molecular mobility and so the water adsorption capacity of the $\mathrm{CH}$ matrix since this is different for amorphous and crystalline regions. Several authors reported the crystalline structure of $\mathrm{CH}$ in films. Zhang, Ding, Ping and Yu (2006) described the development of crystallinity in $\mathrm{CH}$ matrices due to the formation of hydrogen bonds between flexible chains. The more dominated polymorph corresponds to hydrated crystals where water molecules are incorporated in to the crystal lattice (Wan, Wu, Yu and Wen, 2006).

The incorporation of lipid into the film matrix seems to reduce its water adsorption capacity. Nevertheless, when the water content was referred to a free-lipid basis, two groups of samples can be observed at both temperatures. One group consisted of $\mathrm{CH}_{1}$ and $\mathrm{CH}_{1}: \mathrm{OA}_{1}$ films, without significant differences in moisture content (free-lipid basis: $16.0 \pm 0.6 \%$ and $12.6 \pm 0.6 \%$ at $5{ }^{\circ} \mathrm{C}$ and $20^{\circ} \mathrm{C}$, respectively). The other group was composed by the films containing $\mathrm{C}$, which showed slightly lower values (free-lipid basis: $15.0 \pm 1.6 \%$ and $10.1 \pm 0.8 \%$ at $5{ }^{\circ} \mathrm{C}$ and $20{ }^{\circ} \mathrm{C}$, respectively). This result suggested that $\mathrm{C}$ molecules partially interact with $\mathrm{CH}$ chains blocking some active groups for water adsorption, especially at the highest temperature where hydrophobic interactions are promoted (Fabra, Talens and Chiralt, 2010). 
Table 3.2.5 Equilibrium moisture content (EMC), water vapour permeability (WVP) at $\mathrm{RH}$ gradient of $100 / 59 \%\left(T=5{ }^{\circ} \mathrm{C}\right)$ or $100 / 54 \%\left(T=20^{\circ} \mathrm{C}\right)$ and oxygen permeability (OP) at $10{ }^{\circ} \mathrm{C}-59 \% \mathrm{RH}$ or $20{ }^{\circ} \mathrm{C}-54 \% \mathrm{RH}$. Mean values and (standard deviation).

\begin{tabular}{|c|c|c|c|c|c|c|}
\hline \multirow[t]{2}{*}{ Film } & \multicolumn{2}{|c|}{$\begin{array}{c}\text { EMC } \\
\text { (wt. \%) }\end{array}$} & \multicolumn{2}{|c|}{$\begin{array}{c}\text { WVP } \times 10^{11} \\
\left(\mathrm{~g} \cdot \mathrm{m}^{-1} \cdot \mathrm{s}^{-1} \cdot \mathrm{Pa}^{-1}\right)\end{array}$} & \multicolumn{2}{|c|}{$\begin{array}{c}\text { OP } \\
\left(\mathrm{cm}^{3} \cdot \mathrm{mm} \cdot \mathrm{m}^{-2} \cdot \mathrm{atm}^{-1} \cdot \mathrm{day}^{-1}\right)\end{array}$} \\
\hline & $\mathrm{T}=5^{\circ} \mathrm{C}$ & $\mathrm{T}=20^{\circ} \mathrm{C}$ & $\mathrm{T}=5^{\circ} \mathrm{C}$ & $\mathrm{T}=20^{\circ} \mathrm{C}$ & $\mathrm{T}=10^{\circ} \mathrm{C}$ & $\mathrm{T}=20^{\circ} \mathrm{C}$ \\
\hline $\mathrm{CH}_{1}$ & $\begin{array}{c}20.6 \\
(0.4)^{a *}\end{array}$ & $\begin{array}{c}16.20 \\
(0.12)^{\mathrm{a} *}\end{array}$ & $\begin{array}{c}239 \\
(47)^{a^{*}}\end{array}$ & $\begin{array}{c}177 \\
(23)^{a^{*}}\end{array}$ & $\begin{array}{c}0.043 \\
(0.002)^{a^{*}}\end{array}$ & $\begin{array}{c}0.14 \\
(0.03)^{a^{*}}\end{array}$ \\
\hline $\mathrm{CH}_{1}: \mathrm{OA}_{0.25}: \mathrm{C}_{0.25}$ & $\begin{array}{c}16.1 \\
(0.8)^{b *}\end{array}$ & $\begin{array}{c}11.66 \\
(0.17)^{\mathrm{bc} *}\end{array}$ & $\begin{array}{l}228 \\
(41)^{a^{*}}\end{array}$ & $\begin{array}{c}190 \\
(29)^{a^{*}}\end{array}$ & $\begin{array}{c}0.0986 \\
(0.0012)^{b^{*}}\end{array}$ & $\begin{array}{c}0.176 \\
(0.014)^{b^{*}}\end{array}$ \\
\hline $\mathrm{CH}_{1}: \mathrm{C}_{0.5}$ & $\begin{array}{l}17.6 \\
(0.9)^{\mathrm{C*}}\end{array}$ & $\begin{array}{c}12.4 \\
(1.3)^{c^{*}}\end{array}$ & $\begin{array}{c}242 \\
(29)^{\mathrm{ac}}\end{array}$ & $\begin{array}{c}211 \\
(38)^{a}\end{array}$ & $\begin{array}{c}0.13 \\
(0.01)^{\mathrm{bc}}\end{array}$ & $\begin{array}{c}0.162 \\
(0.008)^{\mathrm{ab}}\end{array}$ \\
\hline $\mathrm{CH}_{1}: \mathrm{OA}_{0.5}: \mathrm{C}_{0.5}$ & $\begin{array}{c}13.0 \\
(0.3)^{d *}\end{array}$ & $\begin{array}{c}9.8 \\
(0.4)^{d *}\end{array}$ & $\begin{array}{c}187 \\
(32)^{b^{*}}\end{array}$ & $\begin{array}{c}105 \\
(28)^{b^{*}}\end{array}$ & $\begin{array}{c}0.16 \\
(0.02)^{c^{*}}\end{array}$ & $\begin{array}{c}0.344 \\
(0.017)^{c^{*}}\end{array}$ \\
\hline $\mathrm{CH}_{1}: \mathrm{C}_{1}$ & $\begin{array}{c}15.5 \\
(0.8)^{\mathrm{C*}}\end{array}$ & $\begin{array}{c}10.8 \\
(0.8)^{b d *}\end{array}$ & $\begin{array}{c}274 \\
(54)^{c^{*}}\end{array}$ & $\begin{array}{l}213 \\
(7)^{a^{*}}\end{array}$ & $\begin{array}{c}0.15 \\
(0.02)^{c^{*}}\end{array}$ & $\begin{array}{c}0.217 \\
(0.005)^{d^{*}}\end{array}$ \\
\hline $\mathrm{CH}_{1}: \mathrm{OA}_{1}$ & $\begin{array}{c}12.1 \\
(0.4)^{\mathrm{d} *}\end{array}$ & $\begin{array}{c}9.9 \\
(0.9)^{\mathrm{d} *}\end{array}$ & $\begin{array}{c}172 \\
(27)^{b^{*}}\end{array}$ & $\begin{array}{c}72 \\
(4)^{b^{*}}\end{array}$ & $\begin{array}{c}0.223 \\
(0.014)^{d^{*}}\end{array}$ & $\begin{array}{c}0.44 \\
(0.03)^{\mathrm{e}^{*}}\end{array}$ \\
\hline
\end{tabular}

a, b, c, d, e Different superscripts in the same column indicate $95 \%$ significant differences among formulations. ${ }^{*}$ Superscript indicates $95 \%$ significant differences between temperatures. CH: chitosan, OA: oleic acid, C: Cinnamon leaf essential oil. Subscripts indicate the ratio of film components.

The increase in temperature led to higher OP values whereas WVP values were significantly reduced. The decrease in barrier properties at higher temperatures is explained by the increase in molecular mobility and diffusion phenomena. Nevertheless, the opposite effect observed for WVP could be explained by the effect of the higher equilibrium moisture content reached at $5{ }^{\circ} \mathrm{C}$. An increase in water content also provokes higher molecular mobility, which favours mass transfer phenomena. This effect was also observed by Jiménez, Fabra, Talens and Chiralt (2010) in hydroxypropyl-methylcellulose films containing fatty acids. At both temperatures, WVP values of $\mathrm{CH}$ films were significantly reduced by $\mathrm{OA}$ incorporation, which coincides with the results previously reported by Vargas, Albors, Chiralt and González-Martínez (2009). However, the addition of $C$ significantly increased the WVP of the films $(p<0.05)$. This suggests that particular interactions of the $\mathrm{EO}$ compounds with $\mathrm{CH}$, as deduced from water sorption data, make the matrix more open to the transport of water molecules, despite the theoretical increase of the hydrophobic nature of the matrix due to the presence of lipids. This agrees with their plasticizing effect commented on above. Similar effects were 
found by Bonilla, Atarés, Vargas and Chiralt (2012) in CH films containing basil or thyme essential oils. WVP of $\mathrm{CH}_{1}: \mathrm{OA}_{0.25}: \mathrm{C}_{0.25}$ was in the range of pure $\mathrm{CH}$ films while $\mathrm{CH}_{1}: \mathrm{OA}_{0.5}: \mathrm{C}_{0.5}$ showed significantly lower values $(p<0.05)$.

At both temperatures, the addition of OA or $\mathrm{C}$ led to a significant increase in OP of the pure chitosan films, especially at the highest lipid content, as was observed for hydroxypropyl-methylcellulose films with ginger essential oil (Atarés, Pérez-Masiá and Chiralt, 2011). The liquid state of OA and C, together with their hydrophobic character, facilitates the oxygen transport in the film due to the increase of the oxygen solubility in the matrix. However, it is remarkable that pure OA seems to promote OP of the films to a greater extent than $\mathrm{C}$ or lipid blends, which again points to specific interactions of the $\mathrm{EO}$ compounds with $\mathrm{CH}$ molecules in the matrix that affect transport properties.

\subsubsection{Antioxidant activity}

The Trolox equivalent antioxidant capacity (TEAC) of cinnamon leaf essential oil, expressed as $\mu \mathrm{g}$ of sample that show the same activity as $1 \mathrm{mM}$ of Trolox, was $1.09 \pm 0.11$. Table 3.2.6 shows the TEAC values for dry films.

Table 3.2.6 Antioxidant activity expressed as $\mu \mathrm{g}$ of sample that show the same antioxidant activity as $1 \mathrm{mM}$ of Trolox. Mean values and (standard deviations).

\begin{tabular}{lcc}
\hline \multirow{2}{*}{ Sample } & \multicolumn{2}{c}{ TEAC $(\mu \mathrm{g})$} \\
\cline { 2 - 3 } & Dry film & Cinnamon Leaf EO in the dry film \\
\hline $\mathrm{CH}_{1}$ & $54(8)^{\mathrm{d}}$ & - \\
$\mathrm{CH}_{1}: \mathrm{OA}_{0.25}: \mathrm{C}_{0.25}$ & $19.7(1.6)^{\mathrm{c}}$ & $3.3(0.3)^{\mathrm{b}}$ \\
$\mathrm{CH}_{1}: \mathrm{C}_{0.5}$ & $13.4(1.5)^{\mathrm{b}}$ & $4.4(0.5)^{\mathrm{c}}$ \\
$\mathrm{CH}_{1}: \mathrm{OA}_{0.5}: \mathrm{C}_{0.5}$ & $11.0(1.8)^{\mathrm{b}}$ & $2.8(1.8)^{\mathrm{a}}$ \\
$\mathrm{CH}_{1}: \mathrm{C}_{1}$ & $5.1(0.9)^{\mathrm{a}}$ & $2.5(0.9)^{\mathrm{a}}$ \\
$\mathrm{CH}_{1}: \mathrm{OA}_{1}$ & $58(16)^{\mathrm{d}}$ & - \\
\hline
\end{tabular}

a, b, c, d Different superscripts in the same column indicate 95\% significant differences between formulations. CH: chitosan. OA: oleic acid. C: Cinnamon leaf essential oil. EO: essential oil. Subscripts indicate the ratio of film components.

Pure $\mathrm{CH}$ films show very low antioxidant activity (the highest TEAC values), which was not significantly affected by OA addition. On the other hand, all films containing $\mathrm{C}$ showed higher antioxidant activity. The higher the $\mathrm{C}$ content in the dry film, the lower the TEAC value and so, the greater 
antioxidant power. As expected, $\mathrm{OA}$ addition did not significantly affect the antioxidant activity of $\mathrm{C}$ in the films, since $\mathrm{CH}_{1}: \mathrm{C}_{0.5}$ and $\mathrm{CH}_{1}: \mathrm{OA}_{0.5}: \mathrm{C}_{0.5}$ showed similar TEAC values. Therefore, the antioxidant capacity of the films was attributed essentially to this ingredient and, thus, TEAC values were referred to the added $C$ content in the film (Table 3.2.6) to compare the different samples. These TEAC values were in the same range but they were higher than that obtained for pure $\mathrm{C}$, which indicates a loss of antioxidant capacity in the films. This can be explained by the losses in C essential oil during the film preparation, drying and extraction processes, as well as by the partial oxidation of its compounds. However, TEAC values of the $\mathrm{CH}_{1}: \mathrm{OA}_{0.5}: \mathrm{C}_{0.5}$ film were significantly lower than those of $\mathrm{CH}_{1}: \mathrm{C}_{0.5}$, in agreement with the greater retention of $\mathrm{C}$ essential oil compounds during film formation and handling when $\mathrm{OA}$ is present in the formulation.

\subsubsection{Antimicrobial properties}

As shown in Table 3.2.7, cinnamon leaf essential oil showed antifungal activity (inhibition halo was detected) against Aspergillus niger, Botrytis cinerea and Rhizopus stolonifer, providing C content is higher than $0.25 \%$.

Table 3.2.7 Antifungal effect of cinnamon leaf EO and films (expressed as diameter of the inhibition zone). Mean values and (standard deviations).

\begin{tabular}{|c|c|c|c|c|c|c|c|}
\hline \multirow[b]{3}{*}{ Time (days) } & \multicolumn{7}{|c|}{ Inhibition halo (mm) } \\
\hline & \multicolumn{2}{|c|}{ Aspergillus niger } & \multicolumn{3}{|c|}{ Botrytis cinerea } & \multicolumn{2}{|c|}{ Rhizopus stolonifer } \\
\hline & 1 & 3 & 1 & 3 & 6 & 1 & 3 \\
\hline $\mathrm{C}_{0.25}$ & $\mathrm{nh}$ & $\mathrm{nh}$ & NG & $64(5)^{a}$ & $\mathrm{nh}$ & $\mathrm{nh}$ & $\mathrm{nh}$ \\
\hline $\mathrm{C}_{0.5}$ & $50(2)^{a^{*}}$ & $4.0(0.4)^{a^{*}}$ & NG & NG & NG & $29(3)^{a^{*}}$ & $18(2)^{a^{*}}$ \\
\hline$C_{1}$ & $75(5)^{b}$ & $7.3(0.6)^{b}$ & NG & NG & NG & $35(3)^{b}$ & $32(2)^{b}$ \\
\hline $\mathrm{CH}_{1}$ & $\mathrm{nh}$ & $\mathrm{nh}$ & NG & $\mathrm{nh}$ & $\mathrm{nh}$ & $\mathrm{nh}$ & $\mathrm{nh}$ \\
\hline $\mathrm{CH}_{1}: \mathrm{OA}_{0.25}: \mathrm{C}_{0.25}$ & $\mathrm{nh}$ & $\mathrm{nh}$ & NG & $51(4)^{a^{*}}$ & $\mathrm{nh}$ & $\mathrm{nh}$ & $\mathrm{nh}$ \\
\hline $\mathrm{CH}_{1}: \mathrm{C}_{0.5}$ & $22(2)^{a}$ & $19.3(0.9)^{a}$ & NG & $\begin{array}{c}87.0 \\
(1.3)^{b^{*}}\end{array}$ & $\begin{array}{c}85.0 \\
(0.5)^{b^{*}}\end{array}$ & $28(2)^{a^{*}}$ & $24(2)^{a^{*}}$ \\
\hline $\mathrm{CH}_{1}: \mathrm{OA}_{0.5}: \mathrm{C}_{0.5}$ & $20(5)^{a}$ & $20(2)^{a}$ & NG & NG & NG & $26(5)^{a^{*}}$ & $20(4)^{b^{*}}$ \\
\hline $\mathrm{CH}_{1}: \mathrm{C}_{1}$ & $41(12)^{b}$ & $39(4)^{b}$ & NG & NG & NG & $\begin{array}{c}39.2 \\
(1.2)^{b^{*}}\end{array}$ & $33(6)^{c^{*}}$ \\
\hline $\mathrm{CH}_{1}: \mathrm{OA}_{1}$ & $\mathrm{nh}$ & $\mathrm{nh}$ & NG & $\mathrm{nh}$ & $\mathrm{nh}$ & $\mathrm{nh}$ & $\mathrm{nh}$ \\
\hline
\end{tabular}


Above this concentration, the higher the cinnamon leaf essential oil content, the greater the diameter of the inhibition halo. In the case of B. cinerea, total inhibition (no growth) was detected when $\mathrm{C}$ content was higher than $0.25 \%(w / w)$. When films were tested, no inhibition zone was observed when pure $\mathrm{CH}$ or $\mathrm{CH}_{1}: \mathrm{OA}_{1}$ films were placed in the inoculated agar plates or when the $\mathrm{CH}: \mathrm{C}$ essential oil ratio was lower than 0.5 . For the three fungi, the addition of cinnamon leaf oil at a $\mathrm{CH}: \mathrm{C}$ ratio $1: 0.5$ and $1: 1$ led to a fungal growth inhibition zone, which was greater when $\mathrm{C}$ oil ratio increased in the film and was not affected by OA addition. The highest inhibition was detected for $B$. cinerea, which showed no growth for $\mathrm{CH}_{1}: \mathrm{OA}_{0.5}: \mathrm{C}_{0.5}$ and $\mathrm{CH}_{1}: \mathrm{C}_{1}$ films.

Figure 3.2.3 shows the development of the fungal decay of the non-coated (control) and coated strawberries, inoculated with a spore suspension of R. stolonifer, throughout cold storage $\left(10{ }^{\circ} \mathrm{C}-70 \% \mathrm{RH}\right)$ or when stored under ambient conditions $\left(20^{\circ} \mathrm{C}-80 \% \mathrm{RH}\right)$. As expected, fungal decay was faster at higher temperature and higher $\mathrm{RH}$. The effect of coating was more significant at low temperature, which can be explained by the combined effect of temperature and antimicrobial coatings.

At $20{ }^{\circ} \mathrm{C}$ and $80 \% \mathrm{RH}$ (Figure 3.2.3a) the use of chitosan-based coatings, promoted an initial significant decrease in fungal decay, as compared to control samples. The percentage of damaged strawberries decreased when $\mathrm{C}$ was incorporated at a $\mathrm{CH}: \mathrm{C}$ ratio higher than $1: 0.25$, which is in agreement with the in vitro test. No significant effects in terms of antifungal effect were promoted by $\mathrm{OA}$ addition at $20^{\circ} \mathrm{C}$. Whereas non-coated samples lasted for 2 days, coated samples showed a long shelf-life.

In cold storage (Figure 3.2.3b), the lowest percentage of damaged strawberries was detected in samples coated with $\mathrm{CH}_{1}: \mathrm{C}_{0.5}$. In these, fungal decay remained almost constant throughout the whole period of storage (14 days). This effect was not observed in samples coated with $\mathrm{CH}_{1}: \mathrm{OA}_{0.5}: \mathrm{C}_{0.5}$, despite containing theoretically greater amount of $\mathrm{C}$ in line with the greater retention promoted by OA. This could be due to the entrapment of $\mathrm{C}$ compounds in the non-polar core of OA micelles which make their diffusion and antimicrobial action difficult. In this sense, it is remarkable that from about 9 days $\mathrm{CH}_{1}: \mathrm{OA}_{0.5}: \mathrm{C}_{0.5}$ films were more effective than $\mathrm{CH}_{1}: \mathrm{OA}_{0.25}: \mathrm{C}_{0.25}$ in line with the possible greater release of the $\mathrm{C}$ compounds. 

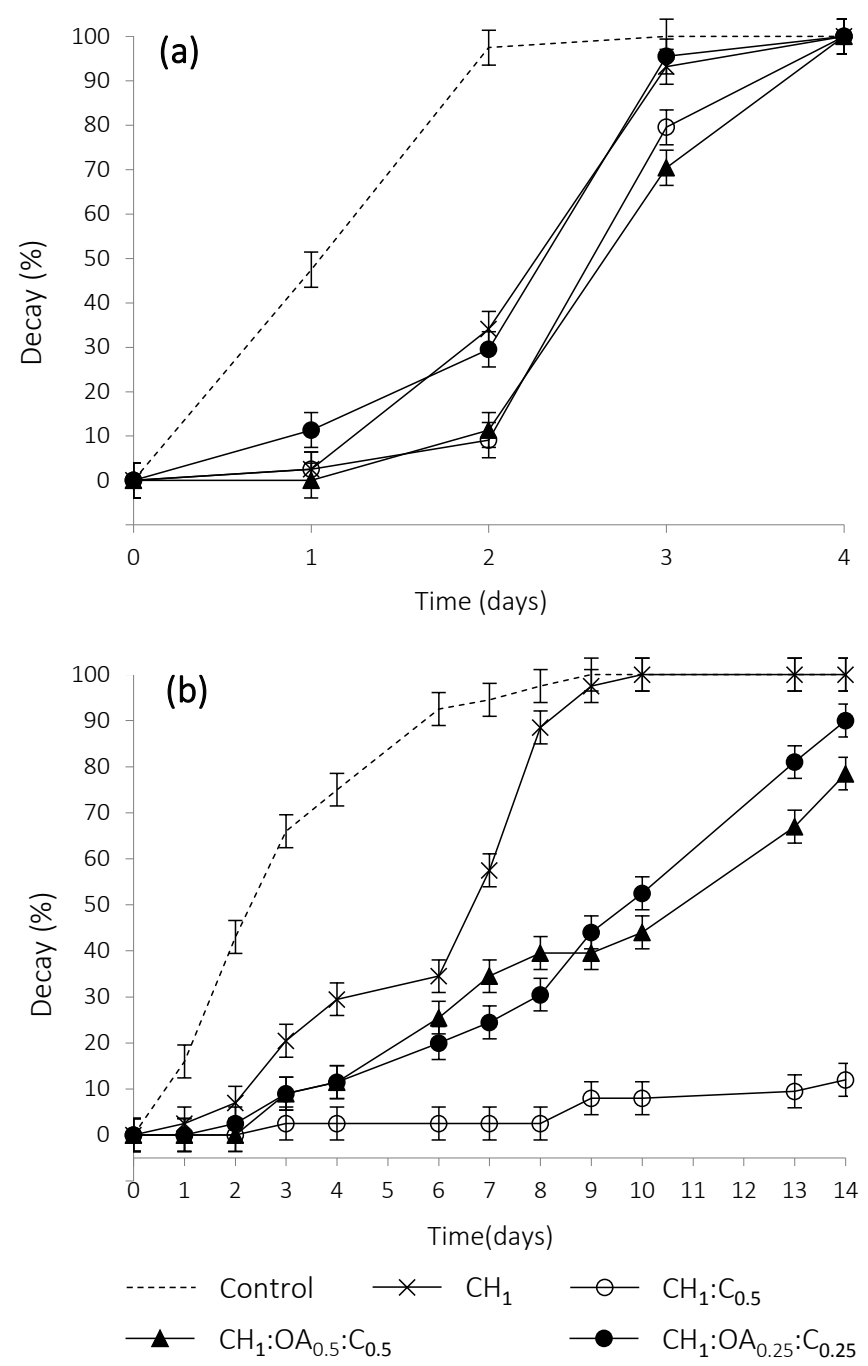

Figure 3.2.3 Fungal decay (expressed as percentage of infected samples) of strawberries inoculated with a $10^{5} \mathrm{spore} / \mathrm{mL}$ suspension of Rhizopus stolonifer and stored at (a) $20{ }^{\circ} \mathrm{C}-80 \% \mathrm{RH}$ and (b) $10{ }^{\circ} \mathrm{C}-70 \% \mathrm{RH}$. OA: oleic acid.

$\mathrm{C}$ : Cinnamon leaf essential oil. Subscripts indicate the ratio of film components.

Figure 3.2.4 shows the total aerobial (a), coliform (b), and moulds and yeast (c) counts for cold-stored samples. All coatings reduced the microbial counts, but the addition of $\mathrm{C}$ led to an increase of the antimicrobial effect of $\mathrm{CH}$ coatings. The higher the $\mathrm{C}$ ratio, the lower the microbial counts. $\mathrm{OA}$ addition had no notable effect on the antimicrobial effect of the coatings, although it reduced the effectiveness in the case of coliform counts. 

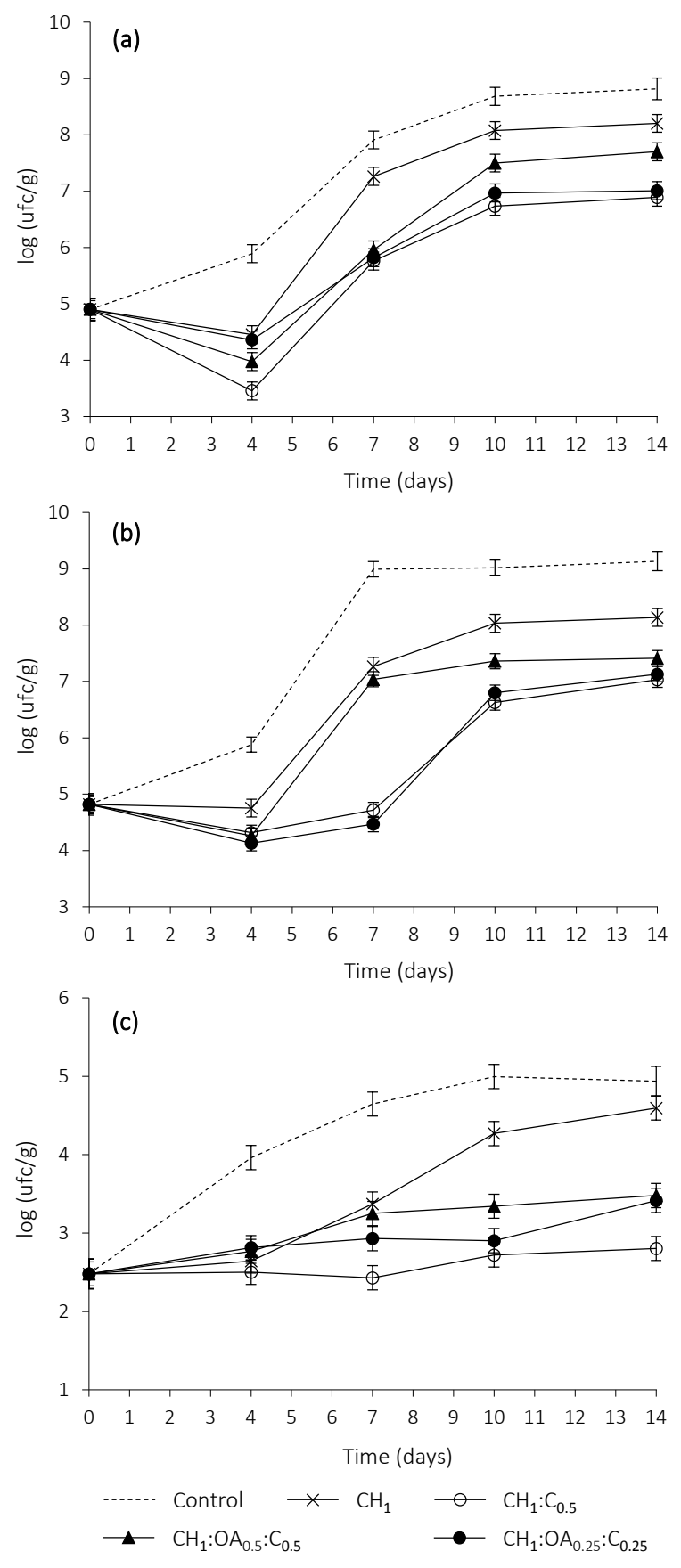

Figure 3.2.4 (a) Total aerobial, (b) moulds and yeasts and (c) coliforms counts of strawberries inoculated with a $10^{5} \mathrm{spore} / \mathrm{mL}$ suspension of Rhizopus stolonifer and stored at $10{ }^{\circ} \mathrm{C}-70 \% \mathrm{RH}$. $\mathrm{CH}$ : chitosan, OA: oleic acid, C: cinnamon leaf essential oil. Subscripts indicate the ratio of film components. 


\section{CONCLUSIONS}

Chitosan-cinnamon leaf essential oil films showed antifungal activity against Aspergillus niger, Botrytis cinerea and Rhizopus stolonifer and allowed for a significantly increase in the self-life of strawberries infected with $R$. stolonifer. Nevertheless, these films showed worse barrier properties than pure chitosan films. The addition of oleic acid to chitosan-cinnamon leaf essential oil films promoted essential oil retention into the film matrix during film drying. Oleic acid incorporation led to a significant reduction in the water vapour permeability and a diminution of the changes in colour and mechanical properties that were promoted by essential oil addition. Oleic acid slightly reduced the antifungal efficacy of the $\mathrm{CH}-\mathrm{C}$ films probably due to the encapsulation of the essential oil, which in turn can limit the release of cinnamon leaf's active compounds to the surface of the coated product. These results suggest that it is possible to formulate antifungal edible films based on chitosan and cinnamon leaf essential oil with adequate properties by the incorporation of oleic acid into the film-forming dispersion.

\section{Acknowledgements}

The authors acknowledge the financial support provided by Universitat Politècnica de València (UPPTE/2012/183) and Ministerio de Ciencia e Innovación (AGL2010-20694). Ángela Perdones also thanks the Universitat Politècnica de València for the FPI grant. 


\section{REFERENCES}

ASTM. Standard test methods for water vapor transmission of materials. Standard designations: E96-95. In Annual Book of ASTM Standards (pp. 406 - 413). ASTM (Philadelphia) 1995.

ASTM. Standard test method for specular gloss. Standard designation D523. In Annual Book of ASTM Standards (Vol.06.01). ASTM (Philadelphia) 1999.

ASTM. Standard test method for tensile properties of thin plastic sheeting. Standard D882. In Annual Book of ASTM Standards (pp. $162-170$ ). ASTM (Philadelphia) 2001.

ASTM. Standard test method for oxygen gas transmission rate through plastic film and sheeting using coulometric sensor. Standard designation D 3985-05. In Annual Book of ASTM Standards (pp. 472-477). ASTM (Philadelphia) 2002.

Atarés, L., Pérez-Masiá, R., Chiralt, A. The role of some antioxidants in the HPMC film properties and lipid protection in coated toasted almonds. Journal of Food Engineering 104:4 (2011) 649 - 656.

Bakkali, F., Averbeck, S., Averbeck, D., Idaomar, M. Biological effects of essential oils $-A$ review. Food and chemical toxicology 46:2 (2008) $446-475$.

Bonilla, J., Atarés, L., Vargas, M., Chiralt, A. Effect of essential oils and homogenization conditions on properties of chitosan based films. Food Hydrocolloids 26:1 (2012) 9 - 16.

CIE. Colorimetry. (2 ${ }^{\text {nd }}$ Ed.). (Technical Report CIE 15.2) Commission Internationale de L'Eclairage (Paris) 1986.

Fabra, M.J., Talens, P., Chiralt, A. Water sorption isotherms and phase transitions of sodium caseinate-lipid films as affected by lipid interactions. Food Hydrocolloids 24: (2010) $384-391$. 
Gennadios, A., Weller, C.L., Gooding, C.H. Measurements errors in water vapour permeability of highly permeable, hydrophilic edible films. Journal of Food Engineering 21:4 (1994) 395 - 409.

Hutchings, J.B. Food and colour appearance. (2 $2^{\text {nd }}$ Ed.). Aspen Publication (Gaithersburg) 1999.

Jiménez, A., Fabra, M. J., Talens, P., Chiralt, A. Effect of lipid self-association on the microstructure and physical properties of hydroxypropyl-methylcellulose edible films containing fatty acids. Carbohydrate Polymers 82:3 (2010) 585 - 593.

McClements, D.J. Food emulsions: principles, practice, and techniques (pp. 341 - 388). CRC Press LLC, Boca Raton (Florida) 2005.

No, H.K., Park, N.Y., Lee, S.H., Meyers, S.P. Antibacterial activity of chitosans and chitosan oligomers with different molecular weights. International journal of food microbiology. 74:1 (2002) 65-72.

Perdones, A., Sánchez-González, L., Chiralt, M., Vargas, M. Effect of chitosan-lemon essential oil coatings on storage-keeping quality of strawberry. Postharvest Biology and Technology 70 (2012) $32-41$.

Re, R., Pellegrini, N., Proteggente, A., Pannala, A., Yang, M., Rice-Evans, C. Antioxidant activity applying an improved ABTS radical cation decoloration assay. Free radical biology and medicine 26:9 (1999) 1231 - 1237.

Sacchetti, G., Maietti, S., Muzzoli, M., Scaglianti, M., Manfredini, S., Radice, M., Bruni, R. Comparative evaluation of 11 essential oils of different origin as functional antioxidants, antiradicals and antimicrobials in foods. Food Chemistry 91:4 (2005) 621-632.

Sánchez-González, L., Cháfer, M., Chiralt, A., González-Martínez, C. Physical properties of edible chitosan films containing bergamot essential oil and their inhibitory action on Penicillium italicum. Carbohydrate Polymers 82:5 (2010) $277-283$.

Sánchez-González, L., Vargas, M., González-Martínez, C., Chiralt, A., Cháfer, M. Use of Essential Oils in Bioactive Edible Coatings. Food Engineering Reviews 3:1 (2011a) 1- 16. 
Sánchez-González, L., Cháfer, M., Chiralt, A., González-Martínez, C. Effect of essential oils on properties of film forming emulsions and films based on hydroxypropylmethylcellulose and chitosan. Journal of Food Engineering 105:2 (2011b) $246-253$.

Sánchez-González, L., Cháfer, M., González-Martínez, C., Chiralt, A., Desobry, S. Study of the release of limonene present in chitosan films enriched with bergamot oil in food stimulants. Journal of Food Engineering 105:1 (2011c) $138-143$.

Singh, G., Maurya, S., deLampasona, M.P., Catalan, C.A.N. A comparison of chemical, antioxidant and antimicrobial studies of cinnamon leaf and bark volatile oils, oleoresins and their constituents. Food and Chemical Toxicology 45:9 (2007) $1650-1661$.

Tharanathan, R.N., Kittur, F.S. Chitin - The undisputed biomolecule of great potential. Critical Reviews in Food Science and Nutrition 43:1 (2003) $61-87$.

Vangalapati, M., Satya S.N., Prakash D.V.S., Avanigadda, S.A. Review on pharmacological activities and clinical effects of cinnamon species. Research Journal of Pharmaceutical, Biological and Chemical 3:1 (2012) $653-663$.

Vargas, M., Pastor, C., Chiralt, A., McClements, D.J., González-Martínez, C. Recent advances in edible coatings for fresh and minimally processed fruits. Critical Reviews in Food Science and Nutrition 48:6 (2008) 496 - 511.

Vargas, M., Albors, A., Chiralt, A., González-Martínez, C. Characterization of chitosan-oleic acid composite films. Food Hydrocolloids 23:2 (2009) $536-547$.

Vargas, M., Perdones, A., Chiralt, A., Cháfer, M., González-Martínez, C. Effect of Homogenization Conditions on Physicochemical Properties of Chitosan-Based Film-Forming Dispersions and Films. Food Hydrocolloids 25:5 (2011) $1158-1164$.

Vargas, M., Sánchez-González, L., Chiralt, A., Cháfer, M., González-Martínez, C. Edible chitosan coatings for fresh and minimally processed foods. In K.L. Yam, D.S. Lee (Eds.), Emerging food packaging 
technologies: Principles and practice. (pp. 66-95). Woodhead Publishing Limited (Cambridge) 2012.

Vu, K.D., Hollingsworth, R.G., Leroux, E., Salmieri, S., Lacroix, M. Development of edible bioactive coating based on modified chitosan for increasing the shelf life of strawberries. Food Research International 44:1 (2011) $198-203$.

Wan, Y., Wu, H., Yu, A., Wen, D. Biodegradable polylactide/chitosan films blend membranes. Biomacromolecules 7:4 (2006) $1362-1372$.

Wang, L., Liu, F., Jiang, Y., Chai, Z., Li, P., Cheng, Y., Jing, H., Leng, X. Synergistic Antimicrobial Activities of Natural Essential Oils with Chitosan Films. Journal of Agricultural and Food Chemistry 59:23 (2011) $12411-12419$.

Zhang, C., Ding, Y., Ping, Q., Yu, L.L. Novel chitosan derived nanomaterials and their micelle-forming properties. Journal of Agricultural and Food Chemistry 54:22 (2006) $8409-8416$. 



\section{CHAPTER 4}

\section{EFFECT OF CHITOSAN COATINGS CONTAINING ESSENTIAL OILS ON TOMATO PLANTS AND FRUITS}

EFFECT ON TOMATO PLANT AND FRUIT OF THE APPLICATION OF BIOPOLYMER-OREGANO ESSENTIAL OILS COATINGS 



\section{EFFECT ON TOMATO PLANT AND FRUIT OF THE APPLICATION OF BIOPOLYMER-OREGANO ESSENTIAL OILS COATINGS}

Ángela Perdones, Núria Tur, Amparo Chiralt, Maria Vargas $^{*}$

Journal of the Science of Food and Agriculture. Accepted.

Department of Food Technology-Institute of Food Engineering for Development, Universitat Politècnica de València, Camino de Vera s/n, 46022 Valencia, Spain.

*Telephone: 0034963877000 Ext.73642 Fax: 0034963877369

e-mail:mavarco@tal.upv.es 


\section{ABSTRACT}

BACKGROUND: Oregano essential oil (EO) was incorporated into film-forming dispersions (FFD) based on biopolymers (chitosan and/or methylcellulose) at two concentration levels. The effect of the application of the FFD was evaluated on tomato plants (cultivar Micro-Tom) at three different stages of development, and on preharvest and postharvest applications on tomato fruits.

RESULTS: The application of the FFD at "3 Leaves" stage caused phytotoxic problems, which were lethal when the EO was applied without biopolymers. Even though plant growth and development were delayed, the total biomass and the crop yield were not affected by biopolymer-EO treatments. When the FFD were applied in the "Fruit" stage the preharvest application of FFD had no negative effects. All FFD containing EO significantly reduced the respiration rate of tomatoes, diminished weight loss during storage. Moreover, biopolymer-EO FFD led to a decrease in the fungal decay of tomatoes inoculated with Rhizopus stolonifer spores, as compared with non-treated fruits and those coated with FFD without EO.

CONCLUSION: The application of biopolymer-oregano essential oil coatings has been proven to be an effective treatment to control $R$. stolonifer in tomato fruit.

Keywords: Coating, preharvest, postharvest, chitosan, methylcellulose, decay. 


\section{INTRODUCTION}

Tomato fruit (Solanum lycopersicum) is one of the most important crops in the world due to its economic and nutritional value. Tomato is a climacteric fruit and has a short postharvest life, which is limited by several factors like transpiration and postharvest diseases. Rhizopus stolonifer is the most predominant fungus of tomato fruit and is also acquired during harvest, handling and transportation (Ramos-García et al., 2012).

Among the plethora of tomato genotypes, Micro-Tom cultivar has being extensively used as model plant based on the following characteristics: short life cycle $(70-90$ days), small plant size $(10-20 \mathrm{~cm})$, small fruit size ( $2 \mathrm{~cm}$ in diameter). This cultivar was developed by crossing Florida Baket and Ohio 4013-3 cultivars (Scott and Harbaugh, 1989). Several studies suggested that Micro-Tom cultivar exhibits the above mentioned characteristics due to several mutations (Lima, Carvalho, Neto, Figueira and Peres, 2004; Martí, Gisbert, Bishop, Dixon and García-Martínez, 2006; Meissner et al., 1997).

Natural ingredients such as antimicrobials obtained from plant sources are becoming of great interest both in crop protection and food preservation due to worldwide awareness of environmental and food safety concerns associated with non-natural additives. The general use of synthetic fungicides in plant protection has resulted in the development of resistances, toxicity to non-target organisms and adverse effects on the environment, among other undesirable outcomes (Matusinsky, Zouhar, Pavela and Novy, 2015). Essential oils are natural antioxidants and antimicrobial lipidic substances extracted from fruits and vegetables with an intense aroma (Bakkali, Averbeck, Averbeck and Idaomar, 2008). The most common components of essential oils are terpens and terpenoids (Smith-Palmer, Stewart and Fyfe, 2001). The composition of essential oils can vary depending on agronomic factors and characteristics of the raw material (Bendahou et al., 2008; Sari et al., 2006). The main components of oregano essential oil (Origanum compactum) are carvacrol, thymol, $\gamma$-terpinene and p-cymene. Essential oils are highly volatile and thus high doses are required in order to achieve the desired antifungal effect, which 
in turn can entail phytotoxicity problems and high application costs. Previous studies have shown the effectiveness of oregano essential oil vapours to control fungal decay in greenhouses in tomato plant (Soylu, Kurt and Soylu, 2010) as well as in tomato fruit by means of postharvest applications (Tzortzakis, 2010). Nevertheless, previous works have pointed out the necessity of controlling the application dose in greenhouses in order to prevent the occurrence of signs of phytotoxicity in tomato plant and in the fruit (Wogiatzi, Gougoulias, Papachatzis, Vagelas and Chouliaras, 2009).

An interesting strategy for reducing dose of EO and decrease their potential adverse effects, is to incorporate them in film-forming dispersions based on biopolymers, such as chitosan and methylcellulose (Sánchez-González, Vargas, González-Martínez, Chiralt and Cháfer, 2011). Chitosan is a biodegradable cationic hydrocolloid with antimicrobial and antioxidant activity that shows excellent film-forming ability (Shiekh, Malik, Al-Thabaiti and Shiekh, 2013; Tharanathan and Kittur, 2003). Chitosan-based films can modify the internal atmosphere of coated products thus delaying fruit ripening and decreasing the respiration rate (Vargas, Pastor, Chiralt and McClements, 2008). Methylcellulose is a biopolymer with good film-forming characteristics, which is colourless, odourless and resistant to fats (Turhan and Sahbaz, 2004). Methylcellulose is compatible with chitosan, yielding composite films with lower water vapour permeability than pure chitosan films (Vargas, Albors, Chiralt and González-Martínez, 2011).

Several studies have reported the effects of the application of chitosan-based edible coatings on different fruits (Vargas, Sánchez-González, Chiralt, Cháfer and González-Martínez, 2012). Chitosan-based coatings inhibited the growth of Botrytis cinerea and improved resistance of tomato fruit against gray mould during storage (Badawy and Rabea, 2009). Chitosan-beeswax-lime EO coatings inhibited the growth of Rhizopus stolonifer in tomato fruit at three different maturity stages throughout storage. However, to the best of our knowledge, there are no published studies on the application of chitosan-methylcellulose based films enriched with oregano essential oil on tomato fruits. 
The aim of this work was to evaluate in tomato plant and fruit the effect of preharvest and postharvest applications of film-forming dispersions based on chitosan and/or methylcellulose containing oregano essential oil.

\section{MATERIALS AND METHODS}

\subsection{Materials}

High molecular weight chitosan (CH) (acetylation degree of $24 \%$, viscosity in glacial acetic acid solution in $1 \%=1.3 \mathrm{~Pa} \cdot \mathrm{s}$. Sigma-Aldrich, USA), Methylcellulose (MC) (VWR, Barcelona, Spain), glacial acetic acid (Panreac, Barcelona, Spain), Tween85 (Sigma-Aldrich, USA), liquid silicone defoamer (Panreac, Barcelona, Spain) and oregano essential oil (EO) (Herbes del Molí, Alicante, Spain) with a composition of $46.1 \%$ carvacrol, $25.6 \%$ thymol, $10.5 \% \gamma$-terpinene and $7.5 \%$ p-cymene as the major elements were used to prepare the FFD.

For the in vivo assays, tomatoes cv. Micro-Tom cultivated under controlled temperature and humidity in greenhouse (ETSEAMN, Universitat Politècnica de València) were used.

Stock culture of Rhizopus stolonifer (CECT 2344, Burjasot, Spain) was used for the in vitro assays. As an enrichment medium for the microbiological analyses buffered peptone water (BPW) (Scharlau, Barcelona, Spain) was used. R. stolonifer was cultured on potato dextrose broth (PDB) (Scharlau, Barcelona, Spain) and bacteriological agar (BA) (Scharlau, Barcelona, Spain). For the counting of the fungi Sabouraud Chloramphenicol (Scharlau, Barcelona, Spain) agar was used.

\subsection{Preparation of the film-forming dispersions and stand-alone films}

Chitosan $(\mathrm{CH})(0.5 \% \mathrm{w} / \mathrm{w})$ was dispersed in an aqueous solution of glacial acetic acid $(0.5 \% \mathrm{v} / \mathrm{w})$ and kept under continuous stirring for $12 \mathrm{~h}$. At the same time, Methylcellulose (MC) $(0.5 \% \mathrm{w} / \mathrm{w})$ was dispersed and heated up to $80^{\circ} \mathrm{C}$ for $10 \mathrm{~min}$. Once dissolved methylcellulose was cooled to $5-10{ }^{\circ} \mathrm{C}$ for $20 \mathrm{~min}$. Both dispersions were mixed in the right proportions to obtain 
the film-forming dispersions (FFD). To prepare $\mathrm{CH} / \mathrm{MC}$-essential oil (EO) FFD, EO was incorporated at 0.25 or $0.5 \%$ (w/w) concentration. Tween 85 $(0.01 \% \mathrm{v} / \mathrm{v})$ and silicone $(0.01 \% \mathrm{v} / \mathrm{v})$ were added in each FFD to favour their extensibility on the plat tissues and to avoid bubble formation, respectively. The formulations were named as follows: $\mathrm{MC}_{0.5}, \mathrm{MC}_{0.25} \mathrm{CH}_{0.25}$, $\mathrm{MC}_{0.5} \mathrm{EO}_{0.25}, \mathrm{MC}_{0.5} \mathrm{EO}_{0.5}, \mathrm{MC}_{0.25} \mathrm{CH}_{0.25} \mathrm{EO}_{0.25}, \mathrm{MC}_{0.25} \mathrm{CH}_{0.25} \mathrm{EO}_{0.5}$ where the subscript stands for the concentration (wt. \%) of the ingredient in the FFD. For in vivo assays two more treatments were used: Aqueous dispersions of $E O$ at $0.25 \%(w / w)$, named as $E_{0.25}$, and $E O$ at $0.5 \%(w / w)$, named as $\mathrm{EO}_{0.5}$. Tween 85 and silicone were also added at $0.01 \% \mathrm{v} / \mathrm{v}$.

All FFD and EO dispersions were homogenized with a rotor-stator (Ultra TurraxT-25 digital, IKA, Germany) at 13,400 rpm for $4 \mathrm{~min}$. The final emulsions were degassed using a vacuum pump (Diaphragm VacuumPump MZ2CNT, Vacuubrand, Germany).

Stand-alone coatings were obtained by casting, pouring an amount of FFD enough for provide a solids surface density of $56 \mathrm{~g} / \mathrm{m}^{2}$ as described by Vargas, Albors, Chiralt and González-Martínez (2009a). All FFD were poured into polystyrene Petri dishes with $90 \mathrm{~mm}$ diameter. The samples were dried for $72 \mathrm{~h}$ at room temperature (about $25^{\circ} \mathrm{C}$ ) and $60 \%$ relative humidity $(\mathrm{RH})$. Dry films were peeled off from the Petri dishes and used for the in vitro assays.

\subsection{Antifungal activity in vitro assays}

PDA medium was sterilized and aseptically poured into sterile Petri dishes with $90 \mathrm{~mm}$ of diameter ( $20 \mathrm{~g}$ per Petri dish). After the culture medium solidified, a $100 \mu \mathrm{L}$ aliquot from a $10^{6}$ spores $/ \mathrm{mL}$ suspension was inoculated on the surface of each Petri dish. The different films were placed on the inoculated surfaces, following the methodology reported by Perdones, Sánchez-González, Chiralt and Vargas (2012). Inoculated and non-coated samples without film were used as control samples. Petri dishes were sealed with Parafilm to avoid dehydration and incubated at $25^{\circ} \mathrm{C}$ (optimal growth temperature of $R$. stolonifer). At different times of storage, Petri dishes content was removed aseptically and placed in a sterile plastic bag with $90 \mathrm{~mL}$ of BPW. The bags were homogenized with a Stomacher (Interscience BagMixer Stomacher $400 \mathrm{~W}$ Homogenizer, France). Serial dilutions were made and then poured into SCA Petri dishes. 
Samples were incubated at $25{ }^{\circ} \mathrm{C}$ for 24 hours before colonies were counted. All the tests were run in triplicate.

\subsection{Application of the treatments on tomato plants and fruits}

The application of all treatments on the tomato plants was made on three different moments according to their stage of development according to the solanaceae BBCH extended scale reference (Feller et al., 1995; Meier, 2001): 113 stage (3 Leaves), 6 stage (Flowers) and 7 stage (Fruits). All applications were made with a pre-pressure sprayer (Menan Agrícola, Algemesí, Valencia, Spain) under controlled conditions of amount of product spilled and nozzle-plant distance. In the first stage, 10 plants per treatment and 10 for control were selected (90 plants). Prior to the application in stage 6 (Flowers), 5 flowers per plant were labelled. After the application of the different treatments, the following parameters were monitored in tomato plants: physiological damage, fruit set ratio (fruits/flowers), fruit size, plant yield and physiological state. In the applications at the stage 7 of development (Fruits), 56 plants with green fruits were sprayed ( 8 plants per treatment) and the fruits were harvested one week after the application of the different treatments. For the postharvest application, green fruits around $2-2.5 \mathrm{~cm}$ in diameter were harvested and transported to the facilities of the Institute of Food Engineering for Development (Valencia, Spain) to apply the different treatments.

\subsection{Respiration rate and weight loss of tomato fruits}

Tomato fruits (15 tomatoes per treatment) were introduced in $940 \mathrm{~mL}$ hermetic glass jar with a septum in the lid for sampling the gas in the headspace every two hours with a gas analyser (PBI Dansensor CheckMate 9900, Ringsted, Denmark). The jars were kept at $25^{\circ} \mathrm{C}$. Two replicates were performed per treatment. The respiration rate, $R R_{i}\left(m g \cdot \mathrm{kg}^{-1} \cdot \mathrm{h}^{-1}\right)$, of the samples in terms of $\mathrm{CO}_{2}$ generation and $\mathrm{O}_{2}$ consumption was determined from the slope of the fitted linear equation of the gas concentration in front of time as described by Vargas, Albors, Chiralt and González-Martínez (2006). In order to record the variation on the sample weight during the storage, fruits were weighed regularly with a balance (Sartorius Extend ED423S, Germany). 


\subsection{Colour of tomato fruits}

The colour of the fruits was determined using a spectrocolorimeter (Minolta CM-3600d, Tokyo, Japan) previously calibrated. CIE-L*a*b* coordinates, hue $\left(h^{*}{ }_{a b}\right)\left(\right.$ Eq. 4.1) and chroma $\left(C^{*}{ }_{a b}\right)$ (Eq. 4.2), were obtained from the reflection spectra of the samples using D65 illuminant $/ 10^{\circ}$ observer (Vargas, Albors, Chiralt and González-Martínez, 2006).

$$
\begin{aligned}
h_{a b}^{*} & =\tan ^{-1}\left(\frac{b^{*}}{a^{*}}\right) \\
C_{a b}^{*} & =\sqrt{a^{* 2}+b^{* 2}}
\end{aligned}
$$

Five fruits per treatment were measured. To avoid the effects of heterogeneity on the raw material, measurements were always carried out in the same 5 previously marked tomatoes.

\subsection{Acidity, pH, soluble solids and maturity index of tomato fruits}

Acidity, $\mathrm{pH}$ and soluble solids were determined in triplicate as described by Perdones, Sánchez-González, Chiralt and Vargas (2012). Acidity was analysed following method AOAC 942.15 (AOAC, 1995), and was expressed as $\mathrm{g}$ of citric acid per $100 \mathrm{~g}$ of sample. In order to measure the $\mathrm{pH}, 3 \mathrm{~g}$ of each sample were weighed and added to $20 \mathrm{~mL}$ of distilled water. Measurement of $\mathrm{pH}$ was carried out by means of a pH-meter (GLP 21+, Crison, Barcelona, Spain). Soluble solids (Brix) were measured with a refractometer (Minolta, Japan). Maturity index (MI) was calculated as the quotient between Brix degrees and acidity.

\subsection{Fungal decay of tomato fruits}

Fully ripe non-treated tomatoes were placed on plastic grilles. One group of samples (20 tomatoes per treatment) was inoculated with $25 \mu \mathrm{L}$ of a Rhizopus stolonifer spore suspension $\left(10^{5}\right.$ spores $\left./ \mathrm{mL}\right)$, and the treatments were applied by spraying (curative treatments). The other group of samples (20 tomatoes per treatment) was first treated with the different treatments by spraying and then inoculated (preventive treatment). Each tomato fruit was inoculated with $25 \mu \mathrm{L}$ of a $R$. stolonifer suspension $\left(10^{5} \mathrm{spores} / \mathrm{mL}\right)$, which was settled to the peduncle scar. 


\subsection{Statistical analysis}

The results were submitted to an analysis of variance (ANOVA) by using STATGRAPHICS Centurion XVI (16.2.04 version) and taking into account the effect of the formulation (treatments). Comparisons were performed through LSD intervals at a $95 \%$ significance level.

\section{RESULTS AND DISCUSSION}

\subsection{In vitro assays}

Stand-alone films were transparent and slightly white as shown in Figure 4.1a. The films were deposited on the inoculated PDA plates and after 3 weeks of storage at $25^{\circ} \mathrm{C}$, all films containing oregano EO inhibited fungal sporulation (Figure 4.1b).
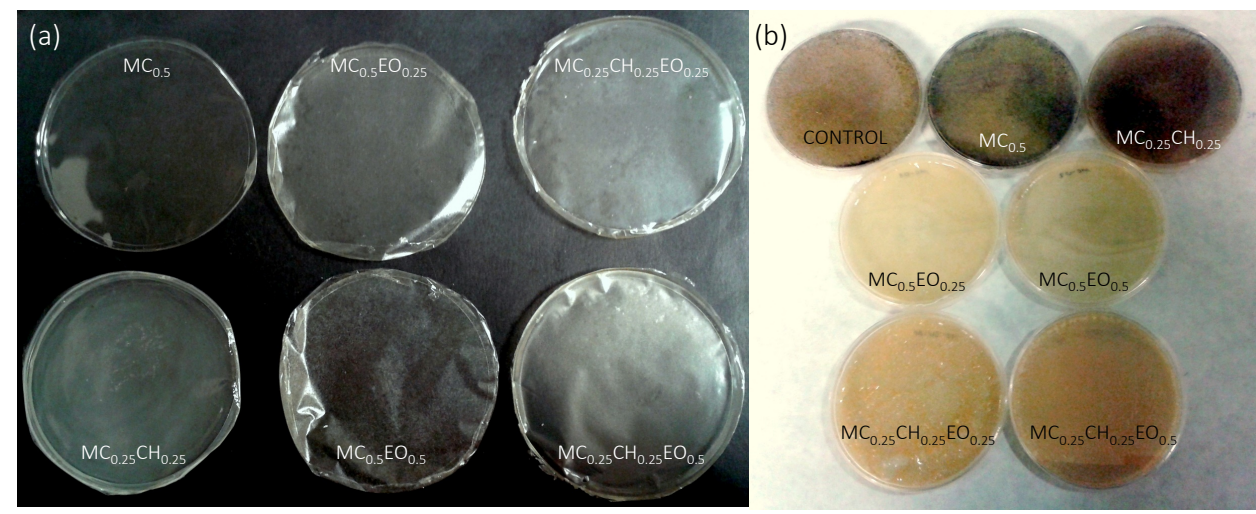

Figure 4.1 (a) Stand-alone films (b) Petri dishes inoculated with the spore suspension of Rhizopus stolonifer and coated with the films and non-coated (control) after 13 days of incubation at $25^{\circ} \mathrm{C}$. MC: methylcellulose, $\mathrm{CH}$ : chitosan,

EO: essential oil. Subscripts indicate the ratio of film components.

The evolution of the $R$. stolonifer counts during storage at $25^{\circ} \mathrm{C}$ is shown in Figure 4.2. At initial time the microbial counts of agar plates coated with films containing $\mathrm{CH}$ and/or EO were significant lower than the counts obtained in non-coated agar plates (control) and in the plates coated with pure polymer films. Similar inhibitory effect against $R$. stolonifer was 
obtained by Alvarado, Barrera, Hernández and Velázquez (2011) by using $\mathrm{CH}$-thyme essential oil films. It is important to point out that in the present study the plates coated with the films that contained EO showed no fungal growth during the whole storage period. MC films did not promote a significant reduction in fungal growth, as compared with control samples. When $\mathrm{CH}$ was added into the formulations, a significant reduction in the microbial counts was obtained during the first week of storage, in agreement with the antimicrobial effect of $\mathrm{CH}$ reported in previous in vitro studies performed with $R$. stolonifer isolated from tomato fruit (El Ghaouth, Arul, Grenier and Asselin, 1992a; Hernández-Lauzardo, Velázquez-del Valle, Veranza-Catelán and Melo-Giorgana, 2010).

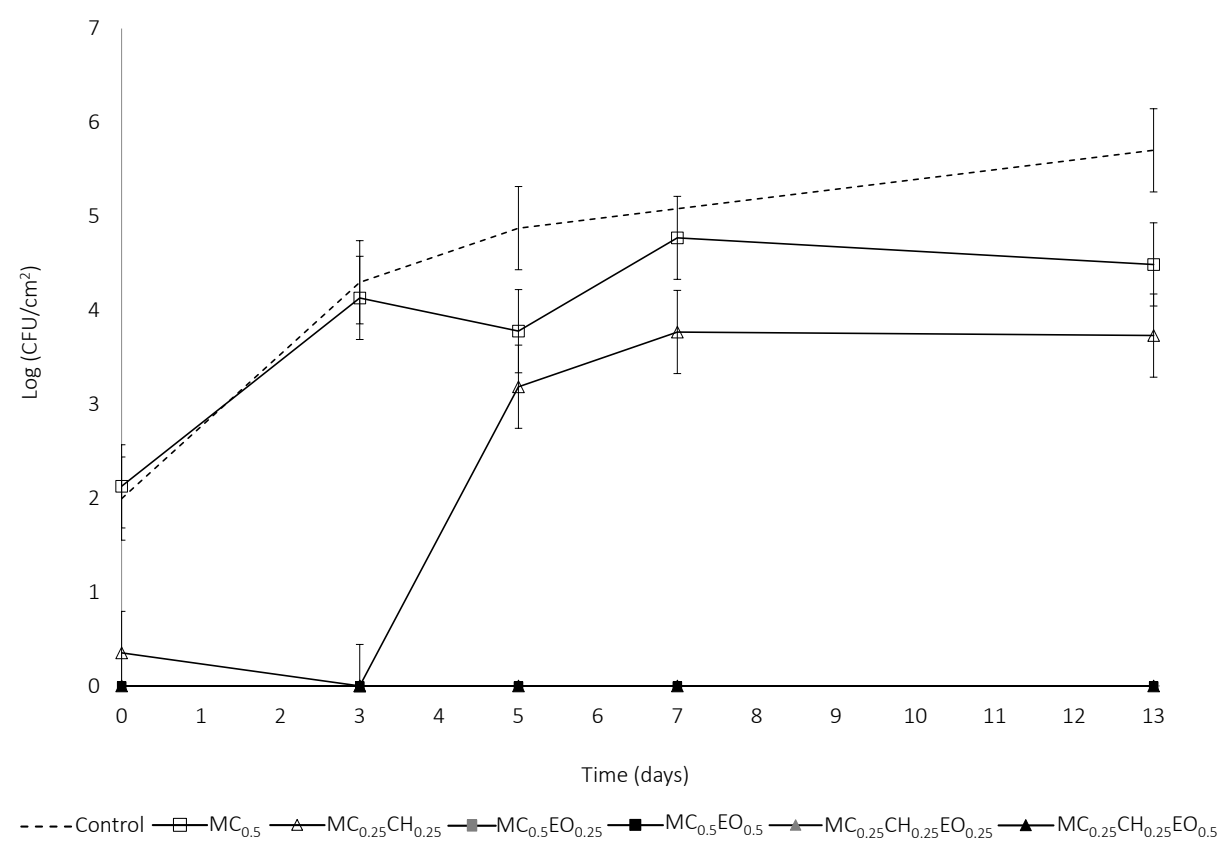

Figure 4.2 Rhizopus stolonifer counts during storage at $25^{\circ} \mathrm{C}$. Average values and

$95 \%$ LSD intervals. MC: methylcellulose, $\mathrm{CH}$ : chitosan, EO: essential oil. Subscripts indicate the ratio of film components.

\subsection{Applications to tomato plant}

The effect of the treatments on Micro-Tom plants in "3 Leaves" stage is shown in Figure 4.3a. The amount of EO applied per plant was higher for the formulations containing the highest EO concentration (0.022 g EO/plant) 
as compared to formulations with the lowest amount of EO (0.011 g/plant), in agreement with the composition of the FFD. After each treatment application, at every development stage, the plant general physiological conditions were visually monitored (Figure 4.3c). Treatments without EO did not promote any visual effect on tomato plants (no damage). The application of $\mathrm{MC}_{0.5} \mathrm{EO}_{0.25}$ led to minor damages, which were maintained throughout the whole monitoring period, with no detectable effects on the normal development of plants. The application of the highest dose of EO led to adverse effects on the physiological state of the tomato plants. In fact, all treatments with the highest EO concentration applied at "3 leaves" stage had lethal effects, being the percentage of death plants significantly lower when the EO was included in the FFD (Figure 4.3a). Taking into account these results, $\mathrm{EO}_{0.5}$ treatment was not used in the applications at "Flowers" and "Fruits" stages. The comparison of the obtained results after the application of $\mathrm{EO}_{0.5}$, with the results shown after the application of the same dose of EO incorporated throughout biopolymer-based FFD points out that chitosan and methylcellulose acted as encapsulating agent, thus promoting a controlled release of the EO and decreasing its potential toxicity.

Previous studies shown the effectiveness of $\mathrm{CH}$ as an encapsulating agent, which allowed the controlled release of coriander and citronella essential oils (Auerswald, Peters, Brückner, Krumbein and Kuchenbuch, 1999; El Ghaouth, Ponnampalam, Castaigne and Arul, 1992b). It is important to point out that due to the physiological damages, plant development was delayed and so blooming. Moreover, some of the damaged plants were affected by other diseases due their weakened physiological state.

Figure $4.3 \mathrm{~b}$ shows the effect of the treatments on tomato plants in the "Flowers" stage. The applications of the treatments were carried out when the first flowers appeared (22 days after starting the experiments at "3 Leaves" stage). The dose of EO per plant, using biopolymer based FFD, was similar to that applied in the experiments performed at "3 Leaves" stage. The treatments had no lethal effects. Non-treated (Control) and plants sprayed with $\mathrm{MC}_{0.5}$ FFD did not show any damage during the whole assay. All plants sprayed with $\mathrm{EO}_{0.25}$ showed permanent damages. The $10 \%$ of plants treated with $\mathrm{MC}_{0.25} \mathrm{CH}_{0.25}$ showed slight damage and no differences between $\mathrm{MC}_{0.5} \mathrm{EO}_{0.25}$ and $\mathrm{MC}_{0.5} \mathrm{EO}_{0.5}$, applications were 
detected; both FFD promoting slight damages. The plants sprayed with $\mathrm{MC}_{0.25} \mathrm{CH}_{0.25} \mathrm{EO}_{0.25}$ and $\mathrm{MC}_{0.25} \mathrm{CH}_{0.25} \mathrm{EO}_{0.5}$ treatments showed medium damages (damage 2) although the level of damages was reduced to 2 weeks after the treatment application.
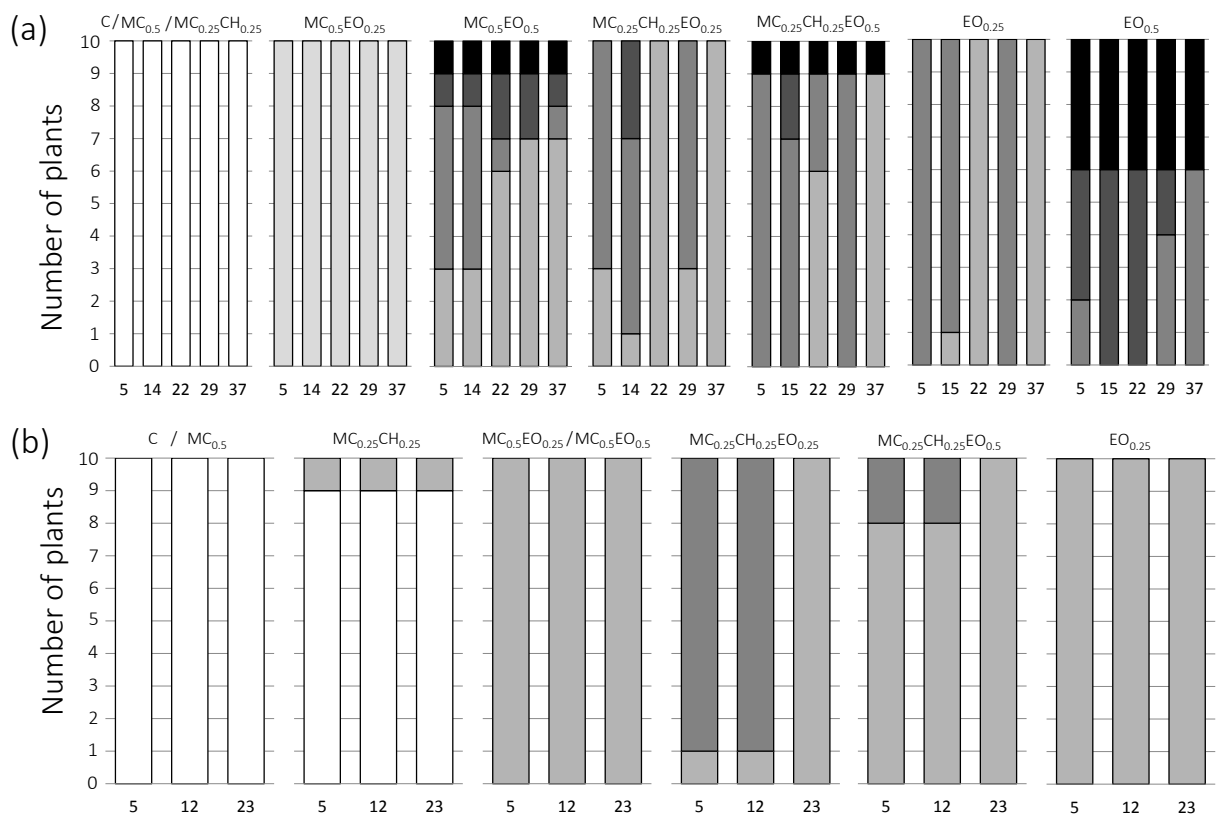

(c)

口 Damage: 3

ㅁ Damage: 2

$\square$ Damage: 1

$\square$ No damage
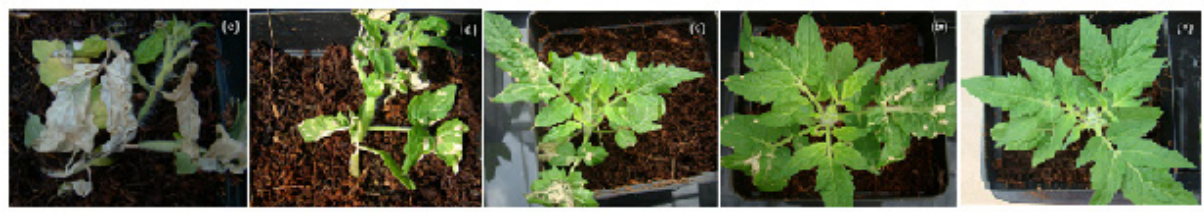

Figure 4.3 (a) Effect of the treatments on Micro-Tom plants in "3 Leaves" stage and (b) "Flowers" stage. (c) Visual rating scale ranges. Treatments with similar results are grouped. $\mathrm{MC}$ : methylcellulose, $\mathrm{CH}$ : chitosan, EO: essential oil. Subscripts indicate the ratio of film components.

The comparison between the level of damages detected in the plants after applications at " 3 Leaves" stage and "Flowers" stage revealed that the application of FFD containing EO had more negative effects on the physiological state of Micro-Tom plants when they were applied at an early stage of development, when the plants have a less developed cuticle. 
Fruit set (number of fruits/number of flowers) and the total weight of yield was determined in plants submitted to the spray applications in the "flowers" stage. Fruit set ratio (\%) and weight of fruit yield (g) for each treatment were: control (57\%, $97.09 \mathrm{~g}), \mathrm{MC}_{0.5}(64 \%, 155.47 \mathrm{~g})$, $\mathrm{MC}_{0.25} \mathrm{CH}_{0.25}(73 \%, 172.82 \mathrm{~g}), \mathrm{MC}_{0.5} \mathrm{EO}_{0.25}(62 \%, 131.45 \mathrm{~g}), \mathrm{MC}_{0.5} \mathrm{EO}_{0.5}$ (76 \%, $176.3 \mathrm{~g}), \mathrm{MC}_{0.25} \mathrm{CH}_{0.25} \mathrm{EO}_{0.25}(42 \%, 89.8 \mathrm{~g}), \mathrm{MC}_{0.25} \mathrm{CH}_{0.25} \mathrm{EO}_{0.5}$ (66 \%, $142.98 \mathrm{~g})$ and $\mathrm{EO}_{0.25}(61 \%, 127.07 \mathrm{~g})$. The application of the different treatments did not have any negative impact over the fruit set. In fact, all FFD, except $\mathrm{MC}_{0.25} \mathrm{CH}_{0.25} \mathrm{EO}_{0.25}$, led to higher fruit set ratio as compared with non-treated plants (control). The relation between fruit set ratio and total fruit yield weight suggested that the treatments did not affect the total amount of fruits and that all of them reached a similar size.

Figure 4.4 shows the total fruit yield and the global weight of these fruits for each treatment, taking into account all plants treated at stage "3 Leaves", "Flowers" and "Fruit" stages. There were no differences in total yield and weight among treatments and the incorporation of EO into the FFD did not affect the global yield.

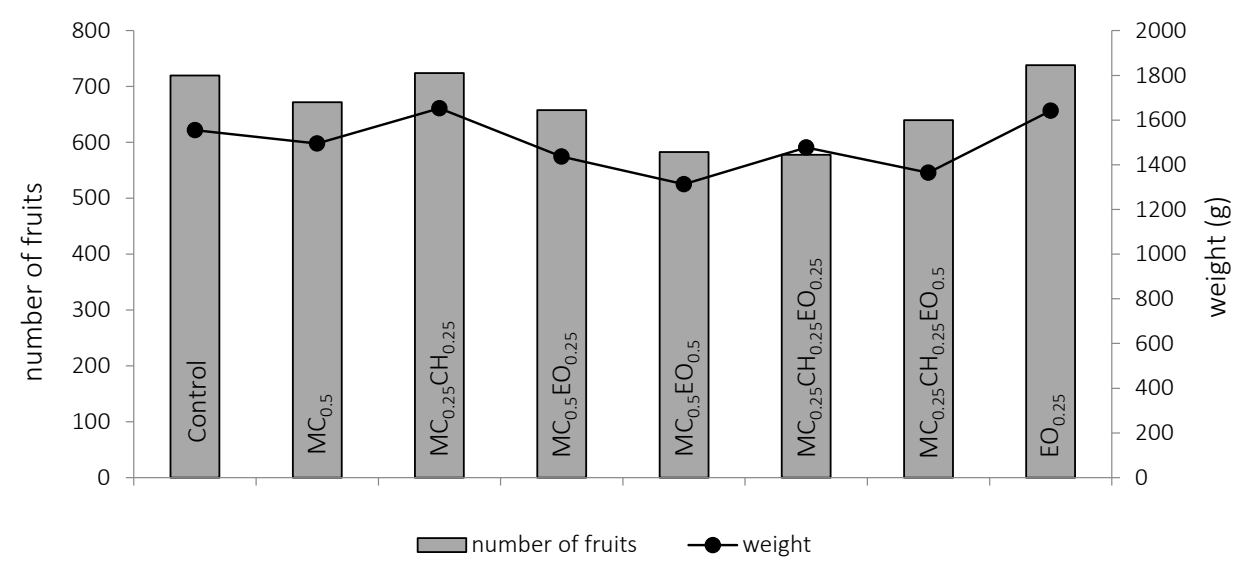

Figure 4.4 Total yield after preharvest applications: number of fruits and weight of yield. MC: methylcellulose, $\mathrm{CH}$ : chitosan, EO: essential oil. Subscripts indicate the ratio of film components.

3.3 Preharvest and postharvest applications to tomato fruits.

Figure 4.5 shows lightness, hue and chroma development of the tomatoes throughout the storage at $25^{\circ} \mathrm{C}$ after preharvest and postharvest 
applications. Lightness significantly decreased at the end of the storage, in line with weight loss and surface dehydration (Vargas, Chiralt, Albors and González-Martínez, 2009b). Colour significantly changed between 6 and 9 days of storage, due to the change from green to red, with no significant effects due to the treatment application. Hue decreased during storage until became red in all samples in line with the ripening progress. No significant effect of treatment application was detected. The incorporation of EO into FFD had no significant effect on the change in the three colour parameters.
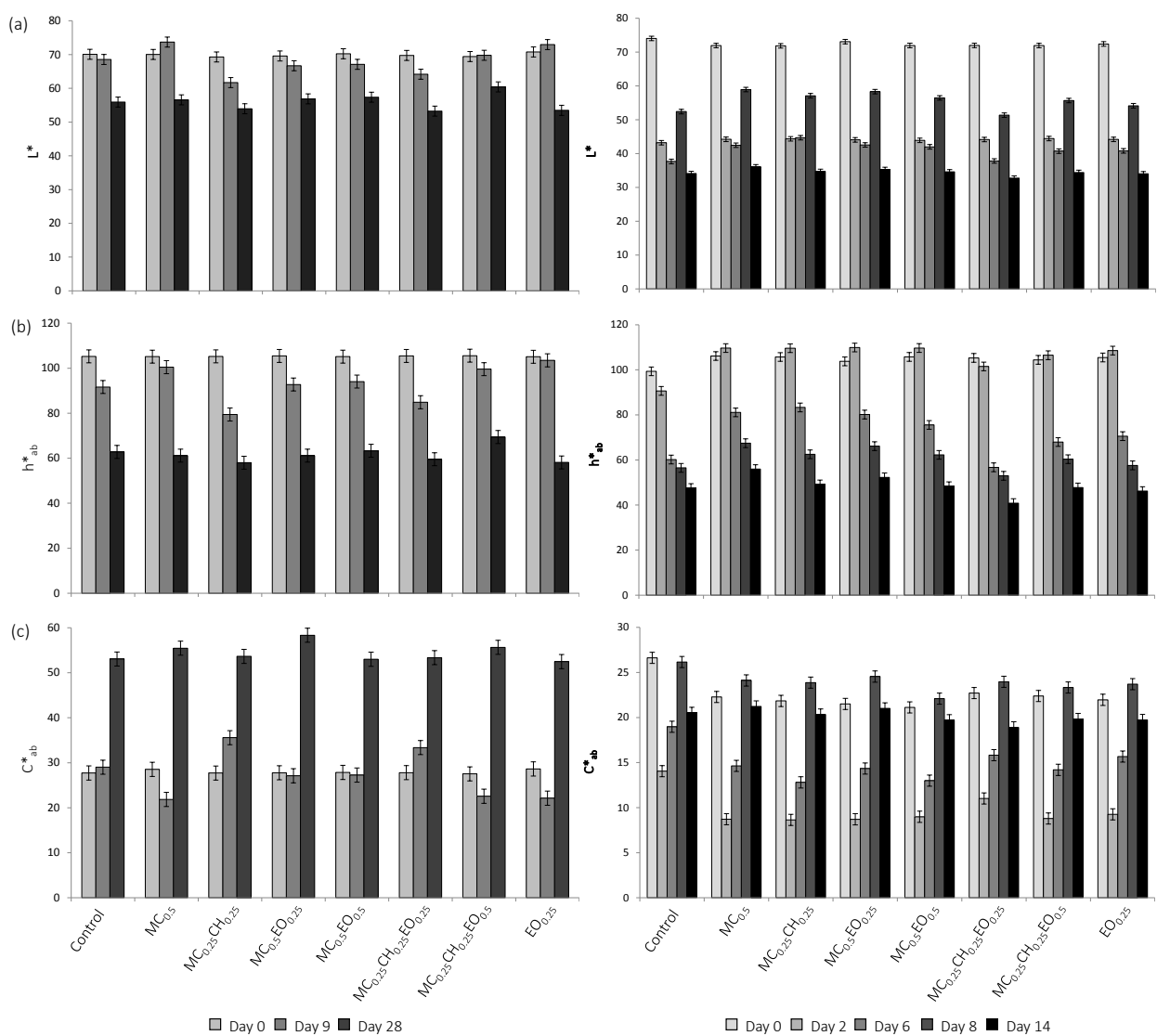

Figure 4.5 Evolution of Lightness $\left(\mathrm{L}^{*}\right)$, hue $\left(\mathrm{h}^{*}{ }_{\mathrm{ab}}\right)$ and chroma $\left(\mathrm{C}^{*}{ }_{\mathrm{ab}}\right)$ of tomatoes at different times of storage at $25^{\circ} \mathrm{C}$ after (a) preharvest and (b) postharvest

treatment application. Average values and 95\% LSD intervals.

MC: methylcellulose, $\mathrm{CH}$ : chitosan, EO: essential oil. Subscripts indicate the ratio of film components. 
Table 4.1 shows the average and standard deviation of the values of acidity, $\mathrm{pH}$, Brix and maturity index ( $\mathrm{MI})$ and weight loss of tomatoes treated before harvesting at the end of the storage at $25^{\circ} \mathrm{C}$. ANOVA showed significant differences $(p<0.05)$ in acidity values among treatments. The application of oregano EO and its incorporation into FFD led to a slight decrease on the acidity values of the samples. Brix and MI were significantly affected by treatment application $(p<0.05)$. Nevertheless, no clear trends were observed when comparing the values of control samples with treated ones, and EO incorporation in the treatments did not affect fruit ripening.

Table 4.1 Acidity (Ac, g. $\left.\mathrm{kg}^{-1}\right)$, $\mathrm{pH}$, soluble solids (Brix), maturity index (MI) and weight loss (WL, \%) of tomatoes treated before harvest (preharvest application) at the end of the storage at $25^{\circ} \mathrm{C}$. Average values and (standard deviation).

\begin{tabular}{|c|c|c|c|c|c|}
\hline Treatment & Ac $\times 10^{-1}$ & $\mathrm{pH}$ & Brix & MI & WL \\
\hline C & $\begin{array}{c}1.03 \\
(0.05)^{c}\end{array}$ & $\begin{array}{c}4.128 \\
(0.012)^{a}\end{array}$ & $\begin{array}{c}5.8 \\
(0.09)^{d}\end{array}$ & $\begin{array}{c}5.6 \\
(0.3)^{b c}\end{array}$ & $\begin{array}{c}10.9 \\
(0.8)^{a}\end{array}$ \\
\hline $\mathrm{MC}_{0.5}$ & $\begin{array}{c}0.97 \\
(0.05)^{b c}\end{array}$ & $\begin{array}{c}4.128 \\
(0.012)^{a}\end{array}$ & $\begin{array}{c}5.02 \\
(0.12)^{a}\end{array}$ & $\begin{array}{c}5.2 \\
(0.2)^{\mathrm{ab}}\end{array}$ & $\begin{array}{c}10.5 \\
(1.4)^{a}\end{array}$ \\
\hline $\mathrm{MC}_{0.25} \mathrm{CH}_{0.25}$ & $\begin{array}{c}0.93 \\
(0.12)^{\mathrm{ab}}\end{array}$ & $\begin{array}{c}4.1250 \\
(0.0105)^{a}\end{array}$ & $\begin{array}{c}5.82 \\
(0.08)^{d}\end{array}$ & $\begin{array}{c}6.4 \\
(0.9)^{d}\end{array}$ & $\begin{array}{c}10.51 \\
(0.05)^{\mathrm{a}}\end{array}$ \\
\hline $\mathrm{MC}_{0.5} \mathrm{EO}_{0.25}$ & $\begin{array}{c}1.04 \\
(0.14)^{\mathrm{c}}\end{array}$ & $\begin{array}{c}4.120 \\
(0.014)^{a}\end{array}$ & $\begin{array}{c}5.00 \\
(0.13)^{a}\end{array}$ & $\begin{array}{c}4.9 \\
(0.7)^{\mathrm{a}}\end{array}$ & $\begin{array}{c}14 \\
(3)^{\mathrm{a}}\end{array}$ \\
\hline $\mathrm{MC}_{0.5} \mathrm{EO}_{0.5}$ & $\begin{array}{c}0.85 \\
(0.04)^{a}\end{array}$ & $\begin{array}{c}4.16 \\
(0.06)^{b}\end{array}$ & $\begin{array}{c}5.45 \\
(0.08)^{b c}\end{array}$ & $\begin{array}{c}6.4 \\
(0.3)^{d}\end{array}$ & $\begin{array}{c}9.9 \\
(0.6)^{\mathrm{a}}\end{array}$ \\
\hline $\mathrm{MC}_{0.25} \mathrm{CH}_{0.25} \mathrm{EO}_{0.25}$ & $\begin{array}{c}0.88 \\
(0.06)^{\mathrm{ab}}\end{array}$ & $\begin{array}{c}4.130 \\
(0.009)^{a}\end{array}$ & $\begin{array}{c}5.5 \\
(0.3)^{c}\end{array}$ & $\begin{array}{c}6.3 \\
(0.5)^{d}\end{array}$ & $\begin{array}{c}9.90 \\
(0.10)^{a}\end{array}$ \\
\hline $\mathrm{MC}_{0.5}: \mathrm{CH}_{0.5}: \mathrm{EO}_{0.5}$ & $\begin{array}{c}0.93 \\
(0.08)^{\mathrm{ab}}\end{array}$ & $\begin{array}{c}4.120 \\
(0.014)^{a}\end{array}$ & $\begin{array}{c}5.13 \\
(0.08)^{a}\end{array}$ & $\begin{array}{c}5.6 \\
(0.5)^{b c}\end{array}$ & $\begin{array}{c}11.471 \\
(0.103)^{a}\end{array}$ \\
\hline $\mathrm{EO}_{0.25}$ & $\begin{array}{c}0.87 \\
(0.09)^{\mathrm{ab}}\end{array}$ & $\begin{array}{c}4.135 \\
(0.014)^{\mathrm{a}}\end{array}$ & $\begin{array}{c}5.32 \\
(0.12)^{b}\end{array}$ & $\begin{array}{c}6.1 \\
(0.6)^{\mathrm{cd}}\end{array}$ & $\begin{array}{c}13.4 \\
(0.4)^{a}\end{array}$ \\
\hline
\end{tabular}

Acidity, $\mathrm{pH}, \mathrm{Brix}, \mathrm{MI}$ and weight loss of the tomatoes treated in postharvest at the end of the storage at $25^{\circ} \mathrm{C}$ are shown in Table 4.2. All parameters (except weight loss) were significantly affected by treatment application $(p<0.05)$, although important variations in the $\mathrm{Ml}$ of samples were not detected. Weight loss of samples treated with formulations containing EO was reduced as compared to control and samples treated with pure 
biopolymer FFD, although the differences were no significant. In general, coatings containing EO provoked a decrease in weight loss of tomatoes during storage. This was notable in postharvest treatments where significant differences in weight loss with respect to the control sample and those coated with FFD without EO were observed.

Table 4.2 Acidity (Ac, $\mathrm{g} \cdot \mathrm{kg}^{-1}$ ), $\mathrm{pH}$, soluble solids (Brix) and maturity index (MI) and weight loss (WL, \%) of tomatoes treated in postharvest at the end of the storage at $25^{\circ} \mathrm{C}$. Average values and (standard deviation).

\begin{tabular}{lccccc}
\hline Treatment & $\mathrm{Ac} . \times 10^{-1}$ & $\mathrm{pH}$ & Brix & $\mathrm{Ml}$ & $\mathrm{WL}$ \\
\hline $\mathrm{C}$ & 0.897 & 4.13 & 5.25 & 5.9 & 24 \\
& $(0.113)^{\mathrm{a}}$ & $(0.03)^{\mathrm{bc}}$ & $(0.08)^{\mathrm{c}}$ & $(0.8)^{\mathrm{ab}}$ & $(7)^{\mathrm{c}}$ \\
$\mathrm{MC}_{0.5}$ & 0.81 & 4.10 & 5.17 & 6.4 & 22 \\
& $(0.09)^{\mathrm{a}}$ & $(0.02)^{\mathrm{b}}$ & $(0.08)^{\mathrm{bc}}$ & $(0.7)^{\mathrm{b}}$ & $(2)^{\mathrm{c}}$ \\
$\mathrm{MC}_{0.25} \mathrm{CH}_{0.25}$ & 0.92 & 4.120 & 5.72 & 6.3 & 27 \\
& $(0.12)^{\mathrm{ab}}$ & $(0.009)^{\mathrm{bc}}$ & $(0.08)^{\mathrm{e}}$ & $(0.9)^{\mathrm{b}}$ & $(6)^{\mathrm{c}}$ \\
$\mathrm{MC}_{0.5} \mathrm{EO}_{0.25}$ & 0.80 & 4.153 & 5.20 & 6.5 & 24.2 \\
& $(0.08)^{\mathrm{a}}$ & $(0.012)^{\mathrm{c}}$ & $(0.09)^{\mathrm{c}}$ & $(0.7)^{\mathrm{b}}$ & $(0.7)^{\mathrm{c}}$ \\
$\mathrm{MC}_{0.5} \mathrm{EO}_{0.5}$ & 0.81 & 4.115 & 4.58 & 5.7 & 5 \\
& $(0.08)^{\mathrm{a}}$ & $(0.014)^{\mathrm{b}}$ & $(0.12)^{\mathrm{a}}$ & $(0.6)^{\mathrm{ab}}$ & $(5)^{\mathrm{a}}$ \\
$\mathrm{MC}_{0.25} \mathrm{CH}_{0.25} \mathrm{EO}_{0.25}$ & 0.795 & 4.15 & 5.1 & 6.4 & 3.5 \\
& $(0.095)^{\mathrm{a}}$ & $(0.02)^{\mathrm{c}}$ & $(0.2)^{\mathrm{b}}$ & $(0.8)^{\mathrm{b}}$ & $(0.6)^{\mathrm{a}}$ \\
$\mathrm{MC}_{0.25} \mathrm{CH}_{0.25} \mathrm{EO}_{0.5}$ & 1.0 & 4.15 & 5.23 & 5.14 & 12 \\
& $(0.2)^{\mathrm{bc}}$ & $(0.05)^{\mathrm{c}}$ & $(0.05)^{\mathrm{c}}$ & $(0.96)^{\mathrm{a}}$ & $(6)^{\mathrm{b}}$ \\
$\mathrm{EO}_{0.25}$ & 1.07 & 4.01 & 5.55 & 5.2 & 17 \\
\hline
\end{tabular}

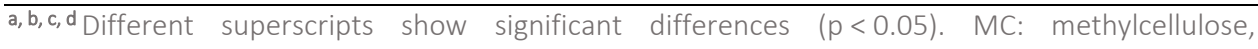
$\mathrm{CH}$ : chitosan, EO: essential oil. Subscripts indicate the ratio of film components.

Figure 4.6 shows the development of respiration rate of the tomato samples in terms of $\mathrm{CO}_{2}$ production and $\mathrm{O}_{2}$ consumption during storage. The kind of treatment, the storage time and the interaction between both factors had a significant effect in the respiration rate of the samples $(p<0.05)$. In all samples, it was observed an increase in the respiration rate at the beginning, after 2 days of storage, due to the stress caused over the samples by the atmosphere changes (Goswami and Mangaraj, 2011). 
In the preharvest application (Figure 4.6a), samples treated with $\mathrm{EO}_{0.25}$ showed a complete different development than the others, especially in terms of oxygen consumption. This could be due to an effect of EO on the fruit metabolism when it was still in the plant, which was maintained during the postharvest storage.
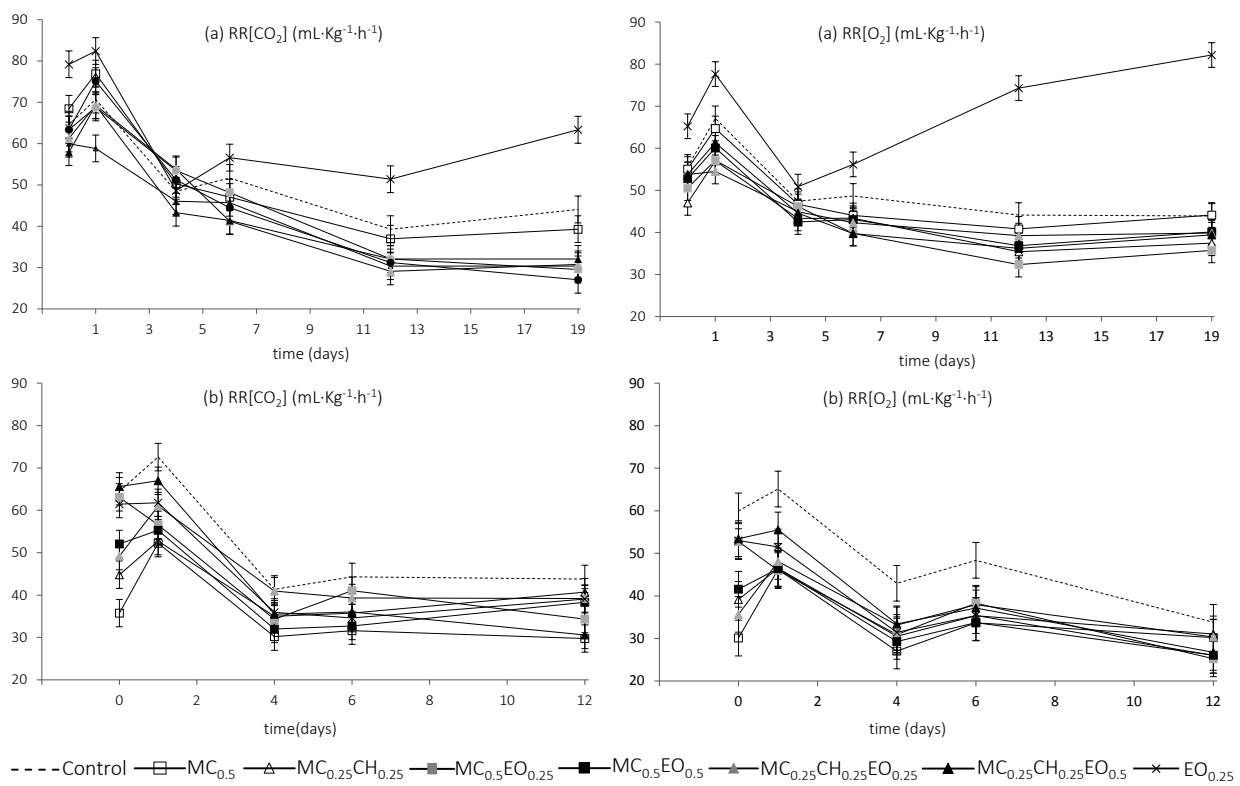

Figure 4.6 Respiration rate in terms of $\mathrm{CO}_{2}$ generation and $\mathrm{O}_{2}$ consumption during storage at $25^{\circ} \mathrm{C}$ after (a) preharvest and (b) postharvest applications. MC: methylcellulose, $\mathrm{CH}$ : chitosan, EO: essential oil. Subscripts indicate the ratio of film components.

For both moments of application, FFD (with or without EO) led to a decrease in the respiration rate of the samples as compared whith non-coated ones (control). Similar results were observed by El Ghaouth, Ponnampalam, Castaigne and Arul (1992b) after the application of chitosan-based coatings on tomatoes.

At 6 days of storage, it was observed an increase in respiration rate values, followed by a respiration rate decrease. This is due to the increase in the tomatoes respiration activity just before the maturity stage (climaterium). This change is common in climacteric fruits such as tomato (Auerswald, Peters, Brückner, Krumbein and Kuchenbuch, 1999). The respiratory quotient (RQ) was not affected by treatment application during storage, 
being all values near to 1 . RQ value for fresh fruits ranges from 0.7 to 1.3 for the aerobic respiration and it is much greater than one when anaerobic respiration takes place (Kader, 1987).

\subsection{Fungal decay}

Figure 4.7 shows the effect of the preventive and curative treatments performed with fully ripened tomato samples inoculated with $R$. stolonifer spores. In preventive applications, all treatments delayed fungal decay as compared with inoculated control samples, although $\mathrm{MC}_{0.5}$ formulation had no notable effect on the control of fungal decay and led to similar percentages of infection than those obtained in control tomatoes. Samples treated with $\mathrm{MC}_{0.25} \mathrm{CH}_{0.25}$ showed lower levels of infection than samples treated with $\mathrm{MC}_{0.5}$, due the effect of $\mathrm{CH}$ on $\mathrm{R}$. stolonifer growth, which coincides with the results obtained in the in vitro assays.

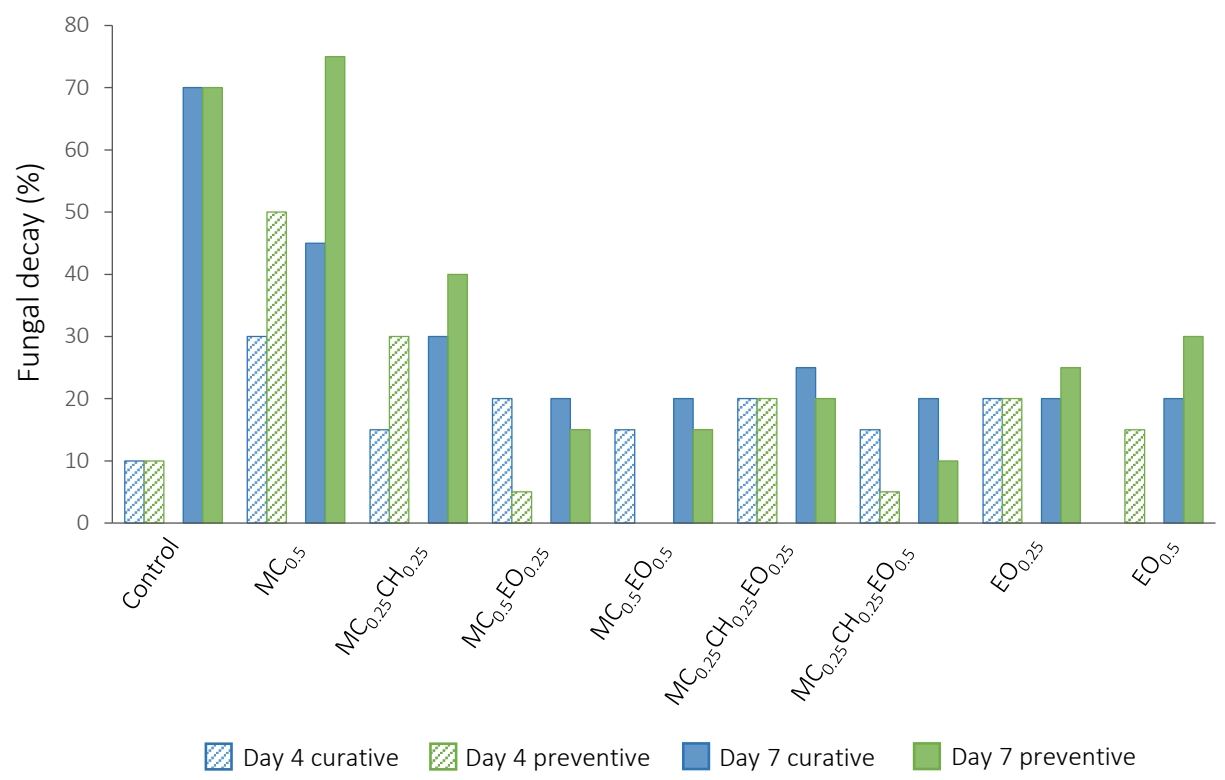

Figure 4.7 Fungal decay (\% of fruits with visible signs of infection) for preventive and curative treatments, at 4 days and 7 days after inoculation with a $10^{5}$ spores/mL suspension of Rhizopus stolonifer. MC: methylcellulose, $\mathrm{CH}$ : chitos an, EO: essential oil. Subscripts indicate the ratio of film components. 
The percentage of infected fruits when samples were treated with formulations containing EO was lower, which indicates that EO incorporation improved the antifungal properties of the biopolymers-based $\mathrm{FFD}$, as observed in the in vitro assays. Samples treated with $\mathrm{MC}_{0.25} \mathrm{CH}_{0.25} \mathrm{EO}_{0.5}$ showed the lowest percentage of fruit infection at 7 days of storage. In general, the preventive applications seem to lead to better results than curative ones when FFD contain EO. However, for $\mathrm{MC}_{0.25} \mathrm{CH}_{0.25}$ preventive treatments a higher fungal decay than in curative applications was obtained. 


\section{CONCLUSION}

Preharvest application of oregano essential oil (EO) to tomato plants promoted phytotoxic effects, which were diminished when EO was incorporated at the same dose into biopolymer-based film-forming dispersion (FFD). Plant growth and development were delayed due to EO application, although total biomass production, fruit set ratio and yield were no affected. Postharvest application of biopolymer-oregano essential oil coatings decreased weight losses during storage and promoted a reduction in the respiration rate of tomatoes, with no effect on the maturity index and $\mathrm{pH}$ of fruits. The incorporation of oregano EO into FFD based on methylcellulose and chitosan has been proven to be an effective treatment to control Rhizopus stolonifer in tomato fruit both in postharvest curative and preventive applications.

\section{ACKNOWLEDGEMENTS}

The authors acknowledge the support provided by Universitat Politècnica de València (SP20120518) and the Spanish Ministerio de Educación y Ciencia (AGL2013-42989-R-AR). Ángela Perdones also thanks the Universitat Politècnica de València for the FPI grant. 


\section{REFERENCES}

Alvarado, A.M., Barrera, L.L., Hernández, A.N., Velázquez, M.G. Actividad antifúngica del quitosano y aceites esenciales sobre Rhizopus stolonifer, agente causal de la pudrición blanda del tomate. Revista Colombiana de Biotecnología 13:2 (2011) 127- 134.

AOAC. Official methods of analysis. (17 $7^{\text {th }}$ Ed.). Association of Analytical Chemists International, (Washington DC) 1995.

Auerswald, H., Peters, P., Brückner, B., Krumbein, A., Kuchenbuch, R. Sensory analysis and instrumental measurements of short-term stored tomatoes (Lycopersicon esculentum Mill.). Postharvest Biology and Technology 15:3 (1999) 323-334.

Badawy, M. E. I., Rabea, E. I. Potential of the biopolymer chitosan with different molecular weights to control postharvest gray mold of tomato fruit. Postharvest Biology and Technology 51:1 (2009) 110-117.

Bakkali, F., Averbeck, S., Averbeck, D., Idaomar, M. Biological effects of essential oils - a review. Food and Chemical Toxicology 46:2 (2008) $446-475$.

Bendahou, M., Muselli, A., Grignon-Dubois, M., Benyoucef, M., Desjobert, J.M., Bernardini, A. F., Costa, J. Antimicrobial activity and chemical composition of Origanum glandulosum Desf. essential oil and extract obtained by microwave extraction: Comparison with hydrodistillation. Food Chemistry 106:1 (2008) 132 - 139.

El Ghaouth, A., Arul, J., Grenier, J., Asselin, A. Antifungal activity of chitosan on two postharvest pathogens of strawberry fruits. Postharvest Pathology and Mycotoxins 82:4 (1992a) 399 - 402.

El Ghaouth, A., Ponnampalam, R., Castaigne, F., Arul, J. Chitosan coating to extend the storage life of tomatoes. HortScience 27:9 (1992b) 1016 - 1018.

Feller, C., Bleiholder, H., Buhr, L., Hack, H., Hess, M., Klose, R., Meier, U., Stauss, R., Van den Boom, T., Weber, E. Phänologische Entwicklungsstadien 
von Gemüsepflanzen: II. Fruchtgemüse und Hülsenfrüchte. Nachrichtenbl. Deut. Pflanzenschutzd 47 (1995) 217 - 232.

Goswami, T.K., Mangaraj, S. Advances in polymeric materials for modified atmosphere packaging (MAP). In J.M. Lagarón (Ed.) Multifunctional and nanoreinforced polymer for food packaging (pp. 164-242). Woodhead Publishing Limited (Cambridge) 2011.

Hernández-Lauzardo, A.N., Velázquez-del Valle, M., Veranza-Catelán, L., Melo-Giorgana, G.E., Guerra-Sánchez, M.G. Effect of chitosan on three isolates of Rhizopus stolonifer obtained from peach, papaya and tomato. Fruits 65:4 245- 253 (2010).

Kader, A.A. Respiration and gas exchange of vegetables. In J. Weichmann (Ed.) Postharvest Physiology of Vegetables (pp. 25 -30). Marcel Dekker, Inc. (New York) 1987.

Lima, J.E., Carvalho, R.F., Neto, A.T., Figueira, A., Peres, L.E.P. Micro-MsK: a tomato genotype with miniature size, short life cycle, and improved in vitro shoot regeneration. Plant Science 167:4 (2004) 753 - 757.

Martí, E., Gisbert, C., Bishop, G.J., Dixon, M.S., García-Martínez, J.L. Genetic and Physiological characterization of tomato cv. Micro-Tom. Journal of Experimental Botany 57:9 (2006) 2037 - 2047.

Matusinsky, P., Zouhar, M., Pavela, R., Novy, P. Antifungal effect of five essential oils against important pathogenic fungi of cereals. Industrial Crops and Products 67 (2015) $208-215$.

Meier, U. Growth stages of mono-and dicotyledonous plants. BBCH Monograph. Federal Biological Research Centre for Agriculture and Forestry (2001).

Meissner, R., Jacobson, Y., Melamed, S., Levyatuv, S., Shalev, G., Ashri, A., Elkind, Y., Levy, A.A. A new model system for tomato genetics. The Plant Journal 12:6 (1997) $1465-1472$.

Perdones, A., Sánchez-González, L., Chiralt, A., Vargas, M. Effect of chitosan-lemon essential oil coatings on storage-keeping quality of strawberry. Postharvest Biology and Technology 70 (2012) $32-41$. 
Ramos-García, M., Bosquez-Molina, E., Hernández-Romano, J., Zavala-Padilla, G., Terrés-Rojas, E., Alia-Tejacal, I., Barrera-Necha, L., Hernández-López, M., Bautista-Baños, S. Use of chitosan-based edible coatings in combination with other natural compounds, to control Rhizopus stolonifer and Escherichia coli DH5 $\alpha$ in fresh tomatoes. Crop Protection 38 (2012) $1-6$.

Sánchez-González, L., Vargas, M., González-Martínez, C., Chiralt, A., Cháfer, M. Use of Essential Oils in Bioactive Edible Coatings. Food Engineering Reviews 3:1 (2011) 1-16.

Sari, M., Biondi, D.M., Kaâbeche, M., Mandalari, G., D'Arrigo, M., Bisignano, G., Saija, A., Daquino, C., Ruperto, G. Chemical composition, antimicrobial and antioxidant activities of the essential oil of several populations of Algerian Origanum glandulosum Desf. Flavour and Fragrance Journal 21:6 (2006) $890-898$.

Scott, J.W., Harbaugh, B.K. Micro-Tom. A miniature dwarf tomato. Florida Agricultural Experimental Station Circular S-370 (1989) 1 - 6.

Shiekh, R.A., Malik, M.A., Al-Thabaiti, S.A., Shiekh, M.A. Chitosan as a novel edible coating for fresh fruits. Food Science and Technology Research 19:2 (2013) $139-155$.

Smith-Palmer, A., Stewart, J., Fyfe, L. The potential application of plant essential oils as natural food preservatives in soft cheese. Food Microbiology 18:4 (2001) $463-470$.

Soylu, E.M., Kurt, S., Soylu, S. In vitro and in vivo antifungal activities of the essential oils of various plants against tomato grey mould disease agent Botrytis cinerea. International Journal of Food Microbiology 143:3 (2010) $183-189$.

Tharanathan, R.N., Kittur, F.S. Chitin - The undisputed biomolecule of great potential. Critical Reviews in Food Science and Nutrition 43:1 (2003) $61-87$.

Turhan, K. Sahbaz, F. Water vapour permeability, tensile properties and solutions of methylcellulose-based edible films. Journal of Food Engineering 
Tzortzakis, N.G. Ethanol, vinegar and Origanum vulgare oil vapour suppress the development of anthracnose rot in tomato fruit. International Journal of Food Microbiology 142:1 (2010) 14- 18.

Vargas, M., Albors, A., Chiralt, A., González-Martínez, C. Quality of cold-stored strawberries as affected by chitosan-oleic acid edible coatings. Postharvest Biology and Technology 41:2 (2006) $164-171$.

Vargas, M., Pastor, C., Chiralt, A., McClements, D.J., González-Martínez, C. Recent advances in edible coatings for fresh and minimally processed fruits. Critical Reviews in Food Science and Nutrition 48:6 (2008) 496 - 511.

Vargas, M., Albors, A., Chiralt, A., González-Martínez, C. Characterization of chitosan-oleic acid composite films. Food Hydrocolloids 23:2 (2009a) $536-547$.

Vargas, M., Chiralt, A., Albors, A., González-Martínez, C. Effect of chitosan-based edible coatings applied by vacuum impregnation on quality preservation of fresh-cut carrot. Postharvest Biology and Technology 51:2 (2009b) $263-271$ (2009b).

Vargas M, Albors A, Chiralt A, González-Martínez, C. Water interactions and microstructure of chitosan-methylcellulose composite films as affected by ionic concentration. LWT - Food Science and Technology 44:10 (2011) $2290-2295$.

Vargas, M., Sánchez-González, L., Chiralt, A., Cháfer, M., González-Martínez, C. Edible chitosan coatings for fresh and minimally processed foods. In K.L. Yam, D.S. Lee (Eds.), Emerging food packaging technologies: Principles and practice (pp. 66-95). Woodhead Publishing Limited (Cambridge) 2012.

Wogiatzi, E., Gougoulias, N., Papachatzis, A., Vagelas, I., Chouliaras, N. Greek oregano essential oils production, phytotoxicity and antifungal activity. Biotechnology and Biotechnological Equipment 23:1 (2009) $1150-1152$. 
CHAPTER 5

\section{RETENTION AND MIGRATION OF ESSENTIAL OILS IN CHITOSAN FILMS}

RETENTION AND MIGRATION OF OREGANO ESSENTIAL OIL IN CHITOSAN BASED FILMS 



\section{RETENTION AND MIGRATION OF OREGANO ESSENTIAL OIL IN CHITOSAN BASED FILMS}

Ángela Perdones, Amparo Chiralt, Maria Vargas*

Department of Food Technology-Institute of Food Engineering for Development, Universitat Politècnica de València, Camino de Vera s/n, 46022 Valencia, Spain.

*Telephone: 0034963877000 Ext.73642 Fax: 0034963877369

e-mail:mavarco@tal.upv.es 


\section{ABSTRACT}

Chitosan-methylcellulose films, as vehicles for oregano essential oil (Origanum compactum) as antimicrobial agent, were studied in terms of their oil retention capacity and migration of actives to different food simulants. The composition of the essential oil was determined by gas chromatography-mass spectrometry (GC-MS). The main compounds of oregano essential oil (EO) were found to be thymol and carvacrol. EO loss during the film formation was determined by gravimetric analysis and by GC-MS. Overall losses of essential oil were around $80 \%$ with a great variability depending on the film formulation. The greatest losses were obtained for the minor compounds of the EO and the lowest losses occurred for carvacrol and thymol. Nevertheless, a high variability was observed in the retention values of each component due to the stochastic contribution of the emulsion destabilization processes and their effect on the compound evaporation during the film drying step. Migration analyses of carvacrol and thymol in several food simulants were affected by the high variability of their retention in the film and it was not possible to observe clear differences among partition coefficients between films and simulants for these compounds. However, the stablished specific migration limit $(60 \mathrm{mg} / \mathrm{kg}$ ) for food contact packaging could be exceeded for carvacrol and thymol when a ratio polymer:essential oil was $1: 1$, especially in aqueous and low $\mathrm{pH}$ media where films swell and release the compounds faster.

Keywords: biopolymer, thymol, carvacrol, food simulant. 


\section{INTRODUCTION}

Essential oils are being increasingly applied in food packaging and preservation due to the interest of consumers in natural food additives. Chitosan-based films have been used for the incorporation of different essential oils such as lemon, basil and thyme (Bonilla, Talón, Atarés, Vargas and Chiralt, 2013; Bonilla, Atarés, Vargas and Chiralt, 2014; Sánchez-González, Vargas, González-Martínez, Chiralt and Cháfer, 2009; Sánchez-González, Cháfer, González-Martínez, Chiralt and Desobry, 2011a; Sánchez-González, Vargas, González-Martínez, Chiralt and Cháfer, 2011b). The polymeric matrix allows for the controlled-release of the active ingredients and previous studies have shown the antimicrobial activity of such coatings (Burt, 2004; Cerisuelo et al., 2012).

Oregano essential oil (Origanum compactum) shows antibacterial properties towards pathogenic microorganisms (Altintas et al., 2013) since it shows high proportions of carvacrol and thymol (Ben Arfa, Combes, Preziosi-Belloy, Gontard and Chalier, 2006). Carvacrol is a phenolic monoterpenoid that inhibits the growth of several bacterial strains such as Enterobacter spp., Listeria spp., Lactobacillus spp. and Pseudomonas spp. (Ben Arfa, Preziosi-Belloy, Chalier and Gontard, 2007; Gutiérrez, Barry-Ryan and Bourke, 2009). Carvacrol has been previously used in active food packaging since it inhibits microbial growth without food contact due to its high volatility (Mascheroni, Guillard, Gastaldi, Gontard and Chalier, 2011; Rodríguez, Batlle and Nerín, 2007). Carvacrol has been listed in the positive list of additives of the EU (Decision 2002/113/EC European Commission) and it has been Generally Recognised as Safe (GRAS) by the US FDA (López, Sánchez, Batlle and Nerín, 2007). Thymol is also a phenolic monoterpenoid that shows antimicrobial activity. Moreover, it has been proven that it prevents lipid oxidation in foods (Tomaino et al., 2005). Thymol is also GRAS and it is included in the UE positive list of aromas (Decision 2002/113/EC European Comission).

Migration of thymol and carvacrol has been previously evaluated in polypropylene films (Ramos, Beltrán, Peltzer, Valente and Garrigós, 2014). 
However, there are no previous studies on the migration of such components from chitosan based films.

When applying films and coatings based on chitosan-essential oils by casting method, it is important to take into account that volatile compounds are removed from the film, in line with water evaporation during drying process. Essential oils losses in chitosan-based films have been previously estimated by considering weight losses (Sánchez-González, Cháfer, González-Martínez, Chiralt and Desobry, 2011a). Nevertheless, the studies into the evaluation of the specific losses of each volatile, taking into account essential oil composition, by gas chromatography are scarce.

Methylcellulose is water-soluble, odourless, tasteless and biodegradable. This cellulose derivative is compatible with chitosan and has yielded more stretchable films with lower water vapour permeability than pure chitosan films (García, Pinotti, Martino and Zaritzky, 2004; Vargas, Albors, Chiralt and González-Martínez, 2011).

The aim of this work was to quantify oregano essential oil losses in chitosan-methylcellulose-based films and to analyse the migration of the major compounds of the essential oil (carvacrol and thymol) in different food simulants.

\section{MATERIALS AND METHODS}

\subsection{Reagents}

To obtain film-forming dispersions (FFD), high molecular weight chitosan (Batch MKBG8530V, acetylation degree: $24.4 \%$, viscosity in $1 \%(\mathrm{w} / \mathrm{w})$ glacial acetic acid solution: $1.406 \mathrm{~Pa} \cdot \mathrm{s}$, Sigma-Aldrich, St. Louis, USA), $98 \%$ acetic acid (Panreac Química, S.A., Castellar del Vallés, Barcelona, Spain), methylcellulose (VWR, Spain), oregano essential oil (Herbes del Molí, Alicante, Spain) were used. The ethanol used for the migration essays was obtained by Panreac (Castellar del Valles, Spain). 


\subsection{Preparation of the film-forming dispersions}

Three different film-forming dispersions (FFD) were prepared. Chitosan was dispersed at $0.5 \%(\mathrm{w} / \mathrm{w})$ in an aqueous solution of acetic acid at $0.5 \%(\mathrm{v} / \mathrm{w})$. Methylcellulose was dispersed in distilled water at $0.5 \%(\mathrm{w} / \mathrm{w})$. Both biopolymer solution were mixed in a 1:1 ratio to obtain $\mathrm{CH}-\mathrm{MC}$ films. Oregano essential (EO) was added to the methylcellulose or the chitosan-methylcellulose dispersion in a total polymer:EO ratio of 1:0.5 and 1:1 to obtain $\mathrm{MC}_{0.5} \mathrm{EO}_{0.25}, \mathrm{MC}_{0.25} \mathrm{CH}_{0.25} \mathrm{EO}_{0.25}$, and $\mathrm{MC}_{0.5} \mathrm{EO}_{0.5}$, $\mathrm{MC}_{0.25} \mathrm{CH}_{0.25} \mathrm{EO}_{0.5}$ FFD, respectively. Polymer-oregano essential oil dispersions were homogenised using a rotor-stator homogenizer (Ultraturrax DI25 Yellow Line, IKA ${ }^{\circledR}$, Staufen, Germany) at 13,400 rpm for 4 min. FFD were poured in Petri dishes with a constant dry solids density (30 g solids $/ \mathrm{m}^{2}$ ) and were allowed to dry at room conditions $\left(25^{\circ} \mathrm{C}\right.$, $60 \% \mathrm{RH}$ ) for $72 \mathrm{~h}$. Films were conditioned in hermetic dessicators at $25^{\circ} \mathrm{C}$ and $54 \% \mathrm{RH}$ generated by an oversaturated $\mathrm{Mg}\left(\mathrm{NO}_{3}\right)_{2}$ solution. Total essential oil losses were estimated by mass balance, taking into account the theoretical amount of solids poured from the FFD and the final weight of the film solids.

\subsection{Volatile analysis}

The composition of oregano essential oil was obtained by injecting it in a $100 \mathrm{mg}$ porous polymer (Tenax ${ }^{\circledR} \mathrm{TA}, 20-35$ mesh) packed into a glass tube, which was introduced in a direct thermal desorber (TurboMatrix TD, Perkin-Elmer TM, CT-USA). Desorption was performed under a $10 \mathrm{~mL} / \mathrm{min}$ helium flow at $240{ }^{\circ} \mathrm{C}$ for $10 \mathrm{~min}$, and the volatiles were cryofocused in a cold trap at $-30^{\circ} \mathrm{C}$. After $1 \mathrm{~min}$, the cold trap was heated up to $250{ }^{\circ} \mathrm{C}$ (at a rate of $99^{\circ} \mathrm{C}$ ) and volatiles were directly transferred onto the head of the capillary column. GC-MS analysis was performed using a Finnigan TRACETM MS (ThermoQuest, Austin, USA). Volatile compounds were separated using a DB-WAX capillary column $(1.0 \mu \mathrm{m} \times 0.32 \mathrm{~mm} \times 60 \mathrm{~m}$, SGE, Australia). Helium was used as the carrier gas at a constant flow rate of $1 \mathrm{~mL} / \mathrm{min}$. The oven was kept at an initial temperature of $40{ }^{\circ} \mathrm{C}$ for $2 \mathrm{~min}$. Then, temperature was increased to $190{ }^{\circ} \mathrm{C}$ at a rate of $4{ }^{\circ} \mathrm{C} / \mathrm{min}$, maintained for $5 \mathrm{~min}$ and finally increased to $230{ }^{\circ} \mathrm{C}$ at $10^{\circ} \mathrm{C} / \mathrm{min}$. The MS interface and source temperatures were 250 and $200{ }^{\circ} \mathrm{C}$, respectively. Electron impact mass spectra were recorded in impact ionisation mode at 
$70 \mathrm{eV}$ and with a mass range of $\mathrm{m} / \mathrm{z} 33-433$. Samples were analysed in triplicate.

The identification of isolated volatile compounds was tentatively carried out by comparing their mass spectra $(\mathrm{m} / \mathrm{z}$ values of the most important ions) with spectral data from the National Institute of Standards and Technology 2002 library, as well as published retention indices. A solution of the homogenous series of normal alkanes (C8 - C20 by Fluka Buchs, Schwiez, Switzerland) was used to determine the retention index.

Volatile composition in the films was obtained following the methodology described by Cerisuelo et al. (2012). To this end, $1 \mathrm{~cm}^{2}$ of the film was introduced into the Tenax ${ }^{\circledR}$ tube and desorption was carried out $220^{\circ} \mathrm{C}$ for 7 min and volatiles were analysed in the GC-MS using helium as a carrier gas at $230^{\circ} \mathrm{C}$. Chromatographic conditions were described as follows: isothermal step at $45^{\circ} \mathrm{C}(7 \mathrm{~min})$, heating up to $\left(220^{\circ} \mathrm{C}, 18^{\circ} \mathrm{C} / \mathrm{min}\right)$ and isothermal final step at $220^{\circ} \mathrm{C}$ (12 min). Volatile compounds were identified and quantified as described above.

Volatile compounds of the FFD and of the films redissolved in water to reach the same polymer concentration to that found in the FFD, were extracted by purge and trap thermal desorption (Peinado, Rosa, Heredia, Escriche and Andrés, 2013). Samples were mixed with $300 \mu$ of the internal standard 2-pentanol $(10 \mathrm{mg} / \mathrm{L})$ a placed into a purging flask and kept in a water bath at $80^{\circ} \mathrm{C}$ for $30 \mathrm{~min}$. Throughout this time, purified nitrogen $(100 \mathrm{~mL} / \mathrm{min})$ was forced through a glass frit placed at the bottom of the flask. The volatile compounds were collected by the stream of bubbles, which passed through the sample and were trapped in a $100 \mathrm{mg}$ porous polymer (Tenax ${ }^{\circledR}$ TA, $20-35$ mesh) packed into a glass tube placed at the end of the system. The aromatic extract was thermally desorbed under a $10 \mathrm{~mL} / \mathrm{min}$ helium flow at $240{ }^{\circ} \mathrm{C}$ for $10 \mathrm{~min}$. GC-MS analysis was performed using a Finnigan TRACETM MS (ThermoQuest, Austin, USA) as described above.

\subsection{Migration assays}

Four liquid food simulants with different polarity were used: water, aqueous solution containing $3 \%$ of acetic acid, aqueous solution of $10 \%$ ethanol and sunflower oil. Pieces of films $\left(6 \mathrm{~cm}^{2}\right)$ were introduced into vials 
containing $10 \mathrm{~mL}$ of each food simulant, which were hermetically closed and slightly stirred for 10 days at $20{ }^{\circ} \mathrm{C}$. The quantification of the amount of thymol and carvacrol released to the simulants was performed by adapting the methodology described by Villa, Gambaro, Mariani and Dorato (2007). A gradient elution was carried out with a mobile phase of acetonitrile and water. Chromatographic separations were carried out with a HPLC system (Waters 2685), equipped with a C18 column and chromatographic acquisitions were obtained at $209.8 \mathrm{~nm}$ by a diode array detector (Waters 2996), which scanned from 200 to $500 \mathrm{~nm}$. Calibration curves were obtained by using dispersions of thymol and carvacrol standards (98\%, Sigma-Aldrich, St. Lois, USA) which were solved in HPLC gradient grade methanol (Scharlab, Spain).

\subsection{Statistical analysis}

The results were analysed by a multifactor analysis of variance (ANOVA) with a $95 \%$ significance level using Statgraphics ${ }^{\circledR}$ Plus Centurion VII. Multiple comparisons were performed through $95 \%$ Fisher's LSD intervals.

\section{RESULTS AND DISCUSSION}

The relative amount of each component of the essential oil is shown in Table 5.1, where the compositional information available in the literature has been also included. The composition obtained in the present study for the main compounds of oregano essential oil (carvacrol and thymol) is similar to that obtained by Mezzoug et al. (2007). However, compositional data reported by Bouhdid et al. (2008) and Babili et al. (2011) are notably different, probably due to the different geographical origin and agronomic factors (Sánchez-González, Vargas, González-Martínez, Chiralt and Cháfer, 2011b; Wogiatzi, Gougoulias, Papachatzis, Vagelas and Chouliaras, 2009). It is noted that the ratio carvacrol/thymol found in the present study (1.6) was higher than that found in previous studies $(1.1-1.2)$.

As a first approach, and to enable comparison with previous studies, essential oil loss after film formation was estimated gravimetrically. The 
average loss was in the range of $82 \% \pm 11 \%$, with no significant differences among film formulations. This value was significantly higher than the one reported in previous studies, where losses of limonene or cinnamon leaf essential oil were found to be around $38 \%$ and $46 \%$, respectively in $\mathrm{CH}-\mathrm{EO}$ films prepared by casting from FFD with $1 \% \mathrm{CH}(\mathrm{w} / \mathrm{w})$ and $0.5 \%(\mathrm{w} / \mathrm{w})$ (Perdones, Vargas, Atarés and Chiralt, 2014; Sánchez-González, Cháfer, González-Martínez, Chiralt and Desobry, 2011a). In the present study, total chitosan concentration in the FFD was $0.25 \%$ and thus, viscous and steric contributions to the EO emulsion stability were lower. Both, viscosity of the continuous phase and availability of chitosan to adsorb at the oil droplet surface contribute to stabilize the film-forming emulsion, inhibiting the droplet flocculation and creaming and compound evaporation at the film surface.

Table 5.1 Composition (wt. \%) of oregano essential oil (Origanum compactum). Present study and bibliographic data.

\begin{tabular}{lcccc}
\hline Compound & $\begin{array}{c}\text { Present } \\
\text { study }\end{array}$ & $\begin{array}{c}\text { Mezzoug etal,. } \\
(2007)\end{array}$ & $\begin{array}{c}\text { Bouhdid et al., } \\
(2008)\end{array}$ & $\begin{array}{c}\text { Babili et al., } \\
(2011)\end{array}$ \\
\hline a-pinene & 0.16 & 1.15 & 0.71 & 0.62 \\
$\beta$-myrcene & 2.29 & 2.58 & 1.87 & 0.33 \\
limonene & 0.35 & 0.51 & 0.37 & - \\
p-cymene & 11.36 & 13.26 & 7.89 & 24.31 \\
$\gamma$-terpinene & 16.78 & 22.90 & 18.20 & 1.1 \\
linalool & 2.49 & 2.91 & 1.73 & 0.57 \\
thymol & 19.77 & 19.36 & 27.50 & 29.74 \\
carvacrol & 31.73 & 22.00 & 30.53 & 36.46 \\
cariophyllene & 1.64 & 3.47 & 2.85 & - \\
cariophyllene oxide & 1.08 & 0.14 & 0.10 & 0.86 \\
\hline
\end{tabular}

Losses of specific compound of the oregano essential oil were also determined by GC-MS by comparing the volatile profile of the FFD (before film drying) with both the volatile profile of the dried film and redissolved film. The chromatogram obtained for the FFD was similar to the one obtained for oregano essential oil, but some of the compounds identified in oregano essential oil were not identified in that of dry and redissolved films. Thus, the global essential oil losses and the specific losses of each compound were calculated taking into account the chromatogram of the FFD and the chromatogram of the redissolved film, which allowed for the identification of a higher number of compounds. Table 5.2 shows 
the values obtained for global and specific losses, together with the boiling point of each one of the identified compounds. A great variability in the values of total and specific losses was obtained, which suggest that non-uniform evaporation of the essential compounds occurred during film formation. This can be due to the stochastic component of emulsion destabilization processes, which led to different amounts of oil creamed at the film-air interface and thus, different degree of evaporation in each film, even within the same formulation. In general, minor components with lower boiling point showed higher percentages of evaporation, but the high variability obtained makes obtaining conclusions difficult.

Table 5.2 Losses of total oregano essential oil and specific compounds. Mean values and (standard deviation).

\begin{tabular}{|c|c|c|c|c|}
\hline \multirow{3}{*}{$\begin{array}{l}\text { Compound } \\
\text { (Boiling point) }\end{array}$} & \multicolumn{4}{|c|}{ Losses $(\%)=$ Area $_{F F D}-$ Area $_{\text {redissolved film }}$} \\
\hline & \multicolumn{4}{|c|}{ Losses $(\%)=\overline{\text { Area }_{F F D}}$} \\
\hline & $\mathrm{MC}_{0.5} \mathrm{EO}_{0.25}$ & $\mathrm{MC}_{0.5} \mathrm{EO}_{0.5}$ & $\mathrm{MC}_{0.25} \mathrm{CH}_{0.25} \mathrm{EO}_{0.25}$ & $\mathrm{MC}_{0.25} \mathrm{CH}_{0.25} \mathrm{EO}_{0.5}$ \\
\hline Oregano EO & $76(4)^{a}$ & $64(13)^{a}$ & $68(4)^{\mathrm{a}}$ & $69(5)^{a}$ \\
\hline $\begin{array}{l}\alpha \text {-pinene } \\
\left(156^{\circ} \mathrm{C}\right)\end{array}$ & $77(5)^{\mathrm{a}}$ & $88(14)^{a}$ & $86(12)^{a}$ & $76(13)^{a}$ \\
\hline $\begin{array}{l}\beta \text {-myrcene } \\
\left(167^{\circ} \mathrm{C}\right)\end{array}$ & $96(6)^{a}$ & $99.4(0.4)^{\mathrm{a}}$ & $97(2)^{a}$ & $100(2)^{a}$ \\
\hline $\begin{array}{l}\text { limonene } \\
\left(176^{\circ} \mathrm{C}\right)\end{array}$ & $90(11)^{a}$ & $98.9(1.4)^{\mathrm{a}}$ & $92(7)^{a}$ & $99(2)^{a}$ \\
\hline $\begin{array}{l}\text { p-cymene } \\
\left(177^{\circ} \mathrm{C}\right)\end{array}$ & $94(9)^{a}$ & $99.3(0.8)^{\mathrm{a}}$ & $97(4)^{a}$ & $99.6(0.3)^{\mathrm{a}}$ \\
\hline $\begin{array}{l}\gamma \text {-terpinene } \\
\left(183^{\circ} \mathrm{C}\right)\end{array}$ & $95(8)$ & $99.1(0.6)^{a}$ & $97(4)^{\mathrm{a}}$ & $99.5(0.4)^{a}$ \\
\hline $\begin{array}{l}\text { linalool } \\
\left(198^{\circ} \mathrm{C}\right)\end{array}$ & $97(5)^{\mathrm{a}}$ & $99.1(0.8)^{\mathrm{a}}$ & $97(4)^{a}$ & $99.3(0.7)^{\mathrm{a}}$ \\
\hline $\begin{array}{l}\text { thymol } \\
\left(232^{\circ} \mathrm{C}\right)\end{array}$ & $87(2)^{b}$ & $60(18)^{a}$ & $70(5)^{\mathrm{ab}}$ & $67(12)^{\mathrm{ab}}$ \\
\hline $\begin{array}{l}\text { carvacrol } \\
\left(238^{\circ} \mathrm{C}\right)\end{array}$ & $81(3)^{b}$ & $46(24)^{a}$ & $61(8)^{\mathrm{ab}}$ & $57(16)^{\mathrm{ab}}$ \\
\hline $\begin{array}{l}\text { cariophyllene } \\
\left(268^{\circ} \mathrm{C}\right)\end{array}$ & $91(7)^{\mathrm{a}}$ & $87(15)^{\mathrm{a}}$ & $73(26)^{\mathrm{a}}$ & $69(12)^{\mathrm{a}}$ \\
\hline $\begin{array}{l}\text { cariophyllene oxide } \\
\left(280^{\circ} \mathrm{C}\right)\end{array}$ & $95(1)^{b}$ & $65(23)^{a b}$ & $67(11)^{\mathrm{ab}}$ & $51(20)^{a}$ \\
\hline
\end{tabular}


Taking into account the initial EO content in the FFD, essential losses during film formation (Table 5.2) and the carvacrol and thymol content of EO (Table 5.1), the final content of carvacrol and thymol in the film could be estimated and the results are shown in Table 5.3, all these affected by the previously mentioned variability. From these values and, by considering the ratio polymer:simulant, the maximum expected concentration values of carvacrol and thymol in the food simulants, assuming total release from the films, were estimated and shown in Table 5.4, together with the analysed contents in the different food simulants after 10 days at $20^{\circ} \mathrm{C}$.

Table 5.3 Estimated initial carvacrol and thymol content in the films (mg/g polymer).

\begin{tabular}{lcccc}
\hline Compound & $\mathrm{MC}_{0.5} \mathrm{EO}_{0.25}$ & $\mathrm{MC}_{0.5} \mathrm{EO}_{0.5}$ & $\mathrm{MC}_{0.25} \mathrm{CH}_{0.25} \mathrm{EO}_{0.25}$ & $\mathrm{MC}_{0.25} \mathrm{CH}_{0.25} \mathrm{EO}_{0.5}$ \\
\hline Carvacrol & 30 & 173 & 62 & 138 \\
Thymol & 13 & 80 & 30 & 66 \\
\hline
\end{tabular}

MC: methylcellulose, $\mathrm{CH}$ : chitosan, EO: essential oil. Subscripts indicate the ratio of film components.

In general, the analysed values were lower than that corresponding to the estimated total release; although comparisons must be done with caution due to the above mentioned variability. In fact, there are three samples, were the analysed values were greater than that expected, which indicates that in these samples, higher EO retention occurred. Likewise, no total coherence of the concentration values was reached, taken into account the respective chemical affinity of migrants with the film matrices and simulants, and the changes induced by simulant in the mass transport resistance of the matrix (Sánchez-González, Vargas, González-Martínez, Chiralt and Cháfer, 2011b). More polar and acid media are expected to decrease the mass transport resistance of the matrix due to the swelling and/or partial polymer solubilisation. In contrast, EO compounds will be more soluble in less polar simulants. Therefore, in order to ensure that the developed coatings meet the requirements for food contact packaging materials (Comission Regulation №10/2011), the total amount of essential oil in the film formulation must be fitted taking into account the losses during the film drying step and the variability associated to this process. In this sense, for the major compounds, thymol and carvacrol, the stablished specific migration limit $(60 \mathrm{mg} / \mathrm{kg}$ ) could be exceeded in aqueous media and 3\% acetic acid solutions, where films swell and release 
the compounds faster, for film formulations containing a polymer:EO ratio of $1: 1$.

Table 5.4. Concentration of carvacrol and thymol in each one of the food simulants and films after 10 days at $20^{\circ} \mathrm{C}$ and estimated values for total release. Mean values and (standard deviation).

\begin{tabular}{|c|c|c|c|c|c|c|}
\hline & Film & Water & $A$ & B & D2 & $\begin{array}{c}\text { Estimated } \\
\text { total release }\end{array}$ \\
\hline \multirow{4}{*}{ 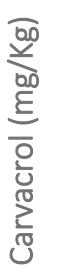 } & $\mathrm{MC}_{0.5} \mathrm{EO}_{0.25}$ & $64(5)$ & $22(13)$ & $28(8)$ & $25(20)$ & 36 \\
\hline & $\mathrm{MC}_{0.5} \mathrm{EO}_{0.5}$ & $35(8)$ & $18(6)$ & $24(10)$ & $11(5)$ & 156 \\
\hline & $\mathrm{MC}_{0.25} \mathrm{CH}_{0.25} \mathrm{EO}_{0.25}$ & $57(12)$ & $8(5)$ & $78(5)$ & $34(12)$ & 75 \\
\hline & $\mathrm{MC}_{0.25} \mathrm{CH}_{0.25} \mathrm{EO}_{0.5}$ & $66(12)$ & $20(12)$ & $132(3)$ & $60(12)$ & 124 \\
\hline \multirow{4}{*}{ 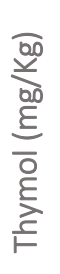 } & $\mathrm{MC}_{0.5} \mathrm{EO}_{0.25}$ & $27(2)$ & $29(15)$ & $18(5)$ & $5(4)$ & 16 \\
\hline & $\mathrm{MC}_{0.5} \mathrm{EO}_{0.5}$ & $15(4)$ & $22(12)$ & $9(4)$ & $5(1)$ & 72 \\
\hline & $\mathrm{MC}_{0.25} \mathrm{CH}_{0.25} \mathrm{EO}_{0.25}$ & $26(5)$ & $2(2)$ & $35(2)$ & $15(6)$ & 36 \\
\hline & $\mathrm{MC}_{0.25} \mathrm{CH}_{0.25} \mathrm{EO}_{0.5}$ & $29(5)$ & $8(5)$ & $62(2)$ & $29(6)$ & 59 \\
\hline
\end{tabular}

Simulant A: ethanol $10 \%$, simulant B: Acetic acid 3\%, simulant D2: sunflower oil. MC: methylcellulose, $\mathrm{CH}$ : chitosan, EO: essential oil. Subscripts indicate the ratio of film components. 


\section{CONCLUSION}

Retention of oregano essential oil in chitosan-methylcellulose films obtained by casting was about $30 \%$ with respect to the added value, according to the changes in the analysed volatile compounds in the film-forming dispersions and in the redissolved films. Nevertheless, a great variability was obtained in the quantification of both total and specific losses of each essential oil compound. This can be explained by the stochastic component of the emulsion destabilization processes, responsible for oil creaming and evaporation from the film surface. Migration values were strongly affected by this variable behaviour. This introduces a level of uncertainty in the expected specific migration levels in different food simulants or foods, since the total migration also depends on the transport driving force and so, on the reached concentration of each compound in the film.

\section{ACKNOWLEDGEMENTS}

The authors acknowledge the financial support provided by Ministerio de Economía y Competividad (AGL2013-42989-R). Ángela Perdones also thanks the Universitat Politècnica de València for the FPI grant. 


\section{REFERENCES}

Altintas, A., Tabanca, N., Tyihác, E., Ott, P.G., Móricz, A.M., Mincsovics, E., Wedge, D.E. Characterization of volatile constituents from Origanum onites and their antifungal and antibacterial activity. Journal of AOAC International 96:6 (2013) $1200-8$.

Babili, F. E., Bouajila, J., Souchard, J. P., Bertrand, C., Bellvert, F., Fouraste, I., Moulis, C., Valentin, A. Oregano: Chemical analysis and evaluation of its antimalarial, antioxidant, and cytotoxic activities. Journal of Food Science 76:3 (2011) C512 - C518.

Ben Arfa, A., Combes, S., Preziosi-Belloy, L., Gontard, N., Chalier, P. Antimicrobial activity of carvacrol related to its chemical structure. Letters in Applied Microbiology 43:2 (2006) 149 - 154.

Ben Arfa, A., Preziosi-Belloy, L., Chalier, P., Gontard, N. Antimicrobial paper based on a soy protein isolate or modified starch coating including carvacrol and cinnamaldehyde. Journal of Agricultural and Food Chemistry 55:6 (2007) $2155-2162$.

Bonilla, J., Talón, M., Atarés, L., Vargas, M., Chiralt, A. Effect of the incorporation of antioxidants on physicochemical and antioxidant properties of wheat starch-chitosan films. Journal of Food Engineering $118: 3(2013) 271-278$.

Bonilla, J., Atarés, L., Vargas, M., Chiralt, A. Effect of Chitosan Essential Oil Films on the Storage-Keeping Quality of Pork Meat Products. Food Bioprocess Technology 7:8 (2014) $2443-2450$.

Bouhdid, S., Skali, S. N., Idaomar, M., Zhiri, A., Baudoux, D., Amensour, M., Abrini, J. Antibacterial and antioxidant activities of Origanum compactum essential oil. African Journal of Biotechnology 7:10 (2008) 1563 - 1570.

Burt, S. Essential oils: Their antibacterial properties and potential applications in foods - a review. International Journal of Food Microbiology $94: 3$ (2004) $223-253$. 
Cerisuelo, J.P., Muriel-Galet, V., Bermúdez, J.M., Aucejo, S., Catalá, R., Gavara, R., Hernández-Muñoz, P. Mathematical model to describe the release of an antimicrobial agent from an active package constituted by carvacrol in a hydrophilic EVOH coating on a PP film. Journal of Food Engineering 110:1 (2012) $26-37$.

Commission Decision 2002/113/EC of 23 January 2002 amending Commission Decision 1999/217/EC as regards the register of flavouring substances used in or on foodstuffs. Official Journal of the European Communities L49.

Commission Regulation (EU) No 10/2011 of 14 January 2011 on plastic materials and articles intended to come into contact with food. Official Journal of the European Union L12.

García, M.A., Pinotti, A., Martino, N.M., Zaritzky, N. E. Characterization of composite hydrocolloid films. Carbohydrate Polymers 56: (2004) 395 - 345.

Gutiérrez, J., Barry-Ryan, C., Bourke, P. Antimicrobial activity of plant essential oils using food model media: Efficacy, synergistic potential and interactions with food components. Food Microbiology 26:2 (2009) $142-150$.

López, P., Sánchez, C., Batlle, R., Nerín, C. Development of flexible antimicrobial films using essential oils as active agents. Journal of Agricultural and Food Chemistry. 55:21 (2007) 8814 - 8824.

Mascheroni, E., Guillard, V., Gastaldi, E., Gontard, N., Chalier, P. Ant-microbial effectiveness of relative humidity-controlled carvacrol release from wheat gluten/montmorillonite coated papers. Food Control 22:10 (2011) $1582-1591$.

Mezzoug, M., Elhadri, A., Dallouh, A., Amkiss, S., Skali, N.S., Abrini, J., Zhiri, A., Baodoux, D., Diallo, B., El Jaziri, M., Idaomar, M. Investigation of the mutagenic and antimutagenic effects of Origanum compactum essential oil and some of its constituents. Mutation Research/Genetic Toxicology and Environmental Mutagenesis 629:2 (2007) 100 - 110. 
Peinado, I., Rosa, E., Heredia, A., Escriche, I., Andrés, A. Influence of processing on the volatile profile of strawberry spreads made with isomaltulose. Food Chemistry 138:1 (2013) 621 - 629.

Perdones, A., Vargas, M., Atarés, L., Chiralt, A. Physical, antioxidant and antimicrobial properties of chitosan-cinnamon leaf oil films as affected by oleic acid. Food Hydrocolloids 36 (2014) $256-264$.

Ramos, M., Beltrán, A., Peltzer, M., Valente, A., Garrigós, M.C. Release and antioxidant activity of carvacrol and thymol from polypropylene active packaging films. LWT-Food Science and Technology 58:2 (2014) $470-477$.

Rodríguez, A., Batlle, R., Nerín, C. The use of natural essential oils as antimicrobial solutions in paper packaging. Part II. Progress in Organic Coatings 60:1 (2007) $33-38$.

Sánchez-González, L., Vargas, M., González-Martínez, C., Chiralt, A., Cháfer, $M$. Characterization of edible films based on hydroxypropylmethylcellulose and tea tree essential oil. Food Hydrocolloids 23:8 (2009) 2102 - 2109.

Sánchez-González, L., Cháfer, M., González-Martínez, C., Chiralt, A., Desobry, S. Study of the release of limonene present in chitosan films enriched with bergamot oil in food simulants. Journal of Food Engineering 105:1 (2011a) 138 - 143 .

Sánchez-González, L., Vargas, M., González-Martínez, C., Chiralt, A., Cháfer, M. Use of Essential Oils in Bioactive Edible Coatings: a review. Food Engineering Reviews 3:1 (2011b) 1-16.

Tomaino, A., Cimino, F., Zimbalatti, V., Venuti, V., Sulfaro, V., De Pasquale, A., Saija, A. Influence of heating on antioxidant activity and the chemical composition of some spice essential oils. Food Chemistry 89:4 (2005) $549-554$.

Vargas, M., Albors, A., Chiralt, A., González-Martínez, C. Water interactions and microstructure of chitosan-methylcellulose composite films as affected by ionic concentration. LWT - Food Science and Technology 44:10 (2011) $2290-2295$. 
Villa, C., Gambaro, R., Mariani, E., Dorato, S. High-performance liquid chromatographic method for the simultaneous determination of 24 fragrance allergens to study scented products. Journal of Pharmaceutical and Biomedical Analysis 44:3 (2007) 755 - 762.

Wogiatzi, E., Gougoulias, N., Papachatzis, A., Vagelas, I., Chouliaras, N. Greek oregano essential oils production, phytotoxicity and antifungal activity. Biotechnology and Biotechnological Equipment 23:1 (2009) $1150-1152$. 


\section{GENERAL DISCUSSION}

Chitosan films and coatings have been obtained, by casting method, with active properties for fruit preservation, by using different strategies: different homogenization conditions of the chitosan film-forming aqueous dispersions and incorporation of different essential oils, selected on the basis of the their aroma compatibility with the coated products (strawberries and tomato) and their previously described antifungal activity. The effect of oleic acid (OA), as emulsifier in the film formulations, was also analysed in its double action: to facilitate the essential oil (EO) emulsification and retention in the films and to improve the water barrier capacity of the films. The blending of chitosan with a neutral and safe polymer, methylcellulose (MC), was also investigated in coating applications to tomato plants in different growth stages to prevent fungal infections. Different approaches led to changes in the film functional properties at the same time that active properties of the films were improved to different extent.

As concerns barrier properties, OA incorporation in the chitosan films (1:1 wt. ratio) reduced water vapour permeability (WVP) values to about $50 \%$ of the chitosan film values, with a small positive effect of microfluidization process, according to the greater reduction of the lipid droplet size, with the subsequent increase in the tortuosity factor for transport of the water molecules through the films. Nevertheless, the induced droplet size reduction by microfluidization did not suppose so relevant improvements in barrier properties as that provoked by the lipid addition. Incorporation of essential oils (basil, cinnamon leaf and thyme) alone or combined with oleic acid was carried out at two different chitosan:lipid ratios (1:0.5 and 1:1). Essential oils did not notably reduced the WVP values of the chitosan films but a significant improvement in water barrier capacity was induced when OA was added at 1:1 or $1: 0.5 \mathrm{CH}: \mathrm{OA}$ ratios. In contrast, lipids promoted oxygen permeability (OP) of the films coherently with the increase in the gas solubility in the film dispersed phase. This effect was more marked for OA than for EO, probably due to the antioxidant activity of the EO compounds which can act as oxygen scavenging agents. Figure D.1 shows the map of the WVP-OP values for the 
different film formulations, and Figure D.2 shows the WVP values of the different $\mathrm{CH}$ films containing different ratios of lipids, where the commented effects can be appreciated.

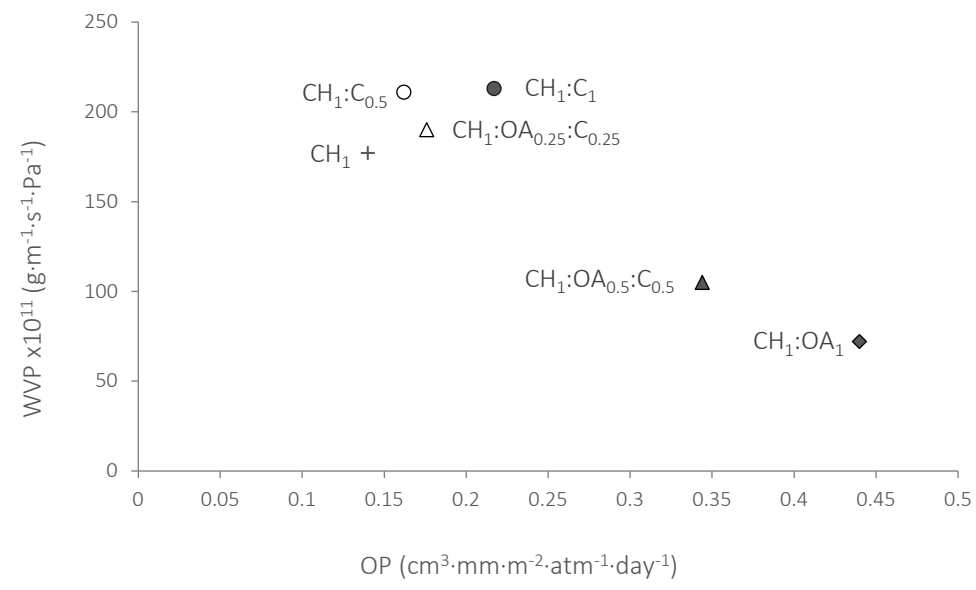

Figure D.1 Map of oxygen and water vapour permeability for chitosan $(\mathrm{CH})$ films with and without oleic acid $(\mathrm{OA})$ and cinnamon leaf essential oil (C) at different ratios.

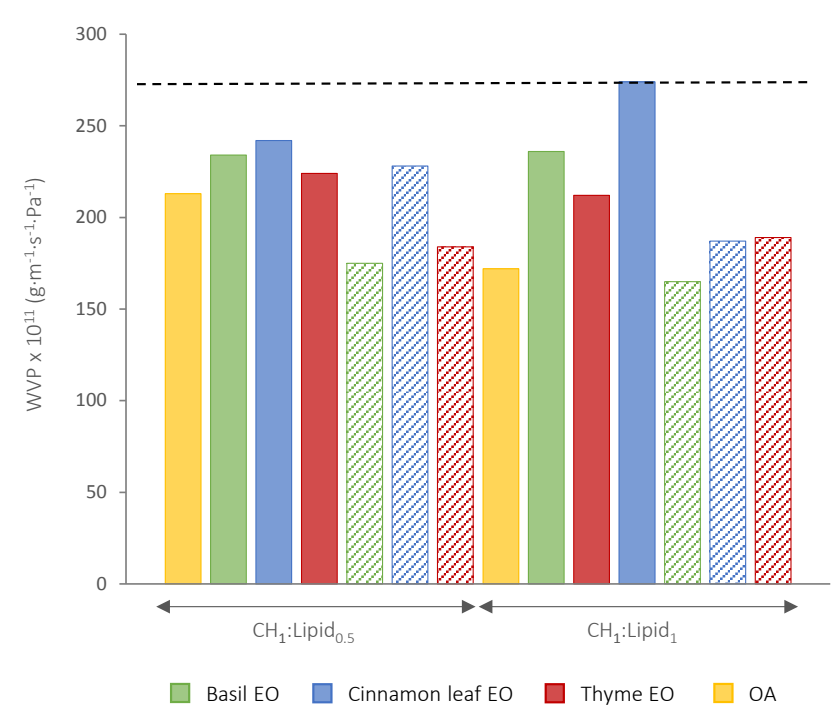

Figure D. 2 Values of the water vapour permeability of the different chitosan films with lipids at different polymer: lipid ratio (1:0.5 and 1:1). Net chitosan films (dashed line), films with pure essential oils (solid bars), films with OA:EO blends (shadowed bars). EO: essential oil, OA: oleic acid. 
Oleic acid incorporation in the chitosan films provoked a decrease in the film stretchability and stiffness (by about $50 \%$ ) with a lesser impact on the resistance to break, slightly depending on the particle size reduction by microfluidization. Addition of essential oils also affected the mechanical response of the films, depending on their composition and their blending or not with oleic acid. In general EO provoked a reduction in the film extensibility, this being more marked for basil and thyme EO. These two essential oils greatly promote film stiffness and resistance to break, whereas cinnamon leaf essential oil slightly reduced these mechanical attributes. This indicates that EO not only contribute to the film structure with the formation of matrix discontinuities (droplets) but they also interact with chitosan, affecting the chain final interactions in the film, depending on the molecular structure of their constituents and the potential bond formation with the $\mathrm{CH}$ groups. Figure D.3 shows the map of tensile strength-\% deformation at break for the different film formulations, where the above commented on effects can be observed.

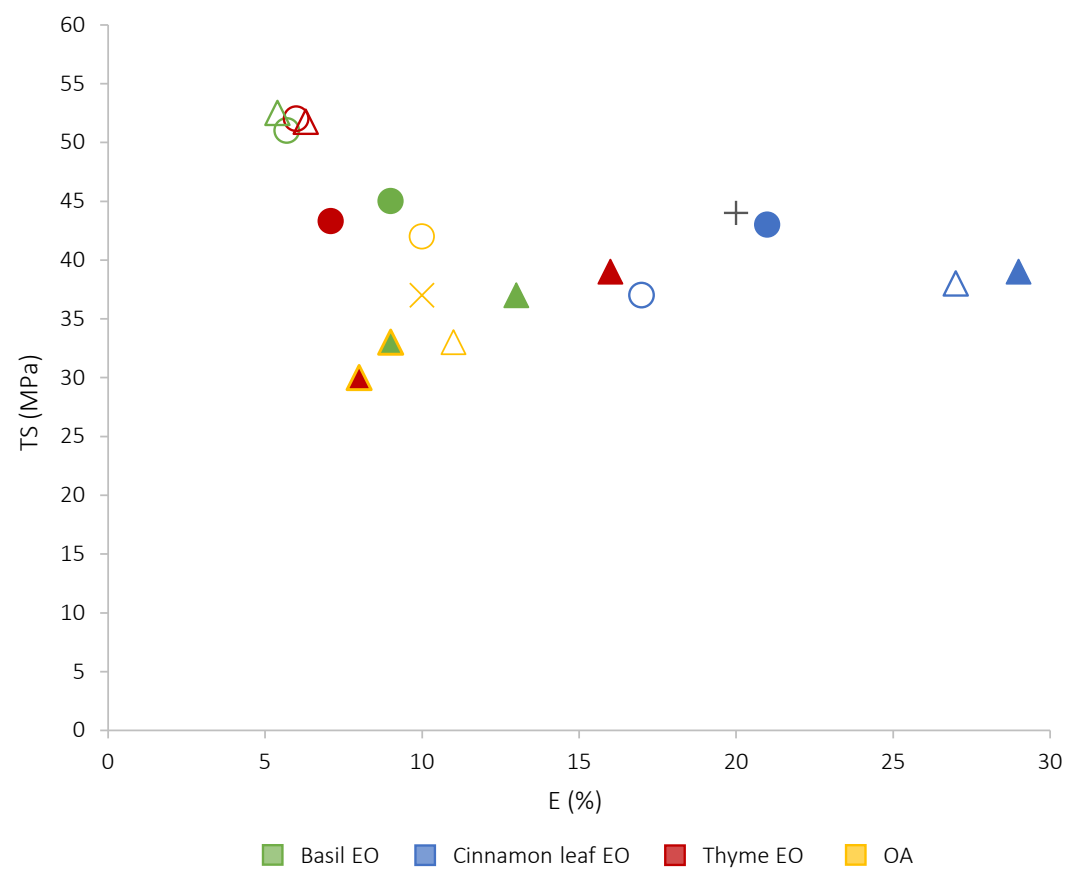

Figure D.3 Map of mechanical properties for the different chitosan based films.

Net CH films (+), films with pure EO (open symbols), films with EO:OA blends

(closed symbols). Polymer:lipid ratios: 1:0.5 (circles) and 1:1 (triangles).

$\mathrm{CH}$ : chitosan, OA: oleic acid, EO: essential oil. 
Optical properties of the chitosan films were also affected by lipid incorporation. Oleic acid reduced the film transparency and gloss depending on the concentration, but provoked small changes in the colour parameters and whiteness index. This effect was expected due to the presence of a dispersed phase in the film matrix, which promoted light dispersion through the film and at the film surface, thus affecting transparency and gloss, respectively. Essential oils caused similar effects, although transparency was less affected, probably due to the minor differences between refractive index of EO and polymer. Nevertheless, EO had greater impact on the colour coordinates and whiteness index of the chitosan films due to the selective light absorption of the constituent compounds. A displacement of the hue to more yellow colour and an increase in colour saturation was observed when EO were present in the chitosan films. Their blend with oleic acid mitigated the colour changes in the films, enhancing the whiteness index, in line with the OA effect on the light dispersion pattern of the film matrices. Figure D.4 shows the chromatic plot for the different film formulations where the particular effect of each EO and its blend with OA can be observed.

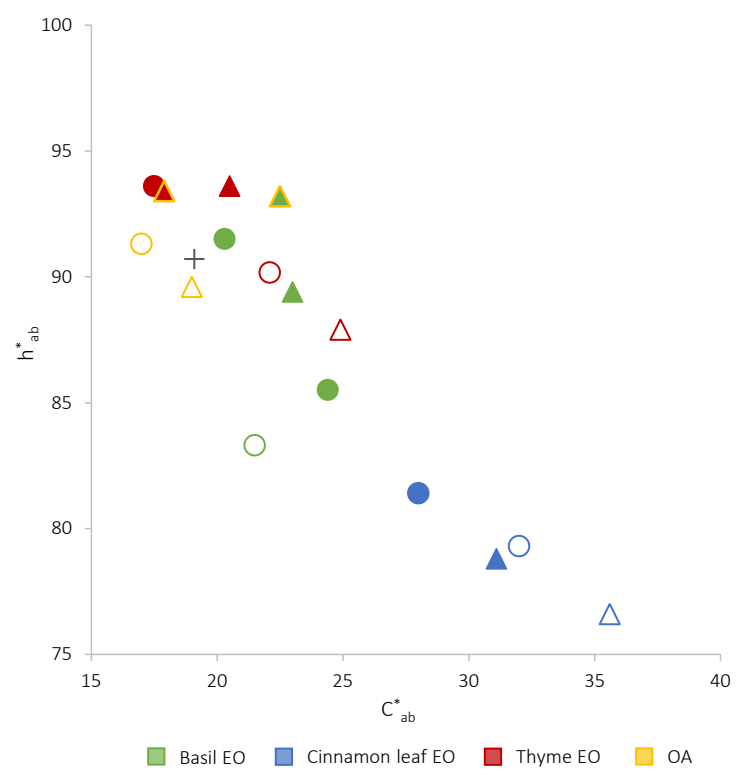

Figure D.4 Chromatic plot for the different chitosan based films. Net CH films (+), films with pure EO (open symbols), films with EO:OA blends (closed symbols).

Polymer:lipid ratios: 1:0.5 (circles) and 1:1 (triangles). CH: chitosan, OA: oleic acid, EO: essential oil. 
An important aspect related with the effect of essential oils on the film properties is their final retention in the dried film, since losses of volatiles occur mainly during the film drying step, associated with the oil droplets migration to the film surface and the compound evaporation, together with water (immiscible compounds) at lower temperature. These losses were estimated to be about $40-50 \%$ of the added EO in the chitosan film-forming emulsions, depending on the emulsion stability and the total lipid creaming during film drying. Lower droplet sizes, higher $\zeta$-potential values and interfacial adsorption of amphiphilic molecules such as oleic acid and chitosan macromolecules, enhanced the emulsion stability and reduced the losses of the essential oils during the film drying step. In fact, films containing OA showed the lowest values of EO losses (about $25 \%$ ). In chitosan-methylcellulose (1:1) blend films higher losses (65-70\%) were reached, in line with the absence of emulsifier (OA) and lower availability of chitosan (less ratio in the emulsion) to the interfacial adsorption and the subsequent emulsion stabilization by steric contribution. Particular constituents of the EO were lost according to their boiling point and their proportion in the oil. The minor components exhibited higher losses. Nevertheless, a great variability was observed in these values, which can be attributed to the stochastic component of the emulsion destabilization processes and their influence on oil losses.

Antifungal effect of chitosan films with and without essential oils was observed in some cases. Cinnamon leaf essential oil, both, free and embedded in the films, was effective at reducing the growth of Aspergillus niger, Botrytis cinerea and Rhizopus stolonifer, although basil and thyme essential oils encapsulated in the films did not exhibit antifungal action against these three fungi. When chitosan coatings with cinnamon leaf essential oil (1:0.5, nominal ratio) were applied to strawberries inoculated with Rhizopus stolonifer, they were very effective at reducing fungal decay of the fruits during 14 days, at $10^{\circ} \mathrm{C}$, at the same time that total coliform counts were maintained at the initial levels. The antifungal efficacy was slightly reduced when oleic acid was present in the film formulation, which indicates that, despite the greater retention in the film, the better encapsulation of active compounds affected their effective release on the fruit surface and thus, their antimicrobial effect. This aspect is highly relevant, since not only the presence of actives in the film, but also their effective and controlled release, is required to ensure their 
antimicrobial action in the product. Therefore, the release studies in food simulants and real foods are necessary before practical applications of active coatings or films. In this sense, migration studies of oregano essential oil encapsulated in chitosan-methylcellulose (1:1) films revealed a great variability in the specific retention of each compound in the films, which affected their total specific migration into food simulants. For the major compounds, thymol and carvacrol, the stablished specific migration limit ( $60 \mathrm{mg} / \mathrm{kg}$ ) for food contact packaging materials could be overcome in aqueous media and $3 \%$ acetic acid solution, where films swell and release the compounds faster. Thus, the total amount of essential oil in the film must be fitted in order to ensure that films fulfil this requirement, taking into account the losses and their variation interval.

Chitosan coatings with lemon essential oil (1:3 nominal ratios) were also active at controlling fungal decay in strawberries. These did not significantly affect the physicochemical parameters of strawberries throughout cold storage, while they slowed down the respiration rate of the fruits. Adding lemon essential oil to the films enhanced the chitosan antifungal activity against Botrytis cinerea, both in vivo and in vitro tests during cold storage of inoculated strawberries. The study of the impact of coatings on the strawberry volatile profile revealed significant changes in the analysed compounds for both, coatings with and without lemon essential oil. Nevertheless, sensory appreciation of these changes was only notable for samples coated with chitosan-lemon oil films. Applications with lower content of the essential oil could improve the sensory perception of the fruits, but antifungal activity of lower lemon oil concentrations might be tested.

The incorporation of oregano essential oil into chitosan based films with the aim of controlling fungal growth in tomato plant and fruits, at preharvest and postharvest conditions, gave interesting results. Blends of chitosan and methylcellulose (1:1) were used to minimize potential damages of the acid chitosan solutions on the plants. Application of treatments at "3 Leaves" stage caused phytotoxic problems, which were lethal when the EO was applied without biopolymers. Even though plant growth and development were delayed, the total biomass and the crop yield were not affected by biopolymer-EO treatments. In the "Fruit" stage, the preharvest treatments had no negative effects. Coatings containing EO significantly reduced the respiration rate of 
tomatoes, diminished weight loss during postharvest storage and were effective to decrease the fungal decay of tomatoes inoculated with Rhizopus stolonifer spores, in agreement with the fungal activity of oregano essential oil and the adequate release of the actives to the tomato surface from the coating matrix

In order to open new perspectives in the use of essential oils as antifungal agents, a screening of the antifungal effect of 10 different essential oils against three common fungi causing fruit spoilage (Aspergillus niger, Botrytis cinerea and Rhizopus stolonifer) were also carried out (Annex I), together with the chemical characterization of their compounds. In this study, different amounts of the oils were impregnated in paper discs and placed in culture plates on the agar surface or fixed to the plate cover, in order to promote compound diffusion in contact with the culture media or their vapour diffusion in the plate head space. In general, the antifungal action was more effective by contact with the culture media than by vapour diffusion, probably due to the greater losses of the volatiles in the vapour phase from the non-hermetically closed plates. This study also reveals notable differences in the antifungal effect of the different essential oils, the cinnamon bark essential oil being the most active to control the growth of the three above mentioned fungi. Nevertheless, some oils showed significant activity at very short times after their application in the culture plates (by comparing with control plates without EO), but their activity greatly decreased after incubation during 7 days. These results could be related with the evaporation and release of actives from the plate. In this sense, entrapping essential oils in the film matrices could ensure their presence for longer times in the media, thus ensuring a more prolonged action. Nevertheless, the release of the adequate amount of the actives as a function of time to inhibit fungal growth must be ensured. Therefore, development of tailored film structures which deliver actives in the required way is necessary. Chitosan matrices can offer this possibility through the selective interactions with actives and other encapsulating agents such as amphiphilic molecules. Chitosan matrices also show the possibility of the $\mathrm{pH}$ induced release. Amino groups in chitosan chains can be more or less charged as a function of the $\mathrm{pH}$, this affecting the interactions of active molecules with the matrix and the partition coefficients of these compounds between film and food phases. 



\section{CONCLUSION}

1 The application of different homogenization conditions to chitosan (CH)-based film-forming dispersions (FFD) led to significant changes in their physicochemical-properties. The use of microfluidization led to a significant decrease in the apparent viscosity of the FFD and modified their rheological behaviour, which changed from shear-thinning to Newtonian with the rise in homogenization pressure. In $\mathrm{CH}$ :oleic acid (OA) FFD, microfluidization led to a significant decrease in particle size and to monomodal, narrower particle size distributions, which in turn affect the properties of the dry films. The use of high homogenization pressures decreases the water vapour permeability of the composite films and leads to milder changes in the mechanical properties that occur when oleic acid is incorporated into the chitosan matrix, while seeming to promote structural links between $\mathrm{OA}$ and $\mathrm{CH}$. The use of microfluidization treatments appears to be a suitable approach to the production of chitosan-based film-forming dispersions with different particle sizes, surface charge and rheological behaviour in order to develop edible films adapted to a specific target application.

2 Chitosan-based edible coatings did not promote significant changes in the physicochemical quality of strawberries throughout cold storage, although they seem to slightly affect the metabolic pattern of the fruit when they contain lemon essential oil (L), as deduced by some differences induced in the respiration behaviour and some colour and mechanical properties. Nevertheless, they induce a better preservation of the fruit in terms of fungal decay, especially when lemon essential oil is incorporated in the coating. According to these results, chitosan-lemon essential oil coatings can be an alternative method with which to extend strawberry shelf-life. Nevertheless, lemon oil should be incorporated at a lesser concentration in the film (lower than 1:3, CH:L ratio) to minimize its impact on the olfactory perception.

3 Chitosan coatings, with and without lemon essential oil, affected the strawberry volatile profile which, in turn, had an impact on the perception of the fruit aroma and flavour. The coatings affected the metabolic pathways of the fruit. Particularly, pure chitosan promoted ester and DMF 
formation in very short time after coating, which could enhance the aroma perception. However, the addition of lemon essential oil to the coatings not only incorporated the lemon essential oil terpenes into the fruit volatiles, but also promoted changes in the cell physiology, enhancing the fermentative process, thus modifying the typical fruit volatile composition. Whereas the effect of chitosan coatings was not sensorially perceived, probably because the differences were within the range of consumer tolerance, the changes induced by lemon essential oil were notably appreciated. Therefore, although lemon essential oil contributed to the prevention of fungal decay, the impact of its application was negative from the point of view of the quality of the fruit's aroma.

4 The essential oil retention in the chitosan films was greatly dependent on the stability of the film-forming emulsion during the film formation. The addition of $\mathrm{OA}$ to the chitosan-essential oil formulations enhanced the emulsion stability and oil retention in the film at the same time that it improved the film water vapour barrier properties. Lipids reduced the film stretchability but when OA was present in the formulation, this reduction was mitigated, as well as the changes in colour provoked by the essential oils. However OA reduced the film transparency to a greater extent than pure essential oils. Chitosan films with basil or thyme essential oils did not inhibit the growth of Aspergillus niger, Botrytis cinerea and Rhizopus stolonifer in an in vitro test.

5 Chitosan-cinnamon leaf essential oil (C) films showed antifungal activity against Aspergillus niger, Botrytis cinerea and Rhizopus stolonifer and allowed for a significantly increase in the self-life of strawberries infected with $R$. stolonifer. Nevertheless, these films showed worse barrier properties than pure chitosan films. The addition of oleic acid to chitosan-cinnamon leaf essential oil films promoted essential oil retention into the film matrix during film drying. Oleic acid incorporation led to a significant reduction in the water vapour permeability and a diminution of the changes in colour and mechanical properties that were promoted by essential oil addition. Oleic acid slightly reduced the antifungal efficacy of the $\mathrm{CH}-\mathrm{C}$ films probably due to the encapsulation of the essential oil, which in turn can limit the release of cinnamon leaf's active compounds to the surface of the coated product. These results suggest that it is possible to formulate antifungal edible films based on chitosan and cinnamon leaf 
essential oil with adequate properties by the incorporation of oleic acid into the film-forming dispersion.

6 Preharvest application of essential oil (EO) to tomato plants promoted phytotoxic effects, which were diminished when EO was incorporated at the same dose into biopolymer-based FFD. Plant growth and development were delayed due to EO application, although total biomass production, fruit set ratio and yield were no affected. Postharvest application of biopolymer-oregano essential oil coatings decreased weight losses during storage and promoted a reduction in the respiration rate of tomatoes, with no effect on the maturity index and $\mathrm{pH}$ of fruits. The incorporation of oregano EO into FFD based on methylcellulose and $\mathrm{CH}$ has been proven to be an effective treatment to control $R$. stolonifer in tomato fruit both in postharvest curative and preventive applications.

7 Retention of oregano essential oil in chitosan-methylcellulose films obtained by casting was about $30 \%$ with respect to the added value, according to the changes in the analysed volatile compounds in the film-forming dispersions and in the redissolved films. Nevertheless, a great variability was obtained in the quantification of both total and specific losses of each essential oil compound. This can be explained by the stochastic component of the emulsion destabilization processes, responsible for oil creaming and evaporation from the film surface. Migration values were strongly affected by this variable behaviour. This introduces a level of uncertainty in the expected specific migration levels in different food simulants or foods, since the total migration also depends on the transport driving force and so, on the reached concentration of each compound in the film. 

ANNEX I 

Table A.1 Identified volatile compounds, \% "relative area" and Retention index (KI: Kovats index and RT: retention time) in basil, bergamot, cinnamon bark, cinnamon leaf, clove, lemon, mint, oregano, rosemary and thyme essential oils analysed by GC-MS.

\begin{tabular}{|c|c|c|c|c|c|c|c|c|c|c|c|c|}
\hline $\mathrm{KI}$ & RT & & Basil & Bergamot & $\begin{array}{c}\text { Cinnamon } \\
\text { bark }\end{array}$ & $\begin{array}{c}\text { Cinnamon } \\
\text { leaf }\end{array}$ & Clove & Lemon & Mint & Oregano & Rosemary & Thyme \\
\hline & & Monoterpenes hydrocarbons & 0.51 & 46.05 & 13.77 & 8.78 & 0 & 89.42 & 6.32 & 29.77 & 37.21 & 15.12 \\
\hline 1042 & 10.14 & $\alpha$-pinene & $0.06(0.01)$ & $1.5(0.3)$ & $1.03(0.13)$ & $1.6(0.5)$ & - & $2.09(0.05)$ & $0.80(0.05)$ & $0.6(0.2)$ & $13.3(0.5)$ & $2.2(0.3)$ \\
\hline 1045 & 10.23 & $\alpha$-thujene & - & - & $0.29(0.04)$ & $0.14(0.01)$ & - & $0.44(0.02)$ & - & $0.5(0.2)$ & - & - \\
\hline 1088 & 11.72 & camphene & - & $0.05(0.02)$ & $0.37(0.03)$ & $0.5(0.2)$ & - & $0.06(0)$ & - & $0.12(0.06)$ & $5.5(0.7)$ & $0.62(0.04)$ \\
\hline 1132 & 13.39 & $\beta$-pinene & $0.05(0.01)$ & $6.5(0.8)$ & $0.35(0.05)$ & $0.6(0.2)$ & - & $13.28(0.06)$ & $1.14(0.05)$ & $0.11(0.04)$ & $0.97(0.05)$ & $0.25(0.03)$ \\
\hline 1146 & 13.92 & sabinene & $0.02(0)$ & $1.1(0.2)$ & $0.10(0.02)$ & - & - & $2.3(0.2)$ & $0.5(0)$ & - & - & $0.61(0.07)$ \\
\hline 1173 & 14.96 & $\Delta 3$-carene & - & - & $0.09(0.02)$ & $0.15(0.05)$ & - & - & - & - & - & - \\
\hline 1185 & 15.44 & $\beta$-myrcene & $0.04(0.01)$ & $1.3(0.2)$ & $0.11(0.02)$ & $0.22(0.07)$ & - & $2.01(0.04)$ & $0.09(0)$ & $1.9(0.6)$ & $4.8(0.3)$ & $2.6(0.3)$ \\
\hline 1190 & 15.64 & $\alpha$-phellandrene & - & - & $1.3(0.2)$ & $1.1(0.3)$ & - & $0.04(0.01)$ & - & $0.14(0.03)$ & - & - \\
\hline 1206 & 16.28 & $\alpha$-terpinene & - & $0.03(0.01)$ & $0.96(0.09)$ & $0.13(0.04)$ & - & $0.22(0.01)$ & $0.10(0.01)$ & $1.5(0.5)$ & $0.30(0.01)$ & - \\
\hline 1227 & 17.07 & limonene & $0.25(0.01)$ & $28.1(0.6)$ & $1.10(0.09)$ & $0.8(0.2)$ & - & $53.9(0.2)$ & $2.49(0.02)$ & $0.3(0.1)$ & $6.7(0.3)$ & $2.18(0.14)$ \\
\hline 1238 & 17.51 & $\beta$-phellandrene & - & $0.10(0.08)$ & $5.2(0.4)$ & $1.2(0.4)$ & - & $0.4(0.2)$ & - & $0.25(0.07)$ & - & $0.46(0.03)$ \\
\hline 1259 & 18.32 & $\beta$-cis Ocimene & - & $0.10(0.02)$ & $0.07(0.01)$ & $0.02(0.01)$ & - & $0.1180 .01)$ & $0.08(0)$ & - & - & - \\
\hline 1274 & 18.88 & $\beta$-trans Ocimene & $0.03(0.01)$ & - & - & $0.03(0.01)$ & - & - & - & - & $0.26(0.01)$ & - \\
\hline 1276 & 18.97 & $\gamma$-terpinene & - & $4.6(0.3)$ & $0.12(0.01)$ & $0.01(0.02)$ & - & $11.93(0.05)$ & $0.29(0)$ & $14(4)$ & $1.88(0.13)$ & $0.54(0.02)$ \\
\hline 1303 & 19.99 & p-cymene & $0.06(0.01)$ & $2.6(0.1)$ & $2.61(0.13)$ & $2.1(0.4)$ & - & $2.09(0.05)$ & $0.68(0.06)$ & $10(2)$ & $3.28(0.16)$ & $5.4(0.2)$ \\
\hline 1314 & 20.42 & terpinolene & - & $0.15(0.02)$ & $0.10(0.01)$ & $0.07(0.02)$ & - & $0.52(0.02)$ & $0.09(0.01)$ & $0.08(0.01)$ & $0.27(0.01)$ & $0.17(0.02)$ \\
\hline 1449 & 25.41 & perillene & - & - & - & - & - & - & - & - & - & $0.09(0.01)$ \\
\hline \multirow[t]{2}{*}{1591} & 30.34 & menthene & - & - & - & - & - & - & $0.07(0.01)$ & - & - & - \\
\hline & & Oxygenated monoterpenes & 92.68 & 18.24 & 7.12 & 7.43 & 0.15 & 7.40 & 84.04 & 5.26 & 56.37 & 80.71 \\
\hline 1237 & 17.44 & 1,8-cineole & $0.43(0.01)$ & - & - & - & - & - & $5.9(0.2)$ & - & $20.0(0.6)$ & - \\
\hline 1478 & 26.44 & Z-linalool oxide (furanoid) & $1.41(0.07)$ & $0.29(0.03)$ & - & $0.07(0.02)$ & - & $0.20(0.02)$ & $0.03(0)$ & - & - & $2.6(0.2)$ \\
\hline 1488 & 26.78 & limonene oxide (Z) & - & $0.7(0.1)$ & - & - & - & - & - & - & - & - \\
\hline 1494 & 27.02 & sabinene hydrate $(Z)$ & - & $0.05(0.02)$ & - & $0.01(0)$ & - & $0.11(0.01)$ & $0.47(0.03)$ & $0.17(0.04)$ & - & $2.4(0.2)$ \\
\hline 1504 & 27.36 & limonene oxide $(E)$ & - & $0.26(0.04)$ & $0.02(0)$ & $0.08(0.03)$ & - & $0.07(0.02)$ & - & - & - & $2.36(0.15)$ \\
\hline 1504 & 27.37 & E-linalool oxide (furanoid) & $1.38(0.06)$ & $0.29(0.03)$ & - & - & - & - & - & - & - & - \\
\hline 1510 & 27.58 & isomenthone & - & - & - & - & - & - & $17.7(0.6)$ & - & - & - \\
\hline
\end{tabular}


Table A.1 (Continued)

\begin{tabular}{|c|c|c|c|c|c|c|c|c|c|c|c|c|}
\hline $\mathrm{KI}$ & RT & & Basil & Bergamot & $\begin{array}{c}\text { Cinnamon } \\
\text { bark }\end{array}$ & $\begin{array}{l}\text { Cinnamon } \\
\text { leaf }\end{array}$ & Clove & Lemon & Mint & Oregano & Rosemary & Thyme \\
\hline & & Oxygenated monoterpenes & 92.68 & 18.24 & 7.12 & 7.43 & 0.15 & 7.40 & 84.04 & 5.26 & 56.37 & 80.71 \\
\hline 1525 & 28.08 & $\beta$-citronellal & - & - & - & - & - & $0.17(0.01)$ & - & - & - & - \\
\hline 1539 & 28.58 & menthone & $0.05(0)$ & - & - & - & - & - & $4.21(0.15)$ & - & - & - \\
\hline 1555 & 29.13 & $\begin{array}{l}\text { 2,6-dimethyl-3,5,7-octatriene- } \\
\text { 2-ol (E) }\end{array}$ & - & $0.02(0)$ & - & - & - & - & - & $0.11(0.03)$ & - & - \\
\hline 1565 & 29.46 & linalyl acetate & - & $0.05(0.03)$ & - & - & - & - & - & - & - & - \\
\hline 1565 & 29.47 & menthyl acetate & - & - & - & - & - & - & $0.77(0)$ & - & - & - \\
\hline 1571 & 29.65 & $\beta$-linalool & $31.9(0.8)$ & $13.1(0.4)$ & $4.2(0.2)$ & $5.3(0.6)$ & $0.04(0.02)$ & $0.29(0.01)$ & $0.41(0)$ & $2.5(0.4)$ & - & $45(2)$ \\
\hline 1569 & 29.59 & camphor & - & - & - & - & - & - & - & - & $23.1(0.4)$ & - \\
\hline 1583 & 30.06 & Z- $\beta$-terpineol & - & - & - & $0.02(0)$ & - & $0.1(0)$ & $0.11(0)$ & - & - & $0.38(0.08)$ \\
\hline 1596 & 30.51 & $\mathrm{p}$-2-menthen-1-ol (E) & - & - & $0.14(0)$ & $0.03(0.01)$ & - & - & - & - & - & $0.77(0.06)$ \\
\hline 1597 & 30.56 & pinocamphone & - & - & - & - & - & - & - & - & $0.22(0.01)$ & - \\
\hline 1599 & 30.63 & isomenthyl acetate & - & - & - & - & - & - & $8.3(0.2)$ & - & - & - \\
\hline 1613 & 31.07 & isopulegol & - & - & - & - & - & - & $0.19(0.02)$ & - & - & - \\
\hline 1623 & 31.40 & bornyl acetate & - & - & - & - & - & - & - & - & $2.21(0.13)$ & $0.70(0.07)$ \\
\hline 1630 & 31.64 & neomenthol & - & - & - & & - & - & $4.8(0.1)$ & - & - & - \\
\hline 1634 & 31.78 & dehydro linalool & - & - & - & - & - & - & - & - & - & $0.7(0.2)$ \\
\hline 1643 & 32.06 & 4-terpineol & $0.04(0.01)$ & $0.06(0.02)$ & $0.8(0.1)$ & $0.23(0.07)$ & - & $0.13(0.01)$ & $1.14(0.05)$ & $0.9(0.1)$ & $1.21(0.11)$ & $15.4(0.7)$ \\
\hline 1659 & 32.61 & p-menth-8-en-2-one & - & - & - & - & - & - & - & $0.13(0.03)$ & - & - \\
\hline 1664 & 32.77 & dihydroterpineol & - & - & - & - & - & - & $0.67(0.04)$ & - & - & - \\
\hline 1660 & 32.64 & $\mathrm{p}$-2-menthen-1-ol (Z) & - & - & $0.12(0)$ & $0.04(0.01)$ & - & - & - & - & - & - \\
\hline 1673 & 33.05 & menthol & $1.38(0.09)$ & - & - & - & - & - & $35.0(0.8)$ & - & $0.05(0.02)$ & - \\
\hline 1680 & 33.27 & E-dihydrocarvone & - & - & - & - & - & - & - & - & - & $0.41(0.02)$ \\
\hline 1700 & 33.95 & pulegone & - & - & - & - & - & - & $2.58(0.01)$ & $0.08(0.01)$ & - & - \\
\hline 1706 & 34.13 & $\begin{array}{l}\text { 2,6-dimethyl, 2,6-Octadiene- } \\
\text { 1,8-diol }\end{array}$ & - & $0.09(0)$ & - & - & - & - & - & - & - & - \\
\hline 1716 & 34.45 & estragole & $53.7(1.3)$ & $0.07(0.02)$ & $0.16(0.02)$ & $0.33(0.08)$ & - & - & - & $0.30(0.04)$ & - & $0.61(0.03)$ \\
\hline 1735 & 35.03 & neral & $0.12(0.02)$ & $0.12(0.03)$ & - & - & - & $0.91(0.07)$ & $0.14(0.01)$ & - & - & - \\
\hline 1725 & 34.70 & carveol & - & - & - & - & - & - & - & $0.16(0.02)$ & - & - \\
\hline
\end{tabular}




\begin{tabular}{|c|c|c|c|c|c|c|c|c|c|c|c|c|}
\hline $\mathrm{KI}$ & RT & & Basil & Bergamot & $\begin{array}{l}\text { Cinnamon } \\
\text { bark }\end{array}$ & $\begin{array}{l}\text { Cinnamon } \\
\text { leaf }\end{array}$ & Clove & Lemon & Mint & Oregano & Rosemary & Thyme \\
\hline 1734 & 35.00 & $\alpha$-terpineol & $0.27(0.02)$ & $0.23(0.03)$ & $0.98(0.04)$ & $0.8(0.2)$ & - & $0.49(0.02)$ & $0.59(0.01)$ & $0.49(0.08)$ & $2.73(0.21)$ & $2.8(0.2)$ \\
\hline 1740 & 35.17 & $\alpha$-terpinyl acetate & - & $0.31(0.03)$ & - & - & - & - & - & - & - & - \\
\hline 1742 & 35.25 & borneol & - & - & $0.21(0.01)$ & $0.24(0.06)$ & - & - & - & $0.30(0.05)$ & $4.0(0.3)$ & $3.8(0.2)$ \\
\hline 1765 & 35.95 & neryl acetate & - & $0.92(0.1)$ & - & - & - & $1.24(0.03)$ & - & - & - & - \\
\hline 1767 & 36.01 & L-verbenone & - & - & - & - & - & - & - & - & $2.27(0.15)$ & - \\
\hline 1773 & 36.21 & E-linalool oxide (piranoid) & - & - & - & - & - & - & - & - & - & $0.32(0.01$ \\
\hline 1780 & 36.43 & geranial & $1.02(0.08)$ & $0.21(0.03)$ & - & - & - & $2.21(0.069$ & - & - & - & - \\
\hline 1780 & 36.43 & piperitol (Z) & - & - & $0.21(0.01)$ & $0.03(0.01)$ & - & - & - & - & - & $0.26(0.03$ \\
\hline 1786 & 36.62 & piperitone & - & - & - & - & - & - & $0.67(0.03)$ & - & - & - \\
\hline 1795 & 36.88 & geranyl acetate & - & $0.91(0.05)$ & - & - & - & $1.49(0.05)$ & - & - & - & - \\
\hline 1791 & 36.75 & carvone & $0.17(0.04)$ & - & - & - & - & - & $0.24(0.02)$ & - & - & - \\
\hline 1793 & 36.82 & Z-linalool oxide (pyranoid) & $0.15(0.03)$ & - & - & - & - & - & - & - & - & $0.40(0.08$ \\
\hline 1798 & 36.98 & p-menthane-1,2,3-triol & - & - & - & - & - & - & - & - & - & $0.71(0.07$ \\
\hline 1825 & 37.80 & geraniol & $0.1(0)$ & $0.18(0.01)$ & - & $0.02(0.01)$ & - & - & $0.03(0)$ & - & - & - \\
\hline 1817 & 37.54 & camphenol & - & - & - & - & - & - & - & - & $0.05(0.01)$ & - \\
\hline 1834 & 38.06 & myrtenol & - & - & - & - & - & - & $0.04(0)$ & - & $0.18(0.02)$ & - \\
\hline 1848 & 38.50 & sabinol (Z) & - & - & $0.19(0.04)$ & $0.15(0.04)$ & - & - & - & - & - & - \\
\hline 1872 & 39.21 & carveol (E) & - & - & - & - & - & - & - & - & - & $0.36(0.03$ \\
\hline 1874 & 39.27 & nerol & - & $0.29(0.02)$ & - & - & - & - & - & - & - & - \\
\hline 1878 & 39.40 & anethole & $0.07(0.01)$ & - & - & - & - & - & $0.07(0.01)$ & - & - & - \\
\hline 1885 & 39.62 & p-cymen-8-ol & - & $0.03(0)$ & $0.09(0.01)$ & $0.13(0.05)$ & - & - & - & $0.17(0.03)$ & $0.31(0.03)$ & - \\
\hline 1899 & 40.05 & dextro-carvone & - & - & - & - & - & - & - & - & - & $0.3(0.3)$ \\
\hline 1903 & 40.19 & carveol (Z) & - & $0.05(0)$ & - & - & - & - & - & - & - & - \\
\hline \multirow[t]{3}{*}{1961} & 42.21 & $\begin{array}{l}\text { 3,7-octadiene-2,6,diol, 2,6- } \\
\text { dimethyl }\end{array}$ & $0.49(0.02)$ & - & - & - & - & - & - & - & - & $0.44(0.03$ \\
\hline & 49.88 & $\begin{array}{l}\text { 3,7-octadiene-3,6-diol, 2,6- } \\
\text { dimethyl }\end{array}$ & - & - & - & - & - & - & - & - & - & $0.20(0.03$ \\
\hline & 59.82 & cinerolon & - & - & - & - & $0.11(0.03)$ & - & - & - & - & - \\
\hline
\end{tabular}


Table A.1 (Continued)

\begin{tabular}{|c|c|c|c|c|c|c|c|c|c|c|c|c|}
\hline $\mathrm{KI}$ & RT & & Basil & Bergamot & $\begin{array}{c}\text { Cinnamon } \\
\text { bark }\end{array}$ & $\begin{array}{c}\text { Cinnamon } \\
\text { leaf }\end{array}$ & Clove & Lemon & Mint & Oregano & Rosemary & Thyme \\
\hline & & Sesquiterpenes hydrocarbons & 4.30 & 1.97 & 6.43 & 8.48 & 20.87 & 2.70 & 3.51 & 2.04 & 4.60 & 0.83 \\
\hline 1518 & 27.86 & ylangene & - & - & - & - & - & - & - & - & $0.12(0.01)$ & - \\
\hline 1530 & 28.25 & copaene & $0.07(0)$ & - & $0.36(0.01)$ & $1.2(0.3)$ & $0.41(0.04)$ & - & - & - & $0.11(0.01)$ & - \\
\hline 1560 & 29.28 & $\beta$-bourbonene & - & - & - & $0.01(0)$ & - & - & $0.30(0.03)$ & - & - & - \\
\hline 1624 & 31.45 & $\alpha$-bergamotene & $1.52(0.09)$ & $0.59(0.05)$ & $0.16(0.05)$ & - & - & $0.84(0.05)$ & - & - & - & - \\
\hline 1634 & 31.78 & $\beta$-elemene & - & - & - & $0.03(0.01)$ & - & - & - & - & - & - \\
\hline 1646 & 32.18 & $\beta$-caryophyllene & $0.17(0.01)$ & $0.31(0.03)$ & $4.74(0.16)$ & $5.54(0.98)$ & $16.6(0.2)$ & - & $2.26(0.01)$ & $1.6(0.2)$ & $3.21(0.18)$ & - \\
\hline 1655 & 32.48 & aromadendrene & - & - & - & $0.10(0.02)$ & - & - & - & - & - & - \\
\hline 1660 & 32.62 & $\gamma$-caryophyllene & - & - & - & - & $0.17(0.03)$ & $0.36(0.01)$ & - & - & $0.05(0.01)$ & $0.8(0.2)$ \\
\hline 1682 & 33.34 & $\beta$-sesquiphellandrene & $0.09(0.01)$ & - & - & - & - & - & - & - & - & - \\
\hline 1692 & 33.69 & $\beta$-farnesene & $0.21(0.01)$ & $0.12(0.01)$ & - & - & - & - & $0.14(0.02)$ & - & - & - \\
\hline 1704 & 34.05 & germacrene D & - & - & $0.04(0)$ & $0.02(0.01)$ & - & $0.20(0.02)$ & - & - & - & - \\
\hline 1722 & 34.62 & $\alpha$-humulene & $0.12(0.02)$ & - & $1.01(0.03)$ & $1.2(0.3)$ & $2.7(0.2)$ & - & $0.10(0.01)$ & $0.09(0.01)$ & $1.11(0.09)$ & - \\
\hline 1733 & 34.96 & $\gamma$-muurolene & - & - & - & - & $0.11(0.03)$ & - & - & - & - & - \\
\hline 1762 & 35.87 & germacrene B & - & - & - & - & - & - & $0.55(0.03)$ & - & - & - \\
\hline 1768 & 36.04 & $\beta$-bisabolene & $0.31(0.03)$ & $0.94(0.07)$ & - & - & - & $1.31(0.02)$ & - & $0.13(0.02)$ & - & - \\
\hline 1768 & 36.04 & $\alpha$-muurolene & - & - & - & $0.05(0.02)$ & $0.05(0.02)$ & - & - & - & - & - \\
\hline 1775 & 36.25 & $\alpha$-farnesene & - & - & - & - & $0.35(0.07)$ & - & - & - & - & - \\
\hline 1797 & 36.95 & isocaryophyllene & $1.81(0.14)$ & $0.02(0.01)$ & - & - & - & - & - & - & - & - \\
\hline 1802 & 37.10 & $\mathrm{~d}$-cadinene & - & - & $0.04(0.01)$ & $0.22(0.07)$ & $0.26(0.06)$ & - & $0.10(0.02)$ & $0.13(0.03)$ & - & - \\
\hline 1810 & 37.34 & $\gamma$-cadinene & - & - & - & $0.06(0.03)$ & $0.06(0.01)$ & - & $0.05(0.01)$ & $0.01(0)$ & - & - \\
\hline 1813 & 37.42 & $\alpha$-curcumene & - & - & $0.08(0)$ & - & - & - & - & - & - & - \\
\hline \multirow[t]{2}{*}{1872} & 39.21 & calamenene & - & - & - & - & $0.11(0.01)$ & - & - & - & - & - \\
\hline & & Oxygenated sesquiterpenes & 1.30 & 0.27 & 1.33 & 0.94 & 2.13 & 0 & 0.72 & 1.06 & 0.36 & 1.24 \\
\hline \multirow[t]{4}{*}{1630} & 31.65 & d-nerolidol & $0.12(0.02)$ & - & - & - & - & - & - & - & - & - \\
\hline & 45.60 & caryophyllene oxide & $0.78(0.06)$ & $0.27(0.02)$ & $1.13(0.04)$ & - & $1.1(0.6)$ & - & $0.34(0.07)$ & $1.1(0.2)$ & $0.36(0.04)$ & $1.07(0.07)$ \\
\hline & 46.83 & E-farnesene epoxide & $0.12(0.01)$ & - & - & - & - & - & - & - & - & - \\
\hline & 48.15 & caryophyllenyl alcohol & - & - & - & - & $1.0(0.2)$ & - & - & - & - & - \\
\hline
\end{tabular}




\begin{tabular}{|c|c|c|c|c|c|c|c|c|c|c|c|c|}
\hline $\mathrm{KI}$ & RT & & Basil & Bergamot & $\begin{array}{l}\text { Cinnamon } \\
\text { bark }\end{array}$ & $\begin{array}{c}\text { Cinnamon } \\
\text { leaf }\end{array}$ & Clove & Lemon & Mint & Oregano & Rosemary & Thyme \\
\hline & 48.29 & humulene oxide II & $0.28(0.03)$ & - & - & $0.47(0.09)$ & - & - & - & - & - & - \\
\hline & 49.75 & ledol & - & - & - & - & - & - & $0.28(0.01)$ & - & - & - \\
\hline & 51.87 & spathulenol & - & - & - & $0.18(0.03)$ & - & - & $0.1(0)$ & - & - & $0.17(0.03)$ \\
\hline & 71.68 & E-Z- $\alpha$-bisabolene epoxide & - & - & $0.19(0.01)$ & $0.30(0.08)$ & - & - & - & - & - & - \\
\hline & & Phenols & 0 & 0 & 6.26 & 59.3 & 59.64 & 0 & 0.09 & 60.48 & 0 & 0.30 \\
\hline \multirow[t]{6}{*}{1928} & 41.05 & safrole & - & - & - & $3.1(0.5)$ & - & - & - & - & - & - \\
\hline & 54.83 & eugenol & - & - & 6.2 & $56(6)$ & $59(3)$ & - & - & - & - & - \\
\hline & 54.85 & thymol & - & - & - & - & - & - & $0.09(0.03)$ & $23(2)$ & - & $0.30(0.04)$ \\
\hline & 57.19 & carvacrol & - & - & $0.09(0)$ & $0.09(0.03)$ & - & - & - & $38(7)$ & - & - \\
\hline & 68.93 & chavicol & - & - & - & $0.16(0.08)$ & $0.31(0.03)$ & - & - & - & - & - \\
\hline & & Alcohols & 0.11 & 0 & 1.66 & 0.54 & 0 & 0 & 0.47 & 0.60 & 0.85 & 0.19 \\
\hline 1411 & 24.01 & 3-octanol & - & - & - & - & - & - & $0.37(0.01)$ & - & $0.34(0)$ & $0.14(0.01)$ \\
\hline 1440 & 25.07 & 2,6-dimethyl-1,5,7-octatrien-3- & - & - & - & - & - & - & - & - & - & $0.06(0.01)$ \\
\hline 1470 & 26.14 & 1-octen-3-ol & - & - & - & - & - & - & $0.11(0)$ & $0.43(0.08)$ & $0.50(0.01)$ & - \\
\hline \multirow[t]{4}{*}{1580} & 29.97 & 1-octanol & $0.11(0)$ & - & - & - & - & - & - & $0.17(0.03)$ & - & - \\
\hline & 47.43 & 3-phenylpropyl alcohol & - & - & $0.26(0.01)$ & $0.25(0.06)$ & - & - & - & - & - & - \\
\hline & 63.62 & cinnamyl alcohol & - & - & $1.40(0.06)$ & $0.29(0.08)$ & - & - & - & - & - & - \\
\hline & & Aldehydes & 0.51 & 0.09 & 46.38 & 3.36 & 0.48 & 0.31 & 0 & 0 & 0 & 0 \\
\hline 1329 & 20.96 & octanal & - & - & - & - & - & $0.07(0.01)$ & - & - & - & - \\
\hline 1431 & 24.74 & nonanal & - & $0.03(0.02)$ & - & - & - & $0.16(0)$ & - & - & - & - \\
\hline 1503 & 27.35 & furfural & - & - & - & - & $0.48(0.05)$ & - & - & - & - & - \\
\hline 1532 & 28.32 & decanal & - & $0.06(0.05)$ & - & - & - & - & - & - & - & - \\
\hline 1543 & 28.72 & decanal & - & - & - & - & - & $0.08(0)$ & - & - & - & - \\
\hline 1753 & 35.59 & melonal & $0.13(0.01)$ & - & - & - & - & - & - & - & - & - \\
\hline 1835 & 38.09 & hydrocinnamaldehyde & - & - & $0.67(0.02)$ & $0.06(0.02)$ & - & - & - & - & - & - \\
\hline \multirow[t]{3}{*}{1953} & 41.92 & Z-cinnamaldehyde & - & - & $0.76(0.03)$ & - & - & - & - & - & - & - \\
\hline & 47.43 & p-anisaldehyde & $0.37(0.0$ & - & - & - & - & - & - & - & - & - \\
\hline & 48.13 & E-cinnamaldehyde & - & - & $44.9(1.5)$ & $3.3(0.3)$ & - & - & - & - & - & - \\
\hline
\end{tabular}


Table A.1 (Continued)

\begin{tabular}{|c|c|c|c|c|c|c|c|c|c|c|c|c|}
\hline KI & RT & & Basil & Bergamot & $\begin{array}{l}\text { Cinnamon } \\
\text { bark }\end{array}$ & $\begin{array}{l}\text { Cinnamon } \\
\text { leaf }\end{array}$ & Clove & Lemon & Mint & Oregano & Rosemary & Thyme \\
\hline & & Aromatic compounds & 0 & 0 & 0.45 & 0.53 & 0 & 0 & 0 & 0.22 & 0.22 & 0 \\
\hline 1291 & 19.53 & styrene & - & - & $0.13(0.01)$ & $0.03(0.01)$ & - & - & - & - & - & - \\
\hline 1474 & 26.30 & $\alpha$-2-dimethyl styrene & - & - & $0.04(0)$ & - & - & - & - & $0.22(0.07)$ & $0.22(0.01)$ & - \\
\hline 1573 & 29.75 & benzaldehyde & - & - & $0.28(0.02)$ & $0.34(0.08)$ & - & - & - & - & - & - \\
\hline \multirow[t]{2}{*}{1774} & 36.24 & Benzyl acetate & - & - & - & $0.17(0.05)$ & - & - & - & - & - & - \\
\hline & & Ketones & 0 & 0 & 0 & 0 & 0.11 & 0 & 0 & 0.1 & 0 & 0 \\
\hline 1208 & 16.33 & 2-heptanone & - & - & - & - & $0.05(0.01)$ & - & - & - & - & - \\
\hline 1282 & 19.17 & 3-octanone & - & - & - & - & - & - & - & $0.10(0.02)$ & - & - \\
\hline \multirow[t]{2}{*}{1417} & 24.24 & 2-nonanone & - & - & - & - & $0.06(0)$ & - & - & - & - & - \\
\hline & & Esters & 0.15 & 32 & 15.29 & 10.49 & 14.79 & 0 & 0.14 & 0 & 0 & 2 \\
\hline 1283 & 19.23 & 2-heptanol acetate & - & - & - & - & $0.06(0.01)$ & - & - & - & - & - \\
\hline 1318 & 20.55 & amyl isovalerate & - & - & - & - & - & - & $0.09(0)$ & - & - & - \\
\hline 1358 & 22.06 & 3-octyl acetate & - & - & - & - & - & - & $0.05(0)$ & - & - & - \\
\hline 1585 & 30.13 & linalyl anthranilate & - & $32(2)$ & - & $0.01(0)$ & - & - & - & - & $0.36(0.03)$ & $1.6(0.1)$ \\
\hline 1835 & 38.11 & methyl salicylate & - & - & - & - & $0.26(0.03)$ & - & - & - & - & - \\
\hline 1908 & 40.35 & benzyl benzoate & - & - & - & $1.2(0.8)$ & - & - & - & - & - & - \\
\hline \multirow[t]{5}{*}{1991} & 43.25 & 3-phenylpropyl acetate & - & - & $0.18(0.02)$ & $0.26(0.07)$ & - & - & - & - & - & - \\
\hline & 46.04 & nerolidyl acetate & $0.15(0.01)$ & - & - & $2.7(0.6)$ & - & - & - & - & - & - \\
\hline & 53.71 & cinnamyl acetate & - & - & $15.1(0.2)$ & $3.0(0.2)$ & - & - & - & - & - & - \\
\hline & 61.19 & eugenyl acetate & - & - & - & $3.4(0.6)$ & $14.5(1.4)$ & - & - & - & - & - \\
\hline & & Others & 0 & 0.80 & 1.26 & 0 & 0.67 & 0 & 4.67 & 0 & 0.00 & 0.05 \\
\hline 1528 & 28.20 & mentho furan & - & - & - & - & - & - & $4.4(0.2)$ & - & - & - \\
\hline \multirow[t]{3}{*}{1724} & 34.67 & lilac lactone & - & - & - & - & - & - & - & - & - & $0.05(0)$ \\
\hline & 67.61 & mint lactone & - & - & - & - & - & - & $0.32(0.03)$ & - & - & - \\
\hline & 75.17 & $\begin{array}{l}\text { ortho methoxy } \\
\text { cinnalmaldehyde }\end{array}$ & - & - & $1.26(0.6)$ & - & - & - & - & - & - & - \\
\hline 1619 & 31.27 & unknown & - & - & - & - & $0.45(0.05)$ & - & - & - & - & - \\
\hline
\end{tabular}




\begin{tabular}{|c|c|c|c|c|c|c|c|c|c|c|c|c|}
\hline $\mathrm{KI}$ & RT & & Basil & Bergamot & $\begin{array}{c}\text { Cinnamon } \\
\text { bark }\end{array}$ & $\begin{array}{c}\text { Cinnamon } \\
\text { leaf }\end{array}$ & Clove & Lemon & Mint & Oregano & Rosemary & Thyme \\
\hline 1694 & 33.73 & unknown & - & - & - & - & $0.22(0.03)$ & - & - & - & - & - \\
\hline 1843 & 38.34 & unknown & - & $0.33(0.07)$ & - & - & - & - & - & - & - & - \\
\hline 1848 & 38.48 & unknown & - & $0.34(0.05)$ & - & - & - & - & - & - & - & - \\
\hline \multirow[t]{2}{*}{1980} & 42.87 & unknown & - & $0.13(0.03)$ & - & - & - & - & - & - & - & - \\
\hline & & TOTAL & 99.56 & 99.74 & 98.56 & 96.23 & 84.36 & 99.82 & 99.98 & 99.53 & 99.95 & 100 \\
\hline
\end{tabular}


Table A.2 Antifungal activity of essential oils on the vegetative growth of Aspergillus niger expressed as \% of inhibition area for test carried out by diffusion-contact with the agar media ( $V+D)$ or head space methods ( $V$ ) (disk fixed to the plate cover) of the essential oils impregnated in a paper disk $(\phi=2 \mathrm{~cm})$.

\begin{tabular}{|c|c|c|c|c|c|c|c|c|c|}
\hline \multirow{2}{*}{ EO } & \multirow{2}{*}{$\begin{array}{l}\text { Time } \\
\text { (days) }\end{array}$} & \multicolumn{2}{|c|}{$2.25 \mathrm{mg}$} & \multicolumn{2}{|c|}{$4.5 \mathrm{mg}$} & \multicolumn{2}{|c|}{$9 \mathrm{mg}$} & \multicolumn{2}{|c|}{$18 \mathrm{mg}$} \\
\hline & & $\mathrm{V}$ & $V+D$ & $\mathrm{~V}$ & $V+D$ & $\mathrm{~V}$ & $V+D$ & $\mathrm{~V}$ & $V+D$ \\
\hline \multirow{2}{*}{ Basil } & 1 & $0(0)$ & $0(0)$ & $0(0)$ & $5(0)$ & $59(7)$ & $95(7)$ & $74(4)$ & $100(0)$ \\
\hline & 7 & $0(0)$ & $0(0)$ & $0(0)$ & $0(0)$ & $0(0)$ & $0(0)$ & $0(0)$ & $5(0)$ \\
\hline \multirow{2}{*}{ Bergamot } & 1 & $0(0)$ & $0(0)$ & $0(0)$ & $5(0)$ & $0(0)$ & $5(0)$ & $0(0)$ & $5(0)$ \\
\hline & 7 & $0(0)$ & $0(0)$ & $0(0)$ & $0(0)$ & $0(0)$ & $0(0)$ & $0(0)$ & $0(0)$ \\
\hline \multirow{2}{*}{ Cinnamon Bark } & 1 & $67(4)$ & $78(2)$ & $88(9)$ & $98(4)$ & $100(0)$ & $100(0)$ & $100(0)$ & $100(0)$ \\
\hline & 7 & $67(4)$ & $75(3)$ & $88(9)$ & $97(5)$ & $100(0)$ & $100(0)$ & $100(0)$ & $100(0)$ \\
\hline \multirow{2}{*}{ Cinnamon Leaf } & 1 & $0(0)$ & $5(0)$ & $32(4)$ & $40(4)$ & $64(6)$ & $72(7)$ & $100(0)$ & $100(0)$ \\
\hline & 7 & $0(0)$ & $5(0)$ & $22(2)$ & $25(4)$ & $48(4)$ & $68(8)$ & $100(0)$ & $94(6)$ \\
\hline \multirow{2}{*}{ Clove } & 1 & $0(0)$ & $5(0)$ & $21(3)$ & $30(3)$ & $44(4)$ & $62(2)$ & $73(5)$ & $100(0)$ \\
\hline & 7 & $0(0)$ & $5(0)$ & $13(2)$ & $21(2)$ & $40(4)$ & $58(6)$ & $59(4)$ & $82(3)$ \\
\hline \multirow{2}{*}{ Lemon } & 1 & $0(0)$ & $5(0)$ & $0(0)$ & $5(0)$ & $0(0)$ & $5(0)$ & $4.0(1.2)$ & $5(0)$ \\
\hline & 7 & $0(0)$ & $0(0)$ & $0(0)$ & $0(0)$ & $0(0)$ & $0(0)$ & $0(0)$ & $0(0)$ \\
\hline \multirow{2}{*}{ Mint } & 1 & $0(0)$ & $5(0)$ & $58(12)$ & 85 (12) & 87 (9) & $100(0)$ & $100(0)$ & $100(0)$ \\
\hline & 7 & $0(0)$ & $0(0)$ & $10.7(1.4)$ & $13.8(1.4)$ & $17(3)$ & $24(3)$ & $100(0)$ & $34(2)$ \\
\hline \multirow{2}{*}{ Oregano } & 1 & $0(0)$ & $5(0)$ & $26(4)$ & $32.8(1.8)$ & $51(4)$ & $59(6)$ & $100(0)$ & $100(0)$ \\
\hline & 7 & $0(0)$ & $0(0)$ & $16(3)$ & $24(3)$ & $49(7)$ & $59(6)$ & $100(0)$ & $90(8)$ \\
\hline \multirow{2}{*}{ Rosemary } & 1 & $0(0)$ & $5(0)$ & $0(0)$ & $5(0)$ & $0(0)$ & $5(0)$ & $4.0(0.6)$ & $5(0)$ \\
\hline & 7 & $0(0)$ & $0(0)$ & $0(0)$ & $0(0)$ & $0(0)$ & $0(0)$ & $0(0)$ & $0(0)$ \\
\hline \multirow{2}{*}{ Thyme } & 1 & $0(0)$ & $8(3)$ & $21(3)$ & $26(5)$ & $67(5)$ & $100(0)$ & $100(0)$ & $100(0)$ \\
\hline & 7 & $0(0)$ & $0(0)$ & $0(0)$ & $0(0)$ & $7(2)$ & $11(2)$ & $16(2)$ & $23(3)$ \\
\hline
\end{tabular}


Table A.3 Antifungal activity of essential oils (EO) on the vegetative growth of Botrytis cinerea expressed as \% of inhibition area for test carried out by diffusion-contact with the agar media ( $V+D)$ or head space methods ( $V$ ) (disk fixed to the plate cover) of the essential oils impregnated in a paper disk $(\phi=2 \mathrm{~cm})$.

\begin{tabular}{|c|c|c|c|c|c|c|c|c|c|}
\hline \multirow{2}{*}{ EO } & \multirow{2}{*}{$\begin{array}{c}\text { Time } \\
\text { (days) }\end{array}$} & \multicolumn{2}{|c|}{$2.25 \mathrm{mg}$} & \multicolumn{2}{|c|}{$4.5 \mathrm{mg}$} & \multicolumn{2}{|c|}{$9 \mathrm{mg}$} & \multicolumn{2}{|c|}{$18 \mathrm{mg}$} \\
\hline & & $\mathrm{V}$ & $V+D$ & $\mathrm{~V}$ & $V+D$ & $\mathrm{~V}$ & $V+D$ & $\mathrm{~V}$ & $V+D$ \\
\hline \multirow{2}{*}{ Basil } & 3 & $0(0)$ & $5(0)$ & $0(0)$ & 5.66 (1.09) & $2.4(0.8)$ & $18(4)$ & $14(2)$ & $30(3)$ \\
\hline & 14 & $0(0)$ & $0(0)$ & $0(0)$ & $0(0)$ & $0(0)$ & $5(0)$ & $0(0)$ & $4.9(0.6)$ \\
\hline \multirow{2}{*}{ Bergamot } & 3 & $0(0)$ & $5(0)$ & $0(0)$ & $5(0)$ & $5(0)$ & $13(2)$ & $8(2)$ & $19(3)$ \\
\hline & 14 & $0(0)$ & $0(0)$ & $0(0)$ & $0(0)$ & $0(0)$ & $0(0)$ & $0(0)$ & $0(0)$ \\
\hline \multirow{2}{*}{ Cinnamon Bark } & 3 & $100(0)$ & $100(0)$ & $100(0)$ & $100(0)$ & $100(0)$ & $100(0)$ & $100(0)$ & $100(0)$ \\
\hline & 14 & $100(0)$ & $100(0)$ & $100(0)$ & $100(0)$ & $100(0)$ & $100(0)$ & $100(0)$ & $100(0)$ \\
\hline \multirow{2}{*}{ Cinnamon Leaf } & 3 & $47(8)$ & $60(9)$ & $100(0)$ & $100(0)$ & $100(0)$ & $100(0)$ & $100(0)$ & $100(0)$ \\
\hline & 14 & $0(0)$ & $5(0)$ & $100(0)$ & $100(0)$ & $100(0)$ & $100(0)$ & $100(0)$ & $100(0)$ \\
\hline \multirow{2}{*}{ Clove } & 3 & $33(3)$ & $42(3)$ & $52(4)$ & $65(5)$ & $100(0)$ & $100(0)$ & $100(0)$ & $100(0)$ \\
\hline & 14 & $0(0)$ & $5(0)$ & $38(3)$ & $53(6)$ & $100(0)$ & $100(0)$ & $100(0)$ & $100(0)$ \\
\hline \multirow{2}{*}{ Lemon } & 3 & $0(0)$ & $5(0)$ & $0(0)$ & $5(0)$ & $0(0)$ & $18(4$ & $9(2)$ & $26(4)$ \\
\hline & 14 & $0(0)$ & $0(0)$ & $0(0)$ & $0(0)$ & $0(0)$ & $0(0)$ & $0(0)$ & $5(0)$ \\
\hline \multirow{2}{*}{ Mint } & 3 & $27(5)$ & $34(6)$ & $48(6)$ & $59(11)$ & $100(0)$ & $100(0)$ & $100(0)$ & $100(0)$ \\
\hline & 14 & $0(0)$ & $5(0)$ & $30(4)$ & $42(4)$ & $100(0)$ & $100(0)$ & $100(0)$ & $100(0)$ \\
\hline \multirow{2}{*}{ Oregano } & 3 & $37(5)$ & $45(9)$ & $68(10)$ & $87(10)$ & $100(0)$ & $100(0)$ & $100(0)$ & $100(0)$ \\
\hline & 14 & $0(0)$ & $5(0)$ & $60(8)$ & $71(13)$ & $100(0)$ & $100(0)$ & $100(0)$ & $100(0)$ \\
\hline \multirow{2}{*}{ Rosemary } & 3 & $0(0)$ & $5(0)$ & $0(0)$ & $5(0)$ & $0(0)$ & $8(3)$ & $8(2)$ & $12(4)$ \\
\hline & 7 & $0(0)$ & $0(0)$ & $0(0)$ & $0(0)$ & $0(0)$ & $0(0)$ & $0(0)$ & $5(0)$ \\
\hline \multirow{2}{*}{ Thyme } & 3 & $0(0)$ & $5(0)$ & $11(3)$ & $14(4)$ & $28(4)$ & $35(8)$ & $63(5)$ & $71(9)$ \\
\hline & 14 & $0(0)$ & $0(0)$ & $0(0)$ & $5(0)$ & $5(0)$ & $5(0)$ & $10(2)$ & $15(5)$ \\
\hline
\end{tabular}


Table A.4 Antifungal activity of essential oils (EO) on the vegetative growth of Rhizopus stolonifer expressed as \% of inhibition area for test carried out by diffusion-contact with the agar media ( $\mathrm{V}+\mathrm{D})$ or head space methods (V) (disk fixed to the plate cover) of the essential oils impregnated in a paper disk $(\phi=2 \mathrm{~cm})$.

\begin{tabular}{|c|c|c|c|c|c|c|c|c|c|}
\hline \multirow{2}{*}{ EO } & \multirow{2}{*}{$\begin{array}{l}\text { Time } \\
\text { (days) }\end{array}$} & \multicolumn{2}{|c|}{$2.25 \mathrm{mg}$} & \multicolumn{2}{|c|}{$4.5 \mathrm{mg}$} & \multicolumn{2}{|c|}{$9 \mathrm{mg}$} & \multicolumn{2}{|c|}{$18 \mathrm{mg}$} \\
\hline & & $\mathrm{V}$ & $V+D$ & $\mathrm{~V}$ & $V+D$ & $\mathrm{~V}$ & $V+D$ & $\mathrm{~V}$ & $V+D$ \\
\hline \multirow{2}{*}{ Basil } & 1 & $0(0)$ & $5(0)$ & $0(0)$ & $5(0)$ & $2.68(0.97)$ & $6.7(1.4)$ & $7(2)$ & $16(3)$ \\
\hline & 7 & $0(0)$ & $0(0)$ & $0(0)$ & $0(0)$ & $0(0)$ & $0(0)$ & $0(0)$ & $5(0)$ \\
\hline \multirow{2}{*}{ Bergamot } & 1 & $0(0)$ & $5(0)$ & $0(0)$ & $5(0)$ & $0(0)$ & $5(0)$ & $0(0)$ & $5(0)$ \\
\hline & 7 & $0(0)$ & $0(0)$ & $0(0)$ & $0(0)$ & $0(0)$ & $0(0)$ & $0(0)$ & $0(0)$ \\
\hline \multirow{2}{*}{ Cinnamon Bark } & 1 & $34(3)$ & $41(4)$ & $56(4)$ & $63(6)$ & $89(9)$ & $100(0)$ & $100(0)$ & $100(0)$ \\
\hline & 7 & $32(3)$ & $41(4)$ & $56(4)$ & $63(6)$ & $79(7)$ & $100(0)$ & $100(0)$ & $100(0)$ \\
\hline \multirow{2}{*}{ Cinnamon Leaf } & 1 & $5.0(1.3)$ & $5(0)$ & $9(2)$ & $14(3)$ & $14(2)$ & $20(3)$ & $28(3)$ & $38(5)$ \\
\hline & 7 & $0(0)$ & $5(0)$ & $6.7(1.2)$ & $8.0(1.4)$ & $8.908(1.005)$ & $16(3)$ & $20(2)$ & $28(2)$ \\
\hline \multirow{2}{*}{ Clove } & 1 & $3.96(1.03)$ & $5(0)$ & $8(2)$ & $12(2)$ & $10.86(0.97)$ & $15.7(1.5)$ & $19(2)$ & $27(5)$ \\
\hline & 7 & $0(0)$ & $5(0)$ & $4.4(0.9)$ & $7(2)$ & $6.61(0.95)$ & $11.21(1.03)$ & $14.4(1.3)$ & $20(2)$ \\
\hline \multirow{2}{*}{ Lemon } & 1 & $0(0)$ & $5(0)$ & $0(0)$ & $5(0)$ & $0(0)$ & $5(0)$ & $0(0)$ & $5(0)$ \\
\hline & 7 & $0(0)$ & $0(0)$ & $0(0)$ & $0(0)$ & $0(0)$ & $0(0)$ & $0(0)$ & $0(0)$ \\
\hline \multirow{2}{*}{ Mint } & 1 & $4.30(1.07)$ & $5(0)$ & $40(4)$ & $61(5)$ & $72(10)$ & $100(0)$ & $100(0)$ & $100(0)$ \\
\hline & 7 & $0(0)$ & $5(0)$ & $0(0)$ & $5(0)$ & $4.0(0.8)$ & $9.9(1.2)$ & $9.0(1.2)$ & $13(2)$ \\
\hline \multirow{2}{*}{ Oregano } & 1 & $5.8(0.8)$ & $11(2)$ & $20(2)$ & $27(3)$ & $31(2)$ & $44(3)$ & $40(2)$ & $55(4)$ \\
\hline & 7 & $0(0)$ & $5(0)$ & $5.9(0.9)$ & $16(2)$ & $13(2)$ & $30(2)$ & $20(2)$ & $40(3)$ \\
\hline \multirow{2}{*}{ Rosemary } & 1 & $0(0)$ & $5(0)$ & $0(0)$ & $5(0)$ & $0(0)$ & $5(0)$ & $0(0)$ & $5(0)$ \\
\hline & 7 & $0(0)$ & $0(0)$ & $0(0)$ & $0(0)$ & $0(0)$ & $0(0)$ & $0(0)$ & $0(0)$ \\
\hline \multirow{2}{*}{ Thyme } & 1 & $3.1(0.7)$ & $5(0)$ & $5.35(1.13)$ & $11(2)$ & $8.8(0.7)$ & $18(2)$ & $24(2)$ & $53(3)$ \\
\hline & 7 & $0(0)$ & $0(0)$ & $0(0)$ & $0(0)$ & $0(0)$ & $5(0)$ & $0(0)$ & $5(0)$ \\
\hline
\end{tabular}


